\title{
A Qualitative Investigation of Deposition Velocities of a Non- Newtonian Slurry in Complex Pipeline Geometries
}
S. T. Yokuda
N. K. Karri
A. P. Poloski
M. Luna
H. E. Adkins
M. J. Minette
A. M. Casella
J. M. Tingey
R. E. Hohimer

May 2009 


\title{
DISCLAIMER
}

This report was prepared as an account of work sponsored by an agency of the United States Government. Neither the United States Government nor any agency thereof, nor Battelle Memorial Institute, nor any of their employees, makes any warranty, express or implied, or assumes any legal liability or responsibility for the accuracy, completeness, or usefulness of any information, apparatus, product, or process disclosed, or represents that its use would not infringe privately owned rights. Reference herein to any specific commercial product, process, or service by trade name, trademark, manufacturer, or otherwise does not necessarily constitute or imply its endorsement, recommendation, or favoring by the United States Government or any agency thereof, or Battelle Memorial Institute. The views and opinions of authors expressed herein do not necessarily state or reflect those of the United States Government or any agency thereof.

\author{
PACIFIC NORTHWEST NATIONAL LABORATORY \\ operated by \\ BATTELLE \\ for the \\ UNITED STATES DEPARTMENT OF ENERGY \\ under Contract DE-AC05-76RL01830 \\ Printed in the United States of America \\ Available to DOE and DOE contractors from the \\ Office of Scientific and Technical Information, \\ P.O. Box 62, Oak Ridge, TN 37831-0062; \\ ph: (865) 576-8401 \\ fax: (865) 576-5728 \\ email: reports@adonis.osti.gov
}

Available to the public from the National Technical Information Service, U.S. Department of Commerce, 5285 Port Royal Rd., Springfield, VA 22161

ph: (800) 553-6847

fax: (703) 605-6900

email: orders@ntis.fedworld.gov

online ordering: http://www.ntis.gov/ordering.htm

This document printed on recycled paper. 
PNNL-17973

WTP-RPT-178 Rev. 0

\section{A Qualitative Investigation of Deposition Velocities of a Non- Newtonian Slurry in Complex Pipeline Geometries}

S. T. Yokuda

A. P. Poloski

H. E. Adkins

A. M. Casella

R. E. Hohimer
N. K. Karri

M. Luna

M. J. Minette

J. M. Tingey

May 2009

Test Scoping Statement(s): SCN 023; 24590-WTP-RTD-RT-07-0002, Rev. 0

Test Specification: 24590-WTP-TSP-RT-07-005, Rev. 0

Test Plan: TP-RPP-WTP-494, Rev. 0

Test Exception(s): none

Pacific Northwest National Laboratory

Richland, Washington 99352 


\section{Completeness of Testing}

This report describes the results of work and testing specified by Test Specification 24590WTP-TSP-RT-07-005, Rev. 0, and Test Plan TP-RPP-WTP-494, Rev. 0. The work and any associated testing followed the quality assurance requirements outlined in the Test Specification, and Test Plan. The descriptions provided in this test report provide an accurate account of both the conduct of the work and the data collected. Test plan results are reported. Also reported are any unusual or anomalous occurrences that are different from expected results. The test results and this report have been reviewed and verified.

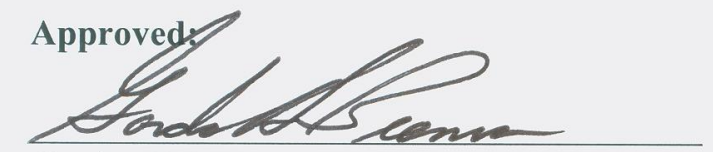

Gordon H. Beeman, Program Manager RPP-WTP Support Program

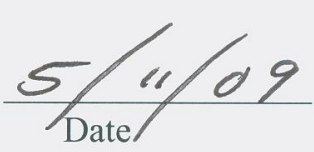




\section{Executive Summary}

The External Flowsheet Review Team (EFRT) has identified the issues relating to the Waste Treatment and Immobilization Plant (WTP) pipe plugging. Per the review's executive summary, "Piping that transports slurries will plug unless it is properly designed to minimize this risk. This design approach has not been followed consistently, which will lead to frequent shutdowns due to line plugging."

To evaluate the potential for plugging, testing was performed to determine critical velocities and velocities for avoiding deposition (VFAD) for the complex WTP piping layout. Critical velocity is defined as the point at which a moving bed of particles begins to form on the pipe bottom during slurry-transport operations whereas VFAD is defined as the velocity at which no particle deposition occurs. Pressure drops across the fittings of the test pipeline were measured with differential pressure transducers, from which the critical velocities and VFADs were determined. A WTP prototype flush system was installed and tested upon the completion of the pressure-drop measurements. Data is also provided for the overflow relief system representing a WTP complex piping geometry with a non-Newtonian slurry. A waste simulant composed of alumina (nominally $50 \mu \mathrm{m}$ in diameter) suspended in a kaolin clay slurry was used for this testing. The target composition of the simulant was $10 \mathrm{vol} \%$ alumina in a suspending medium with a yield stress of $3 \mathrm{~Pa}$.

No publications or reports are available to confirm the critical velocities for the complex geometry evaluated in this testing; therefore, for this assessment, the results were compared to those reported by Poloski et al. (2008) for which testing was performed for a straight horizontal pipe. The results of the flush test are compared to the WTP design guide 24590-WTP-GPG-M-0058, Rev. 0 (Hall 2006) in an effort to inspect flushing-velocity requirements.

The major findings of this testing are as follows:

A complete flow blockage by pipe plugging did not occur at the smallest flow velocity used for the pressure-drop measurements; however, the flow velocity was kept constant by the feedback system of the pump with the variable frequency drive.

Due to high uncertainty in the critical velocity evaluations, VFADs provide the velocities at which it is assured that no particle deposition occurs.

Critical velocities for the fittings used for in this testing are lower than that for a straight horizontal pipe reported by Poloski et al. (2008), except in the case of a tee; however, high uncertainty in the critical velocity evaluations is expected.

For the overflow-relief piping testing, a complete flow blockage by pipe plugging did not occur at the smallest flow rate used for the testing: Three tests with the 8-inch pipe slopes of 1:125, 1:50, and 1:20 were performed by observing the slurry particle deposition process of gravity-driven partially-filled pipe flow through the transparent sections. The observations include: 1) for a test slope of 1:125, substantial solids deposition occurred at the flow rate of $161 \mathrm{gpm}$ and below; 2) for the test slope of 1:50, substantial solids deposition occurred at $93 \mathrm{gpm}$ and below and small amounts of solids deposition at $115 \mathrm{gpm}$; and, 3) for the test slope of 1:20, no deposition occurred at any of the flow rates used in the testing. For all three slopes, removing the deposited particles from the pipe surface was difficult; therefore, it is recommended to assure that the overflow channel system is thoroughly flushed out after a vessel-overflow event.

For the flush system, it was found that a flush-to-line volume ratio of 3 was needed to remove sediment bed from the pipeline test system used for the pressure-drop measurements whereas design-guide 24590-WTP-GPG-M0058, Rev. 0 (Hall 2006) provides a minimum flush-volume ratio of 1.7 for non-Newtonian fluids. 


\section{Acknowledgments}

The authors would like to acknowledge the assistance of the following staff members in supporting the entire project including construction of the flow loop, conducting research, and obtaining the necessary data.
J. M. Alzheimer
C. C. Duncan
K. L. Peterson
S. K. Bapanapalli
A. D. Guzman
J. H. Sachs
B. E. Butcher
C. C. Kovalchick
G. L. Smith
J. Chun
P. J. MacFarlan
L. Zhong
R.C. Daniel
W. R. Park
D. S. Sklarew 


\section{Contents}

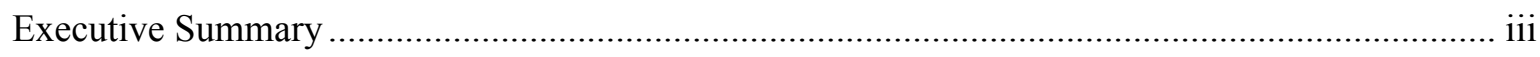

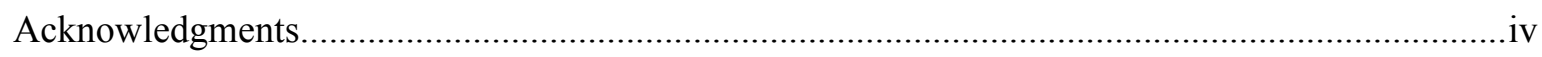

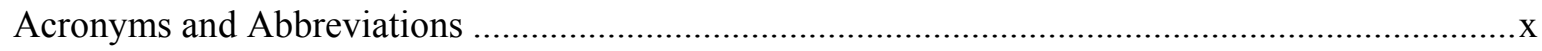

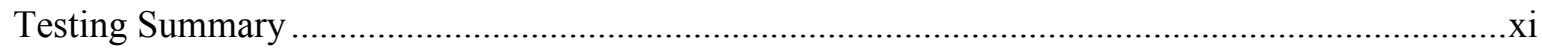

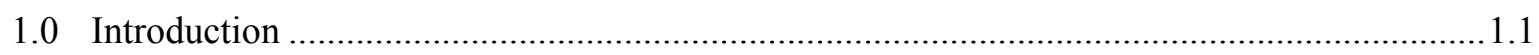

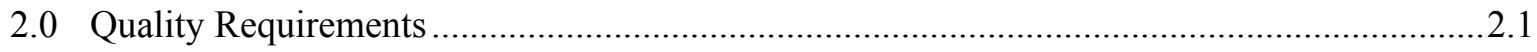

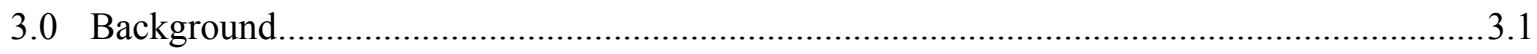

3.1 Critical Velocity and Velocity for Avoiding Deposition (VFAD) ................................... 3.2

3.2 Gravity-Driven Partially-Filled (GDPF) Pipe Flow Test ............................................... 3.3

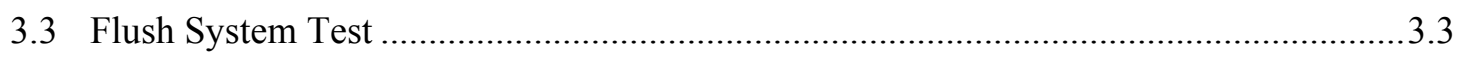

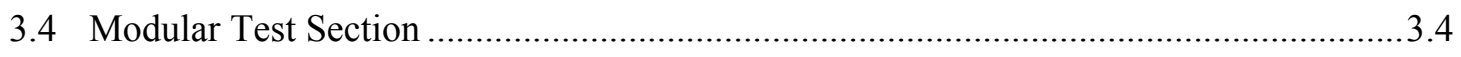

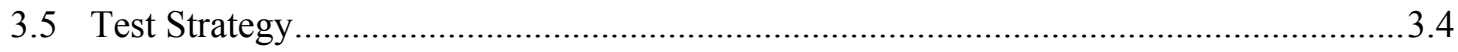

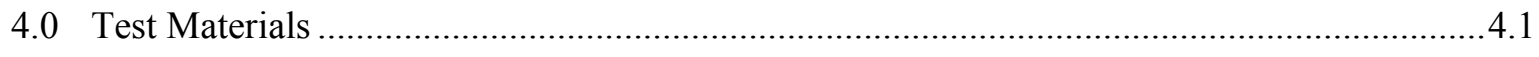

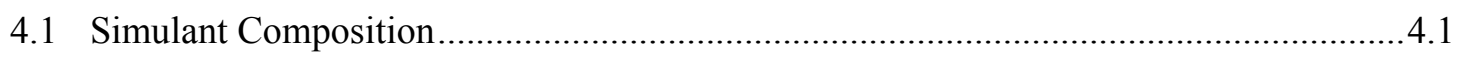

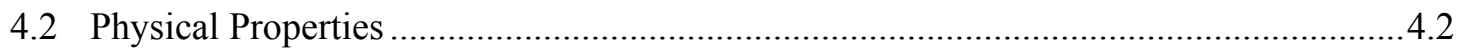

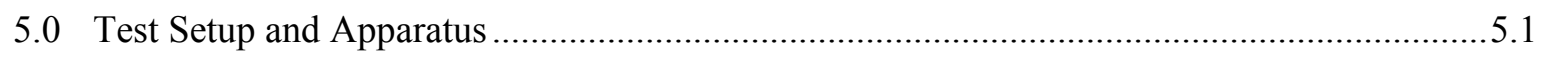

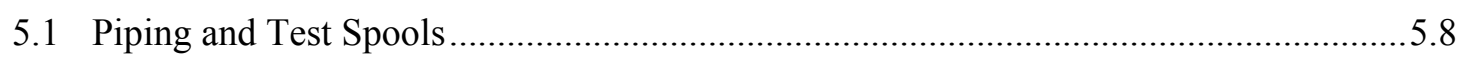

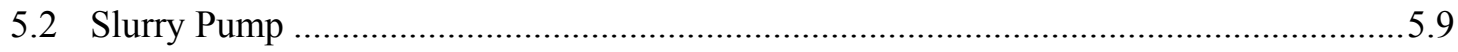

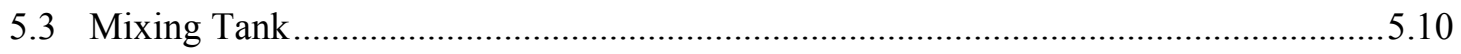

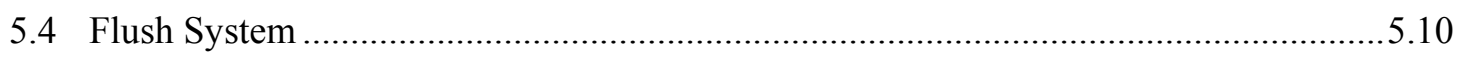

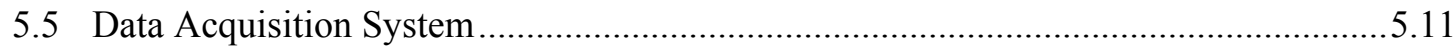

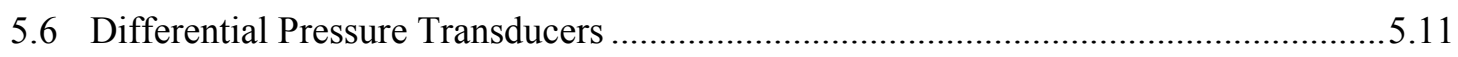

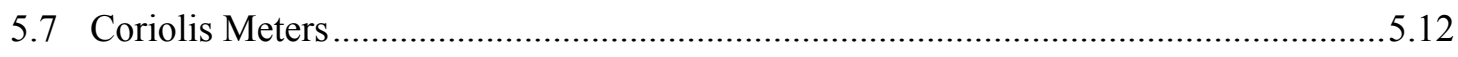

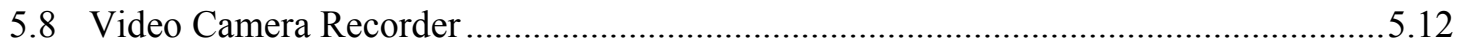

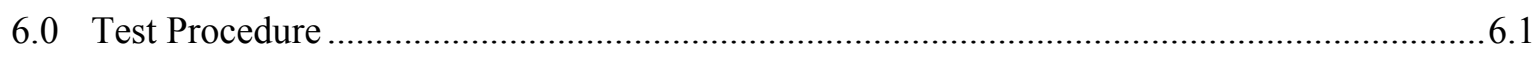

6.1 Procedure for Pressure-Drop Measurement and Flush Tests ........................................6.1

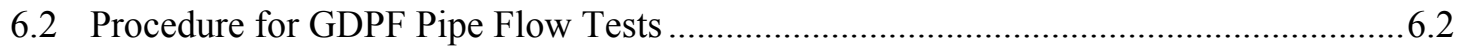

7.0 Critical Velocity and Velocity for Avoiding Deposition................................................... 7.1

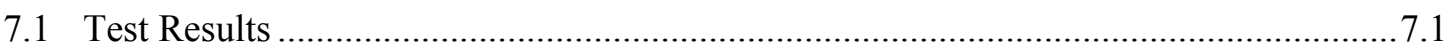

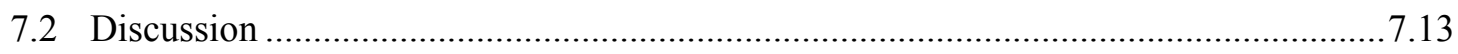

8.0 Gravity-Driven Partially-Filled Pipe Flow Test ........................................................... 8.1

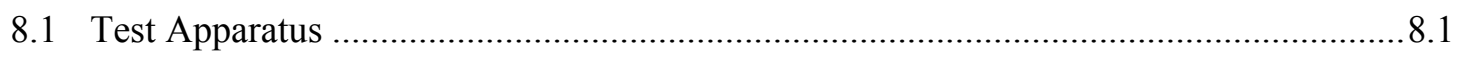

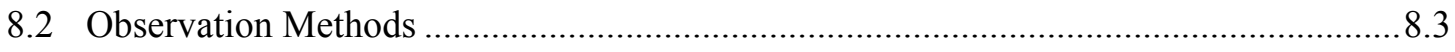

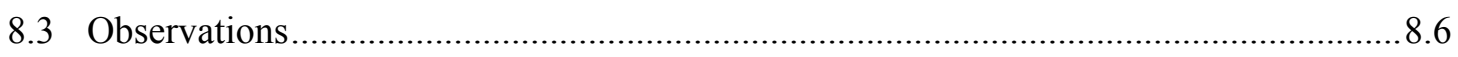

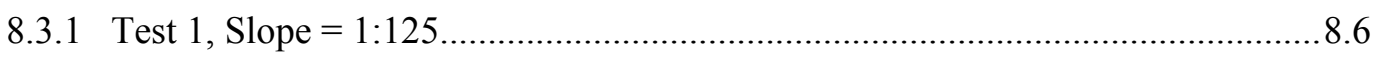

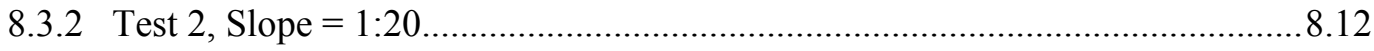




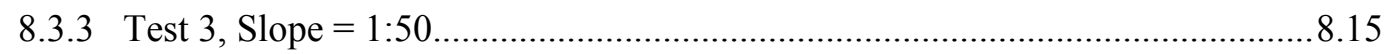

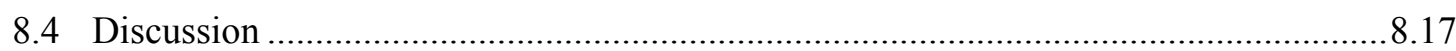

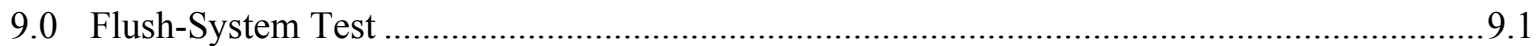

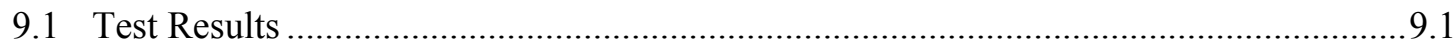

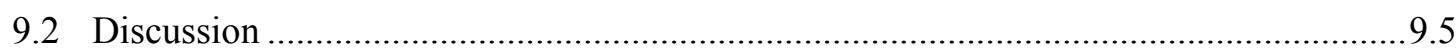

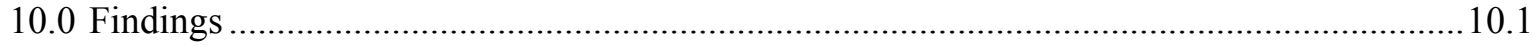

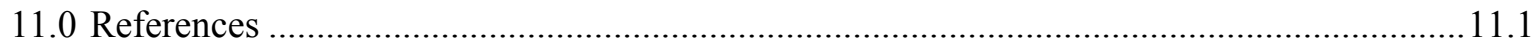




\section{Figures}

Figure 3.1. Pressure drop across a straight horizontal pipeline versus velocity for a non-

Newtonian fluid 3.3

Figure 4.1. Micrograph of 50- $\mu \mathrm{m}$ Alumina (Washington Mills Duralum ${ }^{\circledR} 220$ grit) ....................4.2

Figure 4.2. Shear stress versus shear rate.

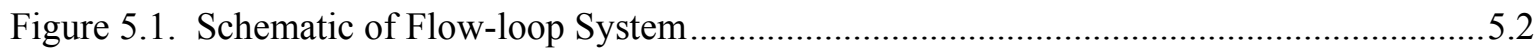

Figure 5.2. Drawing of the gravity-feed and process-drain spool...............................................5.3

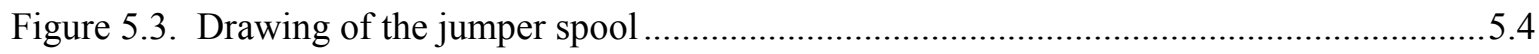

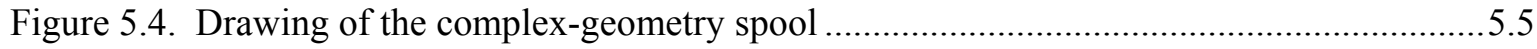

Figure 5.5. Drawing of the reducer and vertical-rise spool......................................................5.6

Figure 5.6. Schematic of the GDPF pipe flow test section ....................................................... 5.7

Figure 5.7. Side view diagram of the GDPF pipe flow test arrangement …...............................5.7

Figure 5.8. Top view diagram of the GDPF pipe flow test section ............................................5.7

Figure 5.9. Photograph of Georgia Iron Works 2X3LCC Slurry Pump (Source:

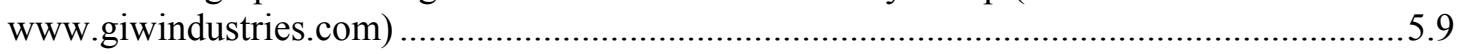

Figure 5.10. Schematic of Mixing Tank Internal Components .................................................5.10

Figure 5.11. Schematic of Flush Tank Internal Components......................................................11

Figure 7.1. Plots of pressure drop vs. pipeline velocity for the gravity-feed and process-drain

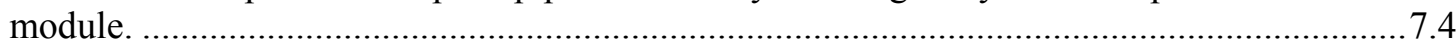

Figure 7.2. Plots of pressure drop vs. pipeline velocity for the jumper module. .......................... 7.6

Figure 7.3. Plots of pressure drop vs. pipeline velocity for the complex geometry module...........7.9

Figure 7.4. Plots of pressure drop vs. pipeline velocity for the reducer and vertical-rise module.7.12

Figure 8.1. Side View Schematic of the GDPF Pipe Flow Test Arrangement .............................. 8.1

Figure 8.2. Top View of GDPF Pipe Flow Test Module ......................................................... 8.2

Figure 8.3. Side View of Upstream Transparent (Clear) Section with Measuring Tape ................8.4

Figure 8.4. Close-up of Transparent (Clear) Section with Measuring Tape .................................8.4

Figure 8.5. Measurement Conversion Parameters .................................................................. 8.5

Figure 8.6. Common Observation Parameters in Transparent (Clear) Sections ............................ 8.6

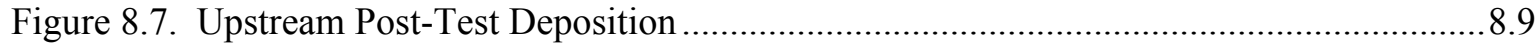

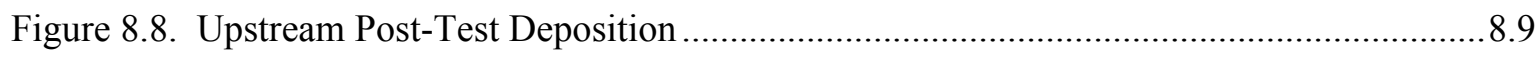

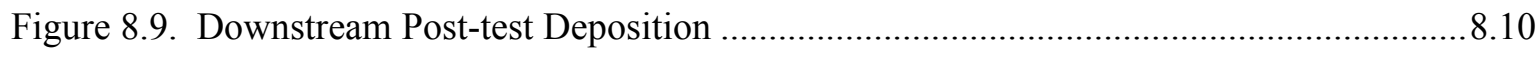

Figure 8.10. Pipe Entrance from Upstream Reservoir ............................................................. 8.10

Figure 8.11. Downstream Reservoir Post-Test ..................................................................... 8.11

Figure 8.12. Pipe End to Reservoir Post-Test ......................................................................... 8.11

Figure 8.13. Upstream Transparent Section, Post Test (Test 2, Slope $=1: 20) \ldots \ldots \ldots \ldots \ldots \ldots \ldots \ldots \ldots . . . . .14$

Figure 8.14. Downstream Transparent Section, Post Test (Test 2, Slope $=1: 20) \ldots \ldots \ldots \ldots \ldots \ldots \ldots . . . .14 .14$

Figure 8.15. Upstream, Slope $=1: 50$, Post-Test Deposition................................................... 8.16

Figure 8.16. Downstream, Slope $=1: 50$, Post-Test Deposition .................................................16 
Figure 8.17. Downstream, Slope $=1: 50$, Post-Test Deposition (Close-up).

Figure 9.1. Flush Data for the gravity-feed and process-drain test module as a flush-to-pipe loopvolume ratio, showing the flush before disk rupture

Figure 9.2. Flush data for the gravity-feed and process-drain test module as a flush-to-pipe loopvolume ratio, showing two complete flushes after disk replacement (continuation of Figure 9.1)

Figure 9.3. Flush data for the jumper test module as a flush-to-pipe loop-volume ratio, showing three complete flushes

Figure 9.4. Flush data for the complex-geometry test module as a flush-to-pipe loop-volume ratio, showing four complete flushes

Figure 9.5. Flush data for the reducer and vertical-rise test module as a flush-to-pipe loopvolume ratio, showing four complete flushes 


\section{Tables}

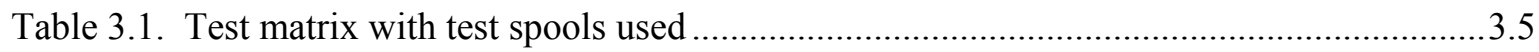

Table 4.1. Slurry Materials Selected for Critical-Velocity Testing .............................................. 4.2

Table 4.2. Properties of Simulant for Gravity-Feed and Process Drain Module Test ...................4.4

Table 4.3. Properties of Simulant for Jumper Module Test .......................................................... 4.5

Table 4.4. Properties of Simulant for Complex-Geometry Module Test .......................................4.6

Table 4.5. Properties of Simulant for Reducer and Vertical-Rise Module Test ............................4.7

Table 4.6. Properties of Simulant for Gravity-Driven Partially-Filled Pipe Flow Test .................4.8

Table 4.7. Particle Size Standard for the Microtrac S3000 Particle Size Analyzer .......................4.9

Table 4.8. Particle Size Standard for the Malvern Mastersizer 2000 Analyzer ...............................4.9

Table 7.1. Critical velocity and VFAD evaluated from the uncorrected DPT data ....................7.16

Table 7.2. Pressure drop, density, yield stress, consistency, and Reynolds number for the gravity-

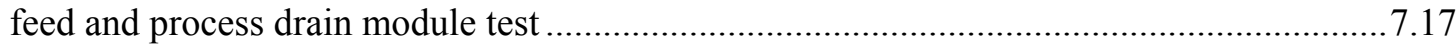

Table 7.3. Pressure drop, density, yield stress, consistency, and Reynolds number for the jumper

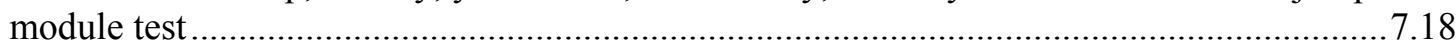

Table 7.4. Pressure drop, density, yield stress, consistency, and Reynolds number for the complex geometry module test.

Table 7.5. Pressure drop, density, yield stress, consistency, and Reynolds number for the reducer

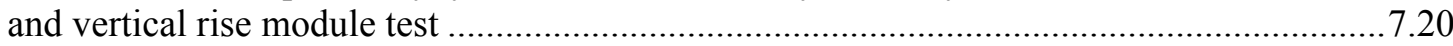

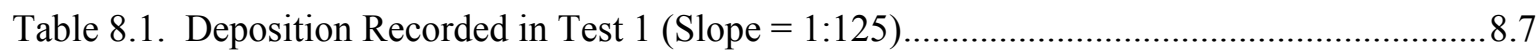

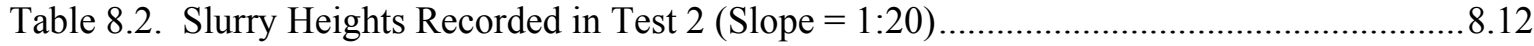

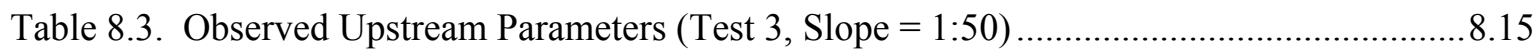

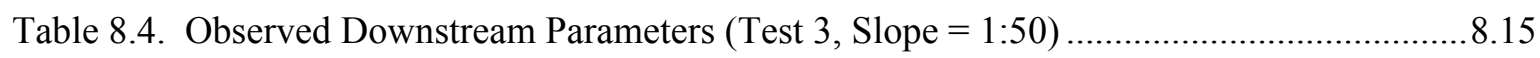




\section{Acronyms and Abbreviations}

$\begin{array}{ll}\text { BNI } & \text { Bechtel National, Inc. } \\ \text { CFR } & \text { Code of Federal Regulations } \\ \text { DOE } & \text { U.S. Department of Energy } \\ \text { DPT } & \text { differential pressure transducer } \\ \text { EFRT } & \text { External Flowsheet Review Team } \\ \text { GDPF } & \text { gravity-driven partially-filled } \\ \text { HLW } & \text { high level waste } \\ \text { NIST } & \text { National Institute of Standards and Technology } \\ \text { ORP } & \text { Office of River Protection } \\ \text { P\&ID } & \text { piping and instrumentation diagram } \\ \text { PNNL } & \text { Pacific Northwest National Laboratory } \\ \text { QA } & \text { quality assurance } \\ \text { QAM } & \text { Quality Assurance Manual } \\ \text { QAP } & \text { Quality Assurance Plan } \\ \text { QARD } & \text { Quality Assurance Requirements and Descriptions } \\ \text { RPP } & \text { River Protection Project } \\ \text { VFAD } & \text { velocity for avoiding deposition } \\ \text { VFD } & \text { variable frequency drive } \\ \text { WTP } & \text { Hanford Waste Treatment and Immobilization Plant } \\ \text { WTPSP } & \text { WTP Support Project } \\ & \end{array}$




\section{Testing Summary}

The U.S. Department of Energy (DOE) Office of River Protection's (ORP) Waste Treatment and Immobilization Plant (WTP) will process and treat radioactive waste that is stored in tanks at the Hanford Site. Piping, pumps, and mixing vessels will transport, store, and mix the high-level waste (HLW) slurries in the WTP.

The WTP pipe plugging issue, as stated by the External Flowsheet Review Team (EFRT) Executive Summary, is as follows: "Piping that transports slurries will plug unless it is properly designed to minimize this risk. This design approach has not been followed consistently, which will lead to frequent shutdowns due to line plugging." (a) Additional details relating to the EFRT summary are provided in a supplemental background document. ${ }^{(b)}$ The WTP Project is implementing a strategy to address the above EFRT issue identified as "Issue M1-Plugging in Process Piping."

The testing described herein is to determine critical velocities and velocities for avoiding deposition (VFAD) for the complex WTP piping layout. Critical velocity is defined as the point where a moving bed of particles begins to form on the pipe bottom during slurry-transport operations whereas VFAD is defined as the velocity at which no particle deposition occurs in the slurry transporting process. Pressure drops across the fittings of the test pipeline were measured, from which critical velocities and VFADs were determined. Upon completion of the pressure-drop measurement, the flow loop was flushed to test the WTP prototype flush system. This testing is also to provide data for the overflow-relief system representing a WTP piping geometry with a non-Newtonian slurry.

A waste simulant composed of alumina (nominally $50 \mu \mathrm{m}$ in diameter) suspended in a kaolin clay slurry was used for this testing. The target composition of the simulant was $10 \mathrm{vol} \%$ alumina in a suspending medium with a yield stress of $3 \mathrm{~Pa}$.

An experimental flow loop was constructed with a modular test section, mixing tank, slurry pump, and instrumentation for measuring flow rate and pressure drop across the modular components. Five spools were tested in this experimental work as follows: a test was performed with a spool installed in the modular test section, and then the modular test section was replaced with the next test spool for the next test.

To measure the pressure drop across the components of a test module, the slurry flow velocity was set to 7.5 or $8 \mathrm{ft} / \mathrm{sec}$ at the beginning of a test. The flow was then decreased in increments and steady-state pressure drop values across the components of the test spool were measured at each flow velocity (note: the feedback system of the pump with the variable frequency drive (VFD) maintained the flow velocity constant during the measurement). A rise in the pressure-drop value as the flow velocity decreases

(a) WTP Project Doc. No. CCN 132846 "Comprehensive Review of the Hanford Waste Treatment Plant Flowsheet and Throughput-Assessment Conducted by an Independent Team of External Experts," March 2006.

(b) WTP Project Doc. No. CCN 132847 "Background Information and Interim Reports for the Comprehensive Review of the Hanford Waste Treatment Plant Flowsheet and Throughput-Assessment Conducted by an Independent Team of External Experts," March 2006. 
indicates that the pipe cross-sectional area is filled with settled slurry particles. The distribution of pressure-drop versus velocity is referred to as a "J-curve." Velocity at which the minimum pressure drop is observed in the J-curve is referred to as the "critical velocity." The VFAD is determined in such a way that pressure drop corresponding to the VFAD is adequately large to assure that slurry flow does not undergo particle deposition from the pressure drop versus velocity curve.

Data for the overflow-relief piping of the WTP geometry with a non-Newtonian slurry were obtained by observing the slurry-particle deposition process. The test was started with the nominal slurry pipeline flow velocity of $8 \mathrm{ft} / \mathrm{sec}$. The flow was then decreased in increments and held constant for a minimum of 30 minutes (note: the feedback system of the pump with the VFD maintained the nominal flow velocity constant during the observation), during which time the observation was performed.

To remove the sediment bed from the system, a WTP prototype flush system was installed and tested. This system consists of a pressure vessel containing an initial charge of water. The pressure was then increased to a target value, nominally 100 to 110 psig. Upon completion of the pressure-drop measurements, a valve was opened, and the high-pressure water flush removed deposited slurry particles from the pipeline loop.

The critical velocities determined are compared to that of a straight horizontal pipe reported by Poloski et al. (2008). The results of the flush test are compared to the WTP design guide 24590-WTPGPG-M-0058, Rev. 0 (Hall 2006) in an effort to inspect the flushing-velocity requirements established in the design guide.

A differential pressure transducer (DPT) was used to measure the pressure drop across a component of a test module. The DPTs measure the pressure drop between the two pressure ports on the test module components that have upward and downward slopes. Due to the density difference between the slurry flowing inside the pipeline of the modular components and water inside the tubes that connect the DPTs to the pressure ports on the modular components, the vertical distances between the two ports on the test module components cause DPT readings to include the hydrostatic pressure due to gravity. This effect was removed from the measured DPT data by adding (or subtracting, in the case of upward flow) the correction factor $\Delta \mathrm{P}_{c}$ to (or from) the DPT readings, with

$$
\Delta \mathrm{P}_{c}=\left(\rho_{\text {Slurry }}-\rho_{\text {water }}\right) g h
$$

where $\rho_{\text {Slurry }}$ is the slurry density

$\rho_{\text {water }}$ is the water density

$g \quad$ is the acceleration due to gravity

$h \quad$ is the vertical distance between the pressure ports on the modular component.

To perform accurate DPT data corrections with Equation [S.1], the following items need to be satisfied: (1) the accurate slurry densities inside the modular components are measured and (2) the DPT pressure tubes that connect the DPTs to the pressure ports on the modular components contain only water.

For this correction of the DPT data, the slurry density obtained with the Coriolis flow meter at a position well upstream of the modular test section was used. Therefore, it is expected that, in low 
velocity conditions, the density given by the Coriolis flow meter differs from the density at the pressure ports where the DPT measurements are performed, possibly due to particle settling. In addition, high uncertainty is expected in the pressure measurements since the static pressure measured by a DPT was the local static pressure in the immediate vicinity of the pressure ports which was considered to be different from the average pressure in the pipe cross section due to the complex flow structure produced by the geometry of the modular component. The high uncertainty in the density and pressure measurements is deemed to be significant for the DPT data analyses, but no corrective method is available.

Table S.1 presents the critical velocities evaluated from the uncorrected DPT data. The uncorrected DPT data can provide only a qualitative description since these data include the hydrostatic pressure due to gravity. The critical velocities reported in Table S.1 were evaluated by applying the critical-velocity definition used by Poloski et al. (2008). However, as seen in Table S.1, the critical velocities correspond in most cases to the smallest velocities used in the tests. The smallest velocities obtained need not to be the critical velocities since the J-curve profile could not be obtained. High uncertainty in DPT data is expected for the lower-velocity region (possibly due to slurry-particle deposition and complex flow structure produced by the geometry of the modular component) and a definite profile of the J-curve was not obtained from the DPT data measured in this testing. Therefore it is not certain that the critical velocities were evaluated from the DPT data obtained.

Table S.1 includes the test spool types with their components used for the pressure-drop measurements. For each test spool, the pressure measurements were repeated in triplicate to confirm the repeatability of the test. The critical velocities reported by Poloski et al. (2008) where the same pipe diameter of 3 inches as that used in this testing and the slurry composition and rheology similar to those used in this testing were used for a straight pipe are also included in Table S.1 for comparison.

The critical velocity of $3.5 \mathrm{ft} / \mathrm{sec}$ evaluated for the fifth component, a $90^{\circ} 3 \mathrm{D}$ elbow, for the repeated third test run of the gravity-feed and process-drain test spool, was due to the fact that the measurement was not performed for velocities less than $2.5 \mathrm{ft} / \mathrm{sec}$ and this value of $3.5 \mathrm{ft} / \mathrm{sec}$ is not considered to be a critical velocity as the J-curve obtained was incomplete. The critical velocity of $2.5 \mathrm{ft} / \mathrm{sec}$ for the second, third, and fourth components for the repeated third test of the gravity-feed and process-drain test spool was the smallest velocity used for this test run. The high uncertainty in the DPT data of the fifth component, a $45^{\circ} 3 \mathrm{D}$ elbow, of the reducer and vertical-rise test spool is expected due to high pressure fluctuations as the pressure drops across the short distance of about 16 inches were measured in highintensity turbulent flow produced by the complex geometry of the modular component. The configuration of the reducer and vertical-rise test spool suggests that the evaluated high critical velocities of 3.5 and $2.5 \mathrm{ft} / \mathrm{sec}$ for the fifth component are unrealistic.

In addition to the critical velocity, the velocity for avoiding deposition (VFAD) is reported in Table S.1. As discussed above, due to the high fluctuations, it is difficult to determined critical velocities since a definite profile of the J-curve was not obtained in this testing. The high uncertainty makes it difficult to use the evaluated critical velocities for the accurate prediction of particle deposition. Therefore, VFADs are used to provide velocities at which it is assured that no particle deposition occurs.

In Table S.1, the obtained VFADs are reported as velocity ranges where slurry flow does not undergo particle deposition. Table S.2 through Table S.5 include uncorrected pressure drops, corrected pressure drops, densities measured at a point upstream of the modular test section, and densities measured at a 
point downstream of the modular test section. These values correspond to the smallest VFADs reported herein. In addition, included in Table S.2 through Table S.5 are Bingham yield stresses, Bingham consistencies, and ranges of Reynolds numbers used for each test run. The Reynolds number of about 4100 for non-Newtonian fluids may be in laminar or transition. The Reynolds numbers were calculated with:

$$
\mathrm{Re}=\frac{\rho_{\text {Slurry }} V D}{\mu_{\text {consistency }}}
$$

where $\rho_{\text {Slurry }} \quad$ is the slurry density

$V \quad$ is the pipeline velocity

$D \quad$ is the pipe internal diameter of 3.068 inches

$\mu_{\text {consistency }}$ is the Bingham consistency.

All Reynolds numbers reported are based on the nominal pipe size of 3 inches (3.068 inches ID) and this characteristic dimension of 3.068 inches does not properly apply to the first modular component, a tee, of the gravity-feed and process-drain test module and the first modular component, a reducer and a $90^{\circ} 3 \mathrm{D}$ elbows, of the reducer and vertical-rise test module. As seen in Table S.1, the VFADs for the second modular component, a $90^{\circ} 3 \mathrm{D}$ elbow, of the jumper test module and for the second and fifth modular components, a $45^{\circ} 3 \mathrm{D}$ elbow, of the reducer and vertical-rise test module were undetermined due to high uncertainty.

From Table S.1, the following findings are reported for the pressure-drop measurements:

- A complete flow blockage by pipe plugging did not occur at the smallest flow velocity used for the testing; however, the flow velocity was kept constant by the feedback system of the pump with the VFD

- Due to high uncertainty in the critical velocity evaluations in the absence of a definite J-curve profile, VFADs provide the velocities at which it is assured that no particle deposition occurs

- A definite profile of the J-curve was not obtained in this testing due to high fluctuations in DPT data

- Smallest velocities obtained in this testing need not to be critical velocities

- Critical velocities for the fittings used for in this testing are lower than that for a straight horizontal pipe reported by Poloski et al. (2008), except in the case of a tee in the gravity-feed and process-drain test spool; however, high uncertainty in the critical velocity evaluations is expected

For the overflow-relief piping test, an 8-inch pipeline test spool with geometry identical to the gravity-feed and process-drain test spool (Section 5 presents the test spools in detail) used for the pressure-drop measurements was used. The tests were performed by observing the particle-deposition process of the gravity-driven partially-filled pipe flow for the spool with three downward slopes of 1:125, 1:50, and 1:20 (a slope of 1:125 indicates one foot of vertical drop/rise for every 125 feet of horizontal distance). For the minimum flow rate of $45 \mathrm{gpm}$ for the 1:125 slope and the minimum flow rate of 33 gpm for the 1:50 and 1:20 slopes, a complete flow blockage by pipe plugging did not occur and the following findings were reported: 
- At the slope of $1: 125,1)$ substantial solids deposition occurred at a flow rate of $161 \mathrm{gpm}$ and below, where 3-inch deposition height in an 8-inch pipe is defined as substantial solids deposition, and 2) it is conceivable that a complete flow blockage is possible under certain conditions

- At the slope of 1:50,1) substantial solids deposition occurred at a flow rate of 93 gpm and below and 2) small amounts of solids deposition occurred at the flow rate of $115 \mathrm{gpm}$

- At the slope of 1:20, no deposition occurred at any of the flow rates used in testing

- For all three slopes, removing the deposited particles from the pipe surface was difficult; therefore, it is recommended to assure that the overflow channel system is thoroughly flushed out after a vesseloverflow event

From the flush tests, it was found that a flush-to-line volume ratio of 3 was needed to remove sediment beds from the flow-loop system with the gravity-feed and process-drain test spool whereas design-guide 24590-WTP-GPG-M-0058, Rev. 0 (Hall 2006) provides a minimum flush-volume ratio of 1.7 for non-Newtonian fluids. The design-guide appears to be satisfied for the jumper test spool, the complex-geometry test spool, and the reducer and vertical-rise test spool. For all of the test spools, the flushing operations were performed with the following caveats:

- The pneumatic flush system must be opened slowly to erode the sediment bed from the top down. If the pneumatic flush system is opened quickly, the sediment bed is simply pushed to the nearest corner, and a granular plug develops and completely fills the line cross-sectional area.

- The flush volume and flush velocity provided by design-guide 24590-WTP-GPG-M-0058, Rev. 0 (Hall 2006) were difficult to achieve manually. Depending on the process line geometry, flows in the range of 500 to $1,000 \mathrm{gpm}$ can be achieved with this system. Since piping volumes may be on the order of 50 to 100 gallons, manually closing a valve to hit this target volume may be challenging. Compounding this problem, valves need to be closed slowly to avoid water hammer. 
Table S.1. Critical velocity and VFAD evaluated from the uncorrected DPT data

\begin{tabular}{|c|c|c|c|c|c|c|c|}
\hline \multirow{2}{*}{$\begin{array}{l}\text { Test } \\
\text { Spool }\end{array}$} & \multicolumn{5}{|c|}{$\begin{array}{l}\text { Evaluated Critical Velocities of Modular } \\
\text { Components (ft/sec) }\end{array}$} & \multirow{2}{*}{$\begin{array}{l}\text { Range of Velocity for } \\
\text { Avoiding Deposition } \\
\text { (VFAD) } \\
\text { (ft/sec) }\end{array}$} & \multirow{2}{*}{$\begin{array}{c}\text { Critical } \\
\text { Velocity of } \\
\text { Straight Pipe } \\
\text { (ft/sec) }\end{array}$} \\
\hline & DPT \# & Component & $\begin{array}{c}\text { Run } \\
1\end{array}$ & $\begin{array}{c}\text { Run } \\
2\end{array}$ & $\begin{array}{c}\text { Run } \\
3\end{array}$ & & \\
\hline \multirow{5}{*}{$\begin{array}{l}\text { Gravity } \\
\text { Feed } \\
\text { and } \\
\text { Process } \\
\text { Drain }\end{array}$} & 1 & Tee & 3.5 & 3.5 & 3.5 & $>=4.0$ & \multirow{18}{*}{2.7} \\
\hline & 2 & $90^{\circ} 3 \mathrm{D}$ Elbow & 2.5 & 1.5 & $2.5^{\wedge}$ & $>=3.5$ & \\
\hline & 3 & $90^{\circ}$ 3D Elbow & 2.0 & 2.0 & $2.5^{\wedge}$ & $>=3.5$ & \\
\hline & 4 & $90^{\circ} 3 \mathrm{D}$ Elbow & $1.5^{\wedge}$ & 2.0 & $2.5^{\wedge}$ & $>=3.5$ & \\
\hline & 5 & $90^{\circ}$ 3D Elbow & 2.0 & $1.0^{\wedge}$ & 3.5 & $>=3.5$ & \\
\hline \multirow{3}{*}{ Jumper } & 1 & $90^{\circ}$ Miter Bend & $0.5^{\wedge}$ & $1.0^{\wedge}$ & $0.5^{\wedge}$ & $>=2.0$ & \\
\hline & 2 & $90^{\circ} 3 \mathrm{D}$ Elbow & $0.5^{\wedge}$ & 3.0 & $0.5^{\wedge}$ & * & \\
\hline & 3 & $90^{\circ}$ Miter Bend & $0.5^{\wedge}$ & $1.0^{\wedge}$ & $0.5^{\wedge}$ & $>=2.0$ & \\
\hline \multirow{5}{*}{$\begin{array}{l}\text { Complex } \\
\text { Geometry }\end{array}$} & 1 & $90^{\circ} 3 \mathrm{D}$ Elbow & 1.0 & $1.0^{\wedge}$ & $0.5^{\wedge}$ & $>=3.0$ & \\
\hline & 2 & $90^{\circ}+45^{\circ} 3 \mathrm{D}$ Elbows & $0.5^{\wedge}$ & $1.0^{\wedge}$ & $0.5^{\wedge}$ & $>=3.0$ & \\
\hline & 3 & $45^{\circ}+45^{\circ}$ 3D Elbows & 1.0 & $1.0^{\wedge}$ & $0.5^{\wedge}$ & $>=3.0$ & \\
\hline & 4 & $90^{\circ} 5 \mathrm{D}$ Elbow & 1.0 & $1.0^{\wedge}$ & 1.5 & $>=3.5$ & \\
\hline & 5 & $90^{\circ} 5 \mathrm{D}$ Elbow & 1.5 & $1.0^{n}$ & 1.5 & $>=3.5$ & \\
\hline \multirow{5}{*}{$\begin{array}{l}\text { Reducer } \\
\text { and } \\
\text { Vertical } \\
\text { Rise }\end{array}$} & 1 & $\begin{array}{c}\text { Reducer }+90^{\circ} 3 \mathrm{D} \\
\text { Elbow }\end{array}$ & $1.5^{\wedge}$ & $1.0^{\wedge}$ & $1.5^{\wedge}$ & $>=3.0$ & \\
\hline & 2 & $45^{\circ} 3 \mathrm{D}$ Elbow & $1.5^{\wedge}$ & $1.0^{n}$ & $1.5^{\wedge}$ & * & \\
\hline & 3 & $45^{\circ} 3 \mathrm{D}$ Elbow & $1.5^{\wedge}$ & $1.0^{\wedge}$ & $1.5^{\wedge}$ & $>=3.0$ & \\
\hline & 4 & $45^{\circ}+45^{\circ}$ 3D Elbows & $1.5^{\wedge}$ & $1.0^{\wedge}$ & $1.5^{\wedge}$ & $>=3.0$ & \\
\hline & 5 & $45^{\circ} 3 \mathrm{D}$ Elbow & 3.5 & $1.0^{n}$ & 2.5 & * & \\
\hline
\end{tabular}


Table S.2. Pressure drop, density, yield stress, consistency, and Reynolds number for the gravity-feed and process drain module test

\begin{tabular}{|c|c|c|c|c|c|c|c|c|c|c|c|c|c|c|c|}
\hline \multicolumn{16}{|c|}{ Gravity Feed and Process Drain } \\
\hline & \multicolumn{3}{|c|}{ Tee } & \multicolumn{3}{|c|}{$90^{\circ} 3 \mathrm{D}$ Elbow } & \multicolumn{3}{|c|}{$90^{\circ} 3 \mathrm{D}$ Elbow } & \multicolumn{3}{|c|}{$90^{\circ} 3 \mathrm{D}$ Elbow } & \multicolumn{3}{|c|}{$90^{\circ} 3 \mathrm{D}$ Elbow } \\
\hline & Run1 & Run2 & Run3 & Run1 & Run2 & Run3 & Run1 & Run2 & Run3 & Run1 & Run2 & Run3 & Run1 & Run2 & Run3 \\
\hline $\begin{array}{l}\text { Uncorrected } \\
\text { Pressure Drop } \\
\text { (psi) at VFAD }\end{array}$ & 0.037 & 0.034 & 0.035 & 0.050 & 0.049 & 0.048 & 0.045 & 0.025 & 0.041 & 0.032 & 0.034 & 0.033 & 0.057 & 0.050 & 0.053 \\
\hline $\begin{array}{c}\text { Corrected } \\
\text { Pressure Drop } \\
\text { (psi) at VFAD }\end{array}$ & 0.044 & 0.041 & 0.042 & 0.062 & 0.061 & 0.060 & 0.058 & 0.037 & 0.053 & 0.044 & 0.046 & 0.046 & 0.066 & 0.059 & 0.062 \\
\hline $\begin{array}{c}\text { Density* }(\mathrm{g} / \mathrm{mL}) \\
\text { at VFAD }\end{array}$ & 1.403 & 1.403 & 1.402 & 1.403 & 1.402 & 1.402 & 1.403 & 1.402 & 1.402 & 1.403 & 1.402 & 1.402 & 1.403 & 1.402 & 1.402 \\
\hline $\begin{array}{c}\text { Density** }(\mathrm{g} / \mathrm{mL}) \\
\text { at VFAD }\end{array}$ & 1.397 & 1.396 & 1.395 & 1.398 & 1.397 & 1.396 & 1.398 & 1.397 & 1.396 & 1.398 & 1.397 & 1.396 & 1.398 & 1.397 & 1.396 \\
\hline \multicolumn{16}{|c|}{ ^ Reynolds numbers are based on the nominal pipe size of 3 inches (3.068 inches ID). } \\
\hline \multicolumn{16}{|c|}{ * The density measurements were taken at a point upstream of the modular test section. } \\
\hline \multicolumn{16}{|c|}{${ }^{\star *}$ The density measurements were taken at a point downstream of the modular test section. } \\
\hline & & & & & & & & & & & & & & & \\
\hline
\end{tabular}


Table S.3. Pressure drop, density, yield stress, consistency, and Reynolds number for the jumper module test

\begin{tabular}{|c|c|c|c|c|c|c|c|c|c|}
\hline \multicolumn{10}{|c|}{ Jumper } \\
\hline & \multicolumn{3}{|c|}{$90^{\circ}$ Miter Bend } & \multicolumn{3}{|c|}{$90^{\circ} 3 \mathrm{D}$ Elbow } & \multicolumn{3}{|c|}{$90^{\circ}$ Miter Bend } \\
\hline & Run1 & Run2 & Run3 & Run1 & Run2 & Run3 & Run1 & Run2 & Run3 \\
\hline $\begin{array}{l}\text { Velocity for } \\
\text { Avoiding } \\
\text { Deposition } \\
\text { (VFAD) } \\
\text { (ft/sec) }\end{array}$ & 2.0 & 2.0 & 2.0 & 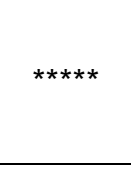 & 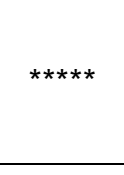 & 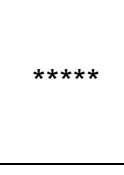 & 2.0 & 2.0 & 2.0 \\
\hline $\begin{array}{l}\text { Uncorrected } \\
\text { Pressure Drop } \\
\text { (psi) at VFAD }\end{array}$ & 0.223 & 0.202 & **** & 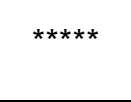 & 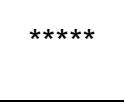 & 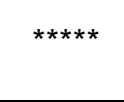 & 0.279 & 0.273 & 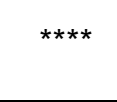 \\
\hline $\begin{array}{l}\text { Corrected } \\
\text { Pressure Drop } \\
\text { (psi) at VFAD }\end{array}$ & 0.105 & 0.085 & **** & 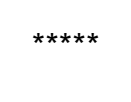 & 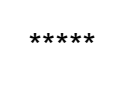 & 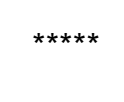 & 0.075 & 0.070 & $\star \star \star \star * ~$ \\
\hline 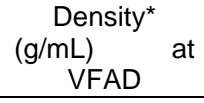 & 1.357 & 1.355 & 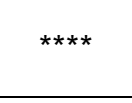 & 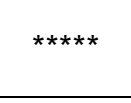 & 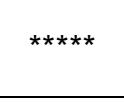 & 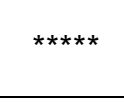 & 1.357 & 1.355 & 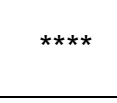 \\
\hline 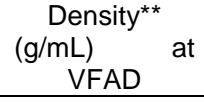 & 1.356 & 1.351 & 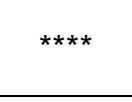 & 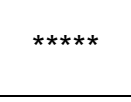 & 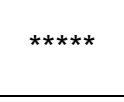 & 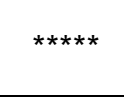 & 1.356 & 1.351 & 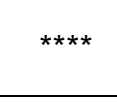 \\
\hline $\begin{array}{l}\text { Bingham Yield } \\
\text { Stress }(\mathrm{Pa})\end{array}$ & 2.83 & 2.79 & 2.45 & 2.83 & 2.79 & 2.45 & 2.83 & 2.79 & 2.45 \\
\hline $\begin{array}{l}\text { Bingham } \\
\text { Consistency } \\
(\mathrm{CP})\end{array}$ & 7.40 & 6.60 & 6.23 & 7.40 & 6.60 & 6.23 & 7.40 & 6.60 & 6.23 \\
\hline $\begin{array}{l}\text { Range of } \\
\text { Reynolds } \\
\text { numbers } \\
\text { used } d^{\star \star \star}\end{array}$ & $\begin{array}{c}2100 \\
\sim \\
35100\end{array}$ & $\begin{array}{c}4700 \\
\sim \\
39300\end{array}$ & $\begin{array}{c}2400 \\
\sim \\
41500\end{array}$ & $\begin{array}{c}2100 \\
\sim \\
35100\end{array}$ & $\begin{array}{c}4700 \\
\sim \\
39300\end{array}$ & $\begin{array}{c}2400 \\
\sim \\
41500\end{array}$ & $\begin{array}{c}2100 \\
\sim \\
35100\end{array}$ & $\begin{array}{c}4700 \\
\sim \\
39300\end{array}$ & $\begin{array}{c}2400 \\
\sim \\
41500\end{array}$ \\
\hline \multicolumn{10}{|c|}{ * The density measurements were taken at a point upstream of the modular test section. } \\
\hline \multicolumn{10}{|c|}{ ** The density measurements were taken at a point downstream of the modular test section. } \\
\hline \multicolumn{10}{|c|}{ 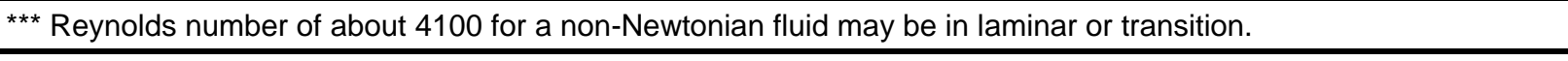 } \\
\hline \multicolumn{10}{|c|}{$\begin{array}{l}\star \star \star \star * \\
\text { performed at this velocity. }\end{array}$} \\
\hline 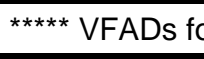 & & & & & & & & & \\
\hline
\end{tabular}


Table S.4. Pressure drop, density, yield stress, consistency, and Reynolds number for the complex geometry module test

\begin{tabular}{|c|c|c|c|c|c|c|c|c|c|c|c|c|c|c|c|}
\hline \multicolumn{16}{|c|}{ Complex Geometry } \\
\hline & \multicolumn{3}{|c|}{$90^{\circ} 3 \mathrm{D}$ Elbow } & \multicolumn{3}{|c|}{$90^{\circ}+45^{\circ} 3 \mathrm{D}$ Elbows } & \multicolumn{3}{|c|}{$45^{\circ}+45^{\circ}$ 3D Elbows } & \multicolumn{3}{|c|}{$90^{\circ} 5 \mathrm{D}$ Elbow } & \multicolumn{3}{|c|}{$90^{\circ} 5 \mathrm{D}$ Elbow } \\
\hline & Run1 & Run2 & Run3 & Run1 & Run2 & Run3 & Run1 & Run2 & Run3 & Run1 & Run2 & Run3 & Run1 & Run2 & Run3 \\
\hline $\begin{array}{l}\text { Velocity for } \\
\text { Avoiding } \\
\text { Deposition } \\
\text { (VFAD) (tt/sec) } \\
\end{array}$ & 3.0 & 3.0 & 3.0 & 3.0 & 3.0 & 3.0 & 3.0 & 3.0 & 3.0 & 3.5 & 3.5 & 3.5 & 3.5 & 3.5 & 3.5 \\
\hline $\begin{array}{l}\text { Uncorrected } \\
\text { Pressure Drop } \\
\text { (psi) at VFAD }\end{array}$ & 0.291 & 0.290 & **** & 0.305 & 0.304 & 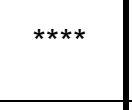 & 0.105 & 0.102 & **** & 0.281 & **** & 0.267 & 0.258 & $\star \star \star \star * ~$ & 0.275 \\
\hline $\begin{array}{l}\text { Corrected } \\
\text { Pressure Drop } \\
\text { (psi) at VFAD }\end{array}$ & 0.045 & 0.044 & **** & 0.045 & 0.045 & 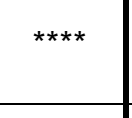 & 0.074 & 0.071 & **** & 0.046 & $* \star \star *$ & 0.059 & 0.065 & $* \star \star *$ & 0.047 \\
\hline $\begin{array}{c}\text { Density* }(\mathrm{g} / \mathrm{mL}) \\
\text { at VFAD }\end{array}$ & 1.333 & 1.332 & **** & 1.333 & 1.332 & 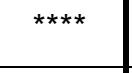 & 1.333 & 1.332 & **** & 1.335 & **** & 1.333 & 1.335 & 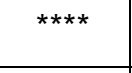 & 1.333 \\
\hline $\begin{array}{c}\text { Density** }(\mathrm{g} / \mathrm{mL}) \\
\text { at VFAD }\end{array}$ & 1.330 & 1.328 & 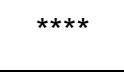 & 1.330 & 1.328 & 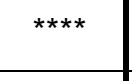 & 1.330 & 1.328 & $\star * \star * \star$ & 1.331 & 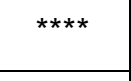 & 1.329 & 1.331 & 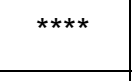 & 1.329 \\
\hline $\begin{array}{l}\text { Bingham Yield } \\
\text { Stress }(\mathrm{Pa})\end{array}$ & 2.71 & 2.85 & 2.75 & 2.71 & 2.85 & 2.75 & 2.71 & 2.85 & 2.75 & 2.71 & 2.85 & 2.75 & 2.71 & 2.85 & 2.75 \\
\hline $\begin{array}{c}\text { Bingham } \\
\text { Consistency (cP) }\end{array}$ & 5.72 & 6.30 & 5.74 & 5.72 & 6.30 & 5.74 & 5.72 & 6.30 & 5.74 & 5.72 & 6.30 & 5.74 & 5.72 & 6.30 & 5.74 \\
\hline $\begin{array}{c}\text { Range of } \\
\text { Reynolds } \\
\text { numbers used }\end{array}$ & $\begin{array}{c}2600 \\
\sim \\
44000\end{array}$ & $\begin{array}{c}4800 \\
\sim \\
40000\end{array}$ & $\begin{array}{c}2500 \\
\sim \\
41100\end{array}$ & $\begin{array}{c}2600 \\
\sim \\
44000\end{array}$ & $\begin{array}{c}4800 \\
\sim \\
40000\end{array}$ & $\begin{array}{c}2500 \\
\sim \\
41100\end{array}$ & $\begin{array}{c}2600 \\
\sim \\
44000\end{array}$ & $\begin{array}{c}4800 \\
\sim \\
40000\end{array}$ & $\begin{array}{c}2500 \\
\sim \\
41100\end{array}$ & $\begin{array}{c}2600 \\
\sim \\
44000\end{array}$ & $\begin{array}{c}4800 \\
\sim \\
40000\end{array}$ & $\begin{array}{c}2500 \\
\sim \\
41100\end{array}$ & $\begin{array}{c}2600 \\
\sim \\
44000\end{array}$ & $\begin{array}{c}4800 \\
\sim \\
40000\end{array}$ & $\begin{array}{c}2500 \\
\sim \\
41100\end{array}$ \\
\hline \multicolumn{16}{|c|}{ * The density measurements were taken at a point upstream of the modular test section. } \\
\hline \multicolumn{16}{|c|}{ ** The density measurements were taken at a point downstream of the modular test section. } \\
\hline \multicolumn{16}{|c|}{ *** Reynolds number of about 4100 for a non-Newtonian fluid may be in laminar or transition. } \\
\hline ressure & & & & & & & & & & & & & & & \\
\hline
\end{tabular}


Table S.5. Pressure drop, density, yield stress, consistency, and Reynolds number for the reducer and vertical rise module test

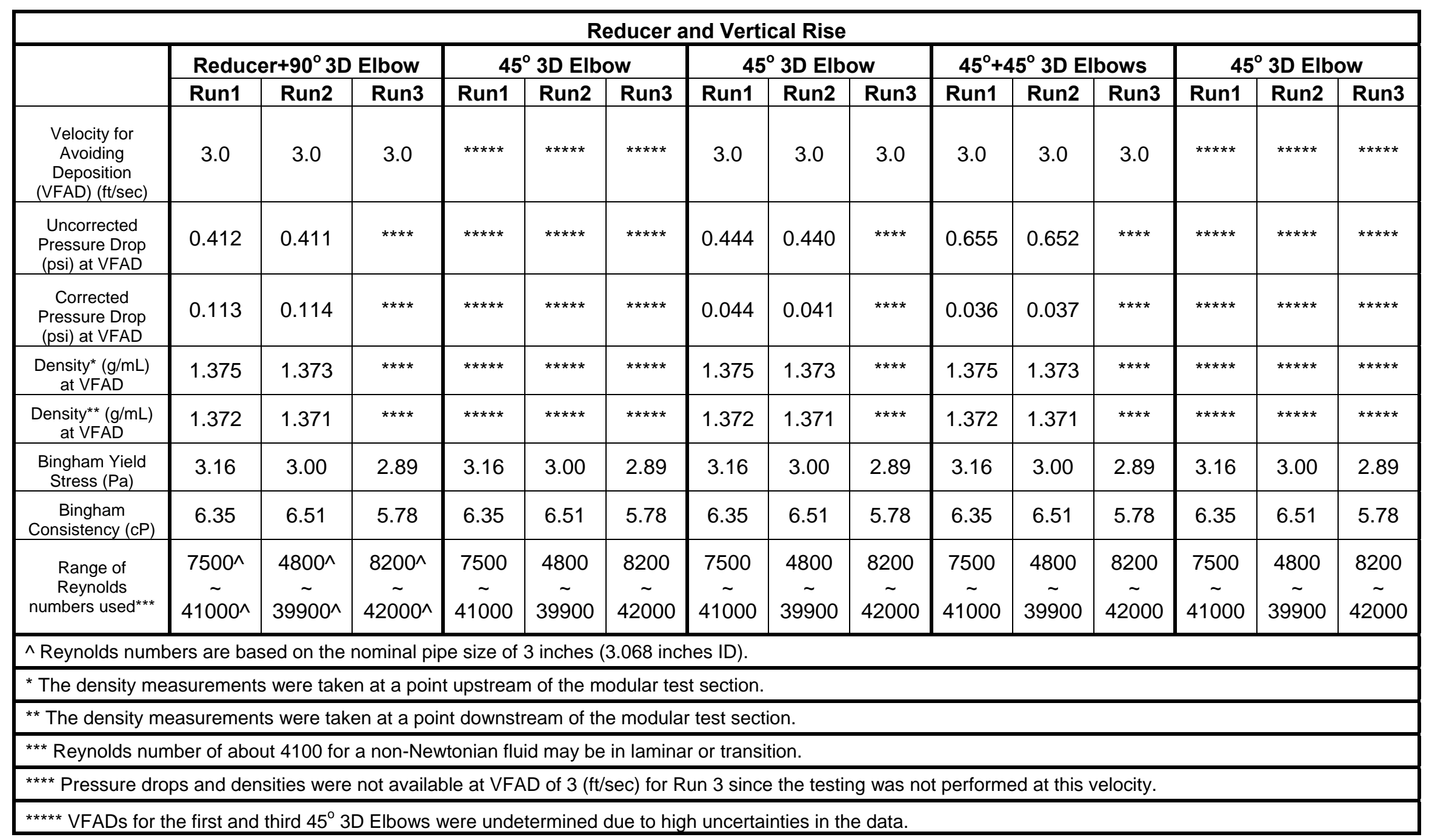




\section{S.1 Test Objectives}

The test objectives are provided in test specification 24590-WTP-TSP-RT-07-005, Rev. 0 (BNI 2007) and PNNL Test Plan TP-RPP-WTP-494, Rev. 0, and test results are discussed in Table S.6.

Table S.6. Test Objectives and Results

\begin{tabular}{|l|l|l|}
\hline Test Objective & $\begin{array}{l}\text { Objective Met? } \\
\text { (Yes/No) }\end{array}$ & Results/Comments \\
\hline $\begin{array}{l}\text { Verify critical flow velocity } \\
\text { correlations used by the WTP } \\
\text { project for physical properties } \\
\text { relevant to Hanford slurries are } \\
\text { conservative }\end{array}$ & NA & $\begin{array}{l}\text { Since the WTP design guide } \\
\text { Newtonian fluids in straight horizontal piping, the } \\
\text { objective of the current testing was to provide } \\
\text { critical velocities and velocities at which no particle } \\
\text { deposition occurs for a non-Newtonian slurry in the } \\
\text { WTP pipeline fittings. The testing also provides } \\
\text { data for an overflow-relief piping layout presented } \\
\text { by a WTP complex geometry. } \\
\text { The WTP design guide }\end{array}$ \\
& & $\begin{array}{l}\text { inadequate for a flushing operation with the be } \\
\text { complex piping geometry with a non-Newtonian } \\
\text { slurry of a yield stress of 3 Pa. }\end{array}$ \\
\hline
\end{tabular}

\section{S.2 Test Exceptions}

No test exception was applied to this investigation.

\section{S.3 Results and Performance Against Success Criteria}

The success criteria are provided in test specification 24590-WTP-TSP-RT-07-005, Rev. 0 (BNI 2007) and PNNL Test Plan TP-RPP-WTP-494, Rev. 0, and test results are discussed in Table S.7.

(a) WTP Project Doc. No. 24590-WTP-GPG-M-0058, Rev 0, Minimum Flow Velocity for Slurry Lines, November 27, 2006. 
Table S.7. Success Criteria and Results

\begin{tabular}{|l|l|}
\hline Success Criteria/Findings & Results \\
\hline Verify that solids do not settle at the design-basis & $\begin{array}{l}\text { In the absence of a design guide, the current testing } \\
\text { provided data for the critical velocities and velocities } \\
\text { at which no particle deposition occurs for a non- } \\
\text { Newtonian slurry in the WTP pipeline fittings. The } \\
\text { evaluated critical velocities were lower than that } \\
\text { reported by Poloski et al. (2008), except for a tee } \\
\text { fitting; however, high uncertainty in the critical } \\
\text { velocity evaluations is expected. This testing also } \\
\text { provides data for an overflow-relief piping layout } \\
\text { presented by a WTP complex geometry. For the flush } \\
\text { system, the design guide recommends a flush-to-line } \\
\text { volume ratio of 1.7 for non-Newtonian fluids; } \\
\text { however, the current testing suggests a minimum } \\
\text { flush-to-line volume ratio was as high as 3. }\end{array}$ \\
\hline $\begin{array}{l}\text { Determine the velocity at which solids settle to } \\
\text { document the design margin. }\end{array}$ & $\begin{array}{l}\text { In the absence of a design guide to predict the critical } \\
\text { velocities for the pipeline layout pertinent to the } \\
\text { current testing, this success criterion is inapplicable. }\end{array}$ \\
\hline $\begin{array}{l}\text { Demonstrate the adequacy of the design basis to } \\
\text { avoid plugging due to particle settling in piping. }\end{array}$ & $\begin{array}{l}\text { A complete flow blockage by pipe plugging did not } \\
\text { occur at the smallest flow velocity used for this } \\
\text { testing; however, the flow velocity was kept constant } \\
\text { by the feedback system of the pump with the variable } \\
\text { frequency drive. }\end{array}$ \\
\hline
\end{tabular}

\section{S.4 Quality Requirements}

PNNL's Quality Assurance Program is based on requirements defined in U.S. Department of Energy (DOE) Order 414.1C, Quality Assurance, and 10 CFR 830, Energy/Nuclear Safety Management, Subpart A-Quality Assurance Requirements (a.k.a. the Quality Rule). PNNL has chosen to implement the requirements of DOE Order 414.1C and 10 CFR 830, Subpart A by integrating them into the Laboratory's management systems and daily operating processes. The procedures necessary to implement the requirements are documented through PNNL's Standards-Based Management System.

PNNL implements the RPP-WTP quality requirements by performing work in accordance with the River Protection Project-Waste Treatment Plant Support Program (RPP-WTP) Quality Assurance Plan (RPP-WTP-QA-001, QAP). Work was performed to the quality requirements of NQA-1-1989 Part I, Basic and Supplementary Requirements, NQA-2a-1990, Part 2.7, and DOE/RW-0333P, Rev. 13, Quality Assurance Requirements and Descriptions (QARD). These quality requirements are implemented through the River Protection Project-Waste Treatment Plant Support Program (RPP-WTP) Quality Assurance Manual (RPP-WTP-QA-003, QAM). 


\section{S.5 Test Conditions}

Test conditions were controlled with administrative hold points. Several hold points are identified in the "Test Conditions" section of test specification 24590-WTP-TSP-RT-07-005, Rev. 0 (BNI 2007). These hold points were translated into PNNL Test Plan TP-RPP-WTP-494, Rev. 0. The status of each of the hold points is summarized in Table S.8:

Table S.8. Status of Project Hold Points

\begin{tabular}{||l|l|l|l||}
\hline \multicolumn{1}{|c|}{ Test Plan } & \multicolumn{1}{|c|}{ Hold Point } & \multicolumn{1}{c|}{$\begin{array}{c}\text { WTP Project } \\
\text { Approved On }\end{array}$} \\
\hline $\begin{array}{l}\text { TP-RPP-WTP-494, } \\
\text { Rev. 0 }\end{array}$ & $\begin{array}{l}\text { \#1 a. BNI approve test plan. } \\
\text { b. BNI approve test simulants. }\end{array}$ & $\begin{array}{l}\text { a. } 6 / 19 / 07 \\
\text { b. } 11 / 9 / 07\end{array}$ & $\begin{array}{l}\text { a.(Signed Test Plan) } \\
\text { b. CCN 163048 }\end{array}$ \\
\cline { 2 - 5 } & $\begin{array}{l}\text { \#2 BNI provide specifications for each } \\
\text { modular system }\end{array}$ & $9 / 19 / 07$ & CCN 160527 \\
\cline { 2 - 5 } & $\begin{array}{l}\# 3 \text { a. BNI approve part number } \\
\text { identification (P\&ID)/drawing before } \\
\text { fabrication. } \\
\text { b. BNI approve test matrix. }\end{array}$ & $\begin{array}{l}\text { a. 9/19/07 } \\
\text { b. 12/17/07 }\end{array}$ & $\begin{array}{l}\text { a. CCN 160527 } \\
\text { b. CCN } 163054\end{array}$ \\
\cline { 2 - 5 } & $\begin{array}{l}\text { \#4 BNI define flush-tank operating } \\
\text { pressures and an acceptable solids residue } \\
\text { after flushing tests. }\end{array}$ & $12 / 17 / 07$ & CCN 163054 \\
\hline
\end{tabular}

\section{S.6 Simulant Use}

A physical simulant was used in this testing. As discussed in the Test Conditions section, hold point \#1 allowed BNI to review and accept the test simulants before testing. The initial simulant for the modular tests was prepared by adding alumina and a premixed kaolin clay and water slurry to the alumina simulant used in the reference case testing by Poloski et al. (2008). Kaolin clay and alumina were added to increase the volume of the simulant while maintaining the rheology and volume fraction of coarse particles. The target composition of the simulant was $10 \mathrm{vol} \%$ alumina suspended in a kaolin clay and water slurry with a Bingham plastic yield stress of $3 \mathrm{~Pa}$. A detailed description of simulants used in the testing is presented in Section 4 of this report.

\section{S.7 Recommended Follow-on Tests}

- Follow-on Test Recommendation \#1-In order to accurately determine the velocity at which solids deposit in piping components by reducing uncertainty in pressure-drop data, it is recommend to set pressure ports on the locations where steady-uniform flow is assured. In addition, it is recommended that the density be measured at the point where the pressure is measured.

- Follow-on Test Recommendation \#2-The overflow-relief piping test performed did not find pipe plugging; however, testing for a longer time period with the smallest flow rate is recommended to observe whether particle deposition continues to develop and plug the system. 
- Follow-on Test Recommendation \#3-It is recommended that the flush system be supplemented by a closed-loop feedback system consisting of a flow meter, a level indicator, and an automatic control valve for flushing operations.

- Follow-on Test Recommendation \#4-In order to increase confidence in the results presented in this report, a series of chemical simulant tests are recommended. Dilutions of the chemical simulant will be made to span the entire range of yield stresses permitted in the plant ( 0 to $30 \mathrm{~Pa}$ ). Data from these tests will be used to validate the conclusions made with the physical simulants used in the reference case testing by Poloski et al. (2008). The chemical simulant should be designed to mimic the chemical, physical, and rheological properties of Hanford tank waste. 


\subsection{Introduction}

The U.S. Department of Energy (DOE) Office of River Protection's (ORP) Waste Treatment and Immobilization Plant (WTP) will process and treat radioactive waste that is stored in tanks at the Hanford Site. Piping, pumps, and mixing vessels will transport, store, and mix the high-level waste slurries in the WTP.

The WTP pipe-plugging issue, as stated by the External Flowsheet Review Team (EFRT) Executive Summary, is as follows: "Piping that transports slurries will plug unless it is properly designed to minimize this risk. This design approach has not been followed consistently, which will lead to frequent shutdowns because of line plugging" (WTP/CCN 132846). ${ }^{(a)}$ Additional details relating to the EFRT summary are provided in a supplemental background document (CCN 132847). ${ }^{\text {(b) }}$ The WTP Project is implementing a strategy to address the above EFRT issue identified as "Issue M1—Plugging in Process Piping." For part of the strategy, the requirements for testing have been established by test specification 24590-WTP-TSP-RT-07-005, Rev. 0 (BNI 2007) in that document, the test objective is specified as "Verify critical flow velocity correlations used by the WTP project for physical properties relevant to Hanford slurries are conservative."

The testing described herein is to determine critical velocities and velocities for avoiding deposition (VFAD) for the complex WTP piping layout. Critical velocity is defined as the point where, during slurry-transport operations, a moving bed of particles begins to form on the pipe bottom whereas VFAD is defined as the velocity at which no particle deposition occurs in the slurry transporting process. Pressure drops across the fittings of the test pipeline were measured, from which critical velocities and VFADs were determined. Upon completion of the pressure-drop measurement, the flow loop was flushed to test the WTP prototype flush system. This testing also provides data for the overflow-relief system representing the WTP piping geometry with a non-Newtonian slurry.

A waste simulant composed of alumina (nominally $50 \mu \mathrm{m}$ in diameter) suspended in a kaolin clay slurry was used for this testing. The target composition of the simulant was $10 \mathrm{vol} \%$ alumina in a suspending medium with a yield stress of $3 \mathrm{~Pa}$.

An experimental flow loop was constructed with a modular test section, mixing tank, slurry pump, and instrumentation for measuring flow rate and pressure drop across the modular components. Five spools were tested as follows: a test was performed with a spool installed in the modular test section and then the modular test section was replaced with the next test spool for the next test.

To measure the pressure drop across the components of a test module, the slurry flow velocity was set to $7.5 \mathrm{or} 8 \mathrm{ft} / \mathrm{sec}$ at the beginning of a test. The flow was then decreased in increments and steady-state pressure-drop values across the components of the test spool were measured at each flow velocity (note:

(a) WTP Project Doc. No. CCN 132846 "Comprehensive Review of the Hanford Waste Treatment Plant Flowsheet and Throughput-Assessment Conducted by an Independent Team of External Experts," March 2006.

(b) WTP Project Doc. No. CCN 132847 "Background Information and Interim Reports for the Comprehensive Review of the Hanford Waste Treatment Plant Flowsheet and Throughput-Assessment Conducted by an Independent Team of External Experts," March 2006. 
the feedback system of the pump with the variable frequency drive (VFD) maintained the flow velocity constant during the measurement). A rise in the pressure-drop value as the flow velocity decreases indicates that the pipe cross-sectional area is filled with settled slurry particles. The minimum point in the pressure drop versus velocity curve is referred to as the critical velocity. The VFAD is determined in such a way that pressure drop corresponding to the VFAD is adequately large to assure that slurry flow does not undergo particle deposition from the pressure drop versus velocity curve.

The data for the overflow-relief piping of the WTP geometry with a non-Newtonian slurry were obtained by observing the slurry particle deposition process. The test was started with the nominal slurry pipeline flow velocity of $8 \mathrm{ft} / \mathrm{sec}$. The flow was then decreased in increments and held constant for a minimum of 30 minutes (note: the feedback system of the pump with the VFD maintained the nominal flow velocity constant during the observation); during which time observations were made.

To remove the sediment bed from the system, a WTP prototype flush system was installed and tested. This system consists of a pressure vessel containing an initial charge of water. The pressure was then increased to a target value, nominally 100 to 110 psig. Upon completion of the pressure-drop measurements, a valve was opened, and the high-pressure water flush removed deposited slurry particles from the pipeline loop.

The critical velocities determined are compared to that of a straight horizontal pipe reported by Poloski et al. (2008). The results of the flush test are compared to the WTP design guide 24590-WTPGPG-M-0058, Rev. 0 (Hall 2006) in an effort to inspect the flushing-velocity requirements as established in the design guide. 


\subsection{Quality Requirements}

PNNL's Quality Assurance Program is based on requirements defined in U.S. Department of Energy (DOE) Order 414.1C, Quality Assurance, and Title 10 of the Code of Federal Regulations (CFR)

Part 830, Energy/Nuclear Safety Management, Subpart A-Quality Assurance Requirements (a.k.a. the Quality Rule). PNNL has chosen to implement the requirements of DOE Order 414.1C and 10 CFR 830, Subpart A by integrating them into PNNL's management systems and daily operating processes. The procedures necessary to implement the requirements are documented through PNNL's Standards-Based Management System.

PNNL implements the RPP-WTP quality requirements by performing work in accordance with the River Protection Project-Waste Treatment Plant Support Program (RPP-WTP) Quality Assurance Plan (RPP-WTP-QA-001, QAP). Work was performed to the quality requirements of NQA-1-1989 Part I, Basic and Supplementary Requirements, NQA-2a-1990, Part 2.7 and DOE/RW-0333P, Rev. 13, Quality Assurance Requirements and Descriptions ( $Q A R D)$. These quality requirements are implemented through the River Protection Project-Waste Treatment Plant Support Program (RPP-WTP) Quality Assurance Manual (RPP-WTP-QA-003, QAM). 


\subsection{Background}

The WTP of the U.S. DOE Office of River Protection (ORP) will process and treat radioactive waste that is stored in tanks at the Hanford Site. The EFRT identifies issues regarding interruptions in the process of the waste transfer operation from the Hanford tank farms to the WTP facility due to pipe plugging caused by settling solids.

The flow regime at the pipeline wall under settling conditions is unstable, and progresses from solid particles settling out of the fluids to the formation of a moving bed of solid particles, and eventually to the formation of a stagnant (stationary) bed of solid particles. In order to prevent mechanical pipeline plugging by the formation of a stationary bed of solid particles, a minimum flow velocity is required to maintain the solid particles in suspension.

The WTP Project has addressed the determination of the critical velocity to preclude solid particles settling and has issued design guide 24590-WTP-GPG-M-058, Rev. 0 (Hall 2006), which provides methods for predicting the critical velocity. The issued WTP design guide 24590-WTP-GPG-M-058, Rev. 0 (Hall 2006) is applicable only to Newtonian fluids in straight horizontal piping. Generally, the critical velocity depends on slurry rheological properties, particle size, particle shape, solids concentration, and piping layout. In fact, some of the Hanford tank slurries are non-Newtonian, and the WTP piping layout is complex as it includes fittings such as short elbows, miter bends, and vertical risers. These fittings can cause stagnation or low-velocity fields where solids tend to settle. Length-of-approach to fittings can also be a critical parameter in plug formation.

Critical velocity tests on physical simulants have been performed, and were reported by Poloski et al. (2008). Tests performed included simulant test particles ranging in density from 2.5 to $8 \mathrm{~g} / \mathrm{cc}$, while the nominal particle sizes ranged from 10 to $100 \mu \mathrm{m}$ with target Bingham-plastic yield-stress values of 0,3 , and $6 \mathrm{~Pa}$. Even though several tank samples had Bingham yield stresses that exceed $6 \mathrm{~Pa}$, fluids with moderate yield stresses were selected by Poloski et al. (2008) since the critical-velocity equations are derived for Newtonian, turbulent flow conditions. Laminar, not turbulent, flow conditions would be observed in fluids with higher yield stresses at flow rates in the $4 \mathrm{ft} / \mathrm{sec}$ velocity range. Poloski et al. (2008) showed that the deposition of slurry particles for the simulants used was a strong function of slurry rheological properties. The critical velocities were calculated with the WTP design guide methodology for simulants whose slurry physical and rheological properties were applicable to the design guide 24590WTP-GPG-M-058, Rev. 0 (Hall 2006) and compared to critical velocities obtained in the tests.

The WTP pipelines are flushed after a slurry transfer to remove solid particles that have settled. The report by Poloski et al. (2008) includes evaluation of the pipeline flushing system velocity and flush volume from the test data, and compares them with those determined with design guide 24590-WTPGPG-M-058, Rev. 0 (Hall 2006) for the simulants and pipeline layout that were applicable to design guide 24590-WTP-GPG-M-058, Rev. 0 (Hall 2006).

From the critical velocity tests reported by Poloski et al. (2008), it is evident that design guide 24590WTP-GPG-M-058, Rev. 0 (Hall 2006) has limited applications to Hanford tank slurries. To provide an analytical guide to design the Hanford pipelines with complex geometry, the WTP has issued design guide 24590-WTP-GPG-M-016, Rev. 2 (Hall 2007) to determine the pressure drop across valves and fittings for Bingham-plastic fluids. However, there is no design guide available to predict critical 
velocity, flush velocity, and flush volume for the complex geometry of the WTP piping layout; the existing experimental database does not include the effect of the pipe fittings on critical velocity determination.

To address the issues of slurry transport from the overfilled vessel to the reservoir of the WTP overflow relief system through an unpressurized (atmospheric pressure) pipe obstructed by slurry particle deposition, the WTP has issued two separate design guides: 1) design guide 24590-WTP-GPG-M-027, Rev. 5(Kloster 2007) to provide piping-slope recommendations for pressure- and gravity-transfer process systems and utility services and 2) design guide 24590-WTP-GPG-M-032, Rev. 3 (Donoso 2007) to provide guidance for sizing vessel overflow nozzles and gravity overflow lines. However, the application of these two design guides includes neither non-Newtonian slurries nor overflow pipelines of complex geometry.

To provide an engineering basis to support DOE ORP obligations to close the issues identified by the EFRP related to pipeline plugging caused by complex piping geometry, testing was performed to determine critical velocity and velocity for avoiding deposition (VFAD) and to inspect the applicability of design guide 24590-WTP-GPG-M-058, Rev. 0 (Hall 2006) for flush velocity, flush volume and flush duration to unique piping geometry (non-horizontal sections) representing the WTP design. In addition, this testing provides data for the WTP overflow relief system with unique piping geometry, representing the WTP design with a non-Newtonian slurry.

\subsection{Critical Velocity and Velocity for Avoiding Deposition (VFAD)}

The WTP has issued design guide 24590-WTP-GPG-M-016, Rev. 2 (Hall 2007) to determine the pressure drop across valves and fittings for Bingham-plastic fluids. However, this design guide does not provide methods to predict critical velocity.

It is practical to use the distribution of pressure-drop versus velocity for evaluation of the critical velocity. Poloski et al. (2008) measured the pressure drop across a distance of 224.75 inches of a straight horizontal pipe for non-Newtonian fluids for the pipeline velocity range of approximately 1 to $8 \mathrm{ft} / \mathrm{sec}$. A distribution curve typical of the pressure-drop-versus-pipeline-velocity they obtained is shown in Figure 3.1. It is seen in Figure 3.1 that, as the pipeline velocity decreases from the maximum, the pressure drop decreases to the minimum. Below that, while the pipeline velocity continues to decrease, the pressure drop increases. This distribution profile is referred to as a "J-curve." The pipeline velocity at which the minimum pressure drop is observed is referred to as the "critical velocity." Below this critical velocity, the slurry particles are assumed to settle on the bottom of the modular components. The definition of critical velocity used by Poloski et al. (2008) was applied to the current report to evaluate critical velocities for unique piping geometries (non-straight and non-horizontal sections) representing the WTP design. For the data in which the minimum pressure drop is observed at more than a single velocity, the largest velocity at which the minimum pressure drop is observed is defined as the critical velocity. In addition, for the data in which the minimum pressure drop is observed at the smallest velocity as the pressure drop continues to decrease as the velocity decreases, the smallest velocity is defined as the critical velocity in this report.

In addition to the critical velocity, the velocity for avoiding deposition (VFAD) was evaluated in this report. VFAD is defined as the velocity at which no particle deposition occurs. From a distribution of 
pressure-drop versus velocity, VFAD is determined in such a way that pressure drop corresponding to the VFAD is adequately large to assure that slurry flow does not undergo particle deposition. VFAD can be useful for data without a definite J-curve profile from which an accurate critical velocity evaluation is not possible.

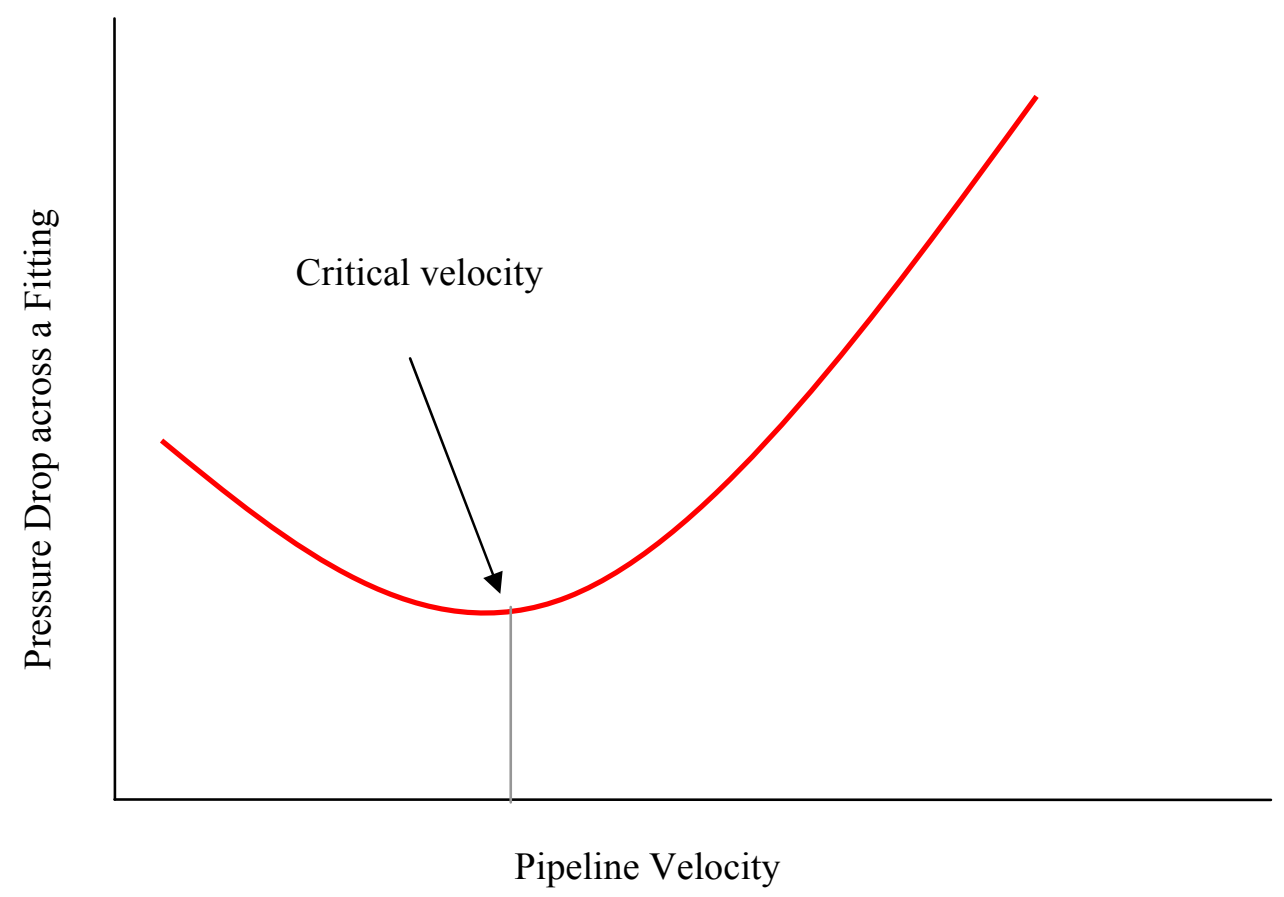

Figure 3.1. Pressure drop across a straight horizontal pipeline versus velocity for a non-Newtonian fluid

\subsection{Gravity-Driven Partially-Filled (GDPF) Pipe Flow Test}

The specifications for an overflow-relief system of gravity-driven partially-filled (GDPF) pipe flow given by design guides 24590-WTP-GPG-M-027, Rev. 5 (Kloster 2007) and 24590-WTP-GPG-M-032, Rev. 3 (Donoso 2007) are applicable to the system in which the fluid of concern is either a Newtonian fluid, with properties similar to water, or Newtonian slurry with a viscosity/specific gravity ratio specified by Table 1 in Appendix A of design guide 24590-WTP-GPG-M-032, Rev.3 (Donoso 2007). The simulant used in this testing had a small but non-zero yield stress, which made it a Bingham plastic.

Three tests were performed with the 8-inch pipe slopes of 1:125, 1:50, and 1:20, respectively, which correspond adequately to those provided in Table 1 of Appendix A of design guide 24590-WTP-GPG-M032, Rev.3 (Donoso 2007). The slurry particle deposition process was observed through the transparent sections and through the open port on the test module, and inspected by inserting a hand through the open port on the test module.

\subsection{Flush System Test}


Design guide 24590-WTP-GPG-M-0058, Rev. 0 (Hall 2006) specifies upper limits on the flushing velocity of $12 \mathrm{ft} / \mathrm{sec}$ and $10 \mathrm{ft} / \mathrm{sec}$ for the process streams with and without the glass-former chemicals (GFC), respectively. This upper limit is in place to limit pipe erosion. The flush volume upper limit is stated at 3 line volumes. The lower flush volume limits are 1.5 and 1.7 line volumes for Newtonian and non-Newtonian process lines, respectively. The flush system testing is conducted to determine whether the flush velocity, flush volume and flush duration provided by design guide 24590-WTP-GPG-M-058, Rev. 0 (Hall 2006) are applicable to the unique piping geometry (non-horizontal sections) representing the WTP design.

The transient flow rate of the flush solution rushing through the test flow loop and density of the simulant flowing into the spent simulant vessel are measured. Since the density of the flush solution is known, an assessment of the effectiveness of the flush can be made.

\subsection{Modular Test Section}

WTP Engineering has provided the general layout of the prototype test loop to be representative of the WTP plant pipe layout. The following mock-up components are tested in the modular test sections of the flow-loop system:

- Miter bends

- Vertical risers

- Gravity feed lines

- Gravity-driven partially-filled (GDPF) pipe flow geometries

- Vessel overflow geometries

- Process drain geometries

- Break pot geometries

For this testing, five slurry loop configurations including the mock-up components listed above were used. The five test spools of these configurations are described in Table 3.1 in the next section. The WTP piping to be represented is 3 inches in diameter.

\subsection{Test Strategy}

An experimental program was implemented to accomplish the test objective to "Verify critical flow velocity correlations used by the WTP project for physical properties relevant to Hanford slurries are conservative" as given in test specification 24590-WTP-TSP-RT-07-005, Rev. 0 (BNI 2007).

Furthermore, the test specification defines the test objective as to: 1) "Perform slurry loop/flushing tests with simulants on a mock-up of unique piping geometry challenges representing the WTP design to confirm that the selected design basis flow velocity is adequate" and 2) "Include jumper connections and long vertical pipelines in flushing tests."

An experimental flow-loop system was constructed with a modular test section. Five spools were tested. The test matrix is given in Table 3.1, where the spools used in this testing are summarized as well. A test was performed with a spool installed in the modular test section, and then the modular test section was replaced with another spool for the next test. Thus, five test sets for five spools were conducted. In order to confirm the repeatability of the tests, the first, second, third, and fourth test sets were repeated in 
triplicate (see Table 3.1). For the fifth test set, the test was performed for 3 different spool slopes as described in Subsection 3.2. Therefore, a total of 15 test runs were conducted. In this testing, as shown in Table 3.1, the first test set is referred to as the "gravity-feed and process-drain module test," the second test set as the "jumper module test," the third test set as the "complex-geometry module test," the fourth test set as the "reducer and vertical-rise module test," and the fifth test set as the "gravity-driven partiallyfilled (GDPF) pipe flow test." For the jumper module test, the test section was set up by connecting the jumper module to the gravity-feed and process-drain module in such a way that slurry flow from the jumper module entered the gravity-feed and process-drain module. The details of the test spools used and the experiment setup are given in Section 5.

Table 3.1. Test matrix with test spools used

\begin{tabular}{|c|c|c|c|}
\hline $\begin{array}{l}\text { Test Set } \\
\text { Number }\end{array}$ & Geometries Tested & $\begin{array}{c}\text { Number } \\
\text { of Test } \\
\text { Runs }\end{array}$ & Test Name \\
\hline 1 & $\begin{array}{ll} & \text { Gravity feed lines } \\
- & \text { Process drain geometries }\end{array}$ & 3 & Gravity-feed and process-drain module test \\
\hline 2 & - $\quad$ Miter bends & 3 & Jumper module test \\
\hline 3 & - Complex geometry & 3 & Complex-geometry module test \\
\hline 4 & $\begin{array}{ll}\text { - } & \text { Reducers } \\
\text { - } & \text { Vertical risers }\end{array}$ & 3 & Reducer and vertical-rise module test \\
\hline 5 & $\begin{array}{ll} & \text { Vessel overflow geometries } \\
\text { - } & \text { Gravity-driven partially-filled } \\
& \text { pipe flow geometries } \\
\text { - } & \text { Break pot geometries }\end{array}$ & 3 & Gravity-driven partially-filled pipe flow test \\
\hline $\begin{array}{c}\text { Total } \\
\text { Test Runs }\end{array}$ & --- & 15 & --- \\
\hline
\end{tabular}

In order to provide the engineering basis to accomplish the test objectives given in test specification 24590-WTP-TSP-RT-07-005, Rev. 0 (BNI 2007), the tests were performed:

0 to evaluate critical velocities and VFADs as described in Subsection 3.1 in the "gravity-feed and process-drain module test," the "jumper module test," the "complex-geometry module test," and "reducer and vertical-rise module test"

0 to inspect the slurry particle deposition process of the GDPF pipe flow as described in Subsection 3.2 in the "GDPF pipe flow test"

o to measure the flush velocity, flush volume and flush duration as described in Subsection 3.3 in the "gravity-feed and process-drain module test," the "jumper module test," the "complexgeometry module test," and "reducer and vertical-rise module test."

The slurry simulant used for this testing consisted of kaolin clay and nominal $50 \mu \mathrm{m}$ alumina $\left(\mathrm{Al}_{2} \mathrm{O}_{3}\right)$ particles suspended in water. The composition of solids in this simulant was such that target Binghamplastic yield stress values of $3 \mathrm{~Pa}$ were achieved for all of the tests conducted. Section 4 describes the simulant used in detail.

The flow-loop system consists of a 400-gallon mixing tank, a Georgia Iron Works slurry pump, a 400-gallon pneumatic flush tank, and a 1,000-gallon capture tank. The test instrumentation includes two Coriolis flow meters to measure the slurry flow rate and the slurry density at the inlet and outlet of the 
flow-loop system, and differential pressure transducers to measure pressure differences across the components of the test modules. The details of the test apparatus are given in Section 5.

The tests for evaluating the critical velocity and the VFAD with the gravity-feed and process-drain test module, the jumper test module, the complex-geometry test module, and the reducer and vertical-rise test module were started with a nominal slurry pipeline flow velocity of either $7.5 \mathrm{or} 8 \mathrm{ft} / \mathrm{sec}$. The flow was then decreased in increments and a steady-state pressure-drop value was measured at each flow velocity. The flow velocity was kept constant during the measurement by the feedback system of the pump with the variable frequency drive (VFD). A rise in the pressure-drop value as the flow velocity decreases indicates that the pipe cross-sectional area is filled with settled slurry particles.

In the repeated test runs of the first, second, third, and fourth test sets, the pressure-drop measurements were not performed at all of the flow velocities at which the measurements were performed in the original test runs.

The test results and discussion are given in Section 7 where the critical velocities are compared to that reported by Poloski et al. (2008) for the same simulant property.

The GDPF pipe flow tests were started with the nominal slurry pipeline flow velocity of $8 \mathrm{ft} / \mathrm{sec}$ where the nominal slurry pipeline flow velocity (or nominal velocity) was measured by the Coriolis meter with a 3-inch pipe. The flow was then decreased in increments and held constant at each flow velocity for a minimum of 30 minutes. During this period, the slurry particle deposition process was observed through the transparent sections and through the open port on the test module, and inspected by inserting a hand through the open port on the test module. The nominal slurry pipeline flow velocity was kept constant during the observation by the feedback system of the pump with the VFD. The results and discussion of the GDPF pipe flow tests are given in Section 8.

In order to remove the sediment bed from the flow-loop system with the modular test sections, a flush system was installed and tested. This system consists of a pressure vessel containing an initial charge of water. The pressure in this vessel was then increased to a target value, nominally 100 to 110 psig. Upon completion of the pressure-drop measurements, a valve was opened, and the high-pressure water flush removed deposited slurry particles from the pipeline loop. The results and discussion of the flush test are given in Section 9. Finally, the findings of this testing are given in Section 10. 


\subsection{Test Materials}

The technical approach to answer the questions posed in Section 3.1 involved building a full-scale pipeline system and evaluating critical velocities and velocities for avoiding deposition (VFAD) on test materials. Reference-case materials were prepared and tested previously, as reported by Poloski et al. (2008). These slurries were designed to possess particle-size, density, and non-Newtonian rheological property values that bounded the range of those expected under WTP operating conditions. The basis for the particle-size, density, and rheological property values tested is explained in detail in Section 4 of the report by Poloski et al. (2008).

A single test material was selected to determine critical velocities and VFADs for the unique piping geometry (non-horizontal sections) representing the WTP design, and whether the flush parameters and specifications provided by the issued design guides 24590-WTP-GPG-M-027, Rev. 5 (Kloster 2007) and 24590-WTP-GPG-M-032, Rev. 3 (Donoso 2007) are applicable to non-Newtonian slurries in these unique piping geometries. Plugging of pipes results when the turbulent and other lifting forces are no longer sufficient to fully maintain suspension and prevent the particles from settling in the bottom of the pipe. Eventually, the bed thickens to form a stationary bed and the pressure gradient to maintain flow increases rapidly, resulting in blockage of the pipe. Rheological properties of the suspending medium and physical properties of the solids determine the flow velocity at which settling begins. These properties include the viscosity and yield stress of the suspending medium, and the density and size of the coarse particles.

Test material was selected that has rheological and physical properties in the center of the range of those tested in the reference case. Alumina particles $(50 \mu \mathrm{m}$ in diameter with a nominal density of 4.0 $\mathrm{g} / \mathrm{cc}$ ) suspended at $10 \mathrm{vol} \%$ in a slurry of kaolin clay with a shear strength target of $3 \mathrm{~Pa}$ was selected as the test material. This selection is similar to a majority of the particles being fed to WTP as described in the report by Poloski et al. (2008) (particles in the 2 to $4 \mathrm{~g} / \mathrm{cm}^{3}$ range as aluminum species) and was one of the test materials used in the reference case tests. A description of the slurry physical and rheological properties of this test material is provided in the following section.

\subsection{Simulant Composition}

Alumina was selected as the coarse particle fraction in the experimental matrix. Alumina has a nominal density of $4.0 \mathrm{~g} / \mathrm{cc}$. A $50-\mu \mathrm{m}$ alumina powder was selected to simulate coarse particles in the middle of the size range observed in actual Hanford tank wastes. A slurry of water and kaolin clay (Feldspar EPK) was used to adjust the rheology of the test simulant to obtain a Bingham yield stress of approximately $3 \mathrm{~Pa}$. The kaolin clay formed the fine particle fraction of the test mixture. The simulant used for these modular tests is in the center of the range of simulants used in the reference case tests (Poloski et al. 2008). A description of the range used in the reference case tests, and justification for the selected range, is provided in the Background section of this report (Section 3.0). Manufacturer and product information for each of the components is shown in Table 4.1. 
Table 4.1. Slurry Materials Selected for Critical-Velocity Testing

\begin{tabular}{|c|c|c|}
\hline \multirow[b]{2}{*}{$\begin{array}{l}\text { Slurry } \\
\text { Density } \\
\left(\mathrm{g} / \mathbf{c m}^{3}\right)\end{array}$} & \multicolumn{2}{|c|}{ Insoluble Particles } \\
\hline & $\begin{array}{l}\text { Coarse } \\
50 \mu \mathrm{m} \\
4 \mathrm{~g} / \mathrm{cm}^{3}\end{array}$ & $\begin{array}{c}\text { Fines } \\
1 \mu \mathrm{m} \\
2-3 \mathrm{~g} / \mathrm{cm}^{3}\end{array}$ \\
\hline $1.33-1.41$ & $\begin{array}{l}\text { Material: } \\
\text { Aluminum Oxide } \\
\text { Manufacturer: } \\
\text { Washington Mills } \\
\text { Product: } \\
\text { Duralum }{ }^{\circledR} \\
220 \text { grit }\end{array}$ & $\begin{array}{l}\text { Material: } \\
\text { Slurries of Kaolin } \\
\text { Clay in Water } \\
\text { Manufacturer: } \\
\text { Feldspar Corp. } \\
\text { Product: } \\
\text { EPK Kaolin }\end{array}$ \\
\hline
\end{tabular}

A scanning electron microscope image of the alumina (coarse particle component) is shown in Figure 4.1. The alumina medium is fractured and angular with at least one dimension being approximately 50 $\mu \mathrm{m}$ in length.

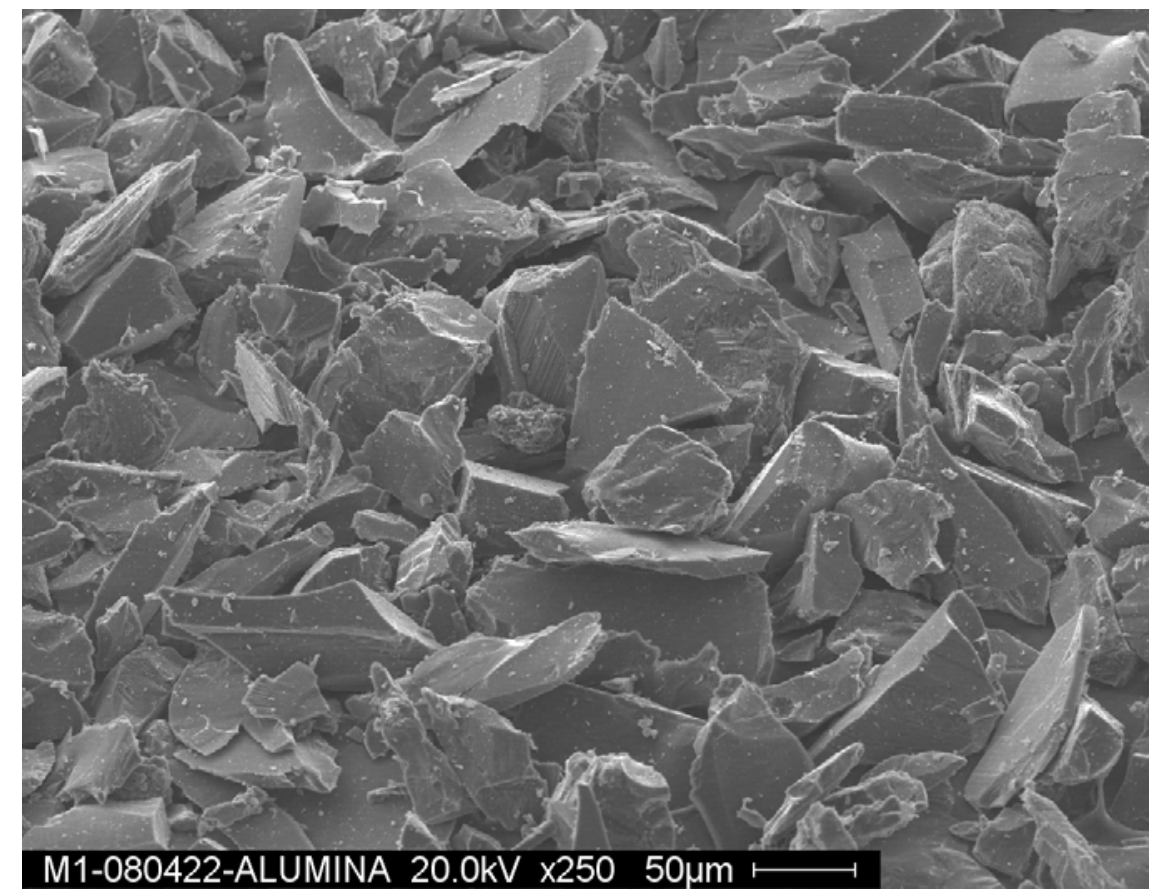

Figure 4.1. Micrograph of 50- $\mu \mathrm{m}$ Alumina (Washington Mills Duralum ${ }^{\circledR} 220$ grit)

\subsection{Physical Properties}

The physical properties of the resulting test slurries are documented in Table 4.2 through Table 4.6 for each geometry tested. For each test, the bulk density of the slurry was measured in situ with Coriolis flow meters while the flow loop and agitation system were operating. The mass of coarse particles was 
determined while preparing the test simulant, and the total volume in the system was measured via level probes in the mixing vessel. These data allow for calculation of the theoretical volume fraction of coarse particles in the flow-loop system. Coupled with the bulk density measured with the Coriolis meter, the density of the interstitial fluid (i.e., water or kaolin/water slurry) can be calculated. From the interstitial fluid density, the fraction of fines (i.e., kaolin clay) and water can be calculated. With this information, the density and compositional data for the coarse, fine, and water fractions can be calculated. Particle densities were taken from data provided by the manufacturer. These values were substantiated by separate laboratory measurements on test samples.

The initial simulant for the modular tests was prepared by adding alumina and a premixed kaolin clay and water slurry to the alumina simulant used in the reference case testing (Poloski et al. 2008). Kaolin clay and alumina were added to increase the volume of the simulant while maintaining the rheology and volume fraction of coarse particles. Additional simulant volume was required because the modular portions of the test loop increased the total volume of the system. The largest volume increase was observed with the gravity-driven partially-filled (GDPF) pipe flow test module which increased the volume of the reference case loop (excluding the tanks) from 60.5 to 106.8 gallons. The mass of alumina in the simulant was calculated from the mass of alumina in the reference-case simulant and the amount of alumina added prior to the modular testing. 
Table 4.2. Properties of Simulant for Gravity-Feed and Process Drain Module Test

\begin{tabular}{|c|c|c|c|c|}
\hline Test Num & & 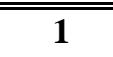 & 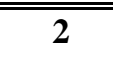 & 3 \\
\hline \multicolumn{5}{|c|}{ Mass per Unit Volume } \\
\hline Coarse Particles & $g / L$ & 393 & 393 & 393 \\
\hline Fine Particles & g/L & 181 & 176 & 178 \\
\hline Water & g/L & 823 & 825 & 825 \\
\hline \multicolumn{5}{|c|}{ Volume Fraction } \\
\hline Coarse Particles & vol\% & $10.4 \%$ & $10.4 \%$ & $10.4 \%$ \\
\hline Fine Particles & vol\% & $7.2 \%$ & $7.0 \%$ & $7.1 \%$ \\
\hline Water & vol\% & $82.3 \%$ & $82.5 \%$ & $82.5 \%$ \\
\hline \multicolumn{5}{|c|}{ Mass Fraction } \\
\hline Coarse Particles & mass \% & $28.1 \%$ & $28.1 \%$ & $28.1 \%$ \\
\hline Fine Particles & mass $\%$ & $13.0 \%$ & $12.6 \%$ & $12.8 \%$ \\
\hline Water & mass $\%$ & $58.9 \%$ & $59.2 \%$ & $59.1 \%$ \\
\hline \multicolumn{5}{|c|}{ Component Density } \\
\hline Coarse Particles & $\mathrm{kg} / \mathrm{L}$ & 3.77 & 3.77 & 3.77 \\
\hline Fine Particles & $\mathrm{kg} / \mathrm{L}$ & 2.5 & 2.5 & 2.5 \\
\hline Water & $\mathrm{kg} / \mathrm{L}$ & 1 & 1 & 1 \\
\hline Bulk & $\mathrm{kg} / \mathrm{L}$ & 1.40 & 1.39 & 1.40 \\
\hline \multicolumn{5}{|c|}{ Particle Size Distribution } \\
\hline $\mathbf{d}_{5}$ & $\mu \mathrm{m}$ & 1.0 & 2.2 & 1.3 \\
\hline$d_{10}$ & $\mu \mathrm{m}$ & 2.2 & 6.6 & 3.1 \\
\hline$d_{20}$ & $\mu \mathrm{m}$ & 6.0 & 36.7 & 9.5 \\
\hline$d_{30}$ & $\mu \mathrm{m}$ & 14.0 & 48.9 & 30.2 \\
\hline$d_{40}$ & $\mu \mathrm{m}$ & 33.8 & 58.4 & 43.2 \\
\hline$d_{50}$ & $\mu \mathrm{m}$ & 46.2 & 67.5 & 53.3 \\
\hline$d_{60}$ & $\mu \mathrm{m}$ & 57.2 & 77.2 & 63.5 \\
\hline $\mathbf{d}_{70}$ & $\mu \mathrm{m}$ & 68.9 & 88.3 & 74.7 \\
\hline $\mathbf{d}_{80}$ & $\mu \mathrm{m}$ & 83.0 & 102.1 & 88.6 \\
\hline$d_{90}$ & $\mu \mathrm{m}$ & 103.5 & 122.1 & 109.0 \\
\hline$d_{95}$ & $\mu \mathrm{m}$ & 120.4 & 138.5 & 125.9 \\
\hline \multicolumn{5}{|c|}{ Bingham Flow Curve $\left(0-800 \mathrm{~s}^{-1}\right)$} \\
\hline Bingham Yield Stress & $\mathbf{P a}$ & 2.97 & 2.82 & 3.07 \\
\hline Bingham Consistency & $\mathbf{c P}$ & 7.16 & 7.82 & 7.28 \\
\hline
\end{tabular}


Table 4.3. Properties of Simulant for Jumper Module Test

\begin{tabular}{|c|c|c|c|c|}
\hline Test Num & & 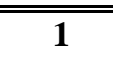 & 2 & $\overline{3}$ \\
\hline \multicolumn{5}{|c|}{ Mass per Unit Volume } \\
\hline Coarse Particles & $g / L$ & 379 & 379 & 379 \\
\hline Fine Particles & g/L & 146 & 142 & 140 \\
\hline Water & $g / L$ & 841 & 843 & 843 \\
\hline \multicolumn{5}{|c|}{ Volume Fraction } \\
\hline Coarse Particles & vol\% & $10.1 \%$ & $10.1 \%$ & $10.1 \%$ \\
\hline Fine Particles & vol $\%$ & $5.9 \%$ & $5.7 \%$ & $5.6 \%$ \\
\hline Water & vol\% & $84.1 \%$ & $84.3 \%$ & $84.3 \%$ \\
\hline \multicolumn{5}{|c|}{ Mass Fraction } \\
\hline Coarse Particles & mass $\%$ & $27.8 \%$ & $27.8 \%$ & $27.8 \%$ \\
\hline Fine Particles & mass $\%$ & $10.7 \%$ & $10.4 \%$ & $10.3 \%$ \\
\hline Water & mass $\%$ & $61.5 \%$ & $61.8 \%$ & $61.9 \%$ \\
\hline \multicolumn{5}{|c|}{ Component Density } \\
\hline Coarse Particles & $\mathrm{kg} / \mathrm{L}$ & 3.77 & 3.77 & 3.77 \\
\hline Fine Particles & $\mathrm{kg} / \mathrm{L}$ & 2.5 & 2.5 & 2.5 \\
\hline Water & $\mathrm{kg} / \mathrm{L}$ & 1 & 1 & 1 \\
\hline Bulk & $\mathrm{kg} / \mathrm{L}$ & 1.37 & 1.36 & 1.36 \\
\hline \multicolumn{5}{|c|}{ Particle Size Distribution } \\
\hline$d_{5}$ & $\mu \mathrm{m}$ & 1.5 & 1.5 & 1.7 \\
\hline$d_{10}$ & $\mu \mathrm{m}$ & 3.1 & 3.0 & 3.6 \\
\hline$d_{20}$ & $\mu \mathrm{m}$ & 8.4 & 8.1 & 10.7 \\
\hline$d_{30}$ & $\mu \mathrm{m}$ & 22.9 & 21.9 & 30.4 \\
\hline$d_{40}$ & $\mu \mathrm{m}$ & 42.9 & 43.1 & 46.2 \\
\hline$d_{50}$ & $\mu \mathrm{m}$ & 53.7 & 54.2 & 55.7 \\
\hline$d_{60}$ & $\mu \mathrm{m}$ & 62.8 & 63.5 & 64.4 \\
\hline $\mathbf{d}_{70}$ & $\mu \mathrm{m}$ & 72.3 & 73.3 & 73.9 \\
\hline $\mathbf{d}_{80}$ & $\mu \mathrm{m}$ & 84.3 & 86.1 & 86.6 \\
\hline$d_{90}$ & $\mu \mathrm{m}$ & 103.6 & 107.7 & 109.2 \\
\hline$d_{95}$ & $\mu \mathrm{m}$ & 123.1 & 131.2 & 134.8 \\
\hline \multicolumn{5}{|c|}{ Bingham Flow Curve $\left(0-800 \mathrm{~s}^{-1}\right)$} \\
\hline Bingham Yield Stress & $\mathbf{P a}$ & 2.83 & 2.79 & 2.45 \\
\hline Bingham Consistency & cP & 7.4 & 6.6 & 6.2 \\
\hline
\end{tabular}


Table 4.4. Properties of Simulant for Complex-Geometry Module Test

\begin{tabular}{|c|c|c|c|c|}
\hline Test Num & & 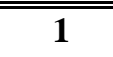 & 2 & 3 \\
\hline \multicolumn{5}{|c|}{ Mass per Unit Volume } \\
\hline Coarse Particles & $g / L$ & 366 & 366 & 366 \\
\hline Fine Particles & $g / L$ & 104 & 102 & 102 \\
\hline Water & $g / L$ & 861 & 862 & 862 \\
\hline \multicolumn{5}{|c|}{ Volume Fraction } \\
\hline Coarse Particles & vol\% & $9.7 \%$ & $9.7 \%$ & $9.7 \%$ \\
\hline Fine Particles & vol\% & $4.1 \%$ & $4.1 \%$ & $4.1 \%$ \\
\hline Water & vol\% & $86.1 \%$ & $86.2 \%$ & $86.2 \%$ \\
\hline \multicolumn{5}{|c|}{ Mass Fraction } \\
\hline Coarse Particles & mass $\%$ & $27.5 \%$ & $27.5 \%$ & $27.5 \%$ \\
\hline Fine Particles & mass $\%$ & $7.8 \%$ & $7.7 \%$ & $7.7 \%$ \\
\hline Water & mass $\%$ & $64.7 \%$ & $64.8 \%$ & $64.8 \%$ \\
\hline \multicolumn{5}{|c|}{ Component Density } \\
\hline Coarse Particles & $\mathrm{kg} / \mathrm{L}$ & 3.77 & 3.77 & 3.77 \\
\hline Fine Particles & $\mathrm{kg} / \mathrm{L}$ & 2.5 & 2.5 & 2.5 \\
\hline Water & $\mathrm{kg} / \mathrm{L}$ & 1 & 1 & 1 \\
\hline Bulk & $\mathrm{kg} / \mathrm{L}$ & 1.33 & 1.33 & 1.33 \\
\hline \multicolumn{5}{|c|}{ Particle Size Distribution } \\
\hline$d_{5}$ & $\mu \mathrm{m}$ & 1.3 & 2.5 & 2.1 \\
\hline$d_{10}$ & $\mu \mathrm{m}$ & 2.5 & 5.7 & 4.6 \\
\hline$d_{20}$ & $\mu \mathrm{m}$ & 6.4 & 23.5 & 16.2 \\
\hline$d_{30}$ & $\mu \mathrm{m}$ & 14.1 & 44.5 & 40.5 \\
\hline$d_{40}$ & $\mu \mathrm{m}$ & 32.8 & 54.1 & 52.0 \\
\hline$d_{50}$ & $\mu \mathrm{m}$ & 47.3 & 61.9 & 60.4 \\
\hline$d_{60}$ & $\mu \mathrm{m}$ & 57.4 & 69.7 & 68.5 \\
\hline$d_{70}$ & $\mu \mathrm{m}$ & 67.5 & 78.8 & 77.9 \\
\hline$d_{80}$ & $\mu \mathrm{m}$ & 80.3 & 91.2 & 90.5 \\
\hline$d_{90}$ & $\mu \mathrm{m}$ & 102.7 & 113.5 & 113.3 \\
\hline $\mathbf{d}_{95}$ & $\mu \mathrm{m}$ & 128.0 & 138.6 & 139.0 \\
\hline \multicolumn{5}{|c|}{ Bingham Flow Curve $\left(0-800 \mathrm{~s}^{-1}\right)$} \\
\hline Bingham Yield Stress & $\mathbf{P a}$ & 2.71 & 2.85 & 2.75 \\
\hline Bingham Consistency & cP & 5.72 & 6.3 & 5.74 \\
\hline
\end{tabular}


Table 4.5. Properties of Simulant for Reducer and Vertical-Rise Module Test

\begin{tabular}{|c|c|c|c|c|}
\hline Test Num & & 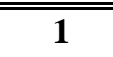 & 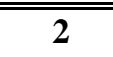 & 3 \\
\hline \multicolumn{5}{|c|}{ Mass per Unit Volume } \\
\hline Coarse Particles & $g / L$ & 408 & 408 & 408 \\
\hline Fine Particles & g/L & 121 & 117 & 111 \\
\hline Water & g/L & 844 & 845 & 847 \\
\hline \multicolumn{5}{|c|}{ Volume Fraction } \\
\hline Coarse Particles & vol\% & $10.8 \%$ & $10.8 \%$ & $10.8 \%$ \\
\hline Fine Particles & vol\% & $4.8 \%$ & $4.7 \%$ & $4.4 \%$ \\
\hline Water & vol\% & $84.4 \%$ & $84.5 \%$ & $84.7 \%$ \\
\hline \multicolumn{5}{|c|}{ Mass Fraction } \\
\hline Coarse Particles & mass \% & $29.7 \%$ & $29.7 \%$ & $29.7 \%$ \\
\hline Fine Particles & mass $\%$ & $8.8 \%$ & $8.5 \%$ & $8.1 \%$ \\
\hline Water & mass $\%$ & $61.5 \%$ & $61.7 \%$ & $62.0 \%$ \\
\hline \multicolumn{5}{|c|}{ Component Density } \\
\hline Coarse Particles & $\mathrm{kg} / \mathrm{L}$ & 3.77 & 3.77 & 3.77 \\
\hline Fine Particles & $\mathrm{kg} / \mathrm{L}$ & 2.5 & 2.5 & 2.5 \\
\hline Water & $\mathrm{kg} / \mathrm{L}$ & 1 & 1 & 1 \\
\hline Bulk & $\mathrm{kg} / \mathrm{L}$ & 1.37 & 1.37 & 1.37 \\
\hline \multicolumn{5}{|c|}{ Particle Size Distribution } \\
\hline $\mathbf{d}_{5}$ & $\mu \mathrm{m}$ & 2.6 & 2.8 & 1.6 \\
\hline$d_{10}$ & $\mu \mathrm{m}$ & 6.2 & 6.6 & 3.3 \\
\hline$d_{20}$ & $\mu \mathrm{m}$ & 26.6 & 27.8 & 9.4 \\
\hline$d_{30}$ & $\mu \mathrm{m}$ & 46.4 & 45.8 & 25.9 \\
\hline$d_{40}$ & $\mu \mathrm{m}$ & 55.9 & 54.9 & 44.4 \\
\hline$d_{50}$ & $\mu \mathrm{m}$ & 63.7 & 62.6 & 54.6 \\
\hline$d_{60}$ & $\mu \mathrm{m}$ & 71.7 & 70.4 & 63.5 \\
\hline $\mathbf{d}_{70}$ & $\mu \mathrm{m}$ & 81.2 & 79.6 & 73.2 \\
\hline $\mathbf{d}_{80}$ & $\mu \mathrm{m}$ & 94.2 & 92.4 & 86.0 \\
\hline$d_{90}$ & $\mu \mathrm{m}$ & 117.7 & 116.0 & 108.5 \\
\hline$d_{95}$ & $\mu \mathrm{m}$ & 144.1 & 143.4 & 133.6 \\
\hline \multicolumn{5}{|c|}{ Bingham Flow Curve $\left(0-800 \mathrm{~s}^{-1}\right)$} \\
\hline Bingham Yield Stress & $\mathbf{P a}$ & 3.16 & 3 & 2.89 \\
\hline Bingham Consistency & $\mathbf{c P}$ & 6.35 & 6.51 & 5.78 \\
\hline
\end{tabular}


Table 4.6. Properties of Simulant for Gravity-Driven Partially-Filled Pipe Flow Test

\begin{tabular}{|c|c|c|c|c|}
\hline Test Nun & & 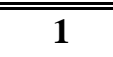 & 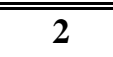 & 3 \\
\hline \multicolumn{5}{|c|}{ Mass per Unit Volume } \\
\hline Coarse Particles & $g / L$ & 455 & 439 & 393 \\
\hline Fine Particles & g/L & 117 & 84 & 93 \\
\hline Water & g/L & 832 & 850 & 858 \\
\hline \multicolumn{5}{|c|}{ Volume Fraction } \\
\hline Coarse Particles & vol\% & $12.1 \%$ & $11.6 \%$ & $10.4 \%$ \\
\hline Fine Particles & vol\% & $4.7 \%$ & $3.4 \%$ & $3.7 \%$ \\
\hline Water & vol\% & $83.2 \%$ & $85.0 \%$ & $85.8 \%$ \\
\hline \multicolumn{5}{|c|}{ Mass Fraction } \\
\hline Coarse Particles & mass \% & $32.4 \%$ & $32.0 \%$ & $29.2 \%$ \\
\hline Fine Particles & mass $\%$ & $8.3 \%$ & $6.1 \%$ & $6.9 \%$ \\
\hline Water & mass $\%$ & $59.2 \%$ & $61.9 \%$ & $63.8 \%$ \\
\hline \multicolumn{5}{|c|}{ Component Density } \\
\hline Coarse Particles & $\mathrm{kg} / \mathrm{L}$ & 3.77 & 3.77 & 3.77 \\
\hline Fine Particles & $\mathrm{kg} / \mathrm{L}$ & 2.5 & 2.5 & 2.5 \\
\hline Water & $\mathrm{kg} / \mathrm{L}$ & 1 & 1 & 1 \\
\hline Bulk & $\mathrm{kg} / \mathrm{L}$ & 1.41 & 1.37 & 1.35 \\
\hline \multicolumn{5}{|c|}{ Particle Size Distribution } \\
\hline $\mathbf{d}_{5}$ & $\mu \mathrm{m}$ & 0.9 & 1.6 & 1.5 \\
\hline$d_{10}$ & $\mu \mathrm{m}$ & 2.0 & 3.8 & 3.8 \\
\hline$d_{20}$ & $\mu \mathrm{m}$ & 4.9 & 11.2 & 11.4 \\
\hline$d_{30}$ & $\mu \mathrm{m}$ & 9.4 & 35.5 & 32.4 \\
\hline$d_{40}$ & $\mu \mathrm{m}$ & 19.6 & 47.6 & 43.6 \\
\hline$d_{50}$ & $\mu \mathrm{m}$ & 36.4 & 57.7 & 53.1 \\
\hline$d_{60}$ & $\mu \mathrm{m}$ & 49.9 & 67.9 & 62.7 \\
\hline $\mathbf{d}_{70}$ & $\mu \mathrm{m}$ & 63.2 & 79.3 & 73.5 \\
\hline $\mathbf{d}_{80}$ & $\mu \mathrm{m}$ & 78.8 & 93.4 & 87.0 \\
\hline$d_{90}$ & $\mu \mathrm{m}$ & 101.2 & 114.1 & 106.6 \\
\hline$d_{95}$ & $\mu \mathrm{m}$ & 119.8 & 131.3 & 122.8 \\
\hline \multicolumn{5}{|c|}{ Bingham Flow Curve $\left(0-800 \mathrm{~s}^{-1}\right)$} \\
\hline Bingham Yield Stress & $\mathbf{P a}$ & 3.25 & 2.8 & 2.77 \\
\hline Bingham Consistency & $\mathbf{c P}$ & 6.43 & 6.48 & 6.78 \\
\hline
\end{tabular}

Particle size distribution of the each of the simulants was measured using laser diffraction technology. A Microtrac S3000 Particle Size Analyzer was used to measure the samples from the jumper module, complex-geometry module, and reducer and vertical-rise module tests. A Malvern Mastersizer 2000 was used to measure the samples from the gravity-feed and process-drain module and GDPF pipe flow tests. Preparation of the samples was similar for both analyzers. Software for the particle size analyzer calculates the particle size distribution from the light scattering patterns using Mie scattering theory. 
Particles with diameters between 0.02 and 1400 microns $(\mu \mathrm{m})$ were analyzed to determine the particle size distribution of the simulants.

Particle size standards were measured prior to measuring the distribution of these simulants. The standard run on the Microtrac was a polydisperse NIST traceable standard with diameters between 10 and 100 microns. The cumulative percent undersize values obtained in the particle size analyzer are compared with certificate values in Table 4.7. The uncertainty, defined as the $95 \%$ confidence, of the reported values (certificate) is provided along with the difference between the measured and reported values. A particle size standard supplied by Malvern was measured prior to performing measurements on the Malvern Mastersizer 2000. The results obtained during the measurement, and the reported values, are provided in Table 4.8. The mean particle size (50\% cumulative undersize) is within the uncertainty of the reported value, and none of the measured values are more than $4 \%$ above the certificate value plus the uncertainty.

Table 4.7. Particle Size Standard for the Microtrac S3000 Particle Size Analyzer

\begin{tabular}{|c|c|c|c|c|c|}
\hline & \multicolumn{5}{|c|}{$\begin{array}{l}\text { Particle Diameter at the Cumulative Percent } \\
\text { Undersize }(\mu \mathrm{m})\end{array}$} \\
\hline & 10 & 25 & 50 & 75 & 90 \\
\hline Certificate Value & 25.37 & 31.68 & 41.26 & 52.62 & 62.93 \\
\hline Uncertainty* & 2.08 & 3.00 & 3.26 & 2.88 & 3.08 \\
\hline Measured Value & 28.19 & 34.86 & 43.36 & 54.10 & 68.13 \\
\hline Difference & 2.82 & 3.18 & 2.10 & 1.48 & 5.20 \\
\hline
\end{tabular}

* 95\% Confidence

Table 4.8. Particle Size Standard for the Malvern Mastersizer 2000 Analyzer

\begin{tabular}{|c|c|c|c|}
\hline & \multicolumn{3}{|c|}{$\begin{array}{c}\text { Particle Diameter at the Cumulative Percent } \\
\text { Undersize }(\mu \mathrm{m})\end{array}$} \\
\hline & 10 & 50 & 90 \\
\hline Certificate Value & 37.64 & 62.55 & 90.72 \\
\hline Uncertainty* & 1.13 & 1.25 & 2.72 \\
\hline Measured Value & 39.75 & 63.25 & 90.37 \\
\hline Difference & 2.11 & 0.70 & 0.35 \\
\hline
\end{tabular}

* Based on upper and lower limit

Small aliquots of the simulant samples $(<1 \mathrm{ml})$ were diluted in water in a variable-speed recirculator (Microtrac VSR for the Microtrac analyzer and Hydro $G$ for the Malvern analyzer) prior to taking the particle size measurements. The total volume of the recirculator is $300 \mathrm{ml}$ for the Microtrac and $800 \mathrm{ml}$ for the Malvern. Appropriate dilutions were determined by the amount of light passing through the diluted material (obscuration), which was measured by the particle size analyzer. Measurements were taken at $45 \%$ of the maximum circulation rate $(90 \mathrm{ml} / \mathrm{sec})$ in the Microtrac and $2000 \mathrm{rpm}$ in the Malvern.

All of the simulant samples were shaken prior to taking aliquots for particle size distribution. Measurements were taken on samples with no further treatment, and on samples that were sonicated after adding a deflocculant. All treatments were performed prior to dilution. Sonication was performed with a Microson ultrasonic cell disruptor with a microtip probe. Twenty short pulses ( $<10$ seconds) were used 
to deagglomerate and/or disperse the particles in the aliquot. To improve the sonication, the samples were diluted by approximately a factor of 10 prior to sonication. A polymer deflocculant (Darvan $821 \mathrm{~A}$ ) was used to improve dispersion of the alumina particles. Particle size data reported were on sonicated aliquots with deflocculant added.

Real-time particle size data was obtained in the pipe loop with a Mettler-Toledo Lasentec ${ }^{\mathrm{TM}}$ focused beam reflectance measurement (FBRM) system. Installation and operation of this system in the pipe loop is described in detail in the reference case testing report (Poloski et al. 2008). Particle size data from the Lasentec system is not provided in this report but is available upon request.

A sample of the simulant was taken from the mixing tank at the beginning of each test and a flow curve was measured to determine what adjustment was needed to match the target rheology of 3-Pa Bingham yield stress. The rheology of the simulant was adjusted to approach the 3-Pa Bingham yield stress target by adding water to reduce the yield stress, or by either removing water via settle/decant or adding $\mathrm{MgSO}_{4}$ to increase the yield stress. On the order of 10 parts per million of $\mathrm{MgSO}_{4}$ were required to significantly raise the yield stress of the slurry. For this reason, the rheological properties sometimes do not follow the same trend as solids concentration. After the rheology was adjusted, another sample was drawn and a flow curve was again measured. Rheology samples were taken at regular intervals (generally every 4 hours) throughout the test.

Flow curves were obtained on a TA Instruments AR2000 rheometer configured with a standard-size recessed end concentric-cylinder geometry with a $1 \mathrm{~mm}$ gap. The shear rate was ramped from 0 to $1000 \mathrm{~s}^{-1}$ over a 5-minute period (Smith and Prindiville 2002). The shear rate was held at $1000 \mathrm{~s}^{-1}$ for 1 minute and then ramped down from 1000 to $0 \mathrm{~s}^{-1}$ over another 5-minute period. An example curve of the shear stress versus the shear rate obtained this testing is shown in Figure 4.2. The temperature of the sample was controlled at $25^{\circ} \mathrm{C}$. Bingham-plastic curve fits were obtained for the up and down ramp portions of the curve over a typical range of 0 to $800 \mathrm{~s}^{-1}$. These upper limits were established because of Taylor vortex formation at higher rotational rates. A description of the Bingham-plastic curve fit model is provided in Appendix A of the reference case testing report (Poloski et al. 2008).

A silicon oil Newtonian viscosity standard was run at regular intervals (at least monthly) to verify that the instrument was working properly. The viscosity of these standards was always within $10 \%$ of the reported value. The yield stress and viscosity values reported for each test in Table 4.2 through Table 4.6 are averages of the Bingham-plastic yield stress and viscosity from each of the up ramp portions of the flow curves measured on the rheology samples, after the target Bingham-plastic yield stress was achieved. The data for all of the curve fits can be obtained from the Laboratory Record Books (LRBs).

Scanning electron microscope images were obtained with an Amray Model 1610T Scanning Electron Microscope (SEM) coupled with an x-ray fluorescence detector. Each sample was attached to a carbon backed microscope stud, carbon coated, and placed within the SEM chamber. SEM analysis was performed according to procedure RPL-611A-SEM Revision 0. System calibration was preformed in 2008. The system is computer controlled using IXRF Microanalysis software, which is also used to analyze the data. 


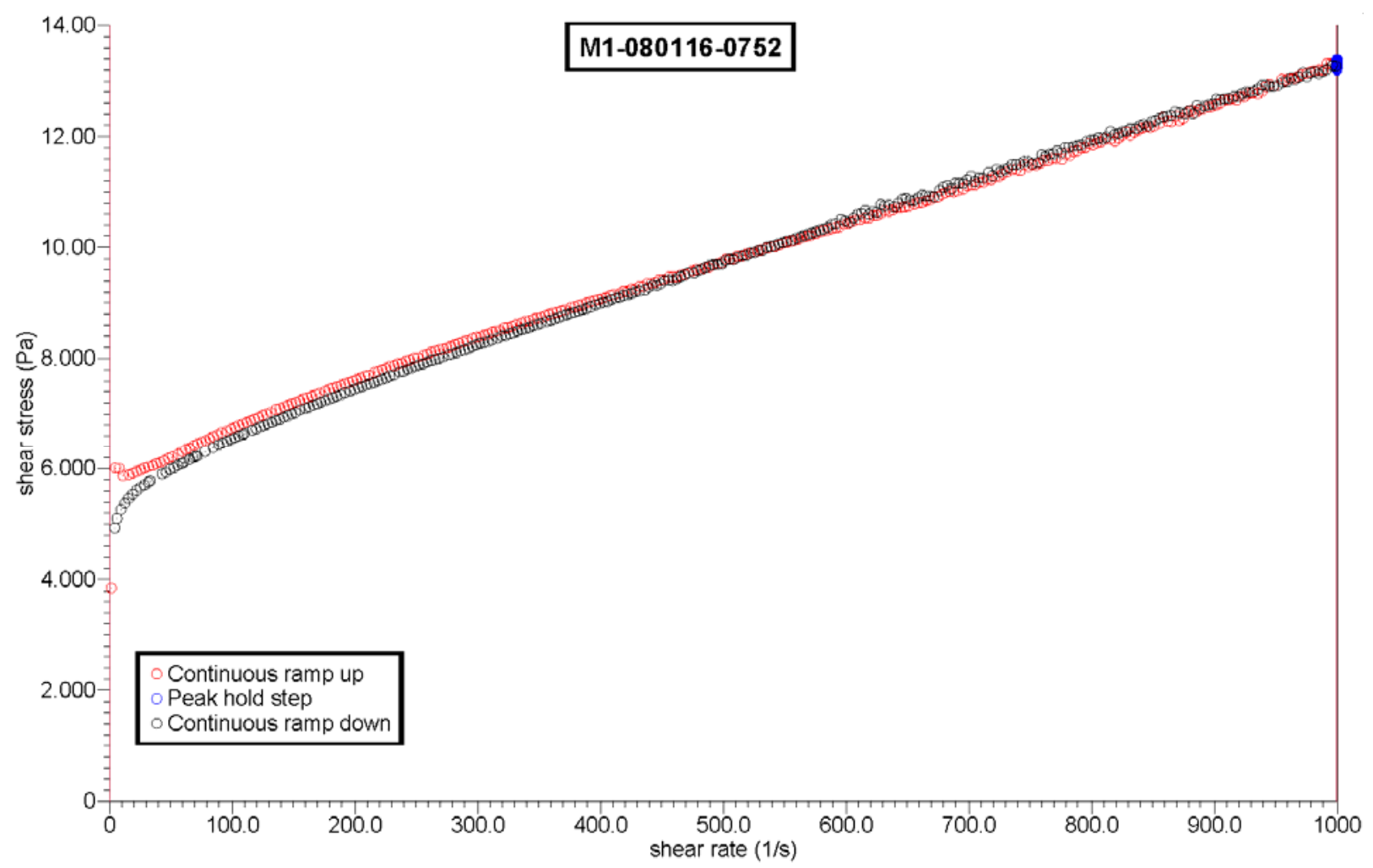

Figure 4.2. Shear stress versus shear rate 


\subsection{Test Setup and Apparatus}

This section describes the flow-loop test setup and the test equipment and instruments. A schematic of the flow-loop test system is shown in Figure 5.1. The drawings for the four test spools, 1) gravity feed and process drain, 2) jumper, 3) complex geometry, and 4) reducer and vertical-rise are given in Figure 5.2 to Figure 5.5. The 8-inch gravity-driven partially-filled (GDPF) pipe spool is described in Figure 5.6 to Figure 5.8. The details of these spools are given in Section 5.1.

Before a test, a batch of simulant is placed in a slurry-mixing tank. During operation, the slurry is transported around the flow loop driven by the slurry pump (P1 in Figure 5.1). The slurry enters an inlet Coriolis flow meter (C-1) and then flows into the modular test section. The pressure-drop measurements across the components of the modular test section are performed with differential pressure transducers for the gravity-feed and process-drain spool, the jumper spool, the complex-geometry spool, and the reducer and vertical-rise spool (see Section 5.1 for the positions of the differential pressure transducers). For the 8-inch GDPF pipe flow test spool, observation though transparent sections is mainly used to inspect the flow sedimentation (see Section 5.1 for the 8-inch GDPF pipe flow test spool). After leaving the modular test section, the slurry flow returns to the mixing tank through an outlet Coriolis flow meter (C-2), and the process is repeated.

A chiller is connected to the mixing tank water jacket to maintain constant temperature throughout the test. The pressure drop across the flow-loop system (flow-loop pressure drop) is measured with a differential pressure transducer. The high pressure port was located approximately five inches downstream of the first Coriolis meter and the low pressure port was located approximately nine feet downstream of the second Coriolis meter.

At the conclusion of the test, the system is flushed by a pneumatically-driven flush tank. A charge of flush water is loaded into the flush tank. The air compressor then charges the air-receiver tank to the target flush pressure. Valves are aligned to isolate the slurry-mixing tank and allow a path from the flush tank, through the flow loop, to a simulant capture tank. The description of the flow-loop test system is provided in the following subsection. 


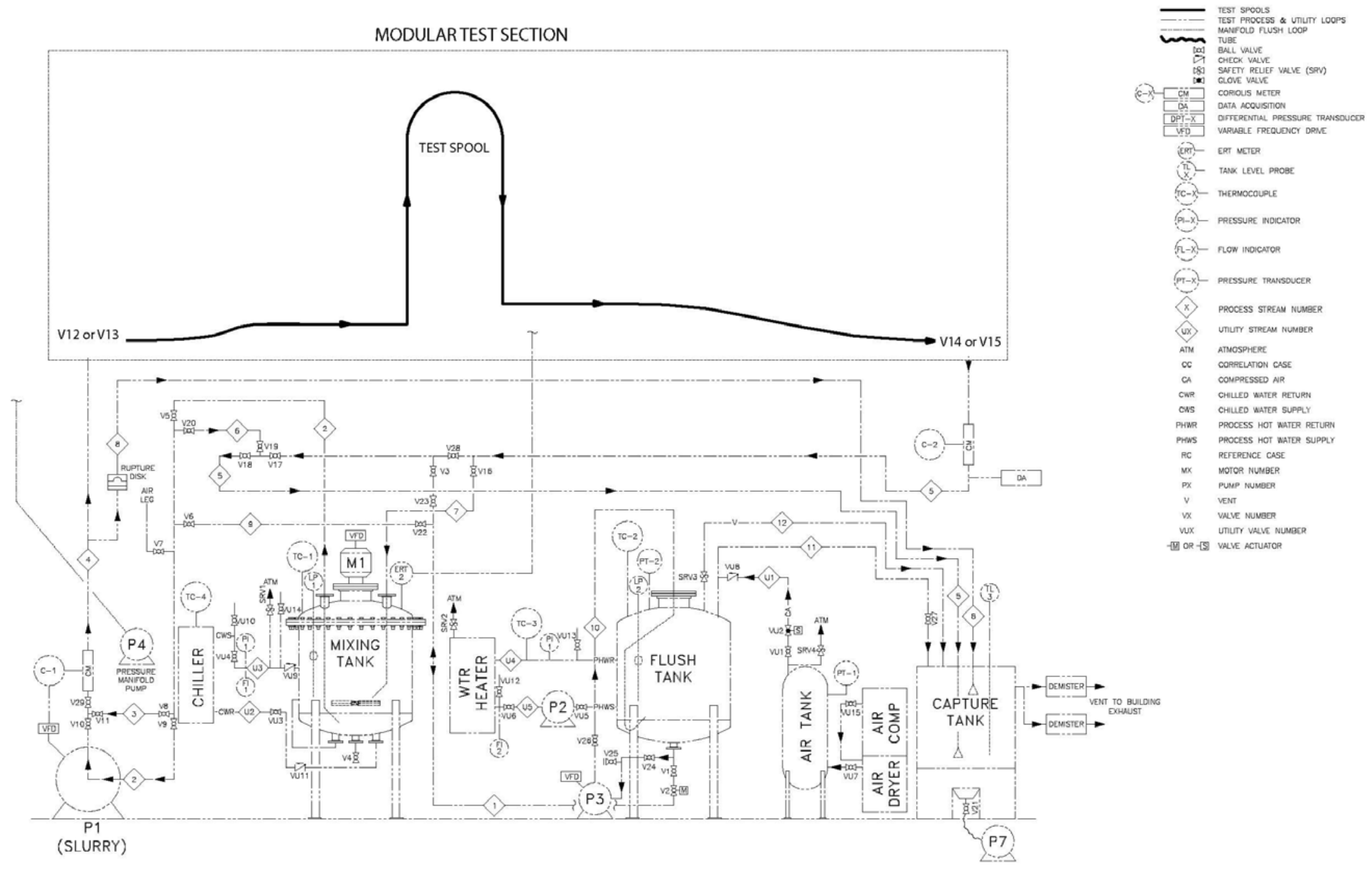

Figure 5.1. Schematic of Flow-loop System

5.2 


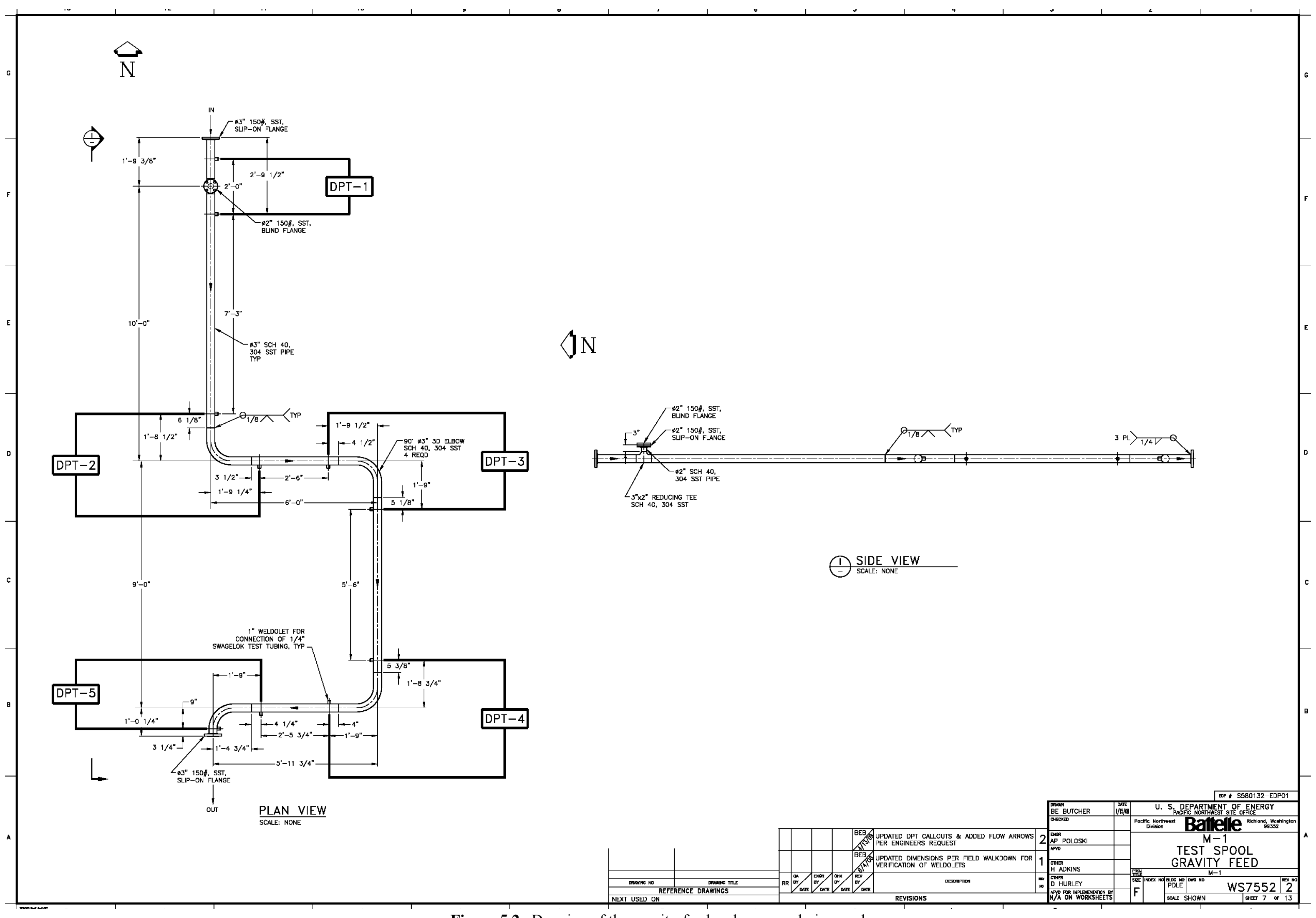

Figure 5.2. Drawing of the gravity-feed and process-drain spool 


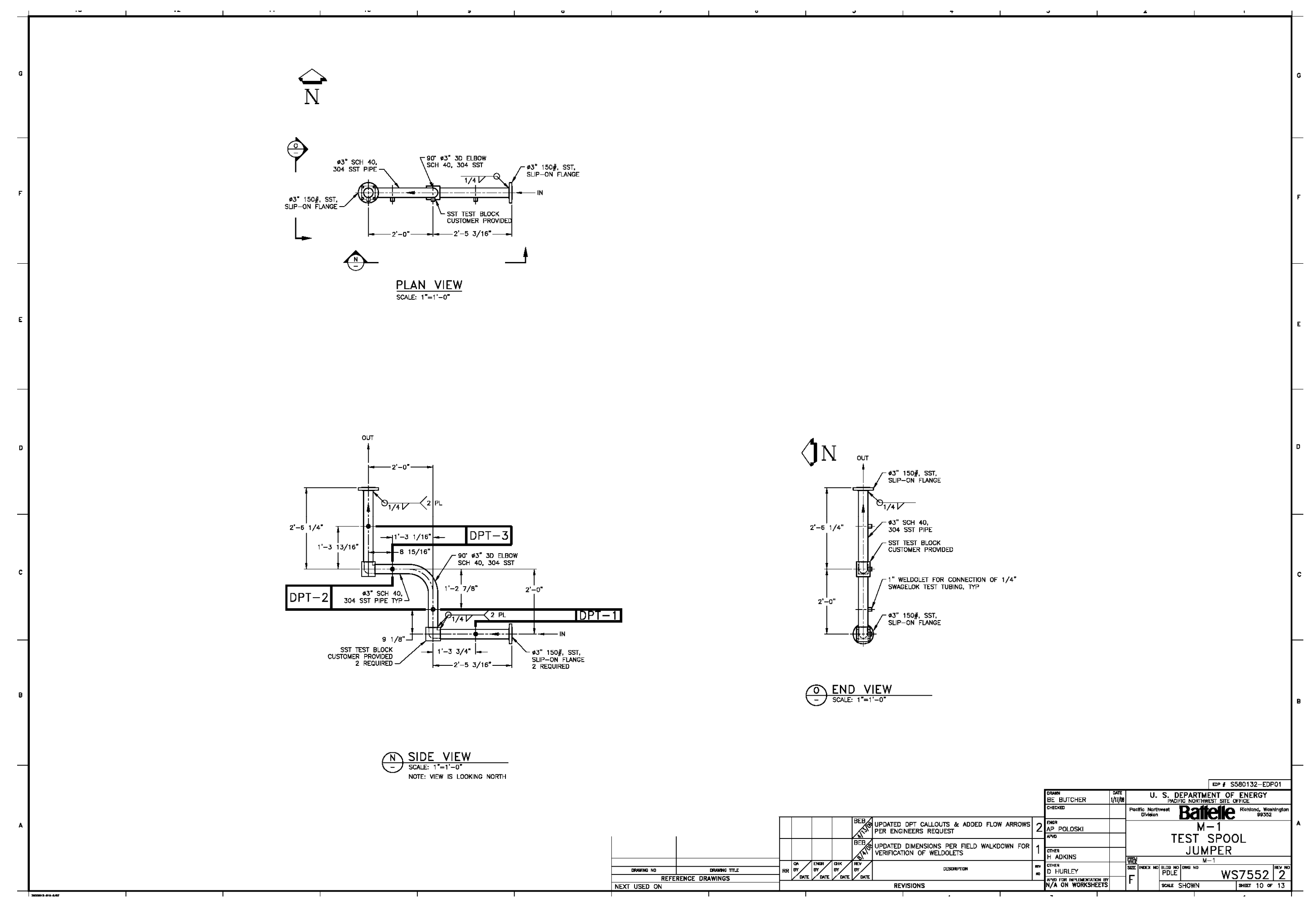

Figure 5.3. Drawing of the jumper spool 


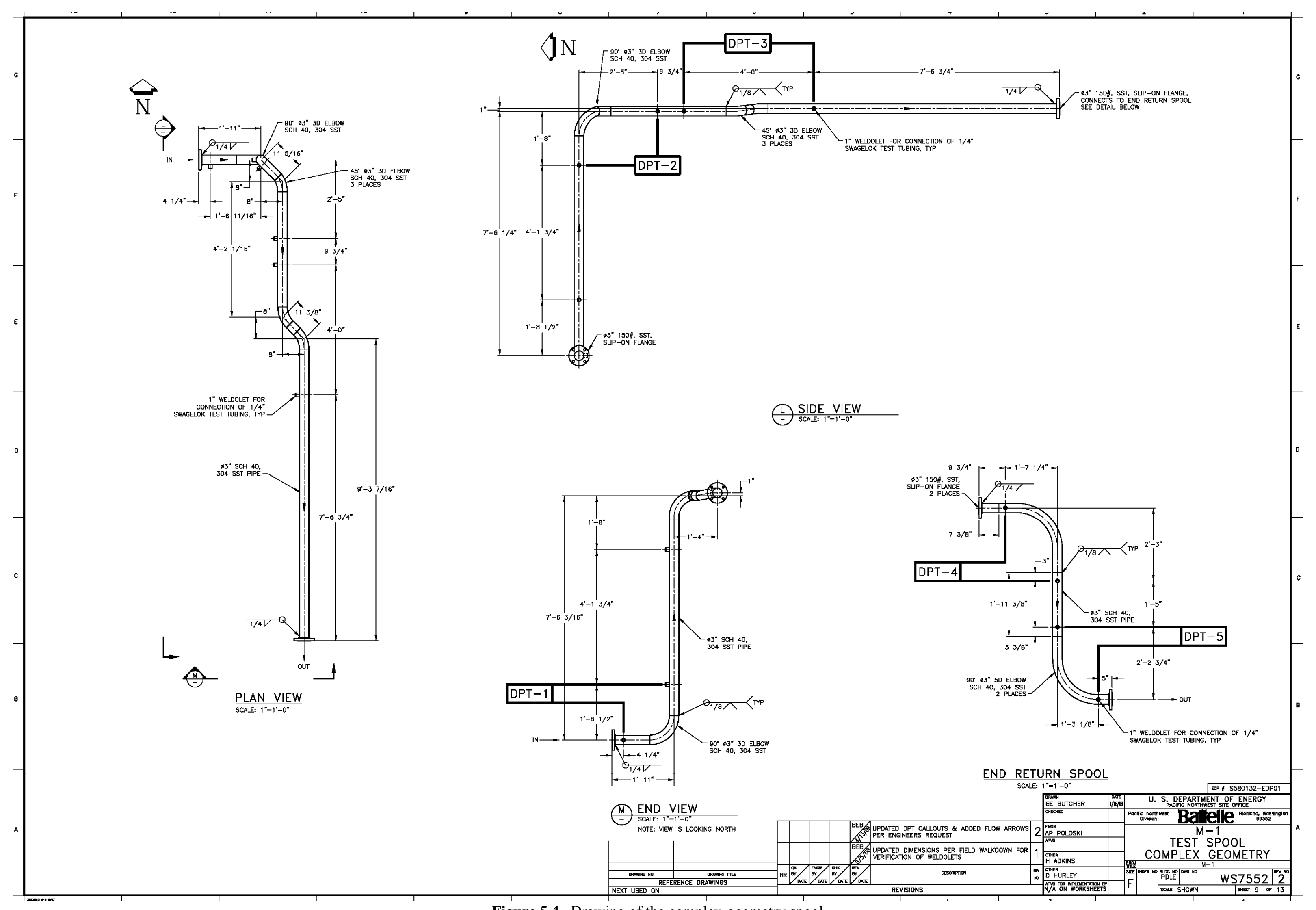

Figure 5.4. Drawing of the complex-geometry spool 


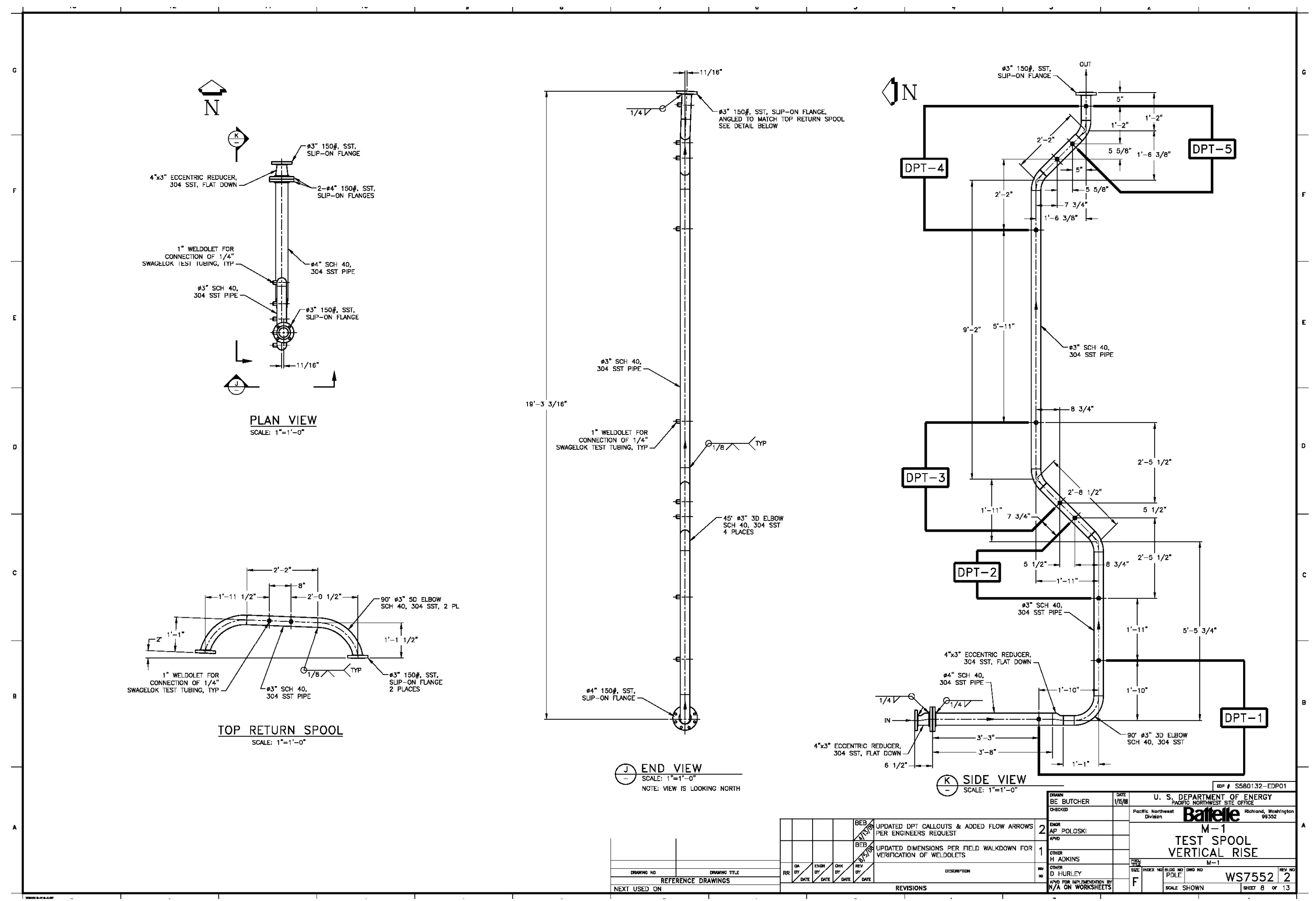

Figure 5.5. Drawing of the reducer and vertical-rise spool 


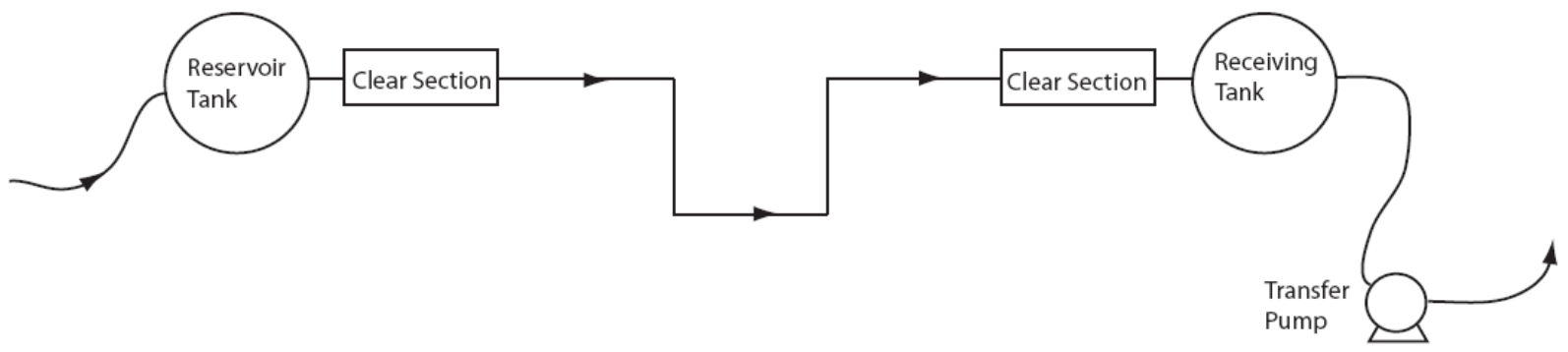

Figure 5.6. Schematic of the GDPF pipe flow test section

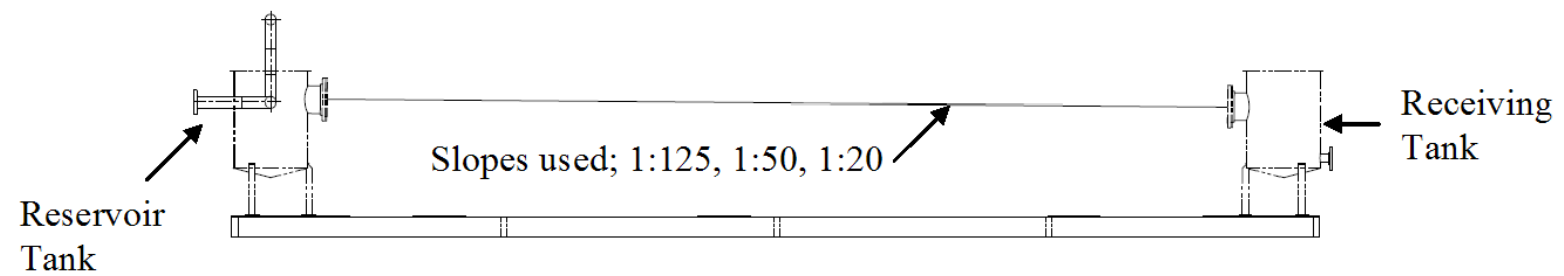

Figure 5.7. Side view diagram of the GDPF pipe flow test arrangement

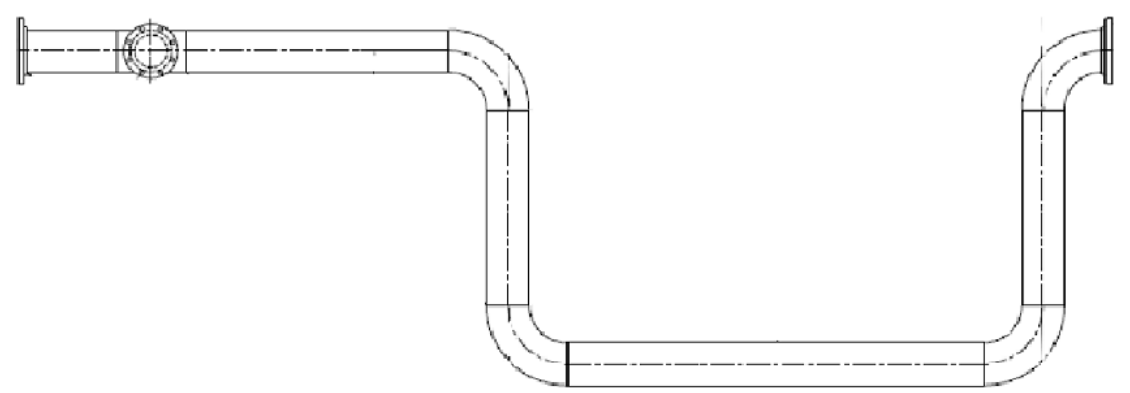

Figure 5.8. Top view diagram of the GDPF pipe flow test section 


\subsection{Piping and Test Spools}

The piping used for the flow-loop system consists primarily of 3-inch, schedule-40, 304-stainless steel (with some recycled 316-stainless steel pieces). The spools used for this testing are described herein.

The pressure-drop measurements across the components of the gravity-feed and process-drain test module, the jumper test module, the complex-geometry test module, and the reducer and vertical-rise test module were performed with a differential pressure transducer (DPT). The DPTs used are referred to as DPT-1, DPT-2, and so on according to their locations as shown in Figure 5.2 to Figure 5.5. The location of a modular component can be easily identified by counting its location starting from the first component of the test module and increasing in the flow direction. The count numbers correspond with the numbers following the abbreviation "DPT." In this manner, a DPT can be easily associated with the modular component across which the DPT is taking measurements.

Figure 5.2 presents the drawing of the gravity-feed and process-drain test module. DPT-1 is used to measure the pressure drop across the first modular component of a tee, followed downstream by DPT-2, DPT-3, DPT-4 and DPT-5 for measurements across the second, third, fourth, and fifth modular components, $90^{\circ} 3 \mathrm{D}$ elbows. This test module is configured so that the slurry flows through modular components with a 1:50 downward slope (Figure 5.2 does not reflect this slope).

Figure 5.3 presents the drawing of the jumper test module. DPT-1 and DPT-3 are used to measure the pressure drop across the first and third modular components, $90^{\circ}$ miter bends. The measurement with DPT-2 is performed for the second modular component, a $90^{\circ} 3 \mathrm{D}$ elbow located between the two $90^{\circ}$ miter bends. The jumper test module is configured so the slurry flows horizontally until the first $90^{\circ}$ miter bend redirects it upward, a $90^{\circ} 3 \mathrm{D}$ elbow returns it to horizontal flow, and the second $90^{\circ}$ miter bend directs it once again to the vertical. Due to time constraints, the jumper test module was set up by connecting the jumper test module to the gravity-feed and process-drain test module in such a way that the slurry flow from the jumper test module entered into the gravity-feed and process-drain test module.

Figure 5.4 presents the drawing of the complex-geometry test module. DPT-1 is used to measure the pressure drop across the first modular component, a $90^{\circ} 3 \mathrm{D}$ elbow, followed downstream by DPT-2 for measurement across the second modular component, a $90^{\circ} 3 \mathrm{D}$ elbow combined with a $45^{\circ} 3 \mathrm{D}$ elbow. The measurement across the third modular component, a combination of two $45^{\circ} 3 \mathrm{D}$ elbows, is performed with DPT-3. Following DPT-3 downstream, DPT-4 and DPT-5 are used for the pressure-drop measurements across the fourth and fifth modular components, $90^{\circ} 5 \mathrm{D}$ elbows.

The complex-geometry module was configured so that the slurry flow entered the first modular component horizontally and was redirected vertically upward through the first component. The second modular component changed the flow direction from vertical to an upward slope 1:20 from horizontal. After passing through the third modular component with the 1:20 upward slope, the flow was redirected vertically downward through the fourth component. The fifth component changed the flow from vertically downward to horizontal. Figure 5.4 does not reflect the 1:20 slope between the exit of the $90^{\circ}$ $3 \mathrm{D}$ elbow (the second component) and the entrance of the $90^{\circ} 5 \mathrm{D}$ elbow (the fourth component). 
Figure 5.5 presents the drawing of the reducer and vertical-rise test module. DPT-1 is used to measure the pressure drop across the first modular component, a reducer combined with a $90^{\circ} 3 \mathrm{D}$ elbow, followed downstream by DPT-2 and DPT-3 for measurements across the second and third modular components, which are $45^{\circ} 3 \mathrm{D}$ elbows. The measurements across the fourth and fifth modular components, two $45^{\circ} 3 \mathrm{D}$ elbows, are performed with DPT-4 and DPT-5.

The reducer and vertical-rise module was configured so the slurry flow entered the reducer horizontally and underwent expansion and reduction before being redirected vertically upward through the $90^{\circ} 3 \mathrm{D}$ elbow (Note: the reducer and $90^{\circ} 3 \mathrm{D}$ elbow comprise the first modular component). This slurry flow remained in the upward direction through the rest of the components of this reducer and vertical-rise test module.

Figure 5.6 to Figure 5.8 present the diagrams of the 8-inch GDPF pipe flow test module. The slurry flow driven by the slurry pump is contained in the 50-gallon reservoir tank before it is introduced into the test section. The slurry flow is then driven by gravity from the slurry height in the reservoir tank through the first transparent section (labeled 'Clear Section' in Figure 5.6), then the four $90^{\circ} 3 \mathrm{D}$ elbows (see Figure 5.8), and finally the second transparent section before it infuses into the 50-gallon receiving tank. The slurry height in the receiving tank is maintained below the pipe end that connected the receiving tank with a transfer pump to avoid interference from the slurry height in the receiving tank on the slurry flow. Three downward slopes of 1:125, 1:50, and 1:20 are used for the 8-inch GDPF pipe flow test module for three tests, respectively (see Figure 5.7).

\subsection{Slurry Pump}

The slurry pump is a Georgia Iron Works GIW 2X3LCC-M9 (LCC-M 50-230.2K M1). A picture of a similar pump is shown in Figure 5.9. The pump is driven by a 15-hp, $1800 \mathrm{rpm}$, totally enclosed fancooled 460-V electric motor produced by Reliance XEX as model P25G3316. This motor is connected to the pump by a belt drive. A Flowserve SL-C single cartridge flushless mechanical seal is used in this pump.

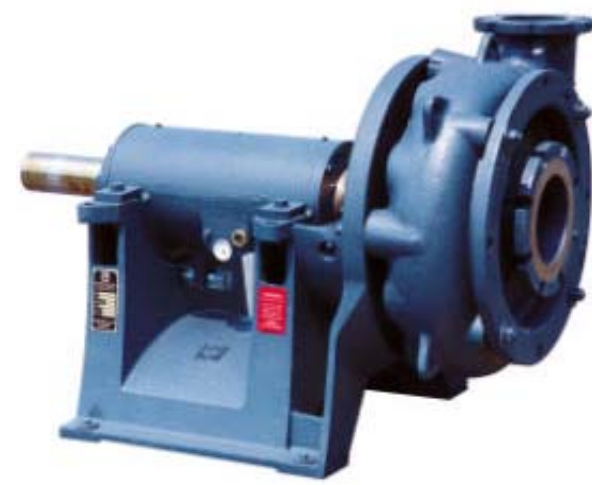

Figure 5.9. Photograph of Georgia Iron Works 2 X3LCC Slurry Pump (Source: www.giwindustries.com) 


\subsection{Mixing Tank}

The mixing tank is a standard four-baffle mixing tank with a 54-inch internal diameter. The maximum capacity of this tank is approximately 400 gallons. The tank is agitated by a 25 -inch-diameter, 4-bladed pitched-blade impeller (4PBT45) driven by a 10-hp overhead electric motor manufactured by Philadelphia Mixers. At full speed, the system rotates at $155 \mathrm{rpm}$. A dip-tube system is used to feed and return the slurry from the test loop. A drawing of the mixing tank internal components is shown in Figure 5.10 .

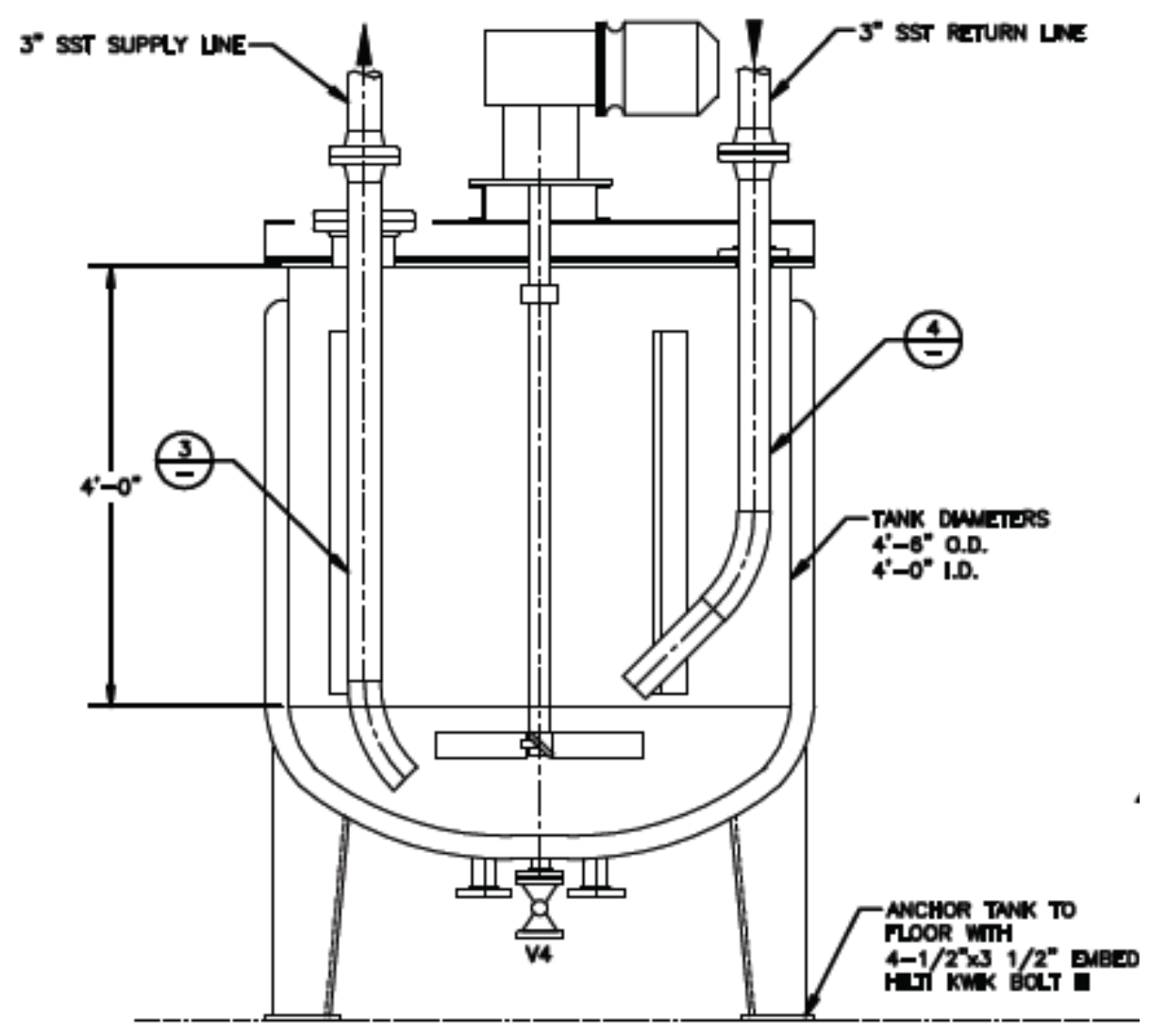

Figure 5.10. Schematic of Mixing Tank Internal Components

\subsection{Flush System}

The flush tank was a "U" stamped pressure vessel (National Board Number 18,365) rated to a maximum working pressure of $150 \mathrm{psig}$. The tank's diameter is $4 \mathrm{ft}$ and its capacity is 400 gallons. The tank is jacketed to allow for temperature control. The flush tank was augmented with a jet mixer system. A drawing of the flush tank's internal components is shown in Figure 5.11. 


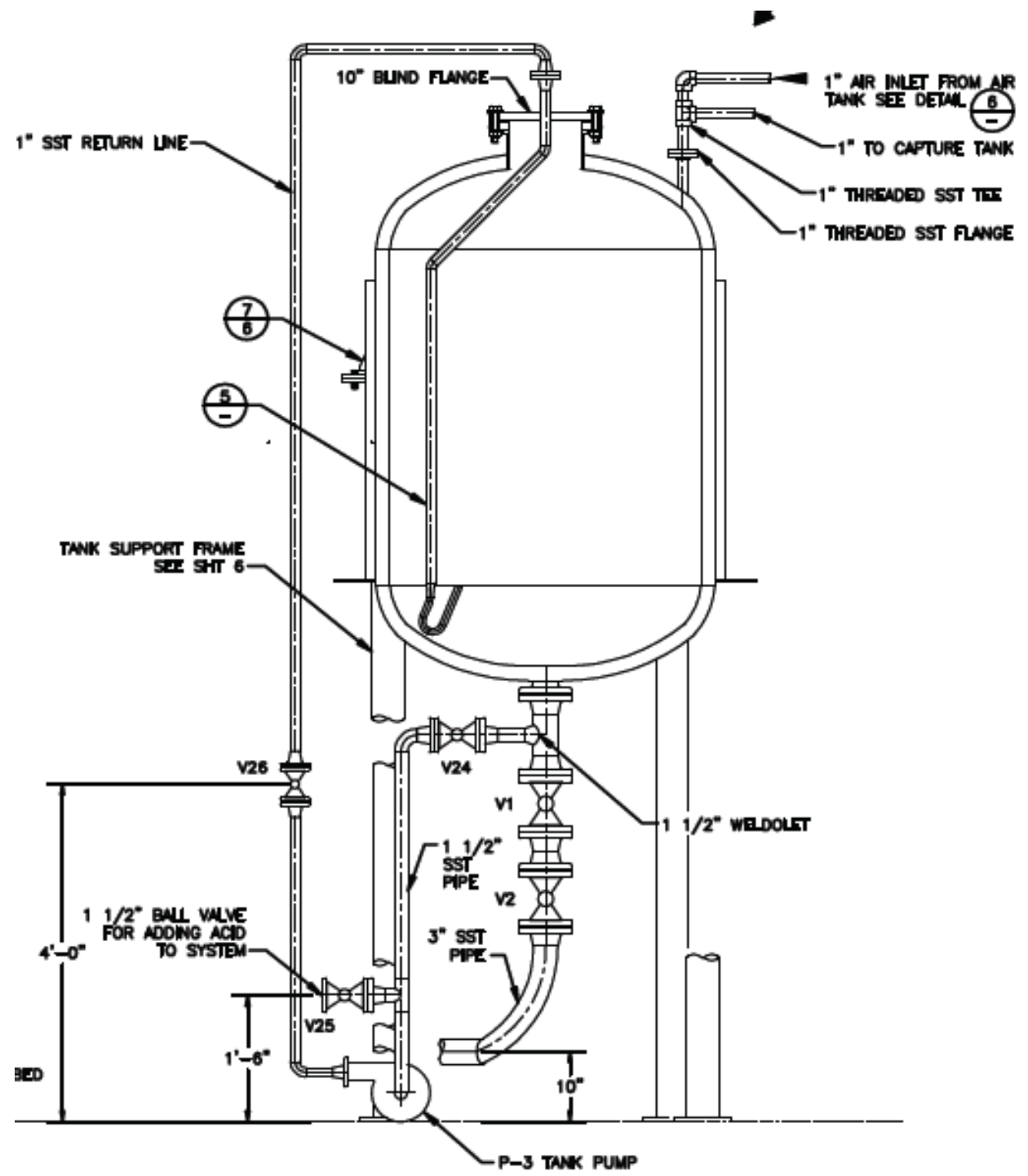

Figure 5.11. Schematic of Flush Tank Internal Components

\subsection{Data Acquisition System}

The data acquisition system took temperature, flow, level, and pressure data from the flow loop and stored it in data files. The system was running National Instruments LabView ${ }^{\mathrm{TM}}$ software with a nominal sampling rate of $300 \mathrm{~ms}$.

\subsection{Differential Pressure Transducers}

Rosemount 1151 differential pressure transducers (DPT) were used for the pressure-drop measurements across the components of the modular test section. The accuracy is $\pm 0.25 \%$ of the measurement within the calibrated span of 0 to 150 inches $\mathrm{H}_{2} \mathrm{O}$ differential. The pressure transducers were connected to the flow loop through open horizontal weldolet connectors. The open design of the 
ports was selected over diaphragm systems to allow for greater pressure sensitivity. Since sediment was expected to fill these ports during operation, a differential-pressure port purge system was also installed. This system allowed the DPTs to be isolated from the flow loop. The differential-pressure ports were then cleaned by briefly flushing lines with high-pressure water. This purge process was implemented as needed throughout testing. Two transducers with differing pressure measurement ranges were connected to a pair of weldolet ports. This allowed for a broad range of pressure measurements to be taken.

\subsection{Coriolis Meters}

The Coriolis meters used during testing were Micro-Motion F-Series sensors designed for 3-inch, schedule-40 pipe and made of 316L stainless steel.

\subsection{Video Camera Recorder}

A Sony ${ }^{\circledR}$ video camera recorder, CCD-TRV138NTSC Hi8, was used for videotaping the slurry flow observation. 


\subsection{Test Procedure}

Tests to determine the effects of the piping geometry on the critical pipeline velocity were performed for the four test spools as described in Section 5. In these tests, the pressure drop was measured across each component of the test spool to evaluate critical velocities and velocities for avoiding deposition (VFAD). After the pressure-drop measurements, the experimental work was continued to test the flushing operation. The experiments to measure the pressure drop and to conduct the flush testing are referred to as "pressure-drop measurement and flush tests" herein. In addition to the pressure-drop measurement and flush tests, three downward pipe slopes of 1:125, 1:50, and 1:20 were used to inspect the particle sedimentation process in the 8-inch gravity-driven partially-filled (GDPF) pipe flow. This testing is referred to as "GDPF pipe flow tests" herein. This section presents the procedures of the pressure-drop measurement and flush tests and the GDPF pipe flow tests.

\subsection{Procedure for Pressure-Drop Measurement and Flush Tests}

In order to produce the pressure-drop distributions from which critical velocities and VFADs were obtained, pressure drop was measured across each component of the gravity-feed and process-drain test module, the jumper test module, the complex-geometry test module, and the reducer and vertical-rise test module. Along with the pressure drop, the flow rate (velocity), slurry density, slurry temperature, mixing and flush tank temperatures, water heater and chiller temperatures, flow-loop pressure drop, and air tank pressure were measured. After taking those measurements, the flushing operation was tested. The procedure for the pressure-drop measurements and the flush operation testing is outlined, as a sequence of steps, below.

1) Start the Data Acquisition System

The data acquisition system was started to record the pressure drop, flow rate (velocity), slurry density, slurry temperature, mixing and flush tank temperatures, water heater and chiller temperatures, flow-loop pressure drop, and air tank pressure.

2) Load Simulant for Testing

The simulant described in Section 4 was loaded into a rinsed and drained mixing vessel and flow loop. Tap water, to be used as the flush solution, was added to the flush vessel.

3) Homogenize Simulant

The mechanical agitator on the mixing vessel was started for solids homogenization. The mixingvessel temperature control system was set to the appropriate value, nominally $25^{\circ} \mathrm{C}$.

4) Start Pipe Flow

The flow-loop pump was started with a target flow velocity of 7.5 or $8 \mathrm{ft} / \mathrm{sec}$ as specified by the cognizant test engineer. The Coriolis meters on the flow loop were used to verify this reading. 


\section{5) Confirm Homogenization}

The mixing-vessel flow loop was operated to determine slurry density in the vessel via Coriolis flow meters. Agitator rotational rates were adjusted such that the solid-volume fractions were within $20 \%$ of the theoretical calculated values for complete homogenization, as well as to minimize the entrainment of air in the pipe loop.

6) Take Samples and Measure Rheological Properties

A grab sample was taken from the mixing vessel, and a flow curve (see Section 4) was measured. During the testing, this rheological property measurement and the DPT purging were performed frequently under the direction of the cognizant test engineer.

7) Determine Steady-State Condition

A flow rate was held constant for a minimum of 30 minutes before a steady-state condition was assumed. If the transient pressure signal indicated a trend after this 30-minute period, the flow was held constant until a steady state was determined by the cognizant test engineer.

The temperature of the slurry was held constant during this testing via automatic temperature control on the jacketed mixing vessel. The temperature was maintained within $\pm 10^{\circ} \mathrm{C}$ of target temperature.

8) Decrease Flow rate

The flow rate was decreased in increments under the direction of the cognizant test engineer and Step 7 was repeated until reaching the minimum velocity specified by the cognizant test engineer.

\section{9) Stop Flow}

The pump was then stopped with the line partially filled with sediment.

10) Switch to Flush Mode

Valves were reconfigured to operate in flush mode. This mode allowed for flow from the flush tank to go to the spent simulant vessel. The flush tank was filled with water, which was then driven through the system at the specified operating pressure.

11) Stop the Data Acquisition System

\subsection{Procedure for GDPF Pipe Flow Tests}

Three downward pipe slopes of 1:125, 1:50, and 1:20 were used to inspect the particle sedimentation process of the 8-inch GDPF pipe flow. In this subsection, the procedure for the GDPF pipe flow tests is outlined, as a sequence of steps, below. 
1) Start the Data Acquisition System

The data acquisition system was started to record the flow rate (velocity), slurry density, slurry temperature, mixing and flush tank temperatures, water heater and chiller temperatures, and air tank pressure.

2) Load Simulant for Testing

The simulant described in Section 4 was loaded into a rinsed and drained mixing vessel and flow loop. Tap water, to be used as the flush solution, was added to the flush vessel.

3) Homogenize Simulant

The mechanical agitator on the mixing vessel was started for solids homogenization. The mixingvessel temperature control system was set to the appropriate value, nominally $25^{\circ} \mathrm{C}$.

\section{4) Start Pipe Flow}

The flow-loop pump was started, under the direction of the cognizant test engineer, with a target flow velocity of $8 \mathrm{ft} / \mathrm{sec}$. The Coriolis meters on the flow loop were used to verify this reading.

\section{5) Confirm Homogenization}

The mixing-vessel flow loop was operated to determine slurry density in the vessel via Coriolis flow meters. Agitator rotational rates were adjusted so the solid-volume fractions were within $20 \%$ of the theoretical calculated values for complete homogenization, as well as to minimize the entrainment of air in the pipe loop.

6) Take Samples and Measure Rheological Properties

A grab sample was taken from the mixing vessel, and a flow curve (see Section 4) was measured. During the testing, this rheological property measurement and the DPT purging were performed frequently under the direction of the cognizant test engineer.

7) Minimum 30-Minute Flow Run

The flow rate was held constant for a minimum of 30 minutes or as instructed by the cognizant test engineer.

During this time period, the slurry deposition process was observed through the transparent sections and inspected by inserting a hand through the open port on the test module; results were recorded in the Laboratory Record Book. Videotaping was performed under the direction of the cognizant test engineer. 
The temperature of the slurry was held constant via automatic temperature control on the jacketed mixing vessel. The temperature was maintained within $\pm 10^{\circ} \mathrm{C}$ of the target temperature.

8) Decrease Flow Rate

The flow rate was decreased in increments under the direction of the cognizant test engineer and Step 7 was repeated until the cognizant test engineer instructed to stop the slurry pump. Videotaping was performed during changes in the flow rate.

9) Inspect Slurry Deposition

With no flow condition after the slurry pump was stopped, the slurry deposition process was inspected by observation through the transparent sections and the open port on the test module. In addition, the inspection was performed by inserting a hand through the open port on the test module. Results were recorded in the Laboratory Record Book.

10) Flush Modular Test Section

Under the direction of the cognizant test engineer, the modular test section was flushed with tap water.

12) Stop the Data Acquisition System 


\subsection{Critical Velocity and Velocity for Avoiding Deposition}

Tests to determine the effects of the piping geometry on the slurry particle deposition were performed for the four test spools. The test spools included the following pipeline configurations: 1) gravity feed and process drain, 2) jumper, 3) complex geometry, and 4) reducer and vertical-rise. This section presents and discusses the results of the tests with these test modules.

\subsection{Test Results}

The pressure drop across each component of the gravity-feed and process-drain test module, the jumper test module, the complex geometry test module, and the reducer and vertical-rise test module was measured with a differential pressure transducer (DPT). The DPTs are referred to as DPT-1, DPT-2, and so on according to their locations (see Figure 5.2 to Figure 5.5). The location of the modular component can be easily identified by counting from the first component of the test module and increasing in the flow direction. The count numbers correspond to the numbers following the abbreviation "DPT." In this manner, a DPT can be simply associated with the modular component across which the DPT is taking measurements.

As described in Subsection 5.1, the DPTs measure the pressure drop between the two pressure ports on the test module components that have rising and falling slopes. Due to the density difference between the slurry flowing inside the pipeline of the modular components, and water inside the tubes that connect DPTs to the pressure ports on the modular components, the vertical distances between the two ports on the test module components cause the DPT readings to include the hydrostatic pressure due to gravity. This effect can be removed from the measured DPT data by adding (or subtracting, in the case of upward flow) the correction factor $\Delta \mathrm{P}_{c}$ to (or from) the DPT readings, with

$$
\Delta \mathrm{P}_{c}=\left(\rho_{\text {Slurry }}-\rho_{\text {water }}\right) g h
$$

where $\rho_{\text {Slurry }}$ is the slurry density

$\rho_{\text {water }}$ is the water density

$g \quad$ is the acceleration due to gravity

$h \quad$ is the vertical distance between the pressure ports on the modular component

To perform accurate DPT data corrections with Equation [7.1], the following items need to be satisfied: (1) the accurate slurry densities inside the modular components are measured and (2) the DPT pressure tubes that connect the DPTs to the pressure ports on the modular components contain only water.

For this correction of the DPT data, the slurry density obtained with the Coriolis flow meter at a position well upstream of the modular test section was used. Therefore, it is expected that, in low velocity conditions, the density given by the Coriolis flow meter differs from the density at the pressure ports where the DPT measurements are performed, possibly due to particle settling. The inaccuracy of the density measurements is considered to cause uncertainty for the data analysis. In addition, high uncertainty is expected in the pressure measurements since the static pressure measured by a DPT was the 
local static pressure in the immediate vicinity of the pressure ports which was considered to be different from the average pressure in the pipe cross section due to the complex flow structure produced by the geometry of the modular component. The high uncertainty in the density and pressure measurements is deemed to significant but no corrective method is available.

In this section, the measured pressure-drop values (DPT data) with and without the correction by applying Equation [7.1] are presented. The uncorrected DPT data can provide only a qualitative description since these data include the hydrostatic pressure due to gravity. It is pointed out that the hydrostatic pressure due to gravity is not constant over a test run since the density changes as the flow velocity changes. For the corrected DPT data, due to the expected high uncertainty in the density and pressure data as discussed above, accurate quantitative analyses are also not available. The data analyses of this study provide only a qualitative description of the pressure drop characteristics across the test module components.

\section{$\underline{\text { Gravity-Feed and Process-Drain Test Module }}$}

Figure 7.1 presents the plots of the pressure-drop distributions as a function of pipeline velocity for the data obtained with DPTs across every modular component of the gravity-feed and process-drain test module. In Figure 7.1, the uncorrected DPT data are given in the left column while the right column includes the corrected DPT data. The top plots of Figure 7.1 are for the data of the first test, the middle plots are for the data of the second test, a repetition of the first, and the bottom plots are for the data of the third test, another repetition. DPT-1 was used to measure the pressure drop across the first modular component, a tee, followed downstream by DPT-2, DPT-3, DPT-4 and DPT-5 for the measurements across the second, third, fourth, and fifth modular components, which were $90^{\circ} 3 \mathrm{D}$ elbows (see Figure 5.2). This test module was configured so the slurry flowed through the modular components with a 1:50 downward slope (Figure 5.2 does not reflect this slope). The hydrostatic pressure due to the 1:50 slope is small. Therefore, the differences between uncorrected and corrected data for this test module are expected to be small.

The general characteristic of the distributions observed in Figure 7.1 is that, as the pipeline velocity decreases from a maximum, the pressure-drop value across the modular components decreases to a minimum and then slightly increases while the pipeline velocity continues to decrease. In some cases, the minimum pressure-drop values are observed at the smallest velocities used for the tests (note: the smallest velocity used for the repeated third test was $2.5 \mathrm{ft} / \mathrm{sec}$ ).

Practically, the fluctuations in the smooth curve lines of Figure 7.1 are considered to be caused by the geometry of the modular components since they vary for the repeated tests. Thus, the pressure-drop distributions for the data obtained with DPT-2, DPT-3, and DPT-4, which were used for the measurements across the same fitting of the $90^{\circ} 3 \mathrm{D}$ elbow, could be considered similar.

The data obtained by DPT-5, which measured the pressure difference over the fifth component, a $90^{\circ}$ 3D elbow, deviates from the general characteristic of the pressure-drop and pipeline-velocity distribution, as the distribution includes a spike point at a velocity of $2.5 \mathrm{ft} / \mathrm{sec}$. This spike in pressure drop is observed for the repeated second and third tests as well (note: the repeated tests were performed for selected pipeline velocities). As seen in Figure 7.1, the repeated third test did not take measurements for the pipeline velocities below $2.5 \mathrm{ft} / \mathrm{sec}$; however, it is inferred that the same distribution trend would be 
obtained for the third test as the first and second tests since all of the measured values agree with each other for these three test runs.

The cause of the spike in DPT-5 data produced is not certain, however it can be pointed out that the low-pressure port of DPT- 5 was located at the end point of the $90^{\circ} 3 \mathrm{D}$ elbow where the slurry flow entered the straight section of the modular component, and was located on the inner side of the $90^{\circ}$ elbow arc (see Figure 5.2). The slurry particles were considered to be more uniformly distributed in highvelocity flow due to the high momentum of flow turbulence. However, as the velocity decreased to about $3 \mathrm{ft} / \mathrm{sec}$, the flow might enter the transition regime between turbulent and laminar flow. At the pipeline velocity of $3 \mathrm{ft} / \mathrm{sec}$, flowing in the $90^{\circ}$ elbow arc, the slurry particles might experience a larger centrifugal force than the longitudinal force given by the carrier fluid due to the reduction in fluid flow momentum. This might cause the higher concentration of particles in the outer side of the $90^{\circ}$ elbow arc and the lower concentration in the inner side. Due to the lower particle density concentration, a significantly lowerthan-average static pressure across the pipeline is expected in the vicinity of the lower-pressure DPT-5 port, which might produce the large spike in pressure differences for the pipeline velocity region from 2 to $3 \mathrm{ft} / \mathrm{sec}$.

The critical velocity of the DPT-1 data for the first modular component of the tee was evaluated to be $3.5 \mathrm{ft} / \mathrm{sec}$, which is markedly larger than those for the other modular components. The cause of this high critical velocity could be that expansion of the cross section area by the tee modular component reduced the slurry flow. Therefore, the slurry flow velocity in this tee section was lower than the pipeline velocity indicated by the Coriolis flow meter, and the particle settlement occurred at a pipeline flow velocity at which the slurry particles were suspended in the flow for the other modular components.

Large fluctuation is observed in all of the DPT data for the low velocity range. Due to the large fluctuation in the DPT data, it is inconclusive that the J-curve profile (see Subsection 3.1) was obtained for the DPT data, except DPT-1 data, of the gravity-feed and process-drain test module. The geometry of the modular components is considered to be responsible for the large fluctuations. Since the locations of the pressure ports used for the pressure-drop measurements were near to the modular components, it is expected that the flow in the vicinities of the pressure ports were unstable and caused the large fluctuation in DPT data. In addition, formation of the unstable bed of particles may cause the large fluctuation in DPT data. For the velocity range lower than $3 \mathrm{ft} / \mathrm{sec}(2 \mathrm{ft} / \mathrm{sec}$ for DPT-5 data), the flow might become laminar and the unstable bed of particles might be formed on the bottom of the modular components. The particles that settled on the bottom of the modular component might be lifted up by the fluid flow and then settle again downstream in this velocity range.

The locations of the pressure ports near to the modular components and the formation of the unstable particle bed are considered to cause the large fluctuation in pressure drop (even a negative value was measured) at these velocities, as seen in Figure 7.1 for the three test runs. 

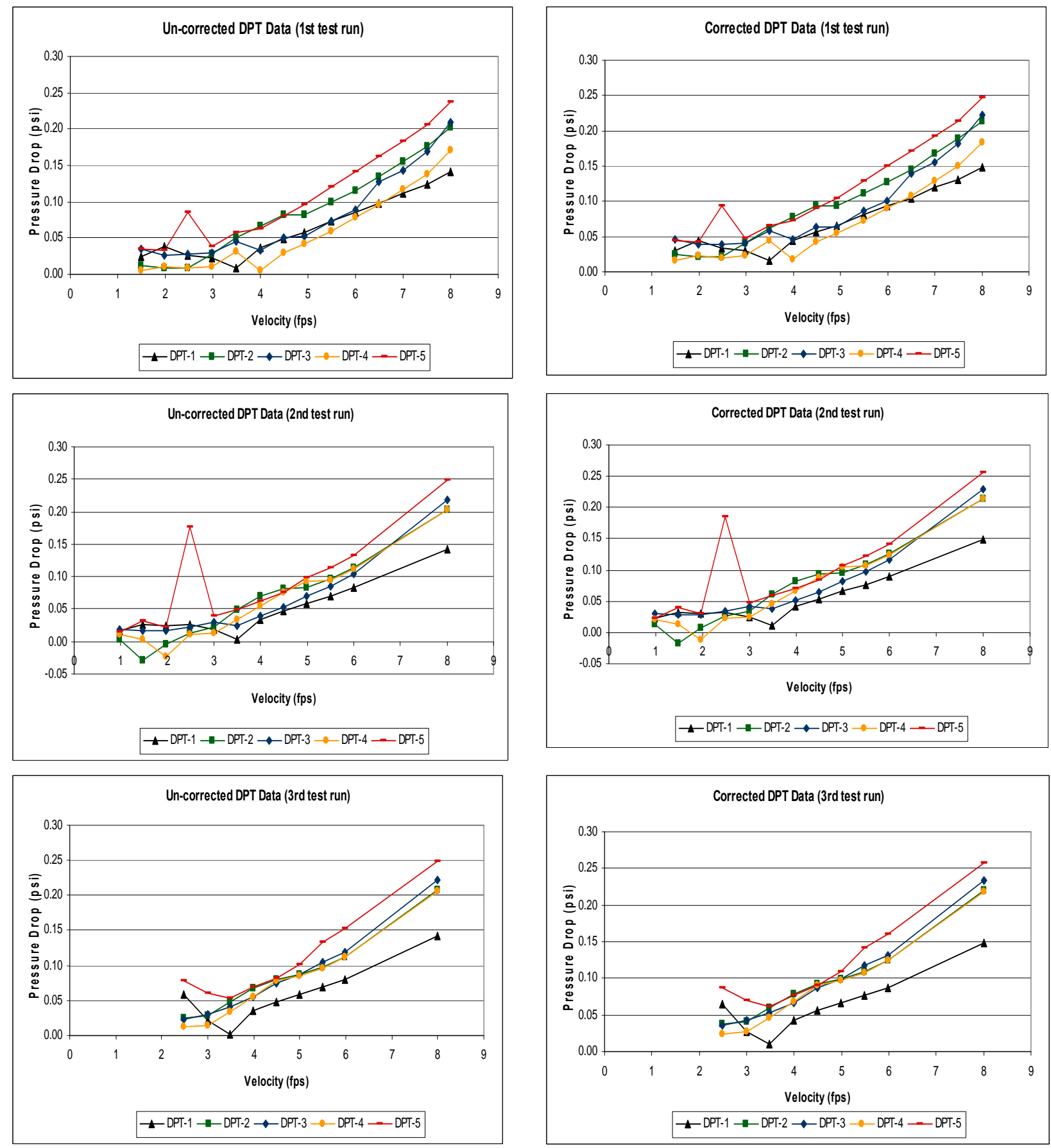

Figure 7.1. Plots of pressure drop vs. pipeline velocity for the gravity-feed and process-drain module. The left column is the uncorrected DPT data and the right column is the corrected DPT data. The top plots are of the first test run, the middle are of the second test run, and the bottom are of the third test run. DPT-1 is the DPT used for the first modular component of the tee, followed downstream by DPT-2, DPT-3, DPT-4, and DPT-5 for the second, third, fourth and fifth components of the $90^{\circ} 3 \mathrm{D}$ elbows, respectively. 


\section{Jumper Test Module}

Figure 7.2 presents plots of the pressure-drop distributions as a function of the pipeline velocity for the data obtained with DPT-1, DPT-2, and DPT-3 for the jumper test module. In Figure 7.2, the uncorrected DPT data are given in the left column while the right column includes the corrected DPT data. The top plots of Figure 7.2 are for the data of the first test, the middle plots are for the data of the second test, a repetition of the first, and the bottom plots are for the data of the third test, another repetition. DPT-1 and DPT-3 were used to measure the pressure drop across the first and third modular components, $90^{\circ}$ miter bends. The measurement with DPT-2 was performed for the second modular component, a $90^{\circ} 3 \mathrm{D}$ elbow located between the two $90^{\circ}$ miter bends (see Figure 5.3). The jumper test module is configured so the slurry flows horizontally until the first $90^{\circ}$ miter bend redirects it upward, a $90^{\circ} 3 \mathrm{D}$ elbow returns it to horizontal flow, and the second $90^{\circ}$ miter bend directs it once again to the vertical.

The general characteristic of the distribution for the data obtained with DPT- 1 and DPT-3 is analogous to that of the gravity-feed and process-drain module as presented in Figure 7.1, whereas the DPT-2 data present a drastically different distribution (negative values for the corrected DPT data). For both the uncorrected and corrected data from the DPT-1 and DPT-3 measurements, the minimum pressure-drop values are observed at the smallest velocities used for the tests.

For this jumper test module, the same port on the modular pipe was used to measure the pressure at the low pressure port of DPT-1 and at the high pressure port of DPT-2. Likewise, the same port on the modular pipe was used to measure the pressure at the low pressure port of DPT-2 and at the high pressure port of DPT-3 (see Figure 5.3). It is seen that the DPT- 2 measurement over the $90^{\circ} 3 \mathrm{D}$ elbow indicates a significantly small gradient in the pressure-drop distribution with high fluctuation. The cause for this may be that the upstream flow entering the second modular component, the $90^{\circ} 3 \mathrm{D}$ elbow, was extremely disturbed by the presence of the first modular component, a $90^{\circ}$ miter bend. Due to the complex flow structure of high-intensity turbulence, the static pressure obtained by DPT-2 could not represent the average pressure of the cross section of the $90^{\circ} 3 \mathrm{D}$ elbow at the location of the high pressure DPT-2 port, and the small gradient in pressure distribution for DPT-2 data could be produced. It seems the flow was regulated by going through the $90^{\circ}$ elbow and less-disturbed flow entered the third modular component of the $90^{\circ}$ miter bend. Thus, DPT- 1 and DPT- 3 could measure a similar pressure-drop distribution.

The high turbulence of the slurry flow generated by the presence of the $90^{\circ}$ miter bends could explain the large gradients in the pressure-drop distributions for the DPT-1 and DPT-3 data seen in Figure 7.2. 

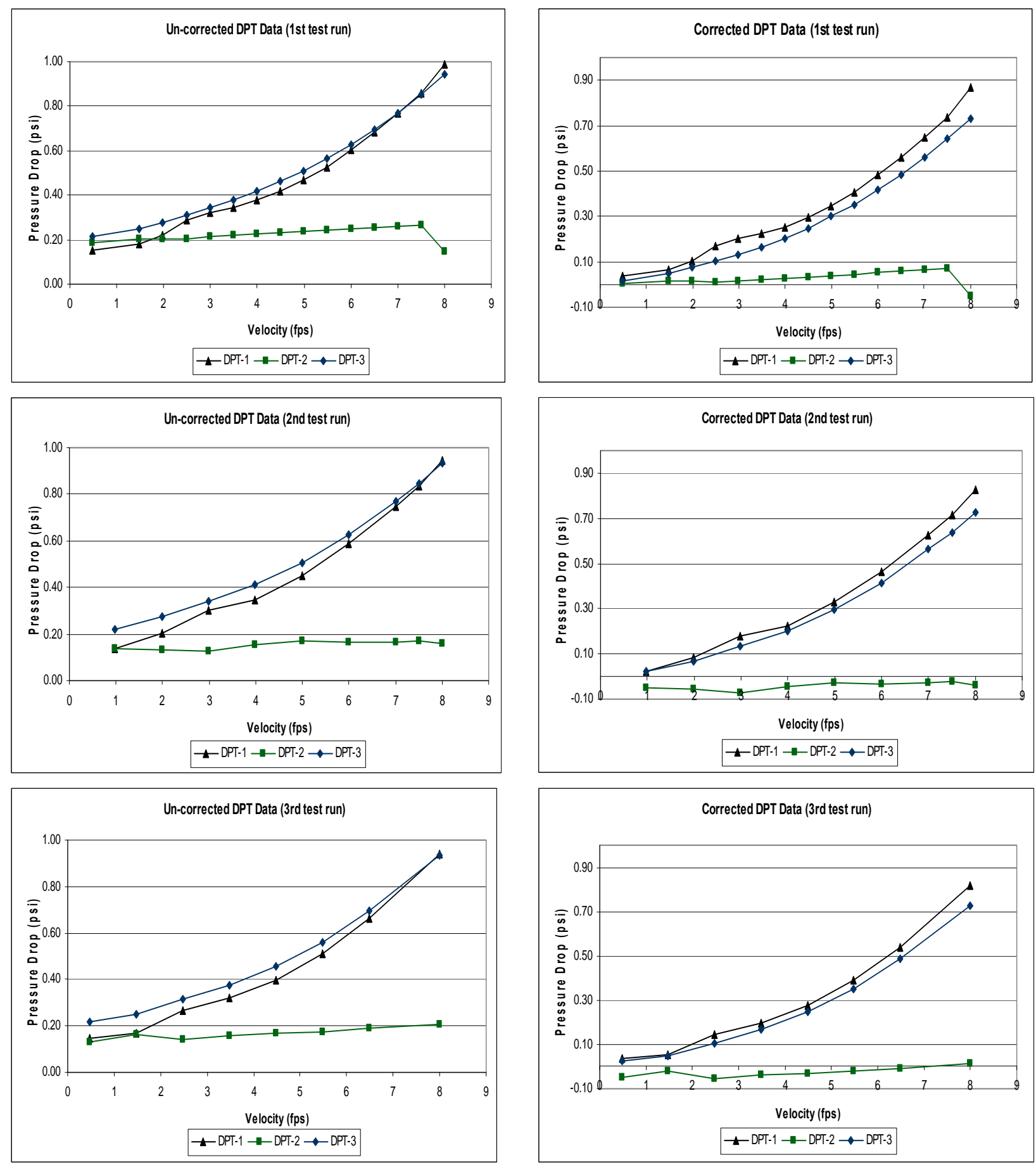

Figure 7.2. Plots of pressure drop vs. pipeline velocity for the jumper module.

The left column is the uncorrected DPT data and the right column is the corrected DPT data. The top plots are of the first test run, the middle are of the second test run and the bottom are of the third test run. DPT- 1 is the DPT used for the first modular component of the $90^{\circ}$ miter bend, followed downstream by DPT- 2 and DPT- 3 for the second and third components, the $90^{\circ} 3 \mathrm{D}$ elbow and the $90^{\circ}$ miter bend, respectively. 


\section{Complex-Geometry Test Module}

Figure 7.3 presents the plots of the pressure-drop distributions as a function of pipeline velocity for the data obtained with DPTs across every modular component of the complex-geometry test module. In Figure 7.3, the uncorrected DPT data are given in the left column while the right column includes the corrected DPT data. The top plots of Figure 7.3 are for the data of the first test, the middle plots are for the data of the second test, a repetition of the first, and the bottom plots are for the data of the third test, another repetition. DPT-1 was used to measure the pressure drop across the first modular component, a $90^{\circ} 3 \mathrm{D}$ elbow, followed downstream by DPT- 2 for the measurement across the second modular component, a $90^{\circ} 3 \mathrm{D}$ elbow combined with a $45^{\circ} 3 \mathrm{D}$ elbow. The measurement across the third modular component, a combination of two $45^{\circ} 3 \mathrm{D}$ elbows, was performed with DPT-3. Following DPT-3 downstream, DPT-4 and DPT-5 were used for the pressure-drop measurements across the fourth and fifth modular components, $90^{\circ}$ 5D elbows (see Figure 5.4).

This complex-geometry module was configured so the slurry flow entered the first modular component horizontally and was redirected vertically upward through the first component. The second modular component changed the flow direction from vertical to an upward slope 1:20 from horizontal. After passing through the third modular component with the 1:20 upward slope, the flow was redirected vertically downward through the fourth component. The fifth component changed the flow from vertically downward to horizontal. Figure 5.4 does not reflect the 1:20 slope between the exit of the $90^{\circ}$ $3 \mathrm{D}$ elbow (the second component) and the entrance of the $90^{\circ} 5 \mathrm{D}$ elbow (the fifth component).

Figure 7.3 shows that the pressure-drop distributions for the uncorrected DPT-4 and DPT-5 data are significantly different from those for the corrected DPT-4 and DPT-5 data. This is because the pressuredrop measurements were performed by connecting the high (or low) DPT ports to the low (or high) pressure ports on these modular components. For the flow in the downward direction with the regular DPT connection setup, the hydrostatic pressure due to gravity causes a DPT to measure a negative value. The reverse DPT connection setup for the DPT-4 and DPT-5 were employed since the hydrostatic pressures due to gravity became adversely larger than the pressure-drop values across modular components in the low velocity region due to the large vertical distances between pressure ports as the negative values became lower than the minimum negative value (-0.169 psig) that DPT-4 and DPT-5 could measure. The DPT-4 and DPT-5 data obtained with the reverse DPT connections were corrected by reversing the sign after applying Equation [7.1] (subtracting the hydrostatic pressure due to gravity from measured DPT-4 and DPT-5 data). Plots in the right column of Figure 7.3 show the correct pressure-drop distributions.

Figure 7.3 shows that, for the uncorrected DPT data, the minimum pressure-drop values are observed at the smallest velocities used for the tests in most cases (see the next subsection for a detailed discussion of critical velocities). For the corrected DPT data, Figure 7.3 shows the same general characteristic of the pressure-drop distribution as seen for the gravity-feed and process-drain test module. The data obtained with DPT-4 and DPT-5 show the same spike as seen in the DPT-5 data for the gravity-feed and processdrain test module. As in the case of the gravity-feed and process-drain module, the low pressure port of DPT- 5 of this complex-geometry test module was located at the end point of the $90^{\circ} 5 \mathrm{D}$ elbow where the slurry flow enters the straight section of the modular component (see Figure 5.4). The DPT-5 lowpressure port of this complex geometry test module was located at the end point of the $90^{\circ} 5 \mathrm{D}$ elbow, at the height of the central axis of the pipe, while the location of the DPT-5 low pressure port of the gravity- 
feed and process-drain test module was on the inner side of the $90^{\circ}$ elbow arc. Regardless of this difference, it is rational that the same description used for the spike in the gravity-feed and process-drain test module data applies to the spike in DPT-5 data for this complex-geometry test module.

The low-pressure port of DPT- 4 was located 3 inches downstream of the end point of the $90^{\circ} 5 \mathrm{D}$ elbow. It is conjectured that this difference in the low-pressure port location caused the low magnitude of the spike for DPT-4 data. It is interesting to point out that the spike occurred at the pipeline velocity of $2.5 \mathrm{ft} / \mathrm{sec}$ for all of these data.

The pressure-drop distribution for the corrected DPT-3 data is higher than for the other corrected DPT data. The cause of the higher pressure-drop distribution for corrected DPT-3 data is not certain. It is considered possible that the second modular component could produce high intensity turbulence flow as the flow direction was changed from the vertical to an upward 1:20 slope from horizontal by the $90^{\circ} 3 \mathrm{D}$ elbow, and then the slurry flowed through the $45^{\circ} 3 \mathrm{D}$ elbow with a 1:20 slope (see Figure 5.4). This high intensity turbulence flow could cause a high pressure field in the area where the DPT-2 low pressure port and the DPT-3 high pressure port were located (the distance between the DPT-2 low pressure port and the DPT-3 high pressure port is about 10 inches). The turbulence intensity of this flow is considered to be reduced as the slurry flowed though the third modular component, a combination of two $45^{\circ} 3 \mathrm{D}$ elbows, which could reduce the pressure at the DPT-3 low pressure port. Thus, the high pressure at the DPT-3 high pressure port and the low pressure at the DPT-3 low pressure port could be used to explain the high pressure-drop distribution for corrected DPT-3 data. In addition, the high pressure at the DPT-2 low pressure port could cause the low pressure-drop distribution for corrected DPT-2 data.

It is also pointed out that, as seen in Figure 7.3 for the corrected DPT data, large values of the correction factor $\Delta \mathrm{P}_{c}$ were used for data correction except in the case of DPT-3 data. Therefore, it is considered that data corrections were performed with high uncertainty, except in the case of DPT-3 data, as the large values of correction factor $\Delta \mathrm{P}_{c}$ could account for high uncertainty. 

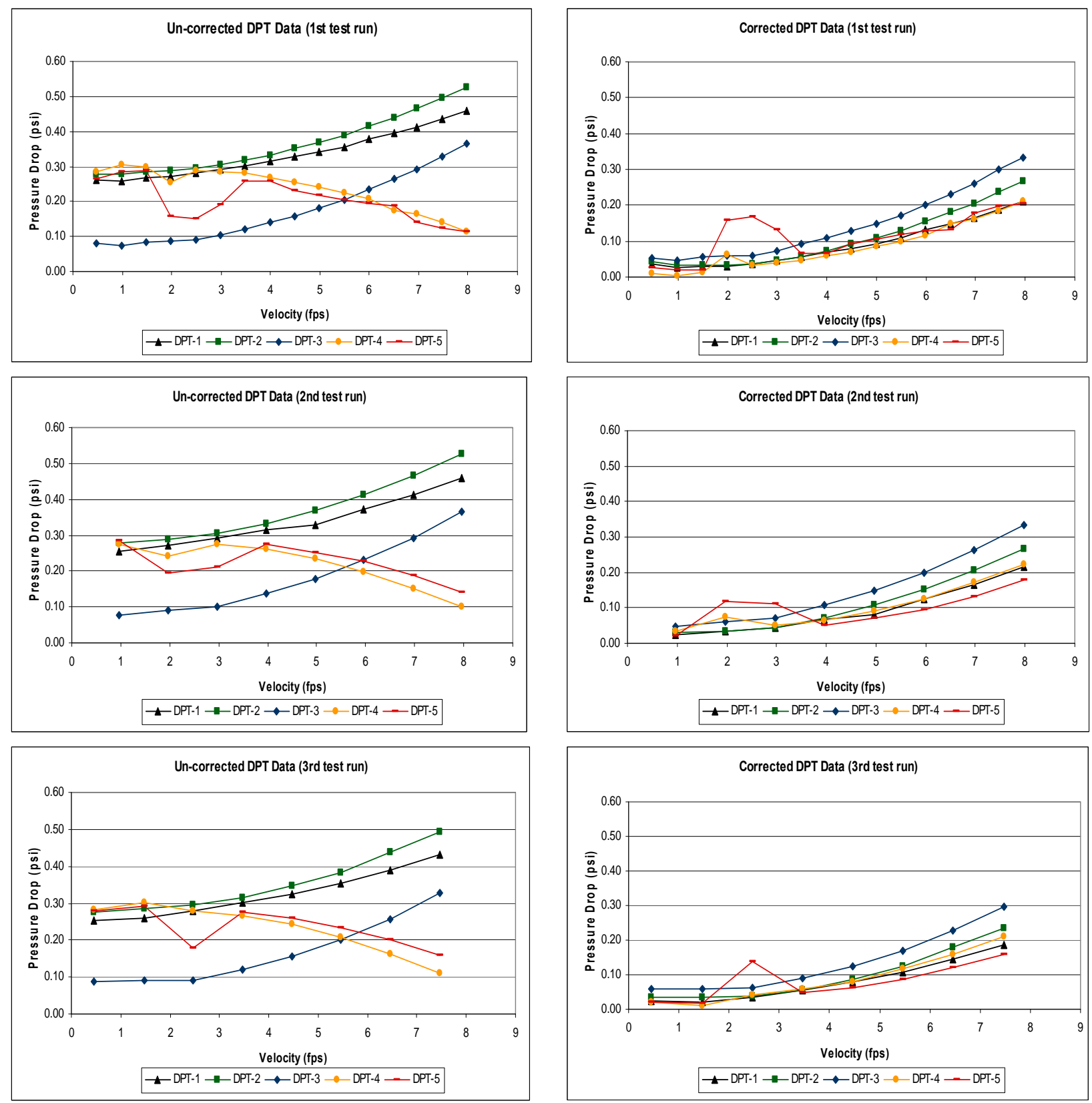

Figure 7.3. Plots of pressure drop vs. pipeline velocity for the complex geometry module.

The left column is uncorrected DPT data and the right column is corrected DPT data. The top plots are of the first test run, the middle are of the second test run and the bottom are of the third test run. DPT- 1 is the DPT used for the first modular component, a $90^{\circ} 3 \mathrm{D}$ elbow, followed downstream by DPT-2 for the second component, a $90^{\circ} 3 \mathrm{D}$ elbow combined with a $45^{\circ} 3 \mathrm{D}$ elbow, followed by DPT-3 for the third component, a combination two $45^{\circ} 3 \mathrm{D}$ elbows. Following DPT-3 downstream are DPT-4 and DPT-5 for the fourth and fifth components, two $90^{\circ} 5 \mathrm{D}$ elbows. 


\section{$\underline{\text { Reducer and Vertical-Rise Test Module }}$}

Figure 7.4 presents plots of the pressure-drop distributions as a function of pipeline velocity for the data obtained with DPTs across every modular component of the reducer and vertical-rise test module. In Figure 7.4, the uncorrected DPT data are given in the left column while the right column includes corrected DPT data. The top plots of Figure 7.4 are for data from the first test, the middle plots are for data from the second test, a repetition, and the bottom plots are for data from the third test, another repetition. DPT-1 was used to measure the pressure drop across the first modular component, a reducer combined with a $90^{\circ} 3 \mathrm{D}$ elbow, followed downstream by DPT-2 and DPT-3 for measurements across the second and third modular components, two $45^{\circ} 3 \mathrm{D}$ elbows. The measurements across the fourth and fifth modular components, $45^{\circ}$ 3D elbows, were performed with DPT-4 and DPT-5 (see Figure 5.5).

This reducer and vertical-rise module was configured so the slurry flow entered the reducer horizontally and underwent expansion and reduction before the flow was redirected vertically upward through the $90^{\circ} 3 \mathrm{D}$ elbow (Note: the reducer and $90^{\circ} 3 \mathrm{D}$ elbow comprise the first modular component). The slurry flow remained in the upward direction through the remaining components of this reducer and vertical-rise test module.

Once again it is pointed out that fluctuations in the smooth curves of Figure 7.4 are considered to be caused by the geometry of the modular components since they vary in the repeated tests. General characteristics of the pressure-drop distribution seen in Figure 7.4 are consistent with those of the gravityfeed and process-drain test module, the jumper test module, and the complex-geometry test module. For the uncorrected DPT data, Figure 7.4 shows that minimum pressure-drop values are observed at the smallest velocities used for the tests in most cases (see the next subsection for a detailed discussion of critical velocities).

It is expected that slurry flow would decelerate as it enters the reducer and accelerate on exit due to the expansion and reduction in area of the reducer. Therefore, the slowed slurry flow inside the 4-inchdiameter reducer resulted in a higher static pressure where the high-pressure port of DPT-1 was located. In addition, it is expected that the slurry flow inside the reducer could undergo slurry particle settlement at the pipeline velocity at which the particles were suspended in the flow. This slurry flow structure could explain the high gradient in the pressure-drop distribution for data obtained with DPT-1 as the lower pressure port was located on the 3-inch diameter pipeline (see both the uncorrected and corrected DPT-1 data in Figure 7.4).

The corrected DPT data in Figure 7.4 shows that the magnitude of the pressure-drop distribution for the DPT-2 data is half of that for DPT-3 data for the higher-velocity region, even though both the DPT-2 and DPT-3 data were measured for $45^{\circ} 3 \mathrm{D}$ elbows. DPT- 2 measured the pressure drop across the first $45^{\circ}$ $3 \mathrm{D}$ elbow, followed downstream by DPT-3 which measured the pressure drop across the second $45^{\circ} 3 \mathrm{D}$ elbow. The distance between the low-pressure port of DPT-2 and the high-pressure port of DPT-3 was about 8 inches. The flow entered the first $45^{\circ} 3 \mathrm{D}$ elbow from a straight pipe section and became high intensity turbulent through the elbow for higher velocities. Since the lower pressure port was located downstream of the elbow, it is possible that turbulence caused a high-pressure field in the vicinity of the lower pressure port of DPT-2. The pressure of the DPT-2 lower pressure port could increase by 
increasing the turbulence intensity as the velocity increased, which could result in the low pressure-drop distribution for DPT-2 data for the high-velocity region, as the higher pressure port could measure the pressure of less turbulent flow since the DPT-2 higher pressure port was located on the straight pipe section upstream of the elbow.

Since the high-pressure port of DPT-3 was located only 8 inches from the low pressure-port of DPT2, the high-turbulence static pressure could be measured in the vicinity of the DPT-3 high-pressure port, which could result in the high pressure-drop distribution for DPT-3 data, as the low-pressure port of DPT3 was located on the straight pipe section downstream of the second $45^{\circ} 3 \mathrm{D}$ elbow.

The fourth modular component for DPT- 4 was composed of two $45^{\circ} 3 \mathrm{D}$ elbows, and was longer than the third modular component, a single $45^{\circ} 3 \mathrm{D}$ elbow for DPT-3. However, Figure 7.4 presents similar pressure-drop distributions for both DPT-3 and DPT- 4 corrected data. The two combined $45^{\circ} 3 \mathrm{D}$ elbows of the fourth modular component were actually followed by a $90^{\circ} 5 \mathrm{D}$ elbow 5 inches downstream of the low-pressure port of DPT-4. Therefore, a high static pressure field could be expected in the vicinity of the DPT-4 low-pressure port due to the presence of the $90^{\circ} 5 \mathrm{D}$ elbow, which could result in a lower pressure drop than that of the two combined $45^{\circ} 3 \mathrm{D}$ elbows in the absence of the $90^{\circ} 5 \mathrm{D}$ elbow.

In Figure 7.4, the data obtained with DPT-5 show a low gradient in the pressure-drop distribution and, for corrected DPT-5 data, high pressure-drop values in the pressure-drop distribution are observed. For the fifth modular component of the reducer and vertical-rise test module, the DPT-4 low-pressure port was used for the DPT-5 low-pressure port as well. Therefore, the DPT-5 low-pressure port could measure comparatively high static pressure due to the presence of the $90^{\circ} 5 \mathrm{D}$ elbow. The DPT- 5 high-pressure port was located downstream of the fourth modular component, a $45^{\circ} 3 \mathrm{D}$ elbow. This elbow could produce a higher-pressure field due to turbulence in the vicinity of the DPT-5 high-pressure port. The pressure at the DPT-5 higher port might remain comparatively high at the lower velocities due to the turbulence produced by the fourth modular component of a $45^{\circ} 3 \mathrm{D}$ elbow and might result in the high pressure-drop values in the pressure-drop distribution of the low gradient. 

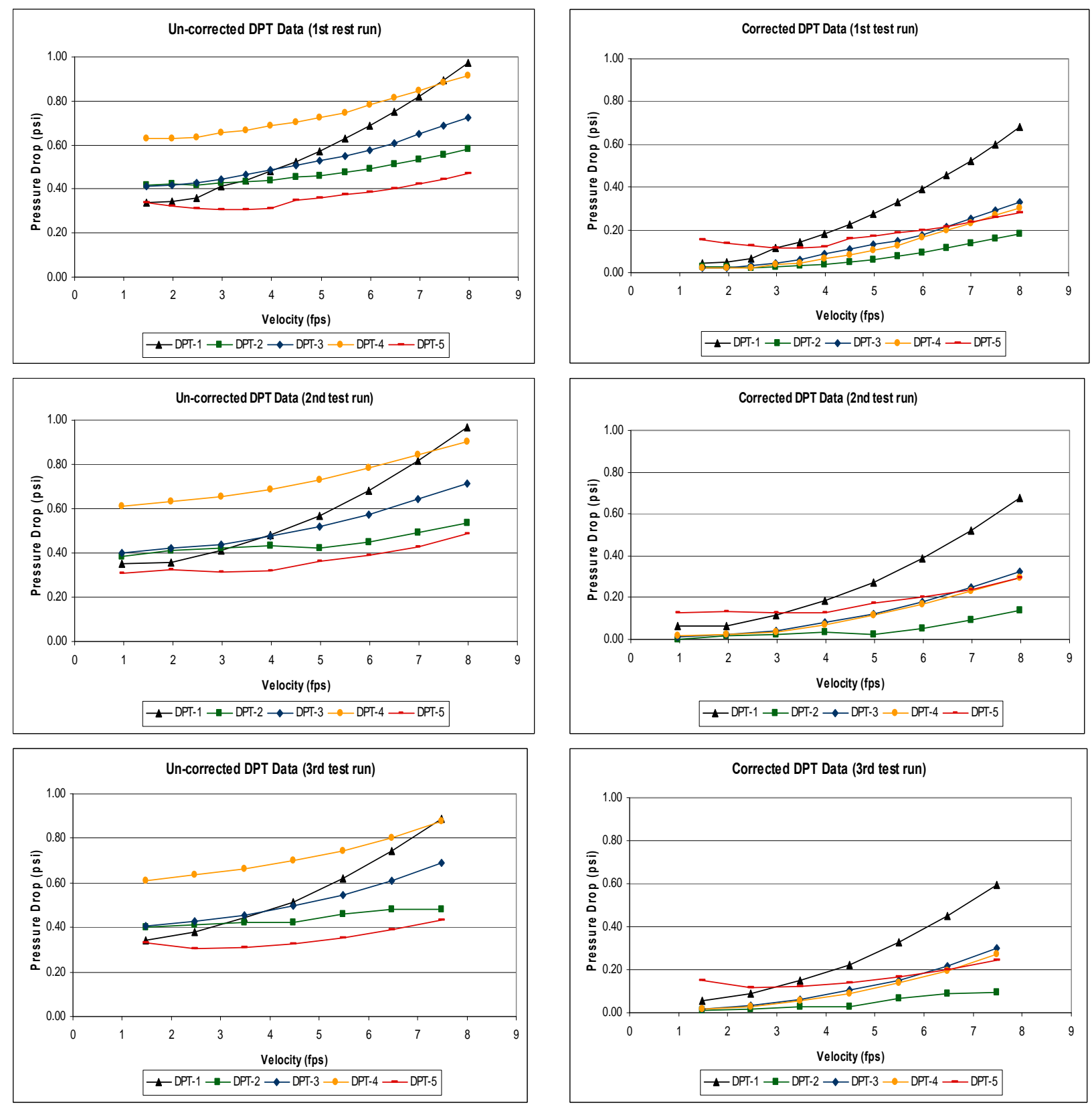

Figure 7.4. Plots of pressure drop vs. pipeline velocity for the reducer and vertical-rise module.

The left column is the uncorrected DPT data and the right column is the corrected DPT data.

The top plots are of the first test run, the middle are of the second test run and the bottom are of the third test run. DPT- 1 is the DPT used for the first modular component, a reducer combined with a $90^{\circ} 3 \mathrm{D}$ elbow, followed downstream by DPT-2 and DPT-3 in that order for the second and third components, $45^{\circ} 3 \mathrm{D}$ elbows. Following DPT-3 downstream are DPT-4 and DPT-5 used for the fourth component, two $45^{\circ} 3 \mathrm{D}$ elbows, and the fifth component, a $45^{\circ} 3 \mathrm{D}$ elbow, respectively. 


\subsection{Discussion}

The pressure drop across each component of the test module spool was measured and Figure 7.1 to Figure 7.4 present the measured pressure-drop distributions as a function of the pipeline velocity for both uncorrected and corrected DPT data. From the pressure-drop versus pipeline-velocity distributions for the uncorrected DPT data, the minima of the pressure-drop values were found with Microsoft Excel spreadsheet function "MIN," and function "VLOOKUP" was used to find velocities corresponding to the obtained minimum pressure-drop values, except the cases of the fourth and fifth components of the complex-geometry module test. For the fourth and fifth components of the complex-geometry module test, function "MAX" was used to find the maxima of the pressure-drop values, and function "VLOOKUP" was used to find velocities corresponding to the obtained maximum pressure-drop values. The evaluated velocities are reported as "critical velocities" herein.

The critical velocities evaluated from uncorrected DPT data for all of the modular components for each test run are summarized in Table 7.1. The critical velocity for a straight horizontal pipe was evaluated and reported by Poloski et al. (2008); Table 7.1 includes the critical velocity for a straight horizontal pipe for comparison. The critical velocities reported in Table 7.1 were based on the critical velocity definition used by Poloski et al. (2008). However, it is seen in Figure 7.1 to Figure 7.4 that pressure-drop-versus-velocity curves do not have a definite profile of the J-curve used to unambiguously determine the critical velocity as used by Poloski et al. (2008) (see Figure 3.1). As seen in Table 7.1, the critical velocities correspond in most cases to the smallest velocities used in the tests. The smallest velocities obtained need not to be the critical velocities since the J-curve profile could not be obtained. The uncorrected DPT data include the hydrostatic pressure due to gravity, as discussed in Subsection 7.1, which is not constant over a test run because density changes as the flow velocity changes. Pressures were considered to be measured with high uncertainty due to the complex flow structure produced by the geometry of the modular component. High uncertainty in uncorrected DPT data is seen from high fluctuation in Figure 7.1 to Figure 7.4 and makes it very difficult to determine the critical velocity. Therefore it is not certain that critical velocities were evaluated from the DPT data obtained.

For the gravity-feed and process-drain module test, the critical velocities for the first modular component, a tee, are $3.5 \mathrm{ft} / \mathrm{sec}$. This high critical velocity could be due to expansion of the crosssectional area of the tee reducing the slurry flow, which resulted in lower slurry flow velocity in this tee section than the pipeline velocity indicated by the Coriolis flow meter, and sedimentation occurred at a pipeline flow velocity at which slurry particles were suspended in the flow for the other modular components. The critical velocity of $3.5 \mathrm{ft} / \mathrm{sec}$ evaluated for the fifth component, a $90^{\circ} 3 \mathrm{D}$ elbow, for the repeated third test run, was because the measurement was not performed for velocities less than $2.5 \mathrm{ft} / \mathrm{sec}$ and this value of $3.5 \mathrm{ft} / \mathrm{sec}$ is not considered to be a critical velocity as the J-curve obtained was incomplete. The critical velocity of $2.5 \mathrm{ft} / \mathrm{sec}$ for the second, third, and fourth components for the repeated third test was the smallest velocity used for this test run. Except for the first modular component, a tee, all modular components of the gravity-feed and process-drain test module present critical velocities lower than those evaluated for a straight horizontal pipe.

For the jumper module test, comparatively higher critical velocities were evaluated for the second component, a $90^{\circ} 3 \mathrm{D}$ elbow, for the second test run. However, as discussed in Subsection 7.1, it is considered that complex flow structure due to high-intensity turbulence caused high fluctuation in the 
pressure data for the second component, a $90^{\circ} 3 \mathrm{D}$ elbow and it is indeterminate whether the critical velocity is obtained for the second component. The critical velocities (smallest velocities) obtained for the first and third components of $90^{\circ}$ miter bend are lower than those evaluated for a straight horizontal pipe.

For the complex-geometry module test, the critical velocities evaluated for all modular components are lower than those evaluated for the straight horizontal pipe. It is indeterminate whether the smallest velocities in Table 7.1 for the complex-geometry test module are critical velocities or merely smallest velocities due to high uncertainty in the DPT data.

For the reducer and vertical-rise module test, the data obtained for the fifth modular component, a $45^{\circ}$ elbow, present high critical velocities of $3.5 \mathrm{ft} / \mathrm{sec}$ for the first test and $2.5 \mathrm{ft} / \mathrm{sec}$ for the third test. A low gradient in the pressure-drop distribution was obtained for this modular component, and the fluctuation in DPT-5 data is high compared with this low distribution gradient. The low gradient of the pressure-drop distribution and the high fluctuation make it difficult to accurately predict the critical velocity. The configuration of this test module suggests that slurry-particle settling inside this modular component is very unlikely to occur and the obtained high values of the critical velocity for this modular component are highly unrealistic.

It is found that the critical velocities evaluated for all components of the reducer and vertical-rise test module except for the fifth modular component, a $45^{\circ}$ elbow, are lower than those evaluated for a straight horizontal pipe. Except for the first component, a reducer combined with a $90^{\circ} 3 \mathrm{D}$ elbow, the geometry of the reducer and vertical-rise test module strongly suggests that the critical velocities in Table 7.1 for the reducer and vertical-rise test module are smallest velocities used in these test runs.

In addition to the critical velocity, the velocity for avoiding deposition (VFAD) is reported in Table 7.1. As discussed above, due to the high fluctuations, it is difficult to determined critical velocities since a definite profile of the J-curve was not obtained in Figure 7.1 through Figure 7.4. The high uncertainty makes it difficult to use the evaluated critical velocities for the accurate prediction of particle deposition. Therefore, VFADs are used to provide velocities at which it is assured that no particle deposition occurs.

In Table 7.1, the obtained VFADs are reported as velocity ranges where slurry flow does not undergo particle deposition. The VFADs were selected from Figure 7.1 through Figure 7.4 (see Subsection 3.1 for the determination of VFAD). As seen in Table 7.1, the VFADs for the second modular component, a $90^{\circ}$ $3 \mathrm{D}$ elbow, of the jumper test module and for the second and fifth modular components, a $45^{\circ} 3 \mathrm{D}$ elbow, of the reducer and vertical-rise test module were undetermined due to the high uncertainty (see Subsection 7.1)

Table 7.2 through Table 7.5 include uncorrected pressure drops, corrected pressure drops, densities measured at a point upstream of the modular test section, and densities measured at a point downstream of the modular test section. These values correspond to the smallest VFADs reported herein. In addition, included in Table 7.2 through Table 7.5 are Bingham yield stresses, Bingham consistencies, and ranges of Reynolds numbers used for each test run. The Reynolds number of about 4100 for non-Newtonian fluids may be in laminar or transition. The Reynolds numbers were calculated with: 


$$
\mathrm{Re}=\frac{\rho_{\text {Slurry }} V D}{\mu_{\text {consistency }}}
$$

where $\rho_{\text {Slurry }}$ is the slurry density

$V \quad$ is the pipeline velocity

$D \quad$ is the pipe internal diameter of 3.068 inches

$\mu_{\text {consistency }}$ is the Bingham consistency.

It is pointed out that all Reynolds numbers reported are based on the nominal pipe size of 3 inches (3.068 inches ID) and this characteristic dimension of 3.068 inches does not properly apply to the first modular component, a tee, of the gravity-feed and process-drain test module and the first modular component, a reducer and a $90^{\circ} 3 \mathrm{D}$ elbows, of the reducer and vertical-rise test module. 
Table 7.1. Critical velocity and VFAD evaluated from the uncorrected DPT data

\begin{tabular}{|c|c|c|c|c|c|c|c|}
\hline \multirow{2}{*}{$\begin{array}{l}\text { Test } \\
\text { Spool }\end{array}$} & \multicolumn{5}{|c|}{$\begin{array}{l}\text { Evaluated Critical Velocities of Modular } \\
\text { Components (ft/sec) }\end{array}$} & \multirow{2}{*}{$\begin{array}{l}\text { Range of Velocity for } \\
\text { Avoiding Deposition } \\
\text { (VFAD) } \\
\text { (ft/sec) }\end{array}$} & \multirow{2}{*}{$\begin{array}{c}\text { Critical } \\
\text { Velocity of } \\
\text { Straight Pipe } \\
\text { (ft/sec) }\end{array}$} \\
\hline & DPT \# & Component & $\begin{array}{c}\text { Run } \\
1\end{array}$ & $\begin{array}{c}\text { Run } \\
2\end{array}$ & $\begin{array}{c}\text { Run } \\
3\end{array}$ & & \\
\hline \multirow{5}{*}{$\begin{array}{l}\text { Gravity } \\
\text { Feed } \\
\text { and } \\
\text { Process } \\
\text { Drain }\end{array}$} & 1 & Tee & 3.5 & 3.5 & 3.5 & $>=4.0$ & \multirow{18}{*}{2.7} \\
\hline & 2 & $90^{\circ} 3 \mathrm{D}$ Elbow & 2.5 & 1.5 & $2.5^{\wedge}$ & $>=3.5$ & \\
\hline & 3 & $90^{\circ} 3 \mathrm{D}$ Elbow & 2.0 & 2.0 & $2.5^{\wedge}$ & $>=3.5$ & \\
\hline & 4 & $90^{\circ} 3 \mathrm{D}$ Elbow & $1.5^{\wedge}$ & 2.0 & $2.5^{\wedge}$ & $>=3.5$ & \\
\hline & 5 & $90^{\circ} 3 \mathrm{D}$ Elbow & 2.0 & $1.0^{\wedge}$ & 3.5 & $>=3.5$ & \\
\hline \multirow{3}{*}{ Jumper } & 1 & $90^{\circ}$ Miter Bend & $0.5^{\wedge}$ & $1.0^{\wedge}$ & $0.5^{\wedge}$ & $>=2.0$ & \\
\hline & 2 & $90^{\circ} 3 \mathrm{D}$ Elbow & $0.5^{\wedge}$ & 3.0 & $0.5^{\wedge}$ & * & \\
\hline & 3 & $90^{\circ}$ Miter Bend & $0.5^{\wedge}$ & $1.0^{\wedge}$ & $0.5^{\wedge}$ & $>=2.0$ & \\
\hline \multirow{5}{*}{$\begin{array}{l}\text { Complex } \\
\text { Geometry }\end{array}$} & 1 & $90^{\circ} 3 \mathrm{D}$ Elbow & 1.0 & $1.0^{\wedge}$ & $0.5^{\wedge}$ & $>=3.0$ & \\
\hline & 2 & $90^{\circ}+45^{\circ} 3 \mathrm{D}$ Elbows & $0.5^{\wedge}$ & $1.0^{\wedge}$ & $0.5^{\wedge}$ & $>=3.0$ & \\
\hline & 3 & $45^{\circ}+45^{\circ} 3 \mathrm{D}$ Elbows & 1.0 & $1.0^{\wedge}$ & $0.5^{\wedge}$ & $>=3.0$ & \\
\hline & 4 & $90^{\circ} 5 \mathrm{D}$ Elbow & 1.0 & $1.0^{\wedge}$ & 1.5 & $>=3.5$ & \\
\hline & 5 & $90^{\circ}$ 5D Elbow & 1.5 & $1.0^{\wedge}$ & 1.5 & $>=3.5$ & \\
\hline \multirow{5}{*}{$\begin{array}{l}\text { Reducer } \\
\text { and } \\
\text { Vertical } \\
\text { Rise }\end{array}$} & 1 & $\begin{array}{l}\text { Reducer }+90^{\circ} 3 \mathrm{D} \\
\text { Elbow }\end{array}$ & $1.5^{\wedge}$ & $1.0^{\wedge}$ & $1.5^{\wedge}$ & $>=3.0$ & \\
\hline & 2 & $45^{\circ} 3 \mathrm{D}$ Elbow & $1.5^{\wedge}$ & $1.0^{\wedge}$ & $1.5^{\wedge}$ & * & \\
\hline & 3 & $45^{\circ} 3 \mathrm{D}$ Elbow & $1.5^{\wedge}$ & $1.0^{\wedge}$ & $1.5^{\wedge}$ & $>=3.0$ & \\
\hline & 4 & $45^{\circ}+45^{\circ}$ 3D Elbows & $1.5^{\wedge}$ & $1.0^{\wedge}$ & $1.5^{\wedge}$ & $>=3.0$ & \\
\hline & 5 & $45^{\circ} 3 \mathrm{D}$ Elbow & 3.5 & $1.0^{\wedge}$ & 2.5 & * & \\
\hline
\end{tabular}


Table 7.2. Pressure drop, density, yield stress, consistency, and Reynolds number for the gravity-feed and process drain module test

\begin{tabular}{|c|c|c|c|c|c|c|c|c|c|c|c|c|c|c|c|}
\hline \multicolumn{16}{|c|}{ Gravity Feed and Process Drain } \\
\hline & \multicolumn{3}{|c|}{ Tee } & \multicolumn{3}{|c|}{$90^{\circ} 3 \mathrm{D}$ Elbow } & \multicolumn{3}{|c|}{$90^{\circ} 3 \mathrm{D}$ Elbow } & \multicolumn{3}{|c|}{$90^{\circ} 3 \mathrm{D}$ Elbow } & \multicolumn{3}{|c|}{$90^{\circ} 3 \mathrm{D}$ Elbow } \\
\hline & Run1 & Run2 & Run3 & Run1 & Run2 & Run3 & Run1 & Run2 & Run3 & Run1 & Run2 & Run3 & Run1 & Run2 & Run3 \\
\hline $\begin{array}{l}\text { Uncorrected } \\
\text { Pressure Drop } \\
\text { (psi) at VFAD }\end{array}$ & 0.037 & 0.034 & 0.035 & 0.050 & 0.049 & 0.048 & 0.045 & 0.025 & 0.041 & 0.032 & 0.034 & 0.033 & 0.057 & 0.050 & 0.053 \\
\hline $\begin{array}{c}\text { Corrected } \\
\text { Pressure Drop } \\
\text { (psi) at VFAD }\end{array}$ & 0.044 & 0.041 & 0.042 & 0.062 & 0.061 & 0.060 & 0.058 & 0.037 & 0.053 & 0.044 & 0.046 & 0.046 & 0.066 & 0.059 & 0.062 \\
\hline $\begin{array}{c}\text { Density* }(\mathrm{g} / \mathrm{mL}) \\
\text { at VFAD }\end{array}$ & 1.403 & 1.403 & 1.402 & 1.403 & 1.402 & 1.402 & 1.403 & 1.402 & 1.402 & 1.403 & 1.402 & 1.402 & 1.403 & 1.402 & 1.402 \\
\hline $\begin{array}{c}\text { Density** }(\mathrm{g} / \mathrm{mL}) \\
\text { at VFAD }\end{array}$ & 1.397 & 1.396 & 1.395 & 1.398 & 1.397 & 1.396 & 1.398 & 1.397 & 1.396 & 1.398 & 1.397 & 1.396 & 1.398 & 1.397 & 1.396 \\
\hline \multicolumn{16}{|c|}{ ^ Reynolds numbers are based on the nominal pipe size of 3 inches (3.068 inches ID). } \\
\hline \multicolumn{16}{|c|}{ * The density measurements were taken at a point upstream of the modular test section. } \\
\hline \multicolumn{16}{|c|}{${ }^{\star *}$ The density measurements were taken at a point downstream of the modular test section. } \\
\hline & & & & & & & & & & & & & & & \\
\hline
\end{tabular}


Table 7.3. Pressure drop, density, yield stress, consistency, and Reynolds number for the jumper module test

\begin{tabular}{|c|c|c|c|c|c|c|c|c|c|}
\hline \multicolumn{10}{|c|}{ Jumper } \\
\hline & \multicolumn{3}{|c|}{$90^{\circ}$ Miter Bend } & \multicolumn{3}{|c|}{$90^{\circ} 3 \mathrm{D}$ Elbow } & \multicolumn{3}{|c|}{$90^{\circ}$ Miter Bend } \\
\hline & Run1 & Run2 & Run3 & Run1 & Run2 & Run3 & Run1 & Run2 & Run3 \\
\hline $\begin{array}{l}\text { Velocity for } \\
\text { Avoiding } \\
\text { Deposition } \\
\text { (VFAD) } \\
\text { (ft/sec) }\end{array}$ & 2.0 & 2.0 & 2.0 & 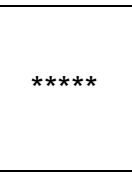 & $* \star \star \star \star *$ & $* * \star \star *$ & 2.0 & 2.0 & 2.0 \\
\hline $\begin{array}{l}\text { Uncorrected } \\
\text { Pressure } \\
\text { Drop (psi) } \\
\text { at VFAD }\end{array}$ & 0.223 & 0.202 & 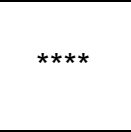 & 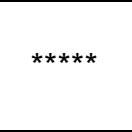 & 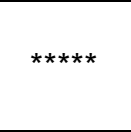 & 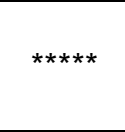 & 0.279 & 0.273 & 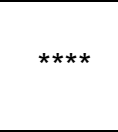 \\
\hline $\begin{array}{l}\text { Corrected } \\
\text { Pressure } \\
\text { Drop (psi) } \\
\text { at VFAD } \\
\end{array}$ & 0.105 & 0.085 & 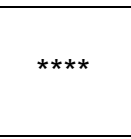 & 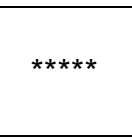 & 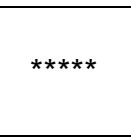 & 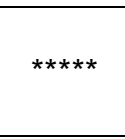 & 0.075 & 0.070 & 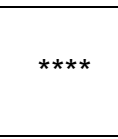 \\
\hline $\begin{array}{l}\text { Density* } \\
(\mathrm{g} / \mathrm{mL}) \\
\text { at VFAD }\end{array}$ & 1.357 & 1.355 & 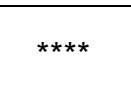 & 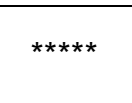 & 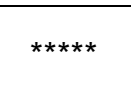 & 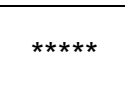 & 1.357 & 1.355 & $\star \star \star \star ~$ \\
\hline $\begin{array}{l}\text { Density** } \\
(\mathrm{g} / \mathrm{mL}) \\
\text { at VFAD }\end{array}$ & 1.356 & 1.351 & 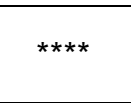 & 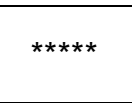 & 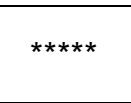 & 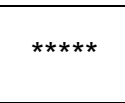 & 1.356 & 1.351 & $\star \star \star \star *$ \\
\hline $\begin{array}{l}\text { Bingham } \\
\text { Yield Stress } \\
(\mathrm{Pa})\end{array}$ & 2.83 & 2.79 & 2.45 & 2.83 & 2.79 & 2.45 & 2.83 & 2.79 & 2.45 \\
\hline $\begin{array}{l}\text { Bingham } \\
\text { Consistency } \\
(\mathrm{CP})\end{array}$ & 7.40 & 6.60 & 6.23 & 7.40 & 6.60 & 6.23 & 7.40 & 6.60 & 6.23 \\
\hline $\begin{array}{l}\text { Range of } \\
\text { Reynolds } \\
\text { numbers } \\
\text { used }{ }^{\star \star \star}\end{array}$ & $\begin{array}{c}2100 \\
\sim \\
35100\end{array}$ & $\begin{array}{c}4700 \\
\sim \\
39300\end{array}$ & $\begin{array}{c}2400 \\
\sim \\
41500\end{array}$ & $\begin{array}{c}2100 \\
\sim \\
35100\end{array}$ & $\begin{array}{c}4700 \\
\sim \\
39300\end{array}$ & $\begin{array}{c}2400 \\
\sim \\
41500\end{array}$ & $\begin{array}{c}2100 \\
\sim \\
35100\end{array}$ & $\begin{array}{c}4700 \\
\sim \\
39300\end{array}$ & $\begin{array}{c}2400 \\
\sim \\
41500\end{array}$ \\
\hline \multicolumn{10}{|c|}{ * The density measurements were taken at a point upstream of the modular test section. } \\
\hline \multicolumn{10}{|c|}{ ** The density measurements were taken at a point downstream of the modular test section. } \\
\hline \multicolumn{10}{|c|}{${ }^{\star \star \star}$ Reynolds number of about 4100 for a non-Newtonian fluid may be in laminar or transition. } \\
\hline \multicolumn{10}{|c|}{$\begin{array}{l}{ }^{* \star \star \star} \text { Pressure drops and densities were not available at VFAD of } 2 \text { (ft/sec) for Run } 3 \text { since the testing was not } \\
\text { performed at this velocity. }\end{array}$} \\
\hline
\end{tabular}


Table 7.4. Pressure drop, density, yield stress, consistency, and Reynolds number for the complex geometry module test

\begin{tabular}{|c|c|c|c|c|c|c|c|c|c|c|c|c|c|c|c|}
\hline \multicolumn{16}{|c|}{ Complex Geometry } \\
\hline & \multicolumn{3}{|c|}{$90^{\circ} 3 \mathrm{D}$ Elbow } & \multicolumn{3}{|c|}{$90^{\circ}+45^{\circ}$ 3D Elbows } & \multicolumn{3}{|c|}{$45^{\circ}+45^{\circ}$ 3D Elbows } & \multicolumn{3}{|c|}{$90^{\circ} 5 \mathrm{D}$ Elbow } & \multicolumn{3}{|c|}{$90^{\circ} 5 \mathrm{D}$ Elbow } \\
\hline & Run1 & Run2 & Run3 & Run1 & Run2 & Run3 & Run1 & Run2 & Run3 & Run1 & Run2 & Run3 & Run1 & Run2 & Run3 \\
\hline $\begin{array}{l}\text { Velocity for } \\
\text { Avoiding } \\
\text { Deposition } \\
\text { (VFAD) (tt/sec) } \\
\end{array}$ & 3.0 & 3.0 & 3.0 & 3.0 & 3.0 & 3.0 & 3.0 & 3.0 & 3.0 & 3.5 & 3.5 & 3.5 & 3.5 & 3.5 & 3.5 \\
\hline $\begin{array}{l}\text { Uncorrected } \\
\text { Pressure Drop } \\
\text { (psi) at VFAD }\end{array}$ & 0.291 & 0.290 & 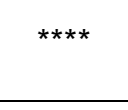 & 0.305 & 0.304 & **** & 0.105 & 0.102 & **** & 0.281 & 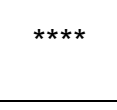 & 0.267 & 0.258 & **** & 0.275 \\
\hline $\begin{array}{c}\text { Corrected } \\
\text { Pressure Drop } \\
\text { (psi) at VFAD } \\
\end{array}$ & 0.045 & 0.044 & 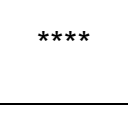 & 0.045 & 0.045 & **** & 0.074 & 0.071 & **** & 0.046 & 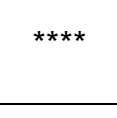 & 0.059 & 0.065 & **** & 0.047 \\
\hline $\begin{array}{c}\text { Density* }(\mathrm{g} / \mathrm{mL}) \\
\text { at VFAD }\end{array}$ & 1.333 & 1.332 & 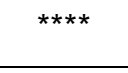 & 1.333 & 1.332 & 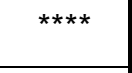 & 1.333 & 1.332 & **** & 1.335 & 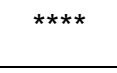 & 1.333 & 1.335 & **** & 1.333 \\
\hline $\begin{array}{c}\text { Density** }(\mathrm{g} / \mathrm{mL}) \\
\text { at VFAD }\end{array}$ & 1.330 & 1.328 & 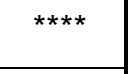 & 1.330 & 1.328 & 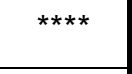 & 1.330 & 1.328 & 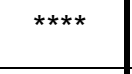 & 1.331 & 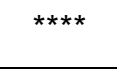 & 1.329 & 1.331 & 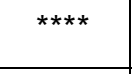 & 1.329 \\
\hline $\begin{array}{l}\text { Bingham Yield } \\
\text { Stress (Pa) }\end{array}$ & 2.71 & 2.85 & 2.75 & 2.71 & 2.85 & 2.75 & 2.71 & 2.85 & 2.75 & 2.71 & 2.85 & 2.75 & 2.71 & 2.85 & 2.75 \\
\hline $\begin{array}{l}\text { Bingham } \\
\text { Consistency (cP) }\end{array}$ & 5.72 & 6.30 & 5.74 & 5.72 & 6.30 & 5.74 & 5.72 & 6.30 & 5.74 & 5.72 & 6.30 & 5.74 & 5.72 & 6.30 & 5.74 \\
\hline $\begin{array}{c}\text { Range of } \\
\text { Reynolds } \\
\text { numbers used }\end{array}$ & $\begin{array}{c}2600 \\
\sim \\
44000\end{array}$ & $\begin{array}{c}4800 \\
\sim \\
40000\end{array}$ & $\begin{array}{c}2500 \\
\sim \\
41100\end{array}$ & $\begin{array}{c}2600 \\
\sim \\
44000\end{array}$ & $\begin{array}{c}4800 \\
\sim \\
40000\end{array}$ & $\begin{array}{c}2500 \\
\sim \\
41100\end{array}$ & $\begin{array}{c}2600 \\
\sim \\
44000\end{array}$ & $\begin{array}{c}4800 \\
\sim \\
40000\end{array}$ & $\begin{array}{c}2500 \\
\sim \\
41100\end{array}$ & $\begin{array}{c}2600 \\
\sim \\
44000\end{array}$ & $\begin{array}{c}4800 \\
\sim \\
40000\end{array}$ & $\begin{array}{c}2500 \\
\sim \\
41100\end{array}$ & $\begin{array}{c}2600 \\
\sim \\
44000\end{array}$ & $\begin{array}{c}4800 \\
\sim \\
40000\end{array}$ & $\begin{array}{c}2500 \\
\sim \\
41100\end{array}$ \\
\hline \multicolumn{16}{|c|}{${ }^{*}$ The density measurements were taken at a point upstream of the modular test section. } \\
\hline \multicolumn{16}{|c|}{ ** The density measurements were taken at a point downstream of the modular test section. } \\
\hline \multicolumn{16}{|c|}{${ }^{* \star \star}$ Reynolds number of about 4100 for a non-Newtonian fluid may be in laminar or transition. } \\
\hline ressure & & & & & & & & & & & & & & & \\
\hline
\end{tabular}


Table 7.5. Pressure drop, density, yield stress, consistency, and Reynolds number for the reducer and vertical rise module test

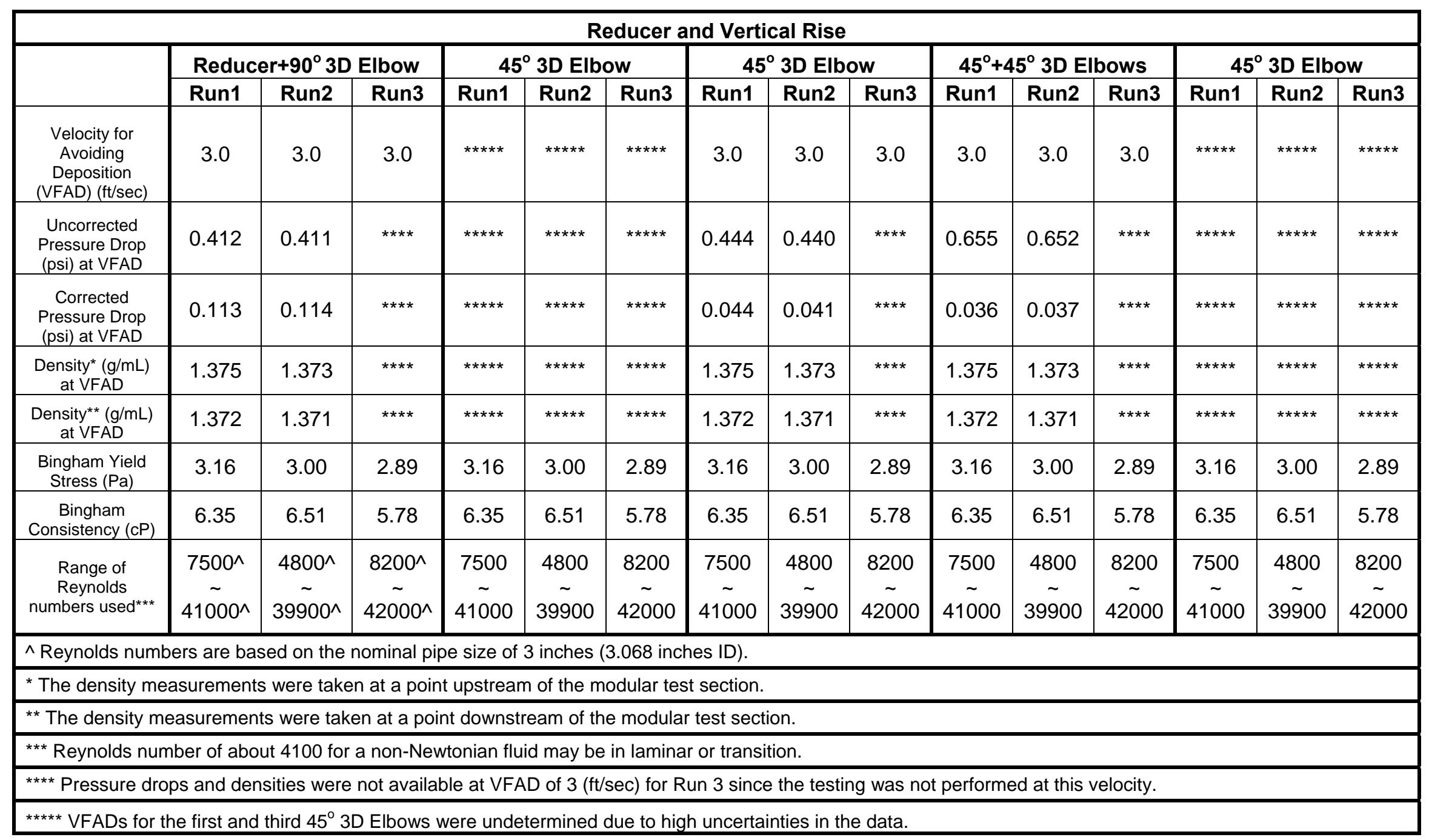




\subsection{Gravity-Driven Partially-Filled Pipe Flow Test}

This section addresses the gravity-driven partially-filled (GDPF) pipe flow tests used to characterize the behavior of slurry flowing from an overfilled vessel through an unpressurized (atmospheric pressure) pipe to a reservoir. The specifications for an overflow relief system are discussed in design guides 24590WTP-GPG-M-032, Rev. 3 (Donoso 2007) and 24590-WTP-GPG-M-027, Rev. 5 (Kloster 2007). Both of these design guides address systems in which the fluid of concern is either a Newtonian fluid with properties similar to water or a Newtonian slurry with a viscosity/specific gravity ratio specified by Table 1 in Appendix A of design guide 24590-WTP-GPG-M-032, Rev. 3 (Donoso 2007). The simulant used in the tests described thus far in this report had a small but non-zero yield stress which made it a Bingham plastic. The GDPF pipe flow tests were conducted with this simulant in order to inspect the particle sedimentation process and to determine how applicable the specifications in the design guides mentioned above are to slurries that are slightly non-Newtonian.

\subsection{Test Apparatus}

The basic components of the experimental setup (i.e., slurry pump, mixing tank, flush tank, capture tank, and connecting pipe) did not change from the previously described modular tests to the GDPF pipe flow tests. However, since the slurry surface of the GDPF pipe flow was open to the atmosphere, it could not be flushed with the flush tank in the same manner in which the previous modular sections were. After a test, the slurry was pumped from the loop directly back to the mixing tank. Thus, the flush tank and capture tank were not used in the GDPF pipe flow tests. Design changes to the flow loop for the GDPF pipe flow tests occurred in the piping between the slurry pump and the return line to the mixing tank, where a test spool was inserted in each of the other modular tests. Figure 8.1 is a side-view schematic of the GDPF pipe flow test arrangement. The two 50-gallon reservoirs shown in Figure 8.1, located at either end of the schematic, were connected by an 8-inch pipe section which contained four $90^{\circ}$ elbows.

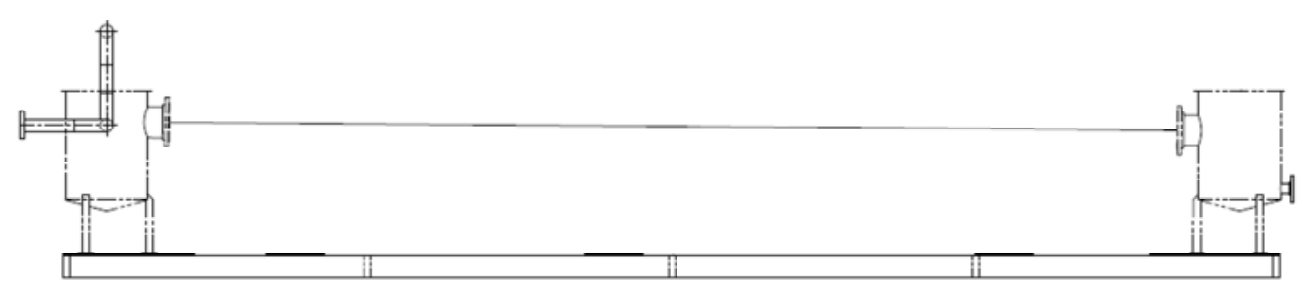

Figure 8.1. Side View Schematic of the GDPF Pipe Flow Test Arrangement

Figure 8.2 is a top-view schematic of the GDPF pipe flow test setup that displays these elbows. The arrangement of the 8-inch piping depicted in Figure 8.2 is properly oriented with respect to Figure 8.1 such that the left side of Figure 8.2 connects to the reservoir that appears on the left side of Figure 8.1 and vice versa. The bend created by the four $90^{\circ}$ elbows in Figure 8.2 is oriented in a way that points out of Figure 8.1 toward the viewer. The observation port indicated in Figure 8.2 was open to the atmosphere and allowed for direct real-time observation of the slurry during operation. Although not pictorially described in Figure 8.2, a transparent section was located at each end of the GDPF pipe flow test module as indicated. Each of these transparent sections was 2 feet in length, making the total linear distance between the two reservoirs 24'4.5". The total flow-length between the two reservoirs was an additional 
$10^{\prime} 8^{\prime \prime}$ (a total of $35^{\prime} 0.5^{\prime \prime}$ ) because of the two 5' 4 " lengths of pipe at the elbows oriented perpendicular to the direct path between the two reservoirs.

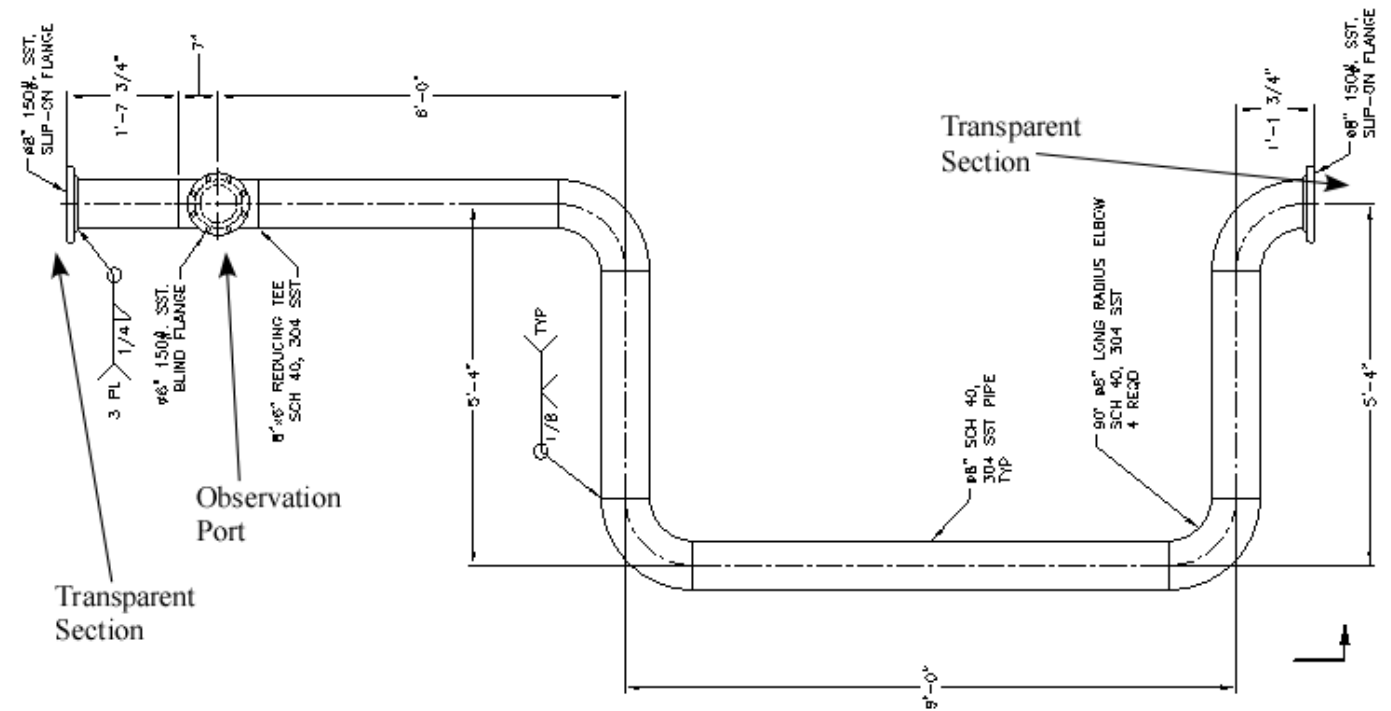

Figure 8.2. Top View of GDPF Pipe Flow Test Module

Each of the reservoirs appearing in Figure 8.1 contained a mixer to prevent particle deposition. A drain was located at the bottom of the second reservoir which was connected to a hose that attached to piping leading back to the mixing tank. A small pump used to sustain continuous flow from the downstream reservoir back to the mixing tank was located in-line just after the second reservoir.

Three tests were run with the configuration shown in Figure 8.1 and Figure 8.2, each having a different slope in the 8-inch pipe between the two reservoirs. These three slopes were 1:125, 1:20, and 1:50, which corresponded relatively well to the slope values listed in Table 1 (1:100, 1:20, and 1:50) of Appendix A of design guide 24590-WTP-GPG-M-032, Rev. 3 (Donoso 2007). Each test was initiated by pumping the slurry from the mixing tank to the upstream reservoir at a velocity of $8 \mathrm{ft} / \mathrm{s}$ (measured within the Coriolis meter, which had an inside diameter of 3 inches), which correlated to a volumetric flow rate through the entire system of $184 \mathrm{gpm}$. When the slurry level within the upstream reservoir reached the opening of the 8-inch section, it began to flow under the force of gravity toward the downstream reservoir. Once flow between the two reservoirs had been established, it was held constant at $184 \mathrm{gpm}$ for a period of at least 30 minutes, after which time it was decreased to the next specified flow rate. This process of incrementally holding the flow constant at a desired rate for a period of at least 30 minutes, and then reducing the flow to the next specified rate, was repeated until steady flows at all specified rates had been achieved. 


\subsection{Observation Methods}

The gravity-driven partially-filled (GDPF) pipe flow tests did not include differential pressure transducer measurements, as did the other modular tests, because the slurry surface was open to the atmosphere. For this reason, system characterization by data analysis, as had been done for previous cases, was not possible. Instead, characterization of slurry behavior for the GDPF pipe flow tests was largely accomplished by visually monitoring the slurry flow through the transparent sections and through physical inspection of the slurry through the open ports, as well as inspecting the 8-inch pipe after the slurry pump had been stopped. Initially, qualitative observations were made about the slurry as it flowed through the transparent sections. Quantitative measurements were made during this initial testing period by holding a ruler up to each transparent section and directly measuring the solids deposition height. To better quantify such observations, a measuring tape was wrapped around each transparent section of the pipe. A picture of the upstream transparent section with this measuring tape in place is shown in Figure 8.3. Figure 8.4 is a close-up view of the measuring tape shown in Figure 8.3. It is a close enough view to show that the slurry height is measured at 5.75 inches on the measuring tape (the 5 cannot be seen in Figure 8.4 due to the presence of the reinforcement bar). Behavior of the slurry within the metal (nontransparent) sections of pipe, which included the four $90^{\circ}$ elbows, had to be deduced from observations of slurry behavior in the transparent sections. 


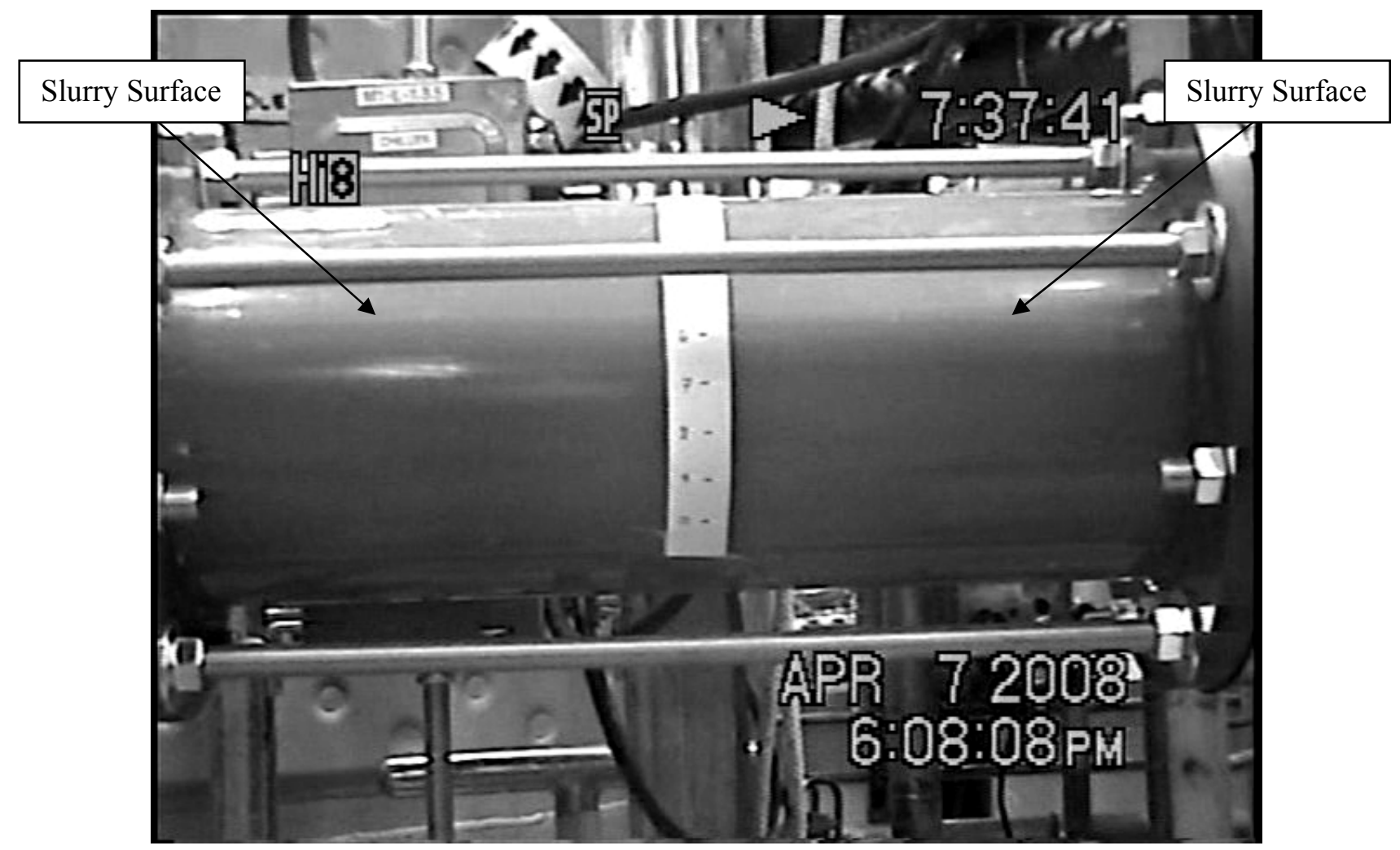

Figure 8.3. Side View of Upstream Transparent (Clear) Section with Measuring Tape

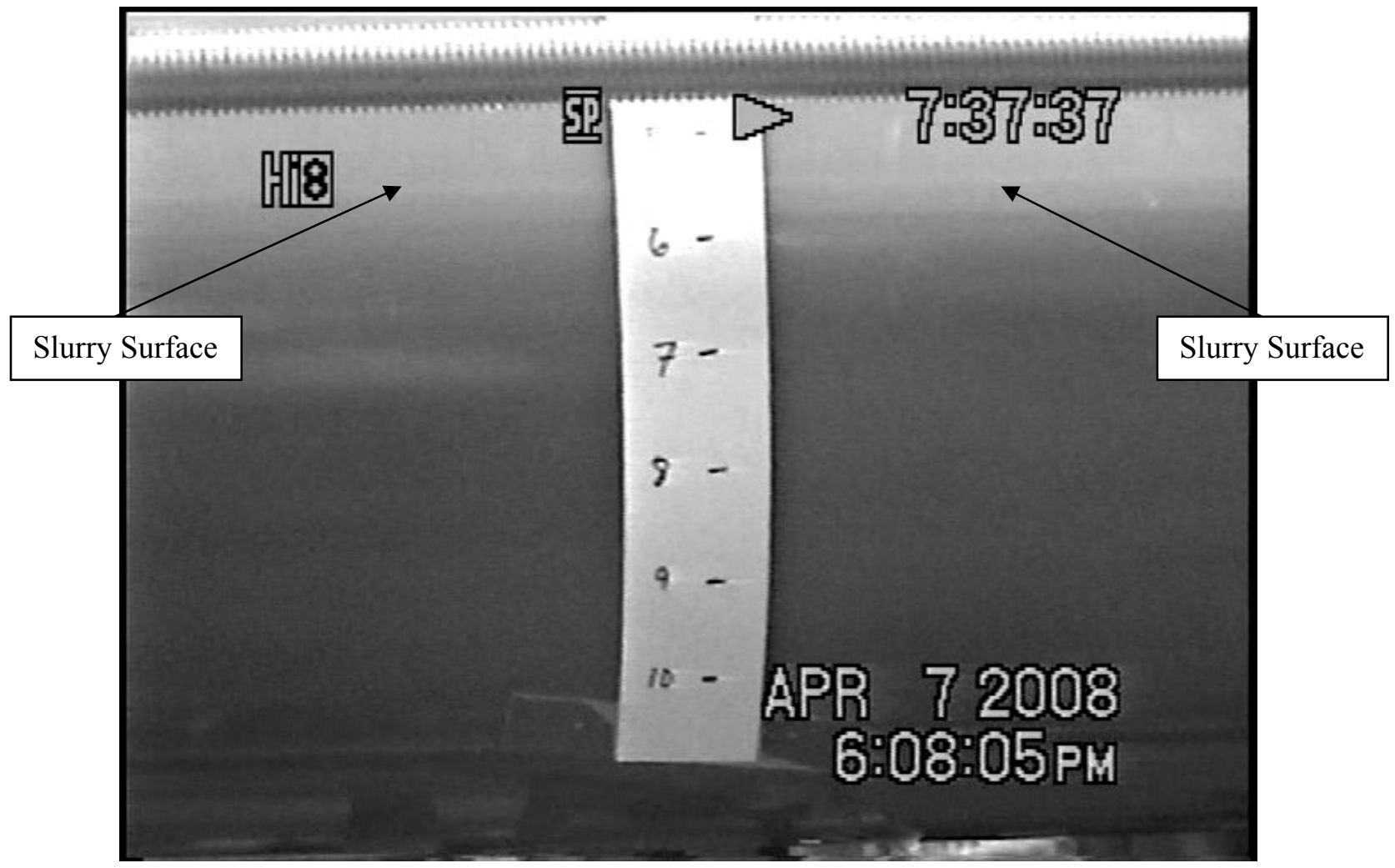

Figure 8.4. Close-up of Transparent (Clear) Section with Measuring Tape 
The value taken from the measuring tape is a measure of the circumferential length from the top of the transparent section to the point of interest. For simplicity, this reading was converted into a vertical height from the bottom of the pipe correlating to a slurry height and a deposition height. Conversion from the measuring tape reading to deposition or slurry height follows from a geometric argument based on Figure 8.5.

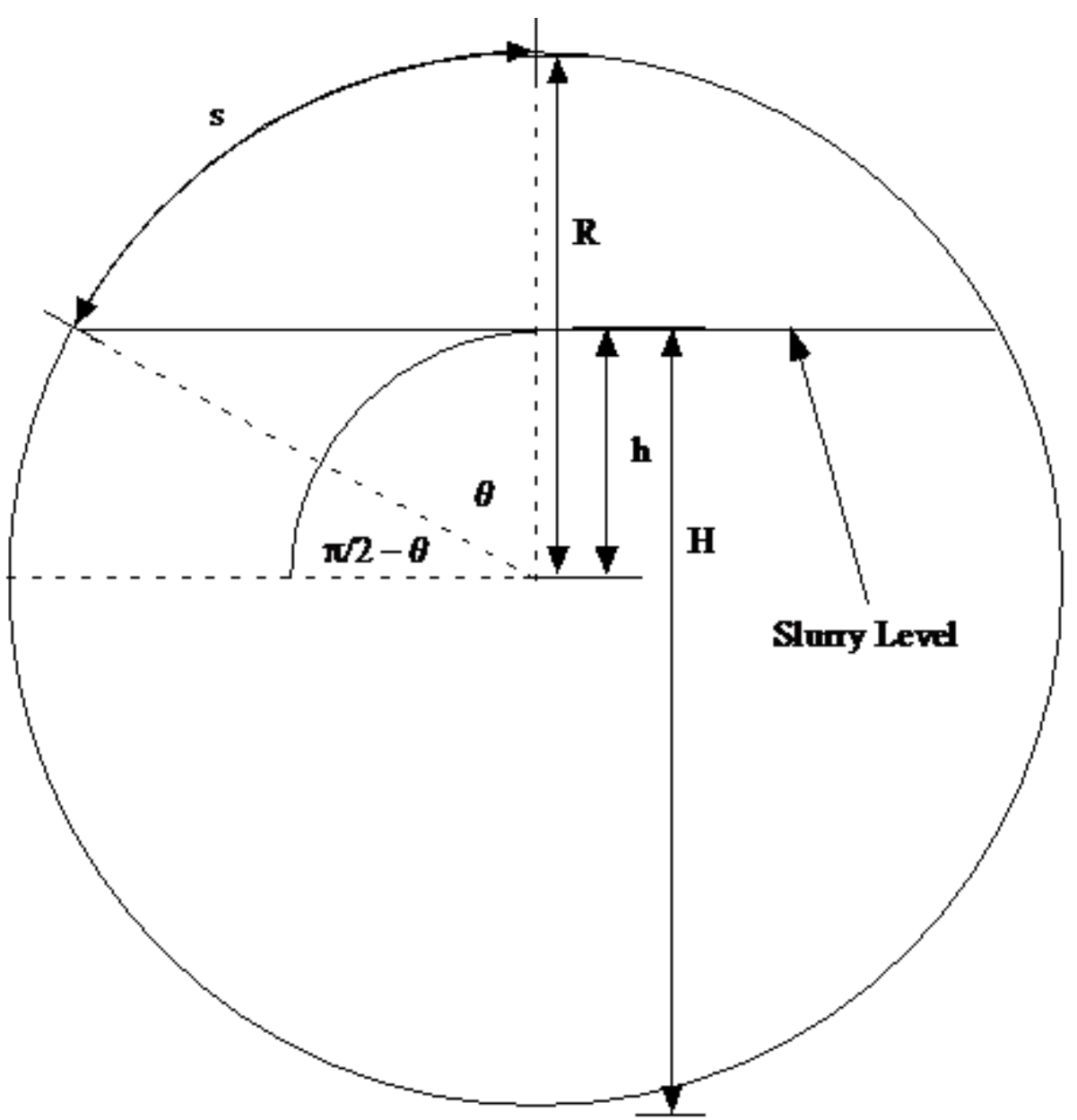

Figure 8.5. Measurement Conversion Parameters

The measurement taken from the measuring tape will be equal to the arc-length "s" that appears in Figure 8.5. This length is related to the radius of the circular cross-section of the pipe by the equation

$$
s=\theta R
$$

The value of $\mathrm{h}$ is then determined with the equation 


$$
h=R \sin \left(\frac{\pi}{2}-\theta\right)
$$

Equation [8.2] is valid even if the value of $\theta$ is greater than $\pi / 2$. The result will simply be a negative value for $\mathrm{h}$. The value of $\mathrm{H}$, which is equal to the height of the slurry or deposition layer, is then computed with the equation

$$
H=R+h
$$

The inside diameter of the pipe used for the GDPF pipe flow tests was 7.981 inches. Standard observations at each flow rate were categorized according to several parameters indicated in Figure 8.6.

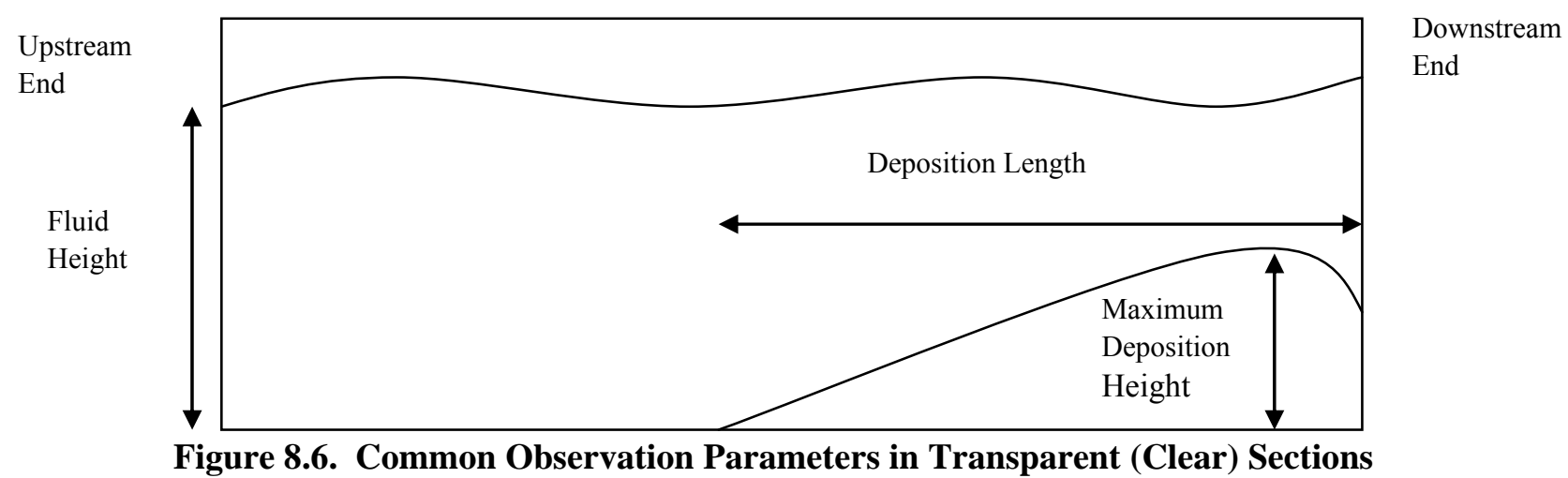

\subsection{Observations}

During each test, observations were recorded in the Laboratory Record Book. Additionally, video recordings were made of slurry behavior in the transparent sections for each flow condition. For flow rates above $3.0 \mathrm{ft} / \mathrm{s}$ in the first test, the solid-deposition measurements were taken directly from a ruler held up to each transparent section. For the lower flow rates in the first test, and all flow rates in the second and third tests, measurements were taken with the measuring tape and converted as described in the previous section.

\subsubsection{Test 1 , Slope $=1: 125$}

Test 1 had the shallowest slope and thus presented the greatest possibility for solids deposition and flow disruption. Table 8.1 lists the maximum deposition heights observed in the upstream and downstream transparent sections at each axial velocity tested. The observed values were recorded just prior to adjustment of the velocity, therefore maximum deposition had occurred for the test condition. The maximum deposition height tended to be at the downstream end of the upstream transparent section, but tended to fluctuate for the downstream section. The deposition length tended to increase for both 
sections as the test progressed to lower velocities. Unfortunately, the deposition length and the axial position of the maximum deposition height were not quantitatively measured due to the continuously shifting shape of the solids deposition. Instead, sketches of the solids deposition patterns in each transparent section were made and recorded in a Laboratory Record Book. Duplications of these sketches are presented in Appendix B.

Table 8.1. Deposition Recorded in Test 1 (Slope $=1: 125)$

\begin{tabular}{|l|l|l|l|}
\hline $\begin{array}{l}\text { Volumetric Flow Rate } \\
(\mathrm{gpm})\end{array}$ & $\begin{array}{l}\text { Axial Velocity } \\
\text { (through 3” Coriolis } \\
\text { meter) (ft/s) }\end{array}$ & $\begin{array}{l}\text { Upstream Clear Section } \\
\text { Maximum Deposition } \\
\text { Height “MDH” (inches) }\end{array}$ & $\begin{array}{l}\text { Downstream Clear Section } \\
\text { Maximum Deposition Height } \\
\text { "MDH" (inches) }\end{array}$ \\
\hline 184 & 8.0 & None Observed & None Observed \\
\hline 173 & 7.5 & None Observed & None Observed \\
\hline 161 & 7.0 & $1^{*}$ & 1 \\
\hline 150 & 6.5 & 1.5 & 1 \\
\hline 138 & 6.0 & 2 & 1 \\
\hline 126 & 2.5 & 1 \\
\hline 115 & 5.5 & 3 & 1.5 \\
\hline 103 & 4.5 & 3 & 1.5 \\
\hline 93 & 4.0 & 3 & 1.5 \\
\hline 80 & 3.5 & 2 & 1.2 \\
\hline 68 & 3.0 & 2.3 & 1.1 \\
\hline 58 & 2.5 & 2.8 & 1.1 \\
\hline 45 & 2.0 & 2.8 & 1.1 \\
\hline *Italicized numbers were taken from measurements performed with a ruler. Non-italicized numbers \\
were taken from measurements performed with a measuring tape. \\
\hline
\end{tabular}

The slurry-fluid height and shape during the tests changed more rapidly and dramatically than the solid-deposition height and shape. These slurry characteristics are included in the sketches mentioned above located in Appendix B. In addition to the sketches, still-frame clips were taken from video recordings of the transparent sections that were taken during testing to corroborate values included in the sketches. Selections from these clips showing slurry-fluid shape and height in each transparent section for each axial flow rate tested are included in Appendix A. The clips are listed in pairs, with a picture of the upstream transparent section placed just above a picture of the downstream section for each test condition. These pictures show that even at a velocity as high as $6 \mathrm{ft} / \mathrm{s}$, slurry in the upstream transparent section became noticeably higher than slurry in the downstream transparent section. Some of this disparity between observations in the two transparent sections is due to more solids deposition in the upstream transparent section than in the downstream transparent section as documented in Table 8.1. The pictures do indicate, however, that the difference between slurry heights in the two transparent sections seems to become greater for lower flow rates. According to Table 8.1, however, the difference in soliddeposition heights in the two transparent sections does not seem to increase in the same pattern as the slurry height difference. This discrepancy is most likely due to solid deposition within the metal (nontransparent) portion of the pipe, where direct visual observation is not possible. Observations through the viewport located just downstream of the upstream transparent section indicated that the solid-deposition layers observed in the upstream transparent section continued down the pipe. It is likely that the soliddeposition layer may be higher near the elbows in the pipe. This would account for what appears in the pictures to be a gradual backup of slurry as the test progressed. 
It is important to understand that the pictures in Appendix A are snapshots of the slurry height in each transparent section at specified times. The slurry did not flow smoothly, but would change shape and height erratically during a test. Thus, during a given test, it would be possible to obtain still frames that indicate that the difference in the slurry heights in the two transparent sections would be quite different than what is indicated by the pictures in the appendix. Effort was taken in the selection of the frames in this report to ensure that a good representation is given of average slurry behavior during a test condition.

Figure 8.7 and Figure 8.8 show two views of the upstream transparent section after the conclusion of the test. Likewise, Figure 8.9 shows the downstream transparent section after conclusion of the test. The material seen in Figure 8.7 through Figure 8.9 is a combination of deposited solids and slurry that failed to drain from the pipe after the pump had stopped. Figure 8.10 through Figure 8.12 show the interiors of the upstream and downstream reservoirs, including the connections with the 8-inch pipe. These figures show that the slurry levels in the reservoirs were not influencing the post-test slurry levels or the solid-deposition levels shown in Figure 8.7 through Figure 8.9.

In the test case with a slope of 1:125, deposition was seen at relatively high flow rates. As shown in Table 8.1 and Figure 8.7 through Figure 8.9, substantial quantities of solids settled during the test where 3-inch deposition height in an 8-inch pipe is defined as substantial solids deposition. These solid deposits were not easily removed from the piping after conclusion of the test. In an attempt to remove the deposits, the slurry was pumped through the pipe at a flow rate of $220 \mathrm{gpm}$. This did not successfully remove the deposits, which ultimately had to be removed with a pressurized water spray. 


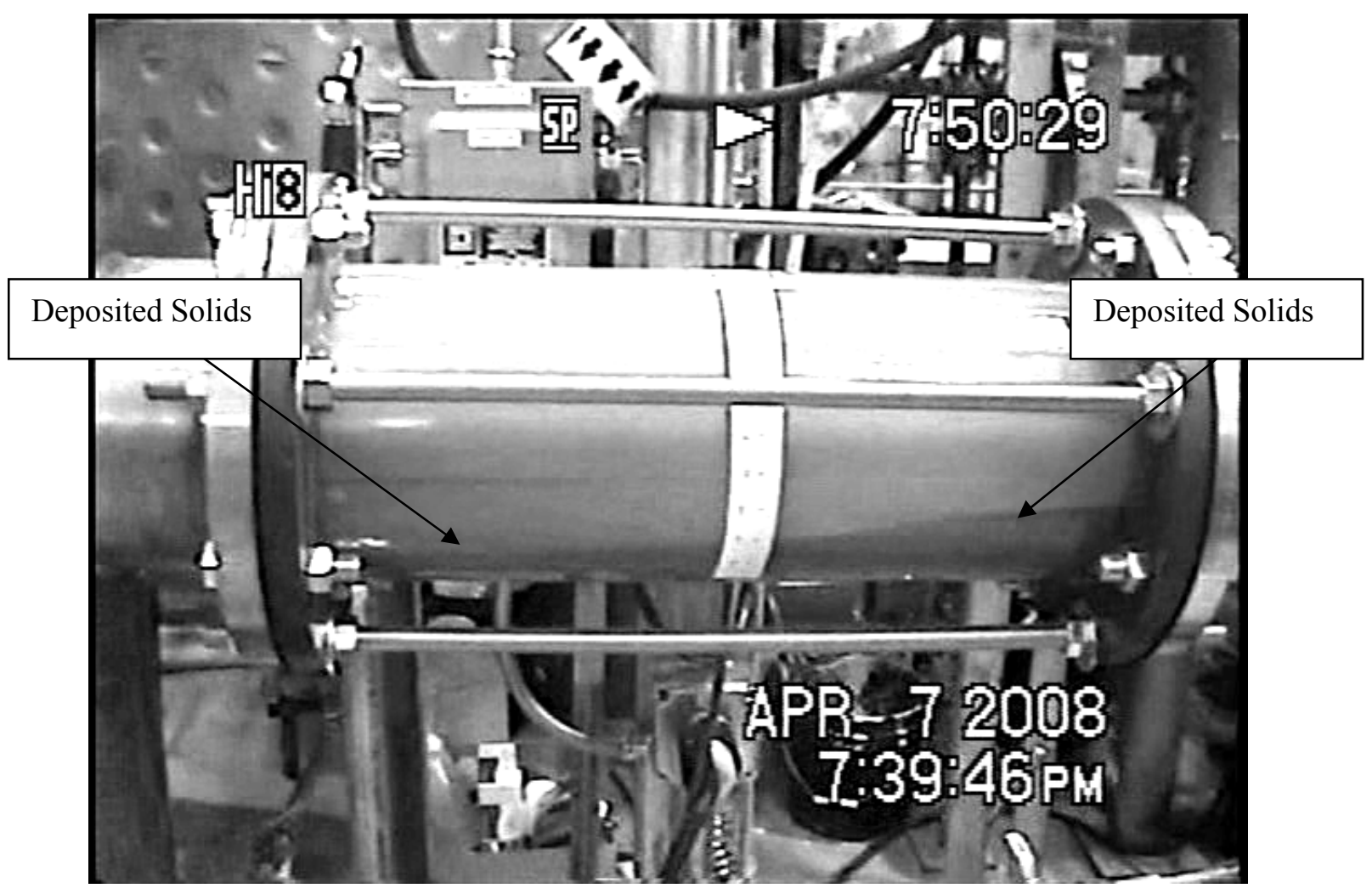

Figure 8.7. Upstream Post-Test Deposition

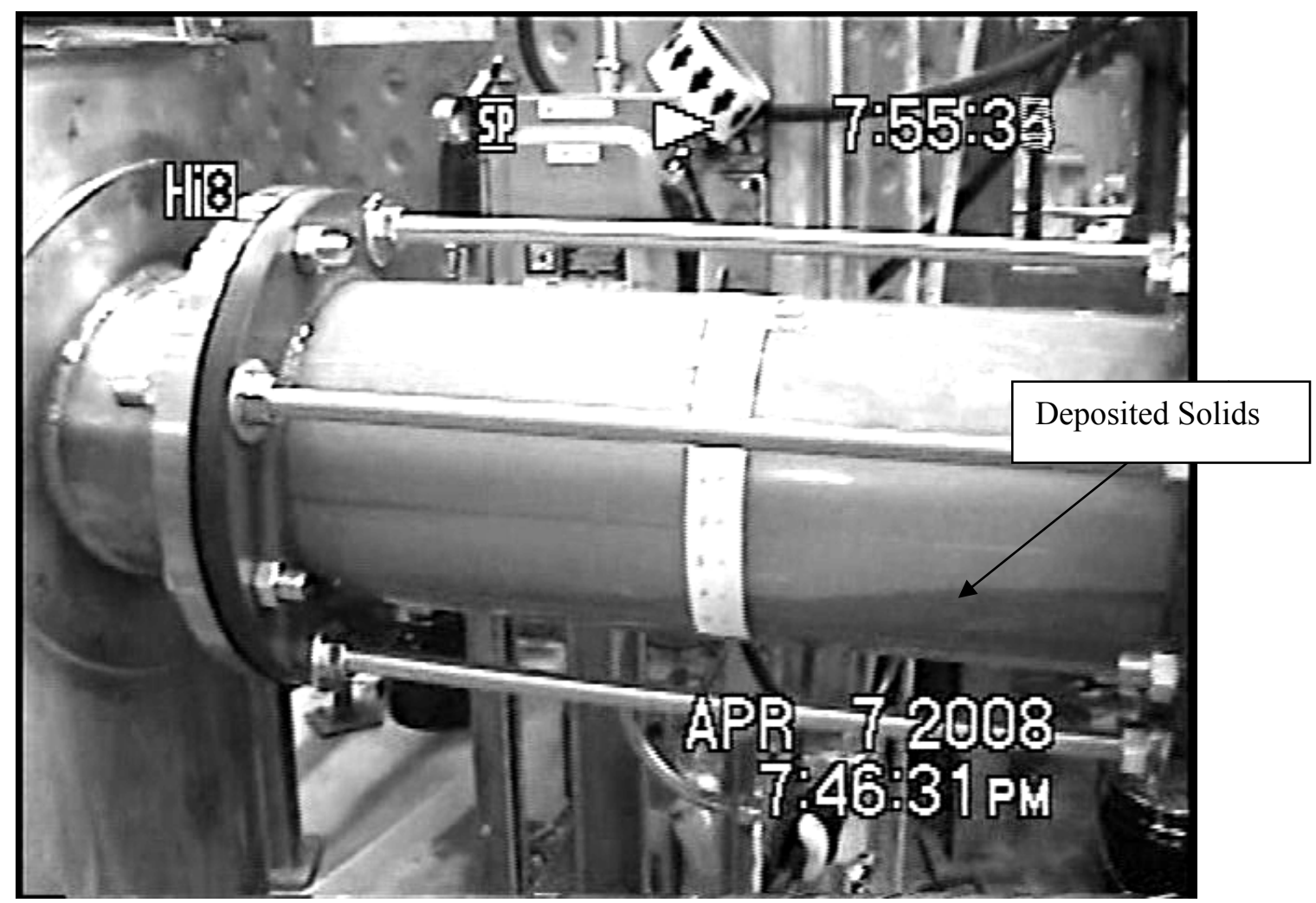

Figure 8.8. Upstream Post-Test Deposition 


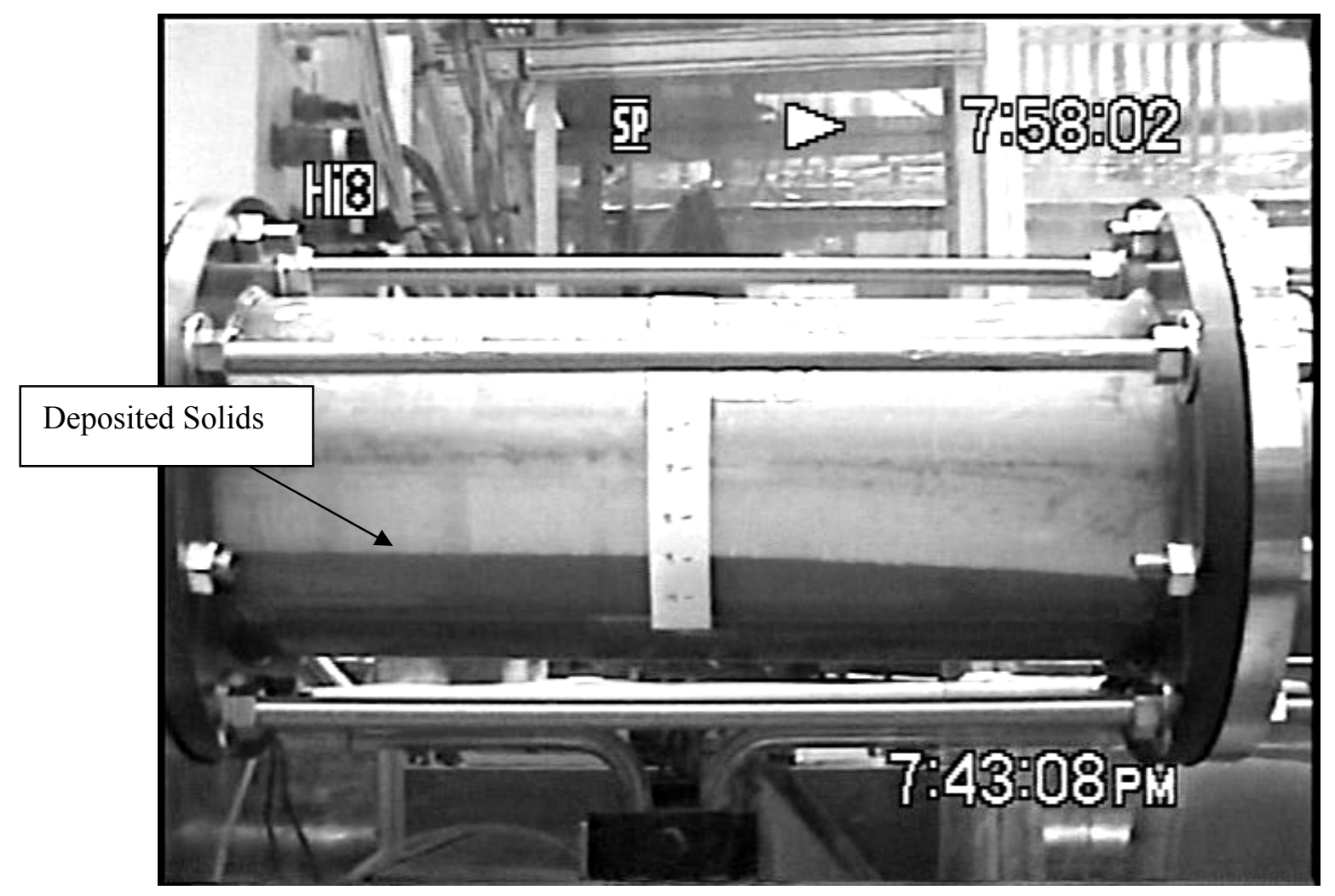

Figure 8.9. Downstream Post-test Deposition

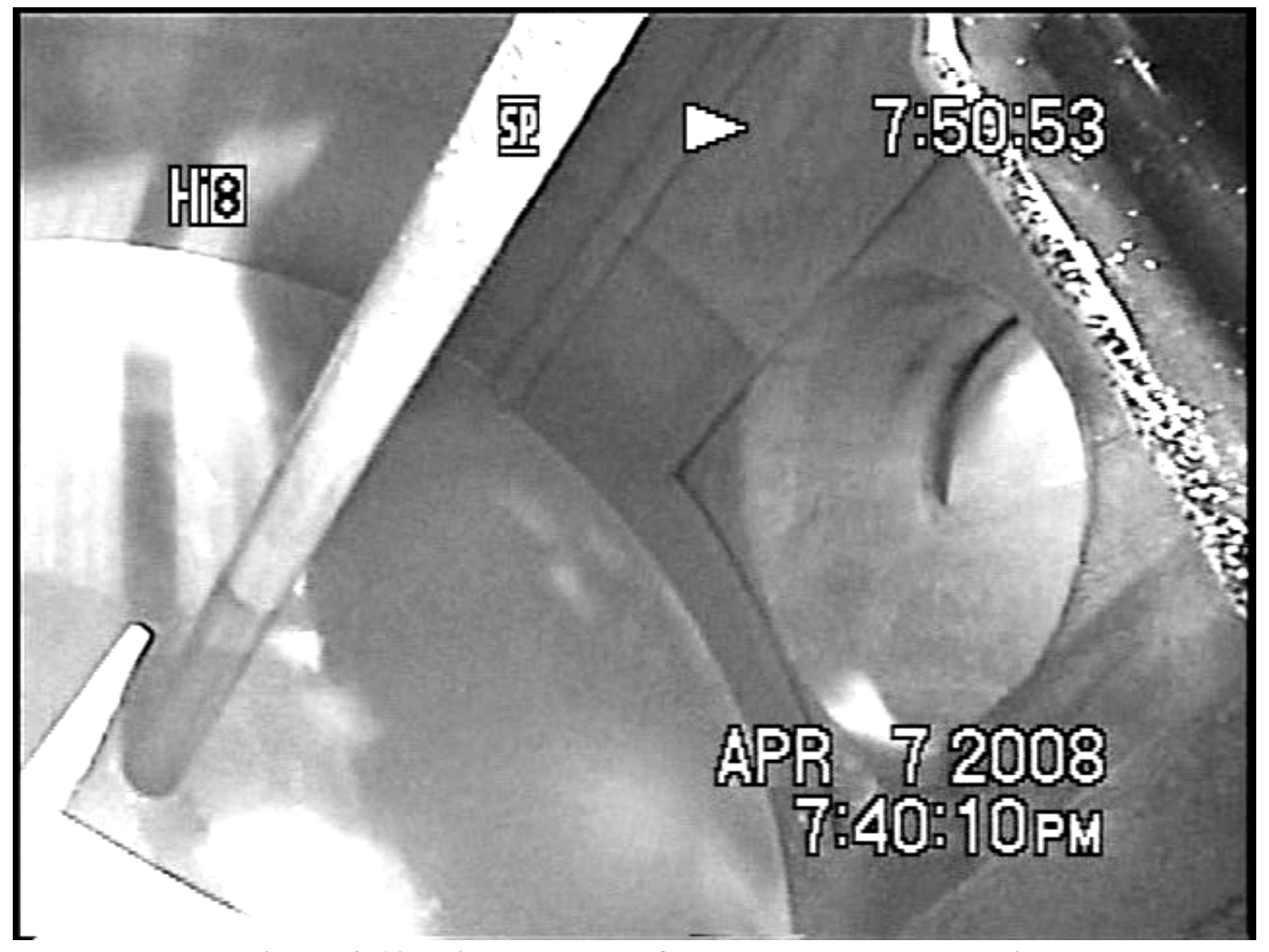

Figure 8.10. Pipe Entrance from Upstream Reservoir 


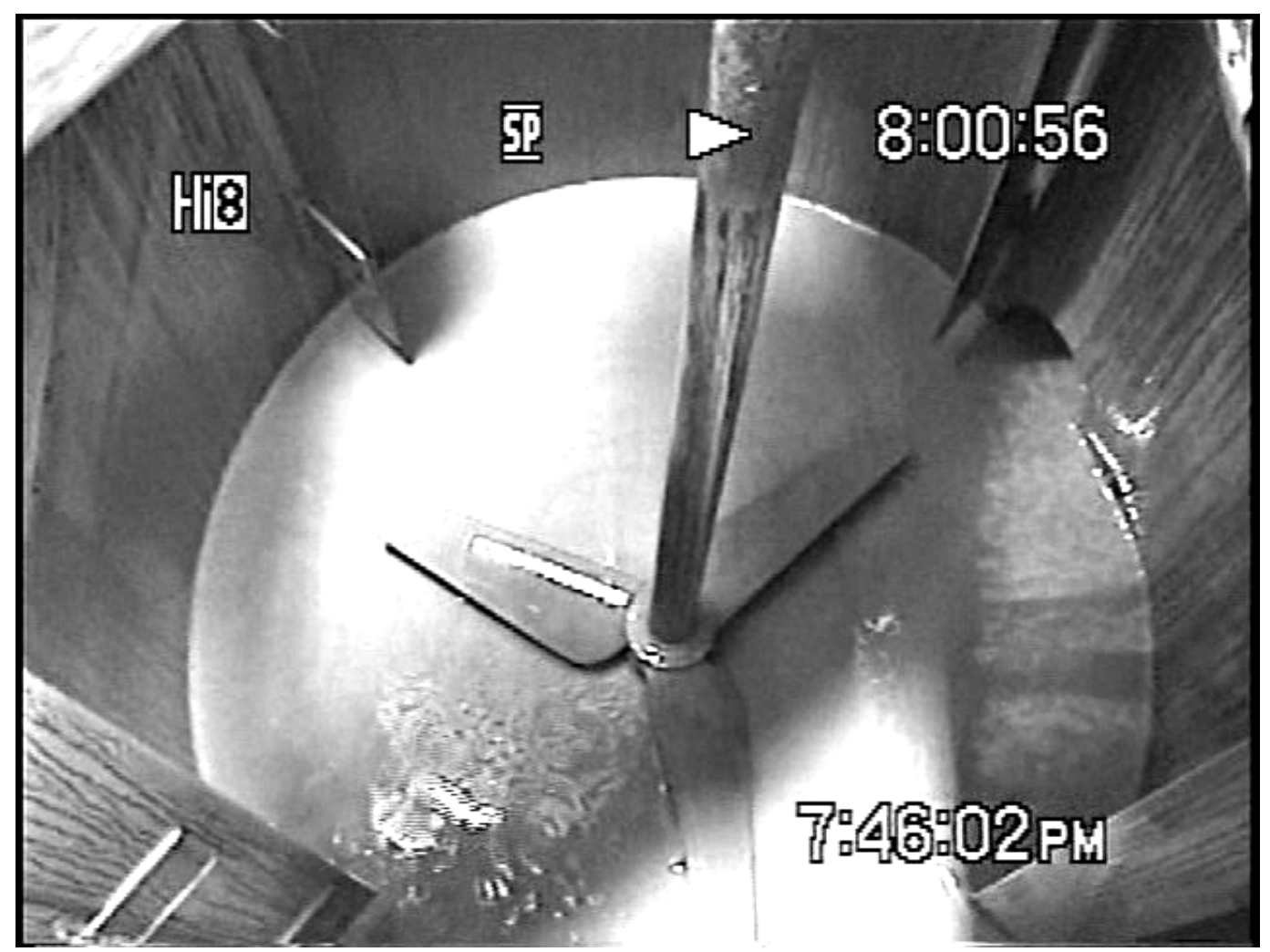

Figure 8.11. Downstream Reservoir Post-Test

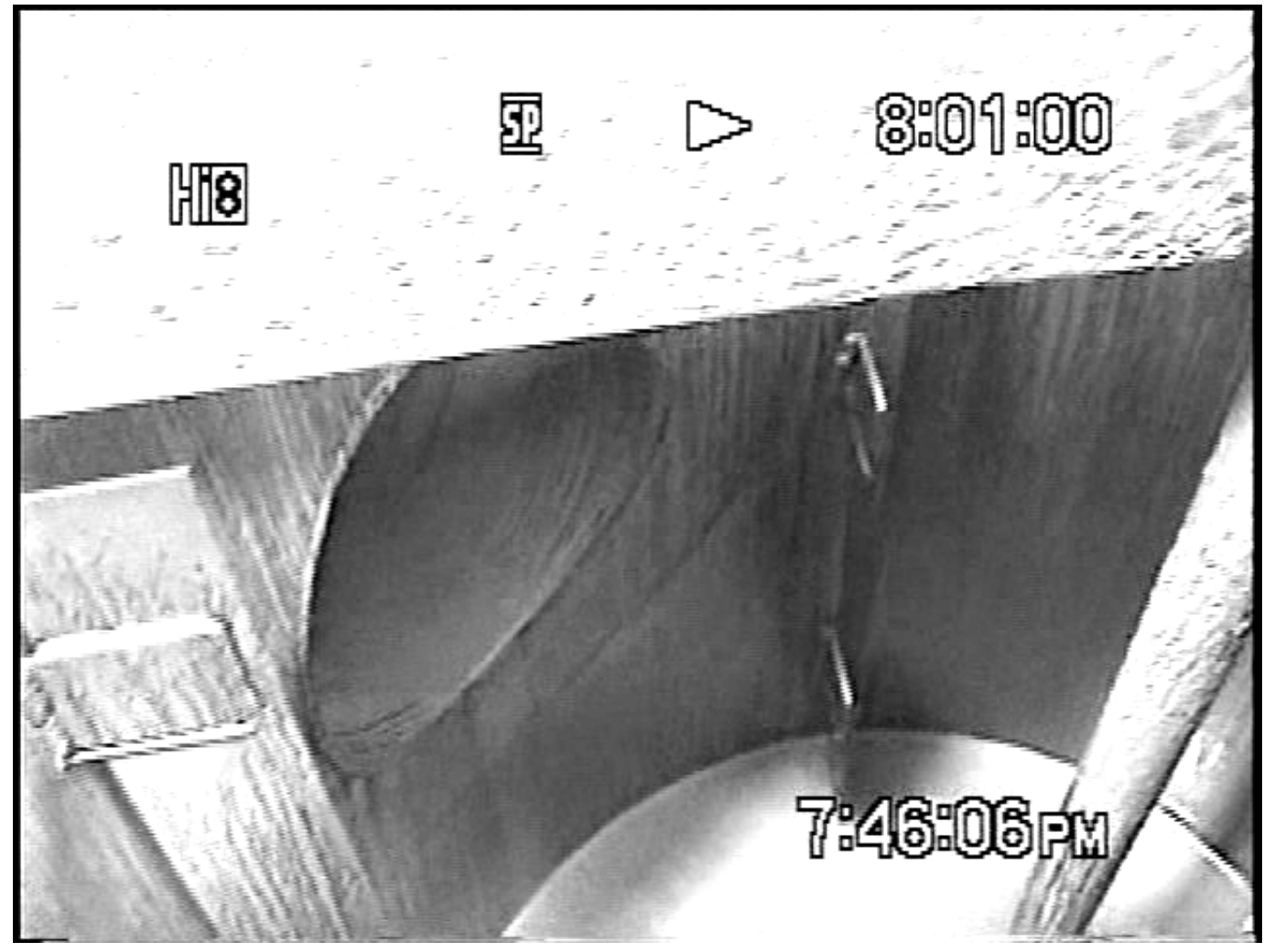

Figure 8.12. Pipe End to Reservoir Post-Test 


\subsubsection{Test 2, Slope $=1: 20$}

Test 2 represented the design with the greatest slope and thus served as a bounding case to determine whether or not the GDPF pipe flow test arrangement would function within the scope of the current tests. In this case, no solids deposition was observed in either transparent section at any flow rate under normal operating conditions. However, a pump malfunction during the test caused the slurry to remain stationary within the pipe for a period of time, which resulted in some solids buildup. After fixing the pump and restarting the test, no deposition was observed at any flow rate under normal operating conditions.

As no solid deposition was directly observed in this test case, observations of the slurry height in each transparent section were recorded. As mentioned in the description of the previous test, the slurry behavior was quite erratic. However, the slurry height was observed over a period of time and the height that most accurately represented the average slurry height was recorded. The observed slurry heights for both transparent sections are recorded in Table 8.2. Contrary to the results from Test 1, the slurry height was greater in the downstream transparent section than in the upstream transparent section for nearly every condition in Test 2 . This was largely an effect of the greater slope and did not provide evidence of solid deposition within the elbows of the pipe until the last test condition of $1.5 \mathrm{ft} / \mathrm{s}$. The decrease in slurry height in the downstream transparent section, and the rise in the upstream transparent section slurry height between the last two test conditions, may be indicative of some solid deposition within the elbows. To supplement the values in Table 8.2, as with the previous test, pictures of the slurry behavior in both transparent sections for each test condition are located in Appendix A. Fewer test cases were run for this slope (only integer-value velocities were studied, except for the final test condition of $1.5 \mathrm{ft} / \mathrm{s}$ ). For some test cases, a regular view and a close-up view of the same transparent section are provided. The close-up views allow the slurry heights to be correlated to values on the measuring tape. Unfortunately, one of the braces used to secure the downstream transparent section obscured the view of the top of the slurry for velocities above $2.0 \mathrm{ft} / \mathrm{s}$. One must be careful not to confuse the brace seen on the back side of the transparent section with the slurry.

Table 8.2. Slurry Heights Recorded in Test 2 (Slope $=1: 20)$

\begin{tabular}{|l|l|l|l|}
\hline $\begin{array}{l}\text { Volumetric Flow Rate } \\
(\mathrm{gpm})\end{array}$ & $\begin{array}{l}\text { Axial Velocity (through } \\
3 \text { " Coriolis meter) }(\mathrm{ft} / \mathrm{s})\end{array}$ & $\begin{array}{l}\text { Upstream Slurry } \\
\text { Height (inches) }\end{array}$ & $\begin{array}{l}\text { Downstream Slurry } \\
\text { Height (inches) }\end{array}$ \\
\hline 184 & 8.0 & 2.3 & 3.3 \\
\hline 161 & 7.0 & 2.3 & 3.3 \\
\hline 138 & 6.0 & 1.9 & 2.8 \\
\hline 115 & 5.0 & 1.9 & 2.3 \\
\hline 93 & 4.0 & 1.5 & 2.1 \\
\hline 68 & 3.0 & 1.3 & 1.9 \\
\hline 45 & 2.0 & $0.9 *$ & 1.3 \\
\hline 33 & 1.5 & 1.8 & 0.9 \\
\hline $\begin{array}{l}* \\
\text { The upstream slurry height of 0.9 was the minimum height observed in this configuration. This } \\
\text { began to occur between to J-curve for determining critical velocities and indicates that deposition }\end{array}$ \\
\hline
\end{tabular}

Figure 8.13 and Figure 8.14 are pictures of the post-test solid deposition in the upstream and downstream transparent sections, respectively. These figures confirm that very little solid deposition 
occurred during the test. However, during the course of Test 2, the pump located downstream of the second reservoir tank broke down and the test had to be postponed. While the system was being reconfigured to transfer slurry from the reservoirs back to the mixing tank, solids were observed to deposit within the tube. After the pump was replaced, Test 2 was completed. Prior to the pump failure, the test condition of $3 \mathrm{ft} / \mathrm{s}$ had been completed, so the final two test conditions of $2 \mathrm{ft} / \mathrm{s}$ and $1.5 \mathrm{ft} / \mathrm{s}$ were run after the pump had been replaced. Figure 8.13 and Figure 8.14 are pictures taken after the conclusion of the $1.5 \mathrm{ft} / \mathrm{s}$ test condition. The material that can be seen in the two pictures is not from solids deposition during the test. Instead, it is slurry that did not drain from the pipe after the slurry pump was shut down. When the pump stopped, the slurry in the pipe continued to flow to the downstream reservoir and the slurry above the entrance level of the 8-inch pipe in the upstream reservoir continued to flow into the pipe. The material that appears in Figure 8.13 and Figure 8.14 is the slurry that remained after the slurry level in the upstream reservoir dropped to the pipe entrance level and the slurry in the pipe stopped flowing into the downstream reservoir. The perspectives shown in the two figures are not the same, making direct comparisons between them difficult. However, there does appear to be more material in the upstream transparent section than in the downstream transparent section. This disparity in the slurry heights in the two transparent sections may be an indication of a gradual increase in remaining material from the downstream to the upstream section of the pipe. 


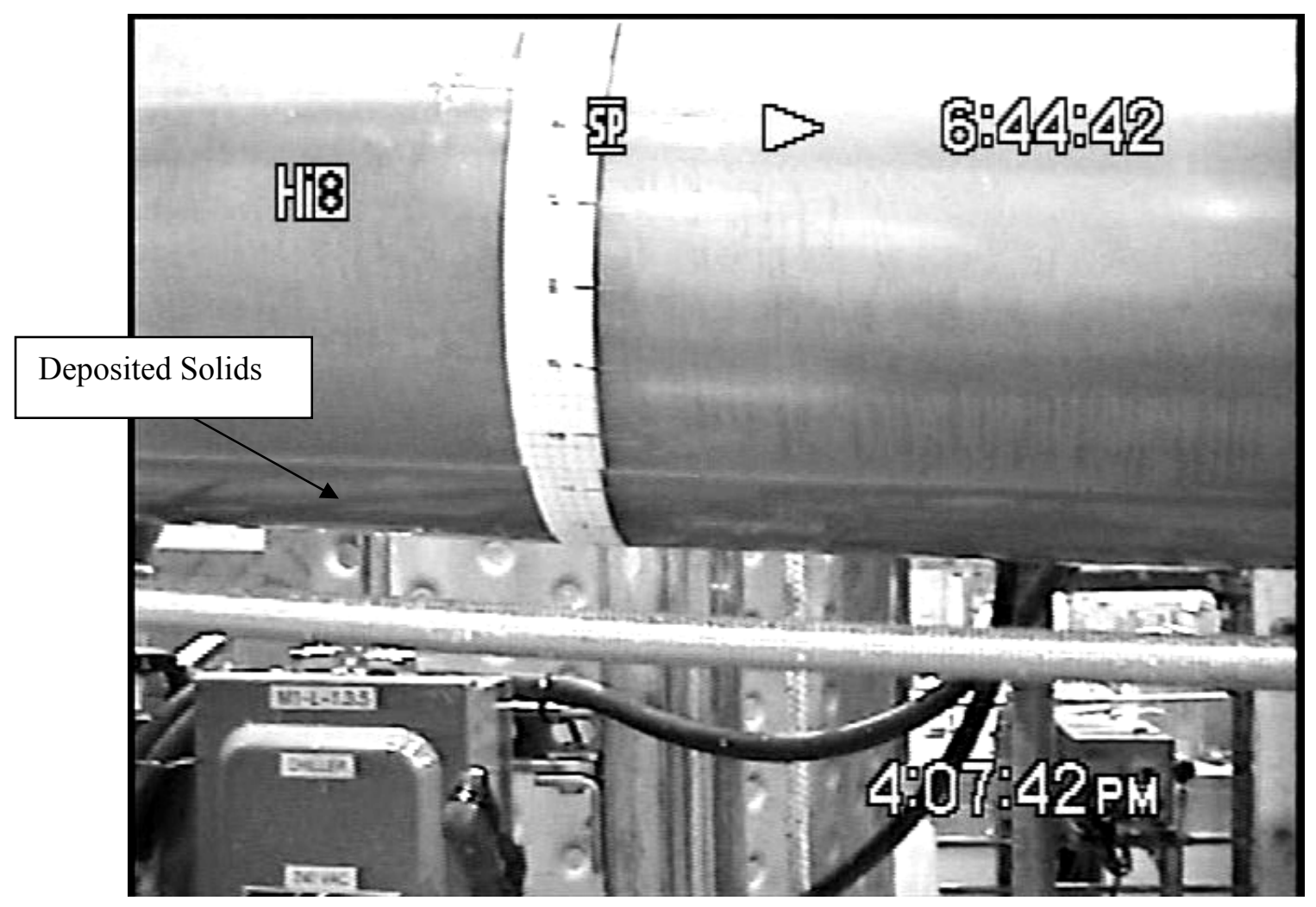

Figure 8.13. Upstream Transparent Section, Post Test $($ Test 2, Slope $=1: 20)$

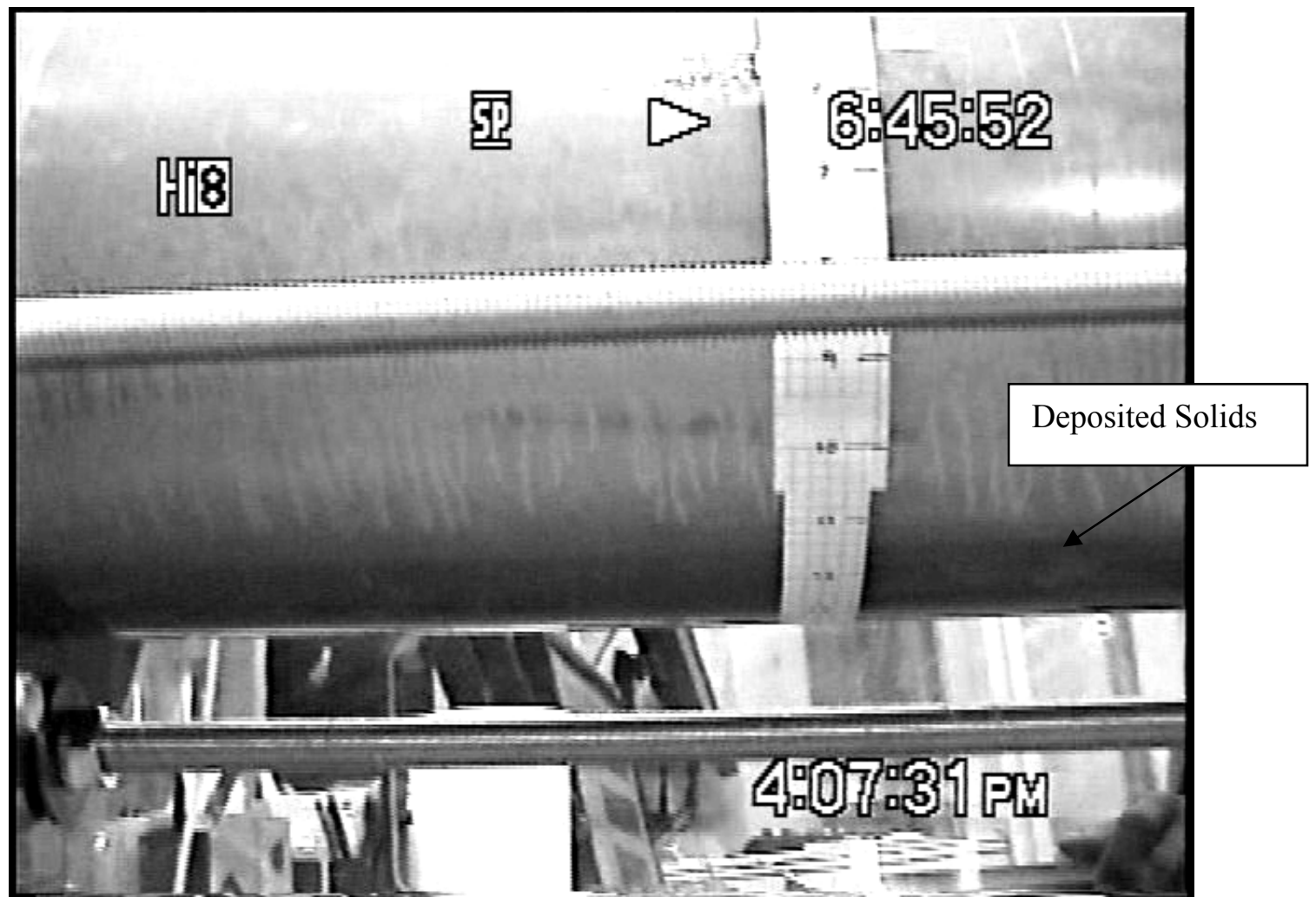

Figure 8.14. Downstream Transparent Section, Post Test $($ Test 2 , Slope $=1: 20)$ 


\subsubsection{Test 3, Slope $=1: 50$}

Test 3 represented a design with an intermediate slope and thus was used to determine a graded relation between the first and second tests. Observations made during Test 3 are recorded in Table 8.3 and Table 8.4. Particle deposition was observed in both transparent sections; however, the deposition occurred at higher flow rates and in greater quantities in the upstream transparent section than in the downstream transparent section. As in Test 1, the slurry height differences between the two transparent test sections for the final three test conditions is likely a result of solid deposition within the elbows of the pipe.

Table 8.3. Observed Upstream Parameters (Test 3, Slope $=$ 1:50)

\begin{tabular}{|l|l|l|l|l|}
\hline $\begin{array}{l}\text { Volumetric Flow } \\
\text { Rate (gpm) }\end{array}$ & $\begin{array}{l}\text { Axial Velocity } \\
\text { (through 3" } \\
\text { Coriolis meter) } \\
(\mathrm{ft} / \mathrm{s})\end{array}$ & $\begin{array}{l}\text { Maximum } \\
\text { Deposition Height } \\
\text { "MDH” (inches) }\end{array}$ & $\begin{array}{l}\text { Deposition Length } \\
\text { (inches) }\end{array}$ & $\begin{array}{l}\text { Slurry Height } \\
\text { (inches) }\end{array}$ \\
\hline 184 & 8.0 & 0 & 0 & 2.8 \\
\hline 161 & 7.0 & 0 & 0 & 2.5 \\
\hline 138 & 6.0 & 0 & 0 & 2.3 \\
\hline 115 & 5.0 & Trace & 14 & 3.0 \\
\hline 93 & 4.0 & 0.1 & 16 & 3.0 \\
\hline 68 & 3.0 & 0.6 & 22 & 3.0 \\
\hline 45 & 2.0 & 0.8 & 22 & 3.0 \\
\hline 33 & 1.0 & 1.5 & 22 & 2.8 \\
\hline
\end{tabular}

Table 8.4. Observed Downstream Parameters (Test 3, Slope $=1: 50)$

\begin{tabular}{|l|l|l|l|l|}
\hline $\begin{array}{l}\text { Volumetric Flow } \\
\text { Rate (gpm) }\end{array}$ & $\begin{array}{l}\text { Axial Velocity } \\
\text { (through 3" } \\
\text { Coriolis meter) } \\
(\mathrm{ft} / \mathrm{s})\end{array}$ & $\begin{array}{l}\text { Maximum } \\
\text { Deposition Height } \\
\text { "MDH” (inches) }\end{array}$ & $\begin{array}{l}\text { Deposition Length } \\
\text { (inches) }\end{array}$ & $\begin{array}{l}\text { Slurry Height } \\
\text { (inches) }\end{array}$ \\
\hline 184 & 8.0 & 0 & 0 & 2.8 \\
\hline 161 & 7.0 & 0 & 0 & 2.5 \\
\hline 138 & 6.0 & 0 & 0 & 2.3 \\
\hline 115 & 5.0 & 0 & 0 & 2.1 \\
\hline 93 & 4.0 & 0 & 0 & 1.9 \\
\hline 68 & 3.0 & 0 & 0 & 1.5 \\
\hline 45 & 2.0 & Trace & 1 & 1.1 \\
\hline 33 & 1.0 & 0.3 & 15 & 1.1 \\
\hline
\end{tabular}

As with the first two tests, still frames from video recordings from both transparent sections at each test condition are located in Appendix A. Figure 8.15 through Figure 8.17 are post-test pictures of the transparent sections. As with the post-test pictures of the other two tests, the material seen in Figure 8.15 through Figure 8.17 is a combination of solid deposits and slurry that did not drain after the pump stopped. 


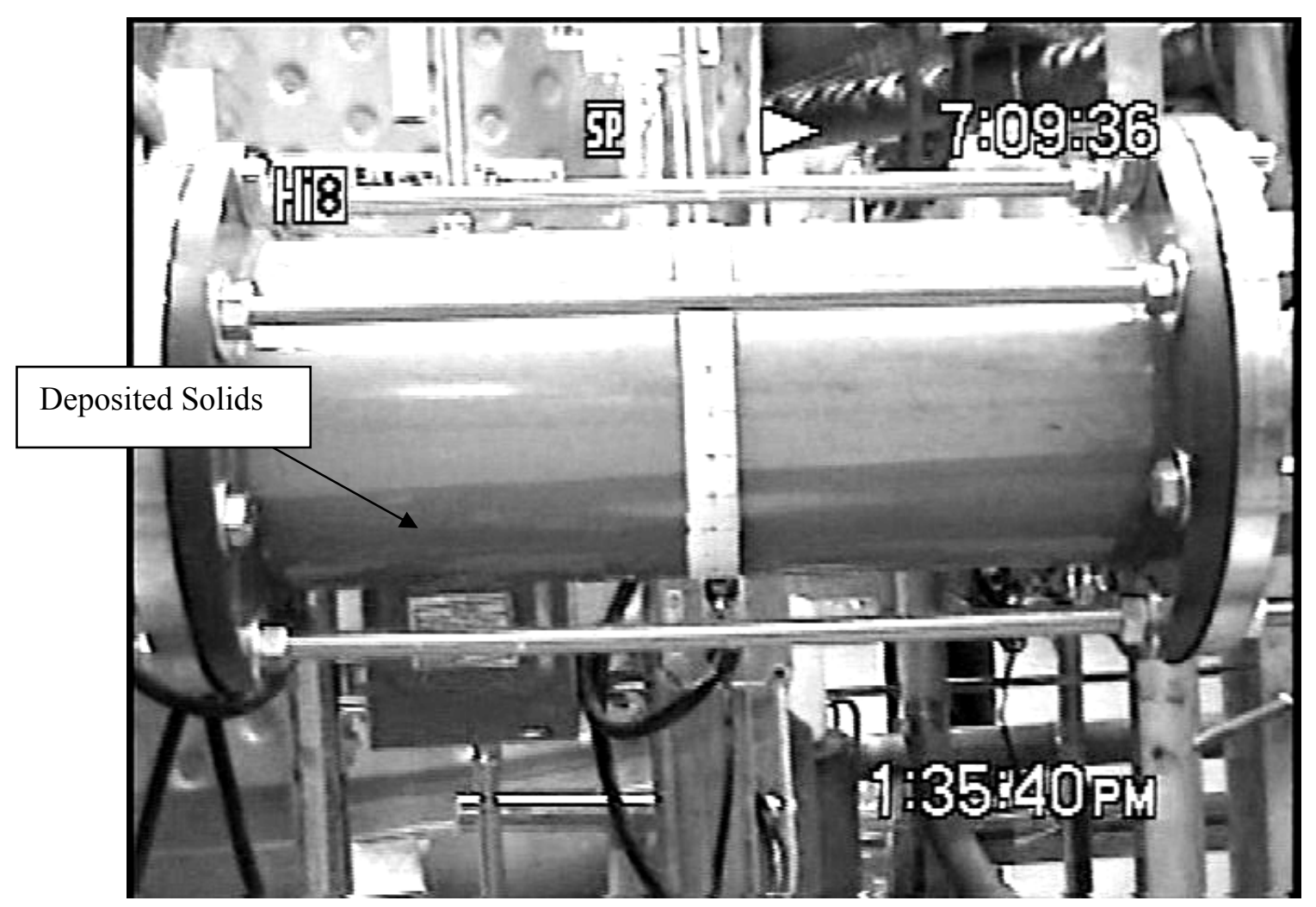

Figure 8.15. Upstream, Slope $=1$ :50, Post-Test Deposition

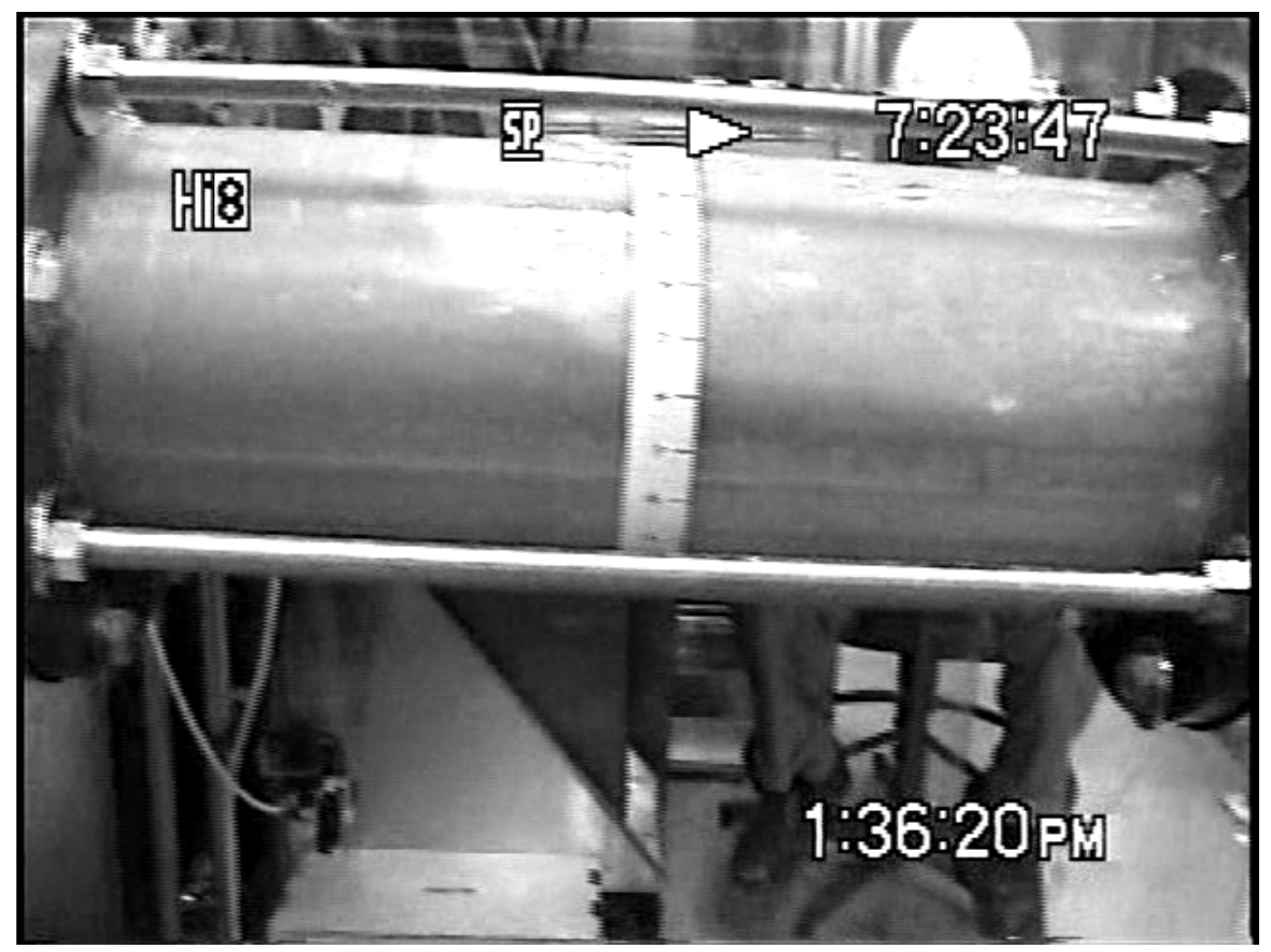

Figure 8.16. Downstream, Slope $=1: 50$, Post-Test Deposition 


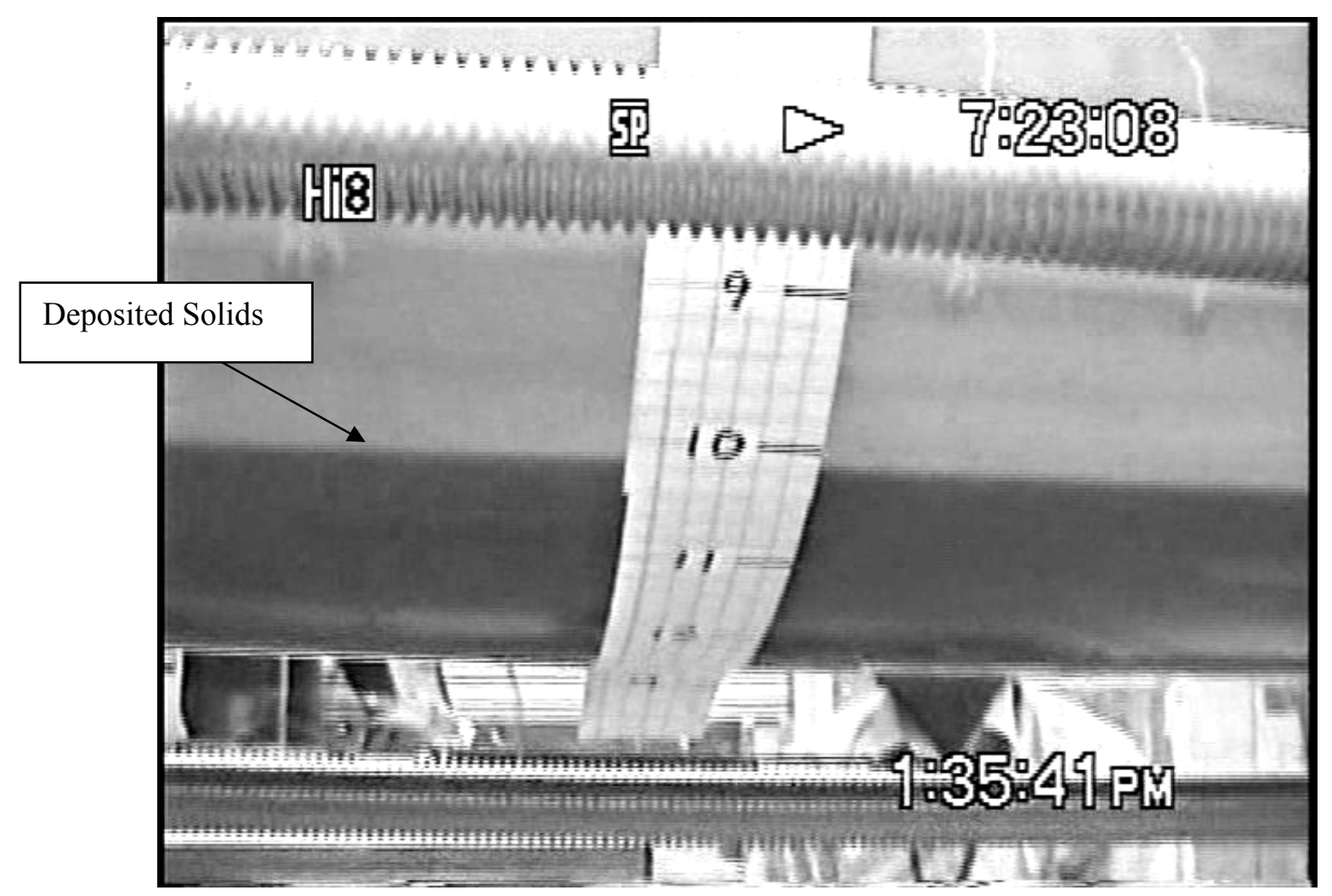

Figure 8.17. Downstream, Slope $=1: 50$, Post-Test Deposition (Close-up)

\subsection{Discussion}

The results of the GDPF pipe flow tests cannot be directly compared to design guides 24590-WTPGPG-M-027, Rev. 5 (Kloster 2007) and 24590-WTP-GPG-M-032, Re. 3 (Donoso 2007) because the tests used a Bingham-plastic slurry and the design guides only address Newtonian fluids and slurries. However, the test results do give some indication of how to design vessel-overflow lines for systems using slurries with yield stresses and viscosities similar to those of the slurry used in the tests. The results are limited in that they do not encompass the full transient nature of any specific overflow conditions. For instance, if the vessel overflow was not steady, but consisted of several "pulses" of slurry flowing at a low flow rate, then it can be expected that more settling would occur than is indicated by the results of this test. This statement is exemplified by the fact that in the test with a pipe slope of 1:20, no solid deposition was seen during normal operation at specified test conditions, but deposition did occur when the slurry was allowed to stand within the pipe for brief periods after the pump malfunction and after conclusion of the test.

The GDPF pipe flow test results suggest that a slope of 1:125 may not be suitable for the slurry type and test conditions used in these tests. For this test condition, solid deposition was observed for flow velocities as high as $7.0 \mathrm{ft} / \mathrm{s}$. Much larger deposition quantities were observed at lower velocities. Additionally, after the completion of the test, these deposits were very difficult to remove from inside the pipe. Although no line plugging was observed over the course of the test, significant deposition of solid 
material was observed. It is possible that given longer term build-up, line plugging may become a problem. The shallowest slope discussed in design guide 24590-WTP-GPG-M-032, Re. 3 (Donoso 2007) is $1: 100$, for which it is suggested that a Newtonian slurry with a viscosity/specific gravity ratio of less than 41 centistokes would properly drain. Although the viscosity/specific gravity ratio of the slurry used in this test was well below this value, it was non-Newtonian and the slope of the pipe was less than 1:100.

Although significant solid deposition did not occur until lower flow velocities in the case of the 1:50 slope relative to the 1:125 slope, the test results indicate that the 1:50 slope may also be inadequate for the conditions considered. Any flow velocity less than $5.0 \mathrm{ft} / \mathrm{s}$ can be expected to result in some solid deposition. As was the case in the system with the 1:125 slope, the solid deposition was difficult to remove from the pipe upon conclusion of the test. Once again, although solid deposition was observed, plugging did not occur during the test, and it is difficult to tell what may have happened had the test been run at lower flow rates for a longer period of time.

The system with a 1:20 slope appeared to be adequate for overflow removal for most of the test conditions considered. Although no solid deposition was observed during normal test conditions, slurry height measurements indicate that deposition may be occurring within the elbows for flow velocities at or below $1.5 \mathrm{ft} / \mathrm{s}$. Additionally, stagnant conditions that occurred at the conclusion of the test resulted in some solid deposition.

Of the three test conditions studied in the GDPF pipe flow tests, only the system with the greatest slope appeared to function as desired during normal test conditions. Even that system, with a slope of 1:20, showed indications of possible deposition at low flow velocities. In each case, stagnant conditions resulted in the formation of solid deposition layers within the pipe, and in each case, these deposits were difficult to flush from the pipe. Even after the pipe had been thoroughly flushed at the end of each test, when the system was disassembled for reconfiguration, it was discovered that deposits remained within the pipe. It is apparent that for any system used, it will be necessary to thoroughly flush out the overflow channel after a vessel-overflow event has occurred. 


\subsection{Flush-System Test}

Design guide 24590-WTP-GPG-M-0058, Rev. 0 (Hall 2006) specifies upper limits on the flushing velocity of $12 \mathrm{ft} / \mathrm{sec}$ and $10 \mathrm{ft} / \mathrm{sec}$ for the process streams with and without the glass-former chemicals, respectively. This upper limit is in place to limit pipe erosion. The flush-volume upper limit is stated as 3 line volumes. The lower flush-volume limits are 1.5 and 1.7 line volumes for Newtonian and nonNewtonian process lines, respectively. The experimental flow loop under each test configuration setup was determined to have approximately 65 gallons of line volume. This section discusses how the prototypic flush performed with respect to the constraints of design guide 24590-WTP-GPG-M-058, Rev. 0 (Hall 2006) for the flow-loop test system with modular test sections of the gravity-feed and processdrain test module, the jumper test module, the complex-geometry test module, and the reducer and vertical-rise test module.

During each test the flush tank (pressure vessel) would be filled with an initial charge of water. Once a set of tests was done under any given configuration, valves were reconfigured to operate in flush mode. This mode allowed for flow from the flush tank to go to the spent-simulant vessel. The pressure in the tank was then increased to a target value, nominally 100 to 110 psig. A valve was opened, and the highpressure water flush removed deposited slurry particles from the pipe loop.

\subsection{Test Results}

Following the procedure presented in Subsection 6.1, a high-pressure flush was conducted after the pressure-drop measurements. The initial charge pressure for line flushes was set between 100 and 110 psig. The flush system was opened, and the data acquisition system recorded pressures, flow rates, and slurry density.

The level in the flush tank was recorded and converted to a volume using a calibration curve. The ratio of the cumulative flush tank volume discharge to the 65-gallon loop volume is used as the flush-toline-volume ratio.

The reported pressure is the flow-loop pressure drop described in Section 5. The reported velocities are from the loop-entrance Coriolis flow meter. If the settled solids in the system form a stationary plug of material, water should flow through that plug slowly, providing a near-zero velocity reading on the system flow meters while the flush-tank level drops.

The reported density is taken from the outlet Coriolis flow meter. When the measured density is high, the flush is still removing particles from the system. As density approaches the value of the flush water, the effectiveness of the flush is nearing completion.

A target flush volume of 1.5 to 2 line volumes was selected, and multiple flushes were performed. This resulted in a total flush-to-line-volume ratio typically between 5 and 6 . After this point, the system was purged with compressed air. This is reflected by the abrupt drop in instrumentation signal at the end of several of the plots. Data from the flush testing is shown in Figure 9.1 to Figure 9.5 for each modular test configuration. The flush operation was conducted in the last test run for each modular test configuration. 
Figure 9.1 and Figure 9.2 belong to the same test flush set as the gravity-feed and process-drain test module. Here, the disk ruptured during the first flush, resulting in replacement of the disk. The disk rupture occurred due to a pressure surge (wave) produced by manually opening the valve rapidly. After the disk replacement, the remaining flushes were continued as shown in Figure 9.2. Figure 9.3, Figure 9.4 and Figure 9.5 show the flush plots for the jumper test module, the complex-geometry test module, and the reducer and vertical-rise test module, respectively.

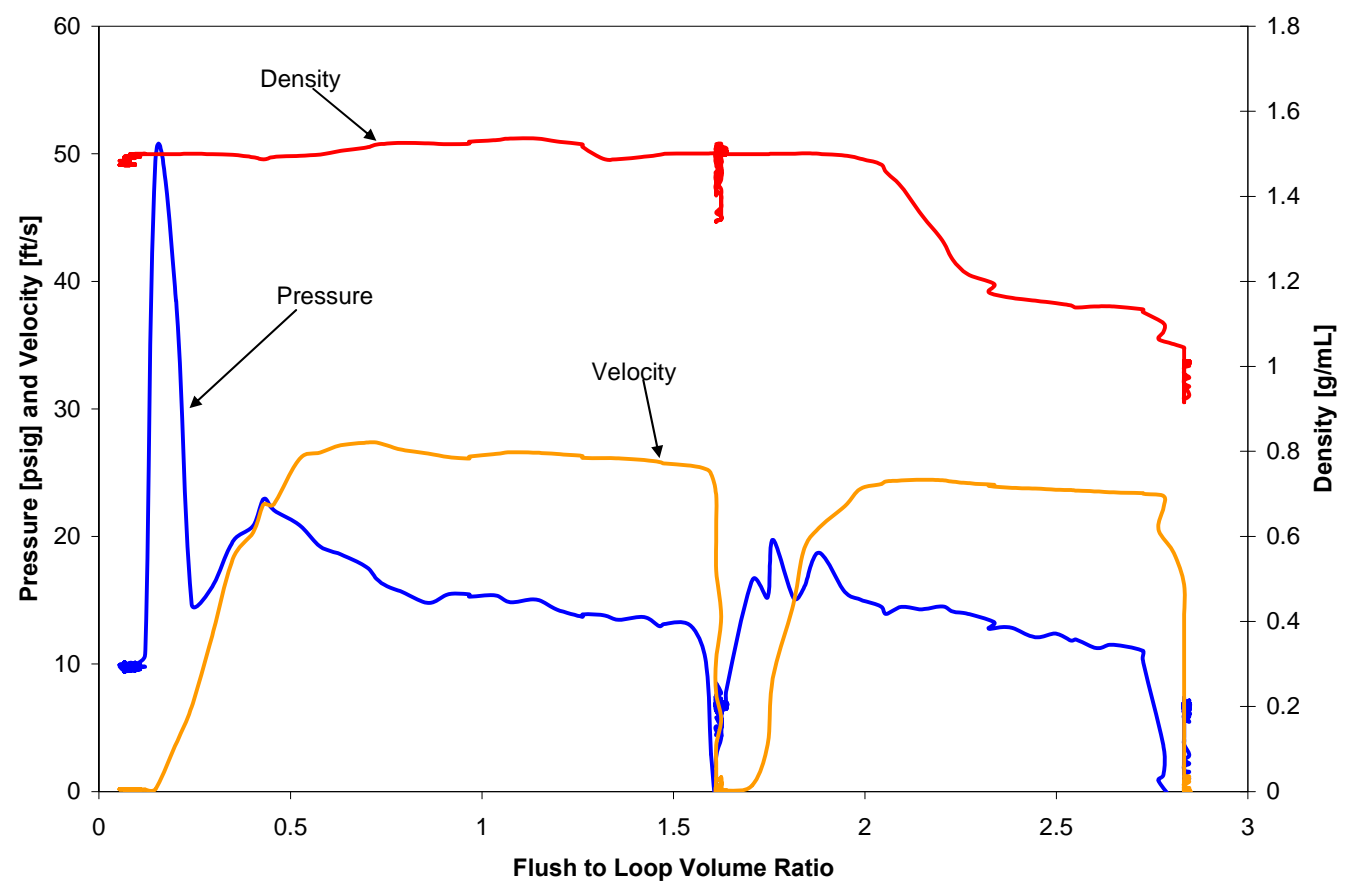

Figure 9.1. Flush Data for the gravity-feed and process-drain test module as a flush-to-pipe loop-volume ratio, showing the flush before disk rupture 


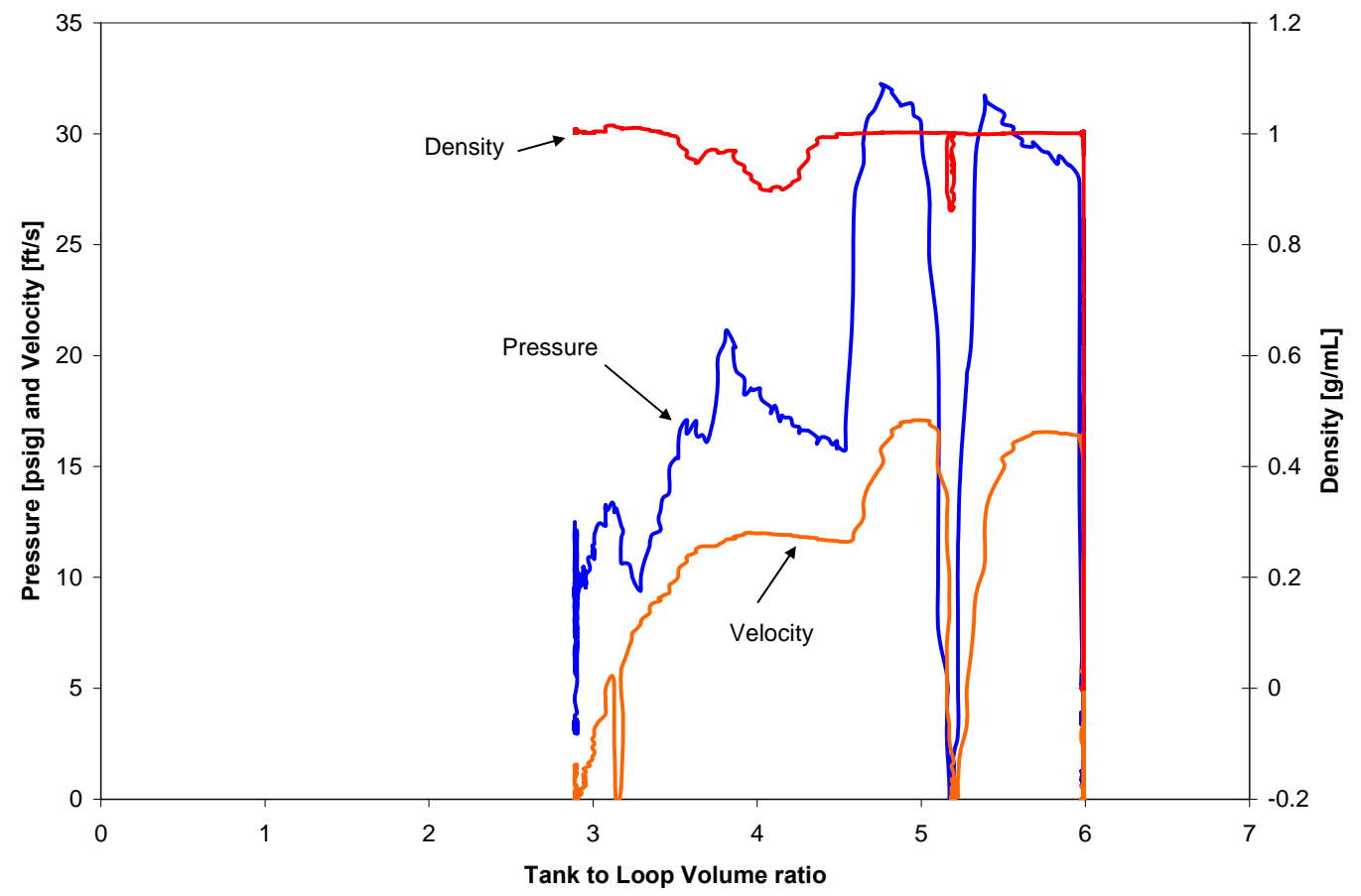

Figure 9.2. Flush data for the gravity-feed and process-drain test module as a flush-to-pipe loop-volume ratio, showing two complete flushes after disk replacement (continuation of Figure 9.1)

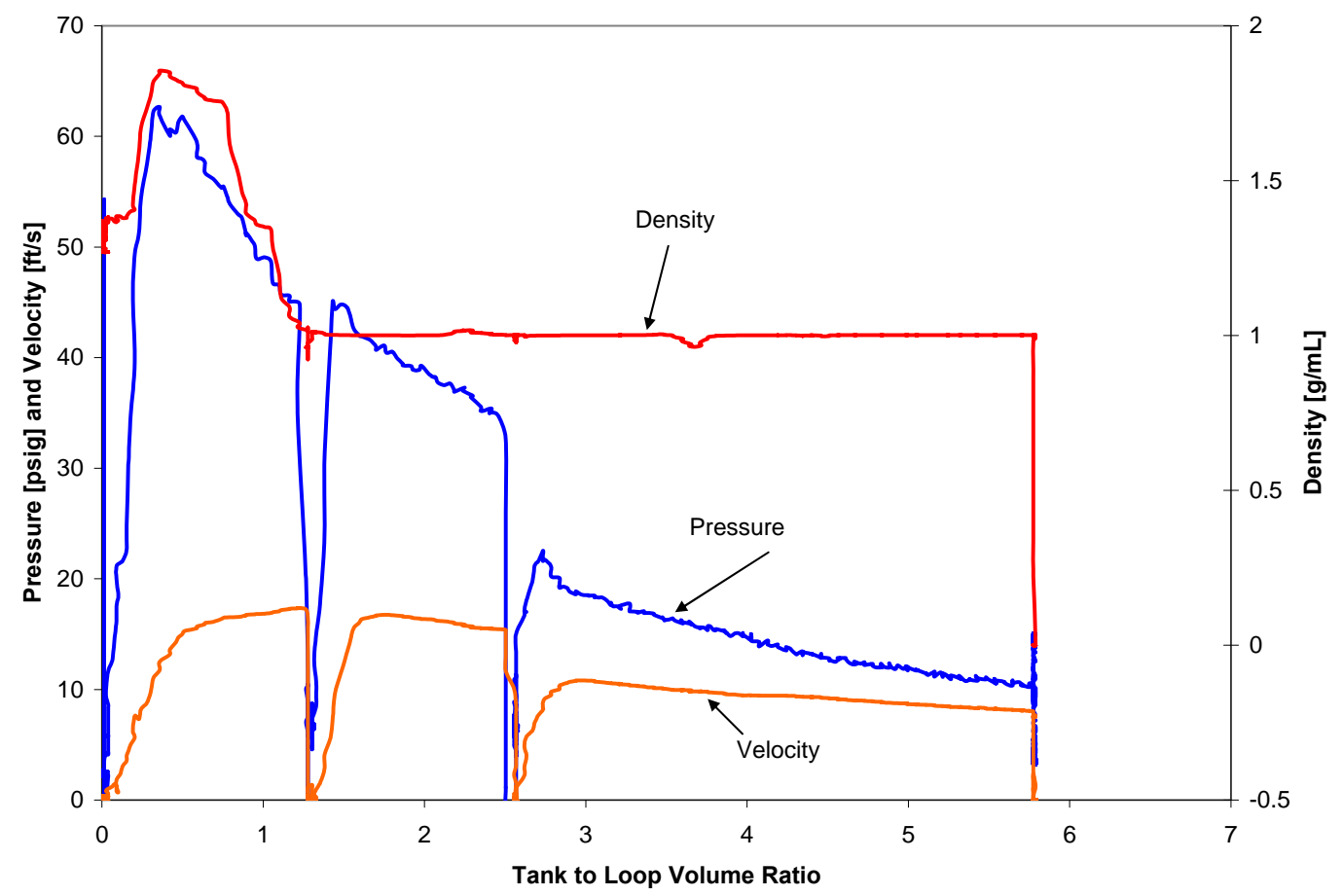

Figure 9.3. Flush data for the jumper test module as a flush-to-pipe loop-volume ratio, showing three complete flushes 


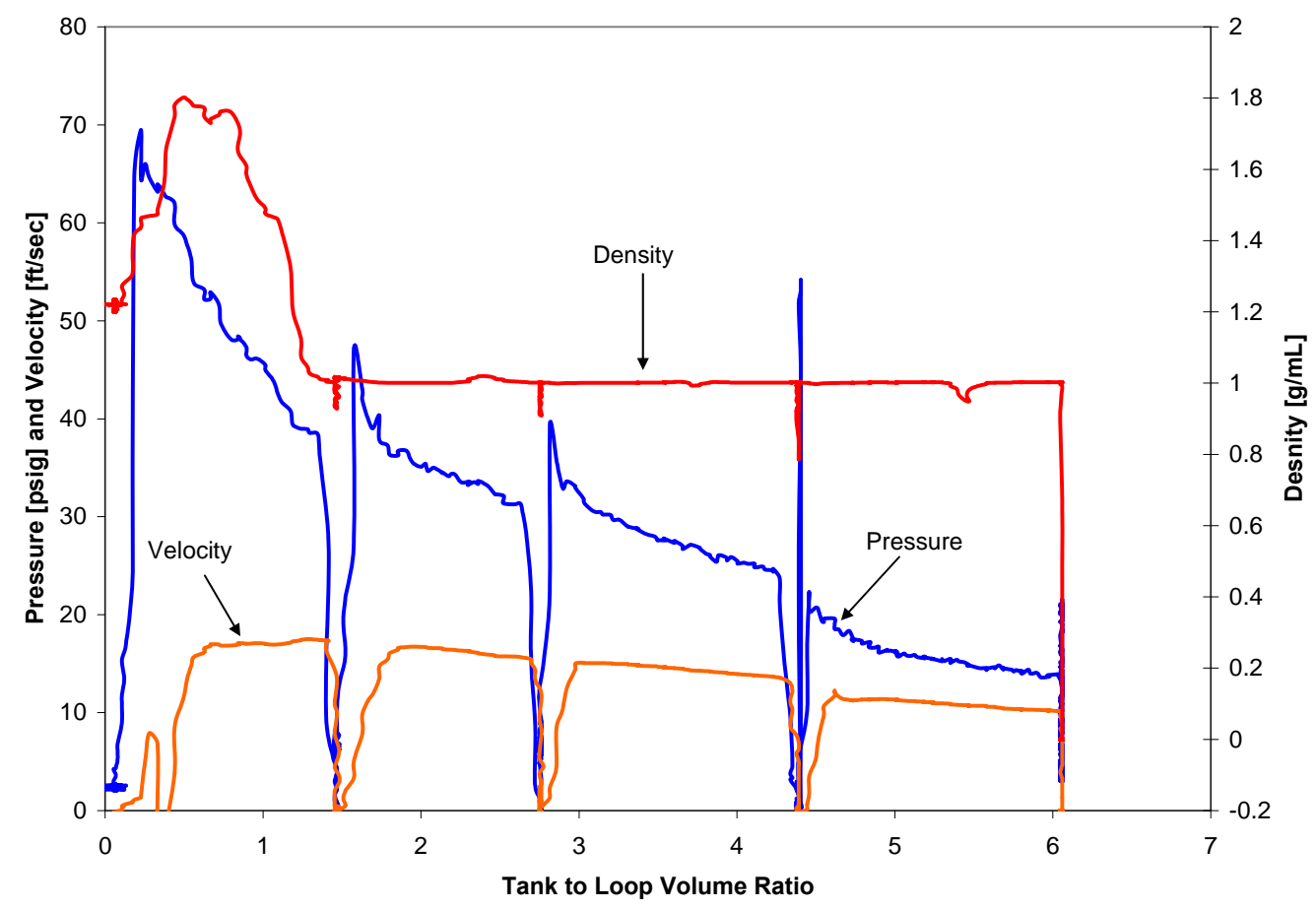

Figure 9.4. Flush data for the complex-geometry test module as a flush-to-pipe loop-volume ratio, showing four complete flushes

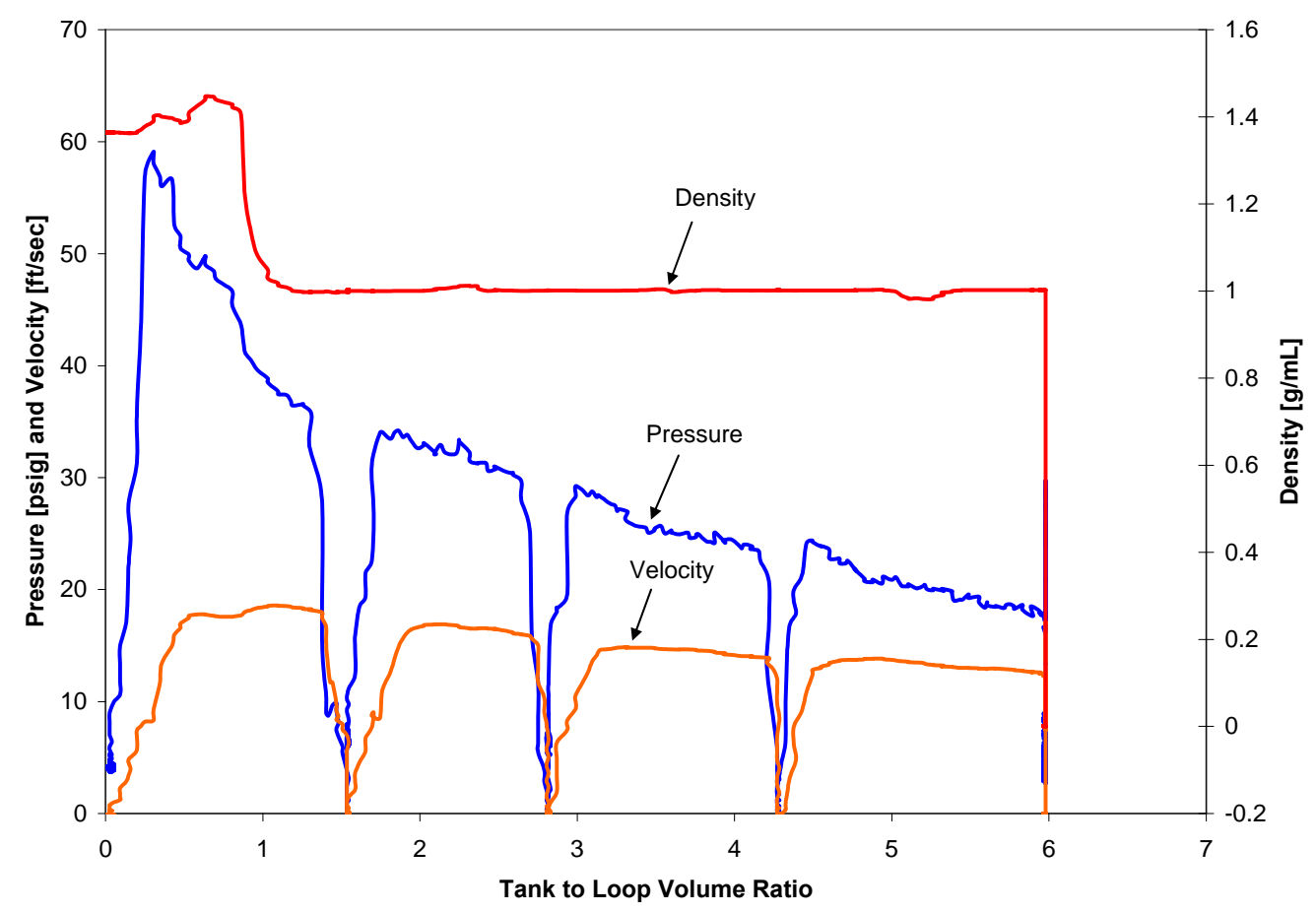

Figure 9.5. Flush data for the reducer and vertical-rise test module as a flush-to-pipe loop-volume ratio, showing four complete flushes 


\subsection{Discussion}

The flushing operations for this testing were performed by employing the recommendation provided by Poloski et al. (2008) as: "The pneumatic flush system must be opened slowly to erode the sediment bed from the top down. If the pneumatic flush system is opened quickly, the sediment bed is simply pushed to the nearest corner, and a granular plug develops and completely fills the line cross-sectional area."

From Figure 9.1 to Figure 9.5, the following observations are made:

o The flush system is effective in removing sediment beds from the flow-loop system

o The total flush-to-line-volume ratio is approximately 6

o For all of the test modules, except the gravity-feed and process-drain test module, the minimum flush-to-line volume ratio of 1.7 (for non-Newtonian fluids) appears to be satisfied

o The flush-to-line volume ratio for the flow-loop system with the gravity-feed and process-drain test module is approximately 2.9

o For all of the test modules, a flush-to-line volume ratio of 3 appears to be sufficient to remove the particles from the flow-loop system

o For all of the test modules, except the gravity-feed and process-drain test module, the highest flushing velocities are nearly $20 \mathrm{ft} / \mathrm{sec}$

o The highest flushing velocity for the flow-loop system with the gravity-feed and process-drain test module is nearly $30 \mathrm{ft} / \mathrm{sec}$

For the flow-loop system with the gravity-feed and process-drain test module, the solid settlement was expected within the "tee" fitting. In addition, the solids were considered to be trapped within all of the $90^{\circ} 3 \mathrm{D}$ elbows. Therefore, it is deemed that these factors caused the higher flush-to-line volume ratio for the flow-loop system with the gravity-feed and process-drain test module.

The values of the flush volume and the flush velocity specified by design guide 24590-WTP-GPG-M0058, Rev. 0 (Hall 2006) were difficult to be satisfied manually. Depending on the process-line geometry, flows in the range of 500 to $1,000 \mathrm{gpm}$ can be achieved with this system. Since the piping volumes may be on the order of 50 to 100 gallons, manually closing a valve to hit this target volume may be challenging. Compounding this problem, the valves need to be closed slowly to avoid water hammer. 


\subsection{Findings}

The following findings are obtained from the test results provided in this report:

- A complete flow blockage by pipe plugging did not occur at the smallest flow velocity used for the testing; however, the flow velocity was kept constant by the feedback system of the pump with the variable frequency drive (VFD)

- Due to high uncertainty in the critical velocity evaluations in the absence of a definite J-curve profile, velocities for avoiding deposition (VFAD) provide velocities at which it is assured that no particle deposition occur

- A definite profile of the J-curve was not obtained in this testing due to high fluctuations in DPT data

- Smallest velocities obtained in this testing need not to be critical velocities

- The critical velocities were evaluated from the uncorrected DPT data by applying the critical velocity definition used by Poloski et al. (2008) and it was found that, except in the case of a tee in the gravityfeed and process-drain test spool, the evaluated critical velocities for the fittings used for in this testing are lower than that for a straight horizontal pipe reported by Poloski et al. (2008) where the same pipe diameter of 3 inches as that used in this testing and the slurry composition and rheology similar to those used in this testing were used; however, high uncertainty in the critical velocity evaluations is expected

- In the overflow-relief piping test, for the minimum flow rate of $45 \mathrm{gpm}$ for the 1:125 slope, and the minimum flow rate of $33 \mathrm{gpm}$ for the 1:50 and 1:20 slopes, a complete flow blockage by pipe plugging did not occur and the following observations are reported:

o At the slope of 1:125, 1) substantial solids deposition occurred at a flow rate of $161 \mathrm{gpm}$ and below, where 3-inch deposition height in an 8-inch pipe is defined as substantial solids deposition, and 2) it is conceivable that a complete flow blockage is possible under certain conditions

o At the slope of 1:50,1) substantial solids deposition occurred at a flow rate of 93 gpm and below and 2) small amounts of solids deposition occurred at the flow rate of $115 \mathrm{gpm}$

o At the slope of 1:20, no deposition occurred at any of the flow rates used in the testing

o For all three slopes, removing the deposited particles from the pipe surface was difficult; therefore, it is recommended to assure that the overflow channel system is thoroughly flushed out after a vessel-overflow event

- From the flush tests, it was found that a flush-to-line volume ratio of 3 was needed to remove sediment beds from the flow-loop system with the gravity-feed and process-drain test spool whereas design-guide 24590-WTP-GPG-M-0058, Rev. 0 (Hall 2006) provides a minimum flush-volume ratio of 1.7 for non-Newtonian fluids. The design-guide appears to be satisfied for the jumper test spool, the complex-geometry test spool, and the reducer and vertical-rise test spool. For all of the test spools, the flushing operations were performed with the following caveats:

o The pneumatic flush system must be opened slowly to erode the sediment bed from the top down. If the pneumatic flush system is opened quickly, the sediment bed is simply pushed to the nearest corner, and a granular plug develops and completely fills the line cross-sectional area. 
o The design guide values for flush volume and flush velocity were difficult to achieve manually. Depending on the process-line geometry, flows in the range of 500 to 1,000 gpm can be achieved with this system. Since the piping volumes may be on the order of 50 to 100 gallons, manually closing a valve to hit this target volume may be challenging. Compounding this problem, valves need to be closed slowly to avoid water hammer.

A definite profile of the J-curve was not obtained in this testing due to high uncertainty in the DPT data. The following are considered sources of the uncertainty:

o The uncorrected DPT data include the hydrostatic pressure due to gravity that varies over a test run since the density changes as the flow velocity changes. The density change is considered to be significant in the lower-velocity region, possibly due to the slurry-particle deposition.

o Complex slurry flow is expected in the immediate vicinity of the pressure ports produced by the geometry of the modular component and considered to cause the high fluctuations in DPT data.

o High uncertainty in the corrected DPT data is expected since the slurry density was measured at a position well upstream of the modular test section and considered to be different, especially in low velocity conditions, from the density at the pressure ports. In addition, the expected complex slurry flow structure produced by the geometry of the modular component might cause density variations. 


\subsection{References}

10 CFR 830. "Nuclear Safety Management." Code of Federal Regulations, U.S. Department of Energy.

Bechtel National, Inc. (BNI). 2007. Evaluation of Waste Slurry Critical Velocity and Line Flush

Capabilities in WTP Process Piping. 24590-WTP-TSP-RT-07-005, Rev. 0, BNI, Richland, Washington.

DOE Order 414.1C. 2005. “Quality Assurance.” U.S. Department of Energy, Washington, D.C.

Donoso ED. 2007. Vessel Overflow and Gravity Line Sizing. WTP Project Doc. No. 24590-WTP-GPGM-032, Rev. 3, Bechtel National, Inc., Richland, Washington.

Hall MN. 2006. Minimum Flow Velocity for Slurry Lines. WTP Project Doc. No. 24590-WTP-GPG-M0058, Rev. 0, Bechtel National, Inc., Richland, Washington.

Hall MN. 2007. Pipe Sizing for Lines with Liquids Containing Solids-Bingham Plastic Model. WTP Project Doc. No. 24590-WTP-GPG-M-016, Rev. 2, Bechtel National, Inc., Richland, Washington.

Kloster G. 2007. Recommended Slopes for Piping Systems. WTP Project Doc. No. 24590-WTP-GPG-M027, Rev. 5, Bechtel National, Inc., Richland, Washington.

Poloski AP. 2007. M1/M6 Flow Loop Testing with Prototypic WTP Test Modules. TP-RPP-WTP-494, Rev. 0, Pacific Northwest National Laboratory, Richland, Washington.

Poloski AP, HE Adkins, J Abrefah, AM Casella, RE Hohimer, F Nigl, MJ Minette, JJ Toth, JM Tingey, and ST Yokuda. 2008. Deposition Velocities of Newtonian and Non-Newtonian Slurries in Pipelines. WTP-RPT-175, Rev. 0 (PNNL-17638), Pacific Northwest National Laboratory, Richland, Washington.

Smith GL, and K Prindiville. 2002. Guidelines for Performing Chemical, Physical, and Rheological Properties Measurements. 24590-WTP-GPG-RTD-001 Rev 0, Bechtel National, Inc., Richland, WA. 


\section{Appendix A: Gravity-Driven Partially-Filled Pipe Flow Test Condition Pictures}

Each picture in this Appendix is identified by location, slope, and velocity. The location is either "Upstream", referring to the upstream transparent section or "Downstream", referring to the downstream transparent section. The slope is either "1:125" which indicates that the picture comes from the first test, "1:20" which indicates that the picture comes from the second test, or "1:50" which indicates that the picture comes from the third test. The listed velocity indicates the velocity at which the slurry was

flowing through the pipe when the picture was taken. 


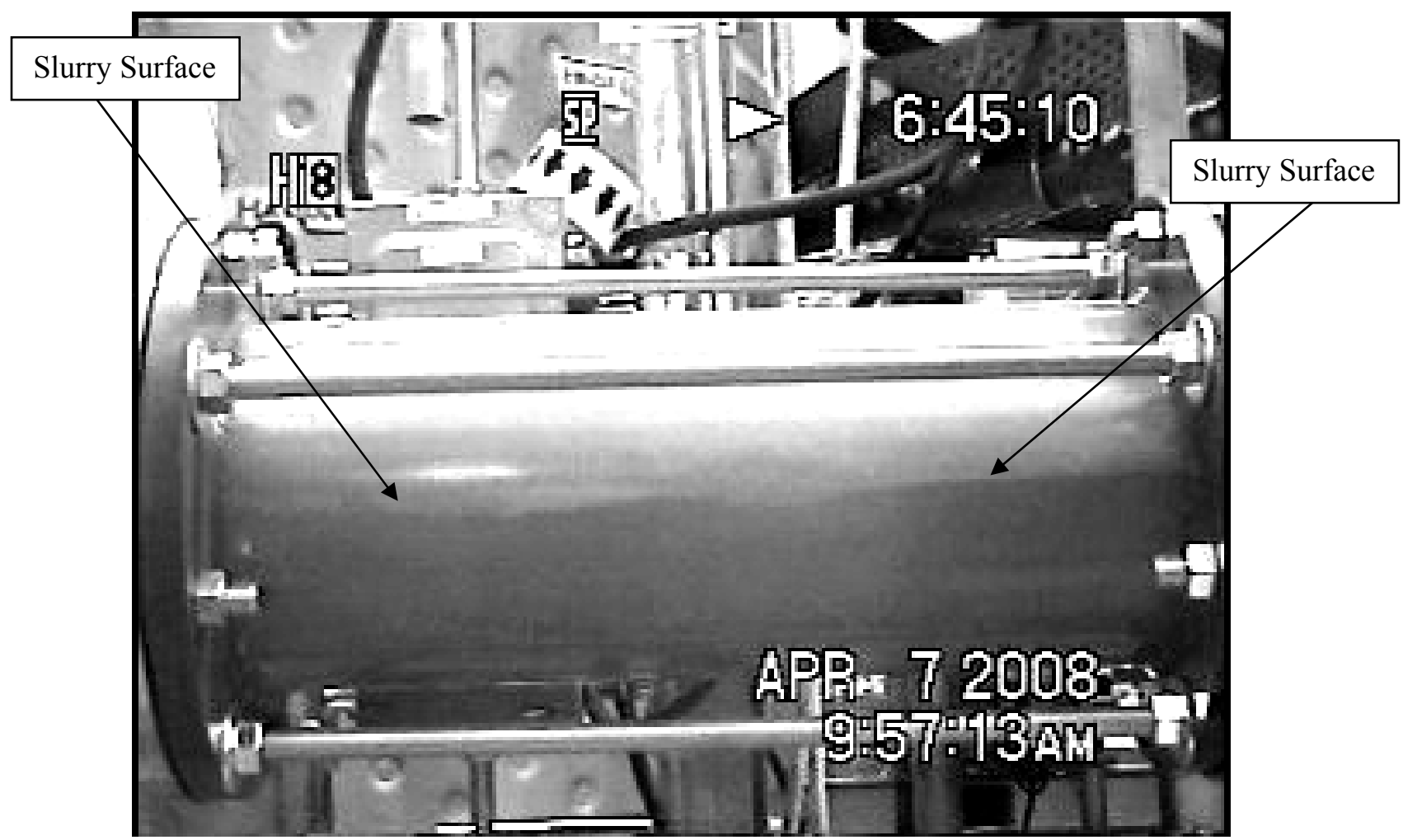

Figure A.1. Upstream, Slope $=1: 125$, Velocity $=8 \mathrm{ft} / \mathrm{s}$

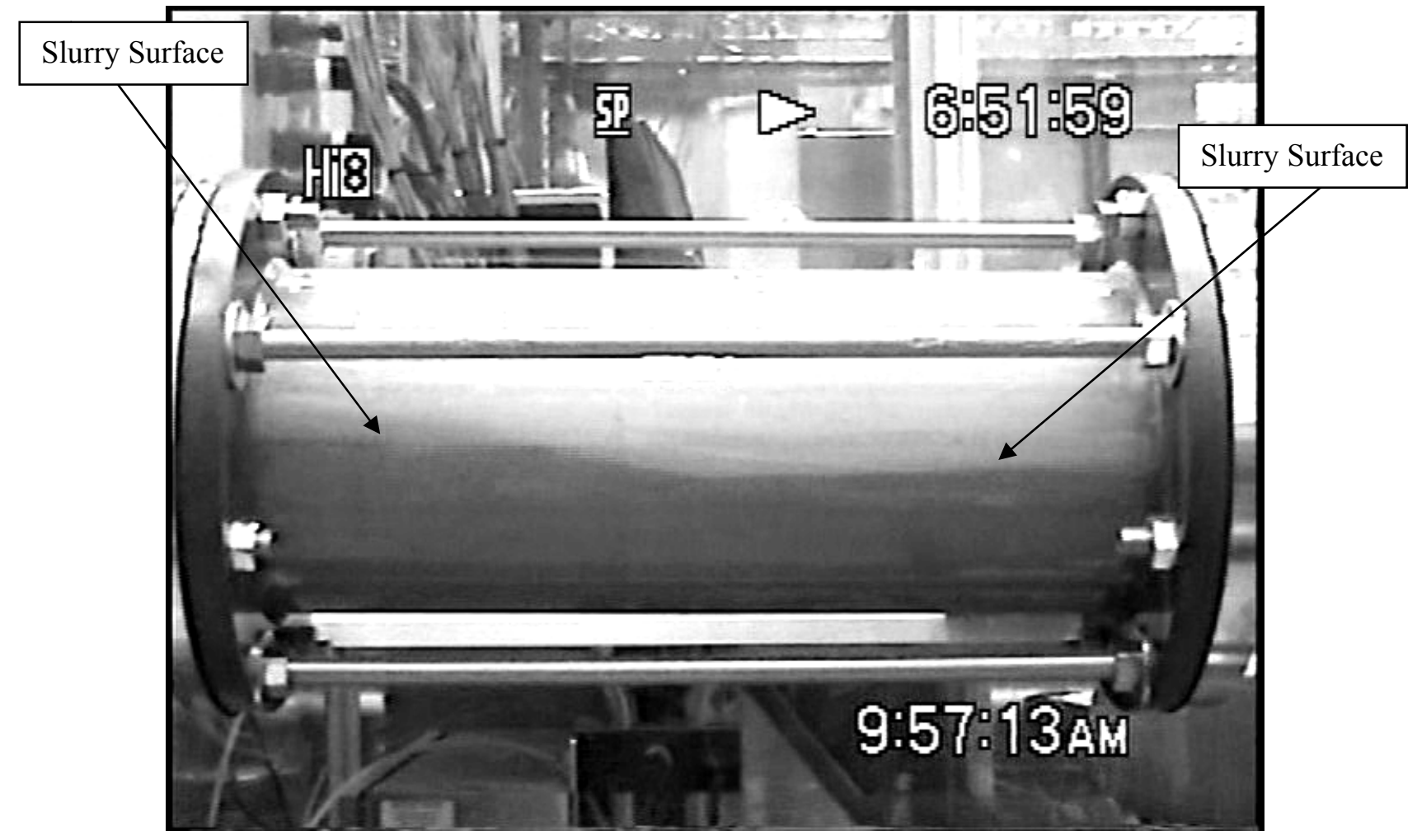

Figure A.2. Downstream, Slope $=1: 125$, Velocity $=8 \mathrm{ft} / \mathrm{s}$ 


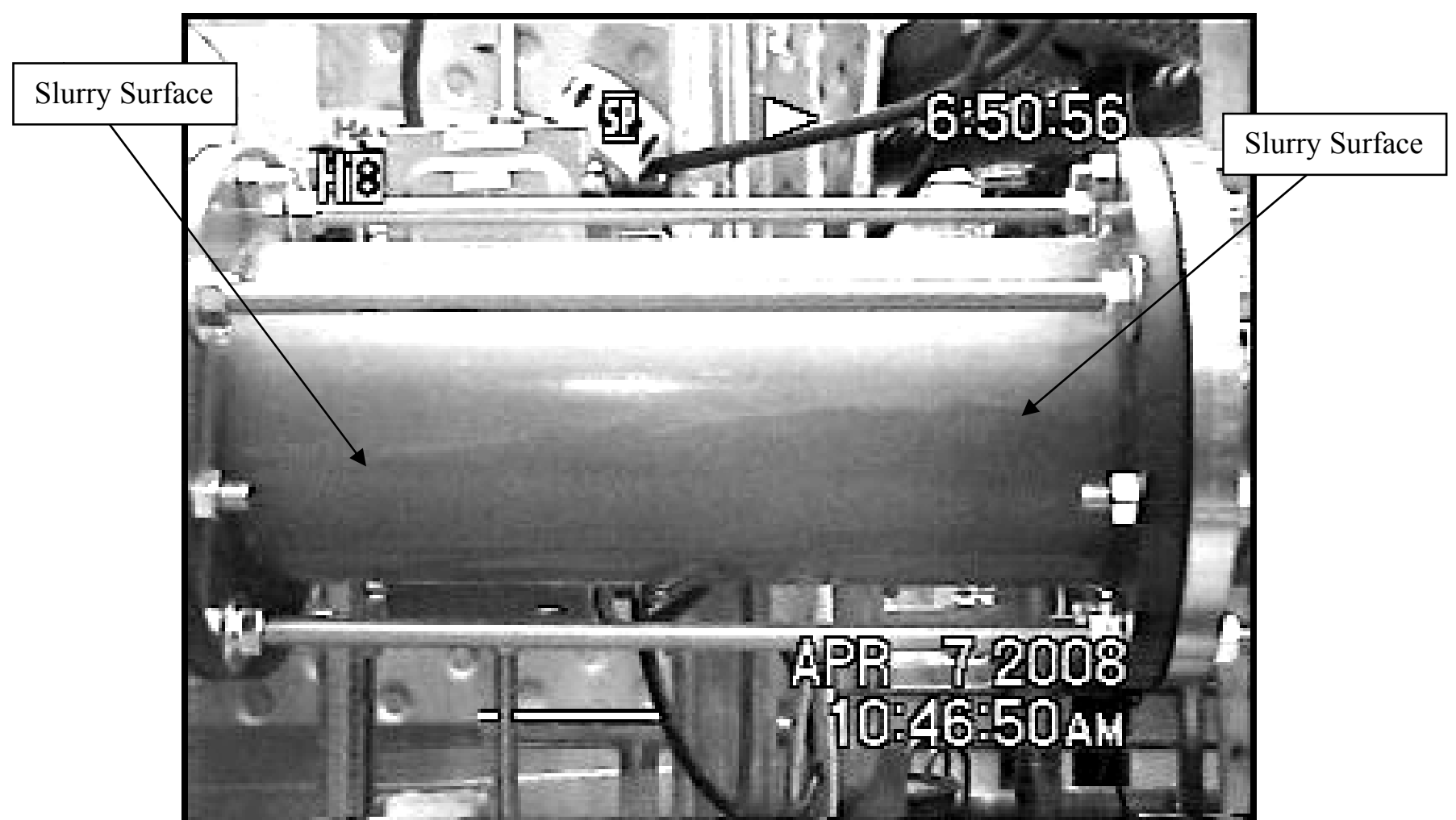

Figure A.3. Upstream, Slope $=1: 125$, Velocity $=7.5 \mathrm{ft} / \mathrm{s}$

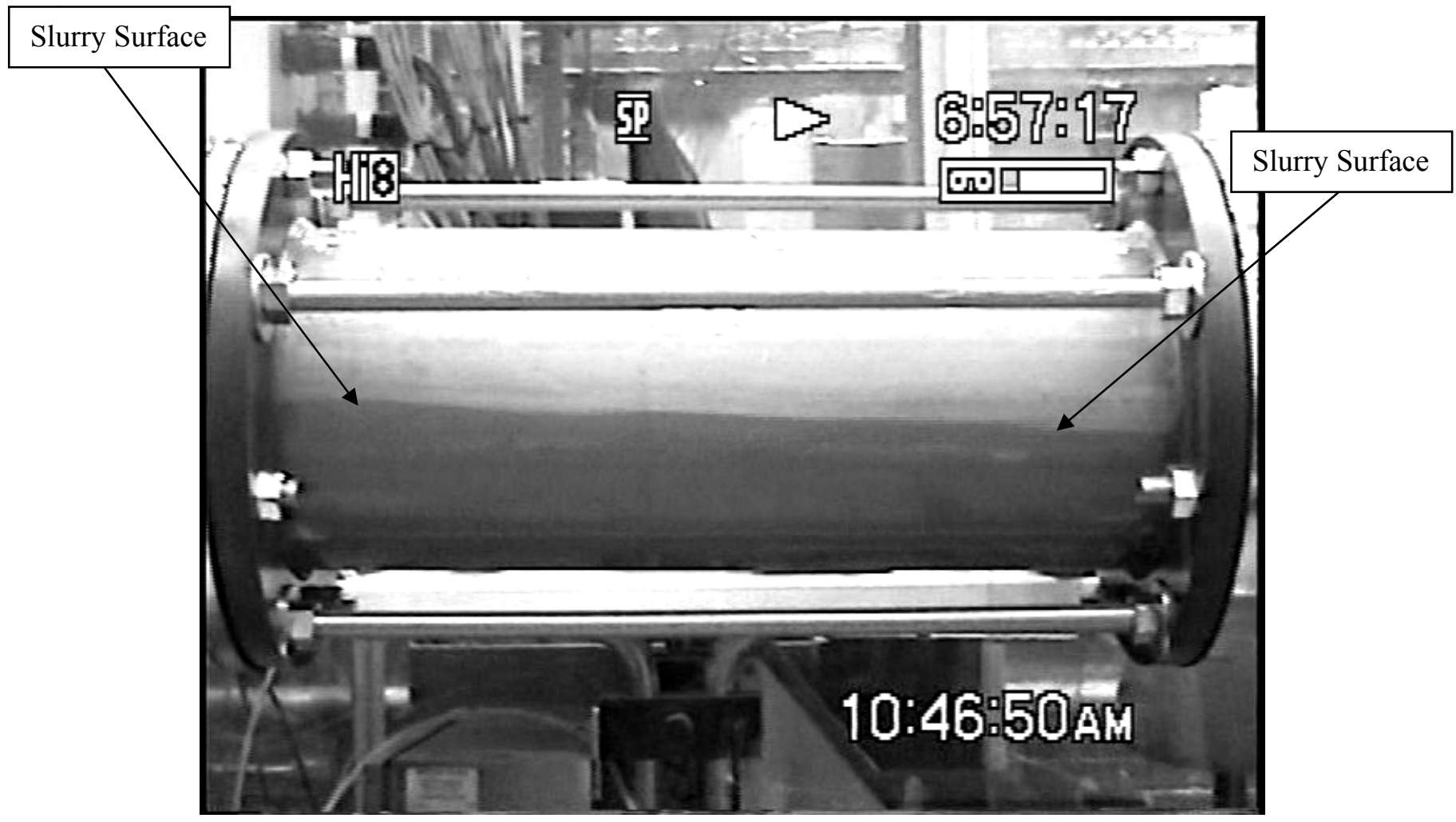

Figure A.4. Downstream, Slope $=1: 125$, Velocity $=7.5 \mathrm{ft} / \mathrm{s}$ 


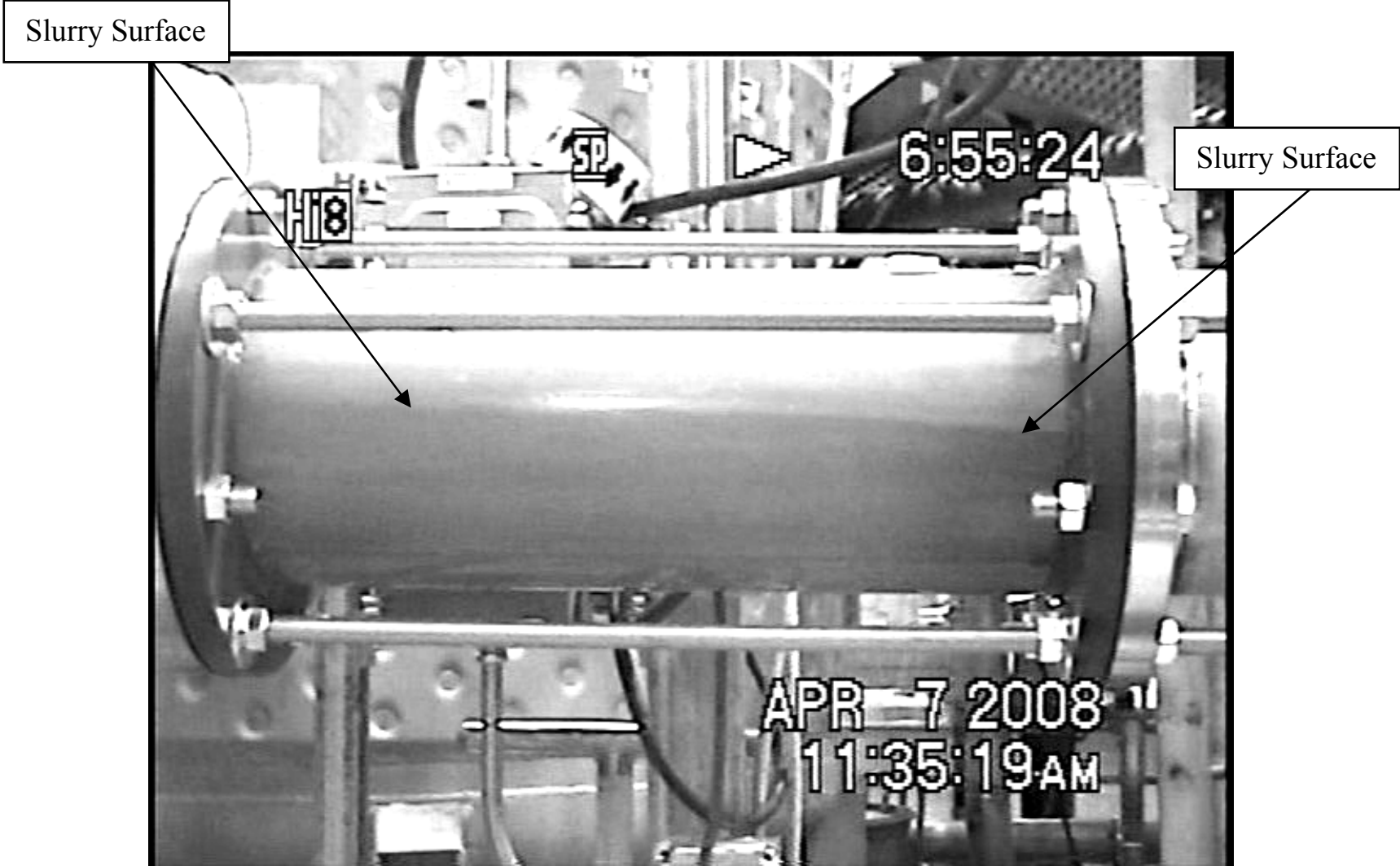

Figure A.5. Upstream, Slope $=1: 125$, Velocity $=7.0 \mathrm{ft} / \mathrm{s}$

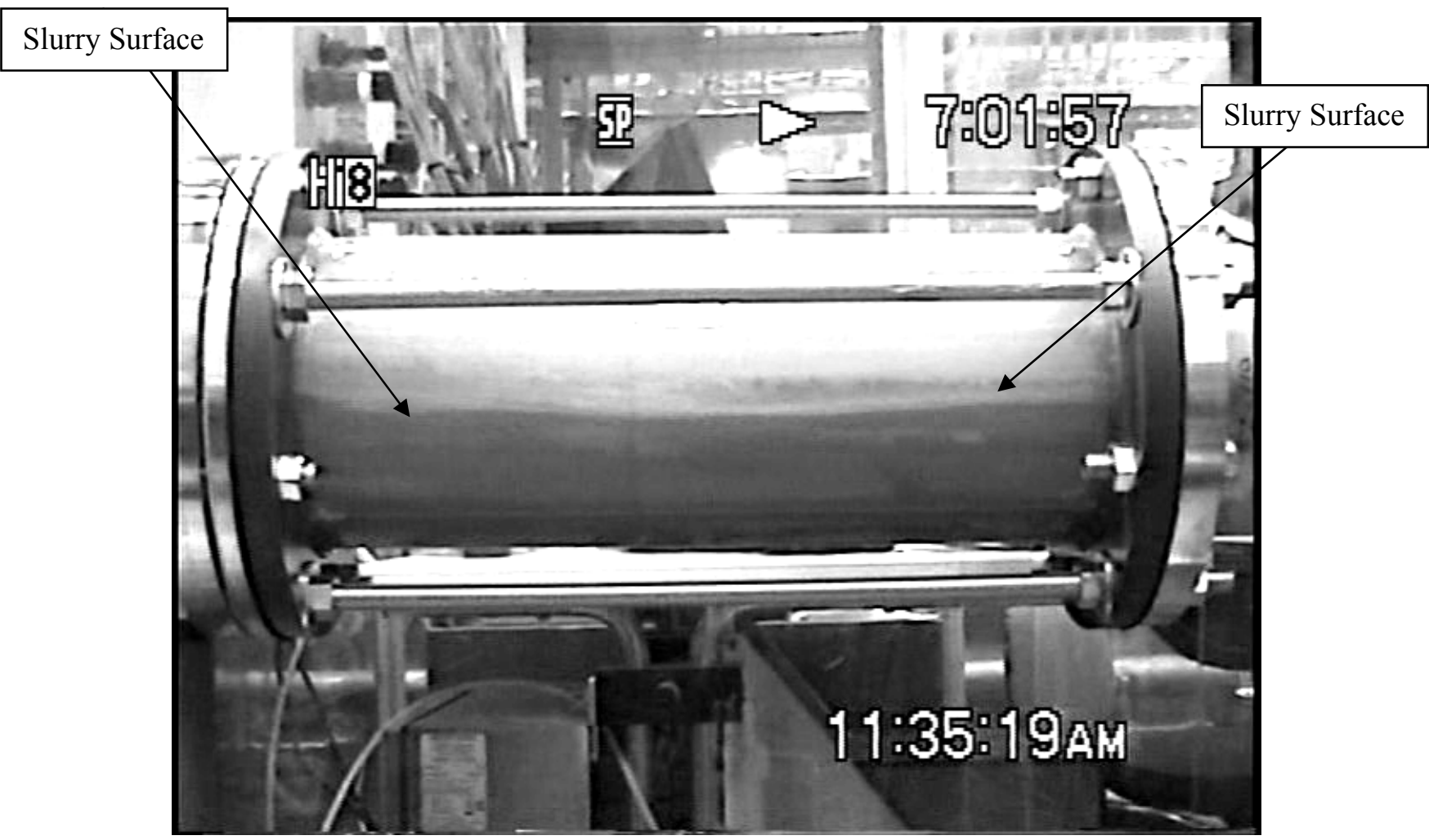

Figure A.6. Downstream, Slope $=1: 125$, Velocity $=7.0 \mathrm{ft} / \mathrm{s}$ 


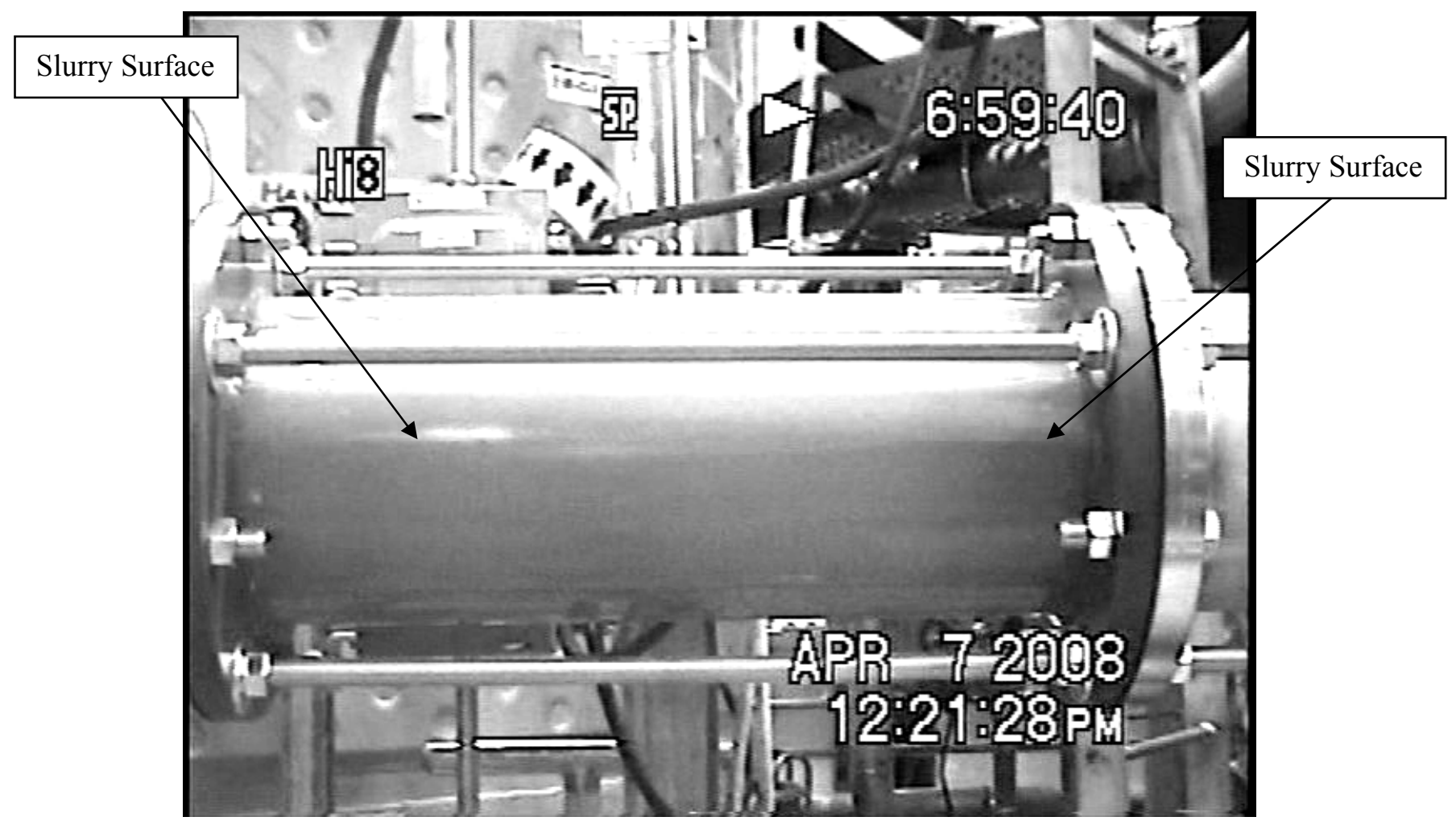

Figure A.7. Upstream, Slope $=1: 125$, Velocity $=6.5 \mathrm{ft} / \mathrm{s}$

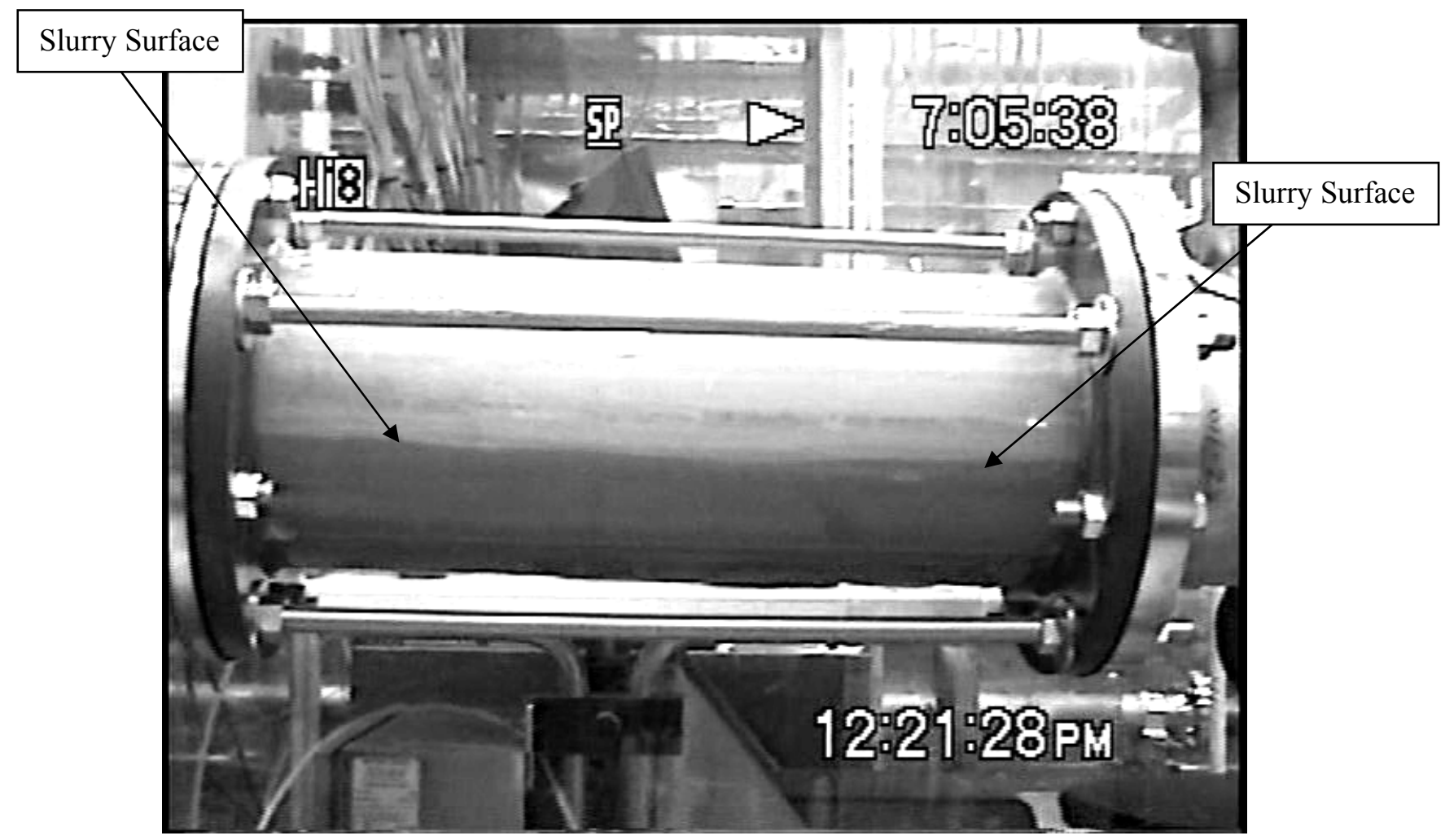

Figure A.8. Downstream, Slope $=1: 125$, Velocity $=6.5 \mathrm{ft} / \mathrm{s}$ 

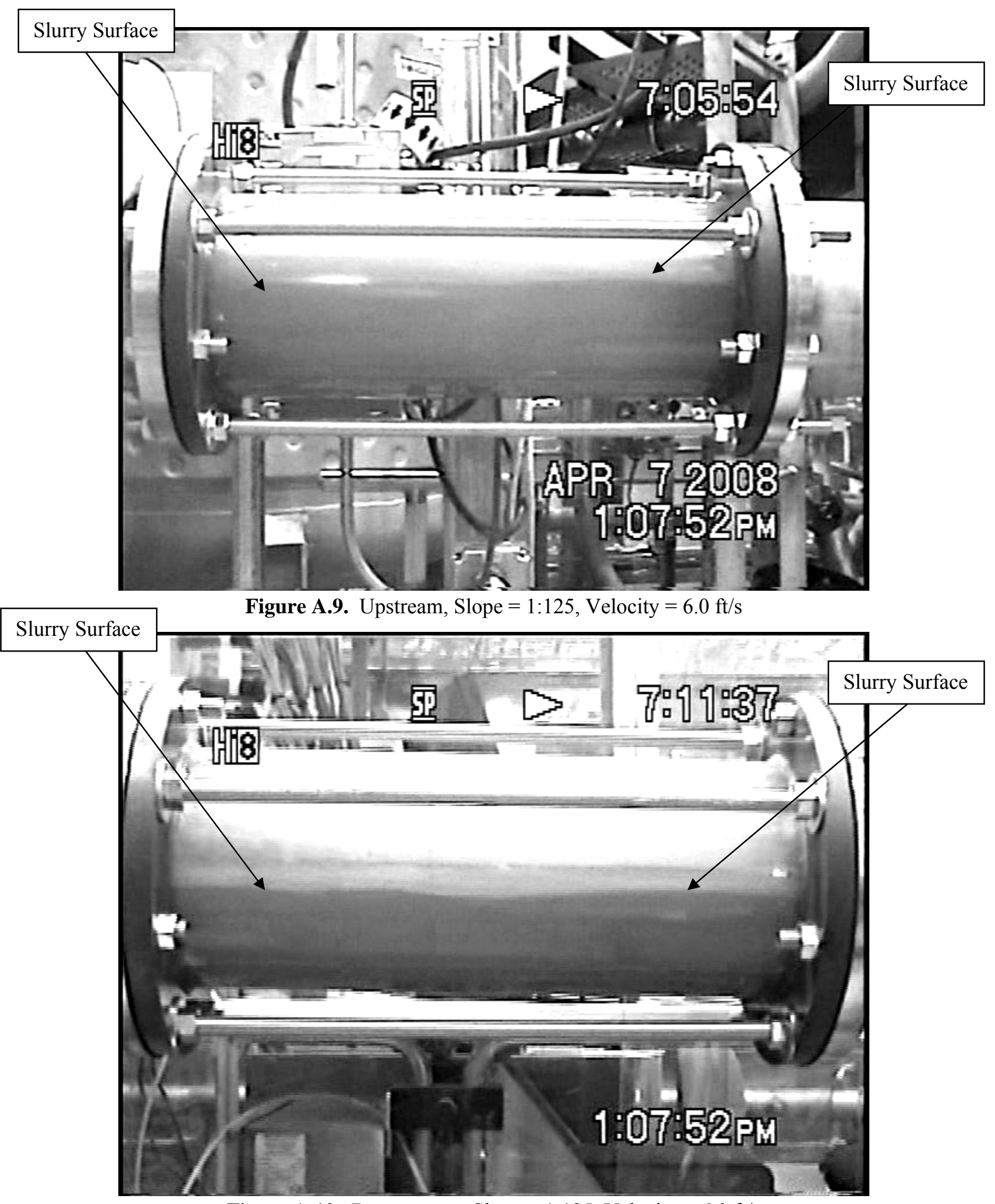

Figure A.10. Downstream, Slope $=1: 125$, Velocity $=6.0 \mathrm{ft} / \mathrm{s}$ 


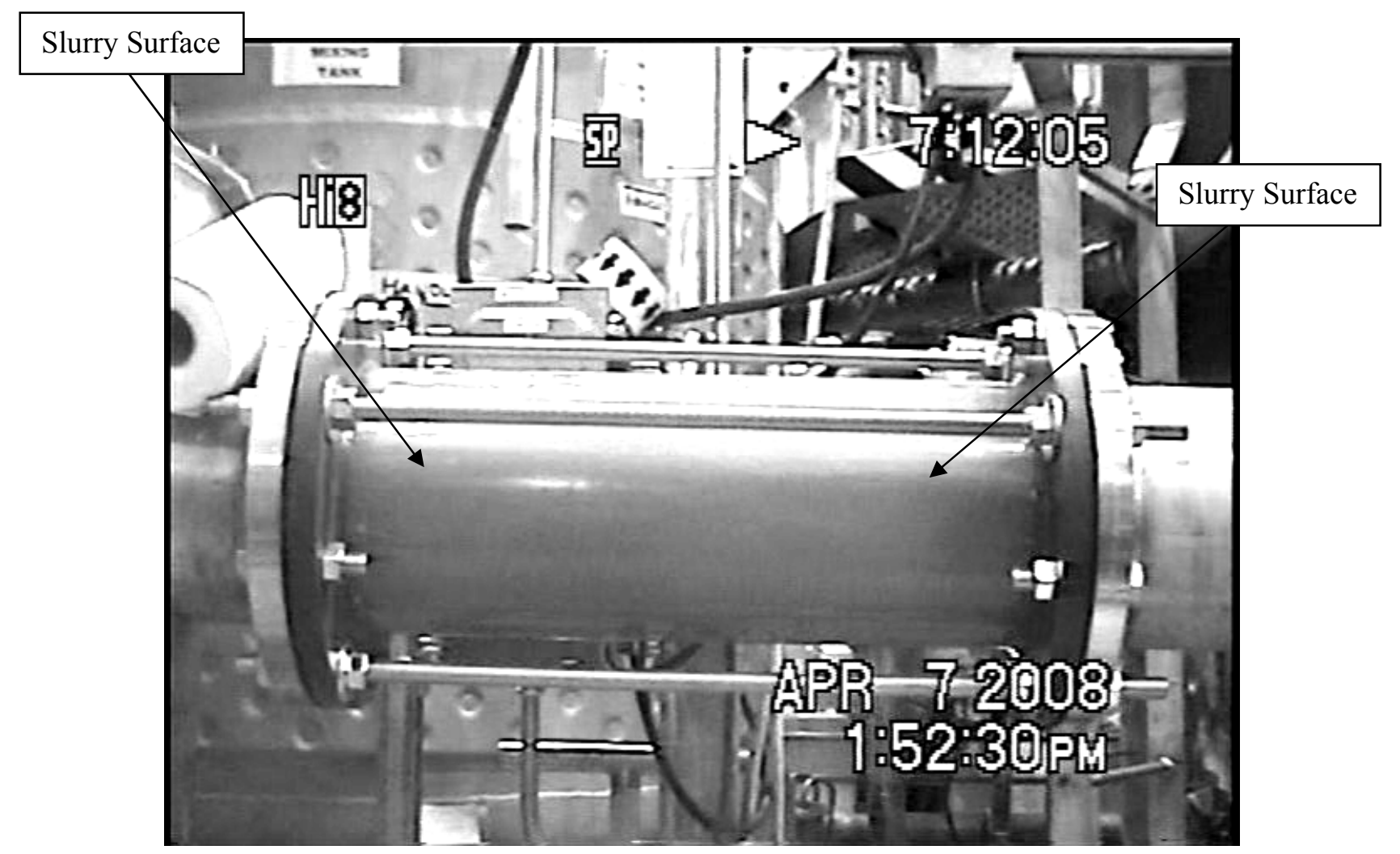

Figure A.11. Upstream, Slope $=1: 125$, Velocity $=5.5 \mathrm{ft} / \mathrm{s}$

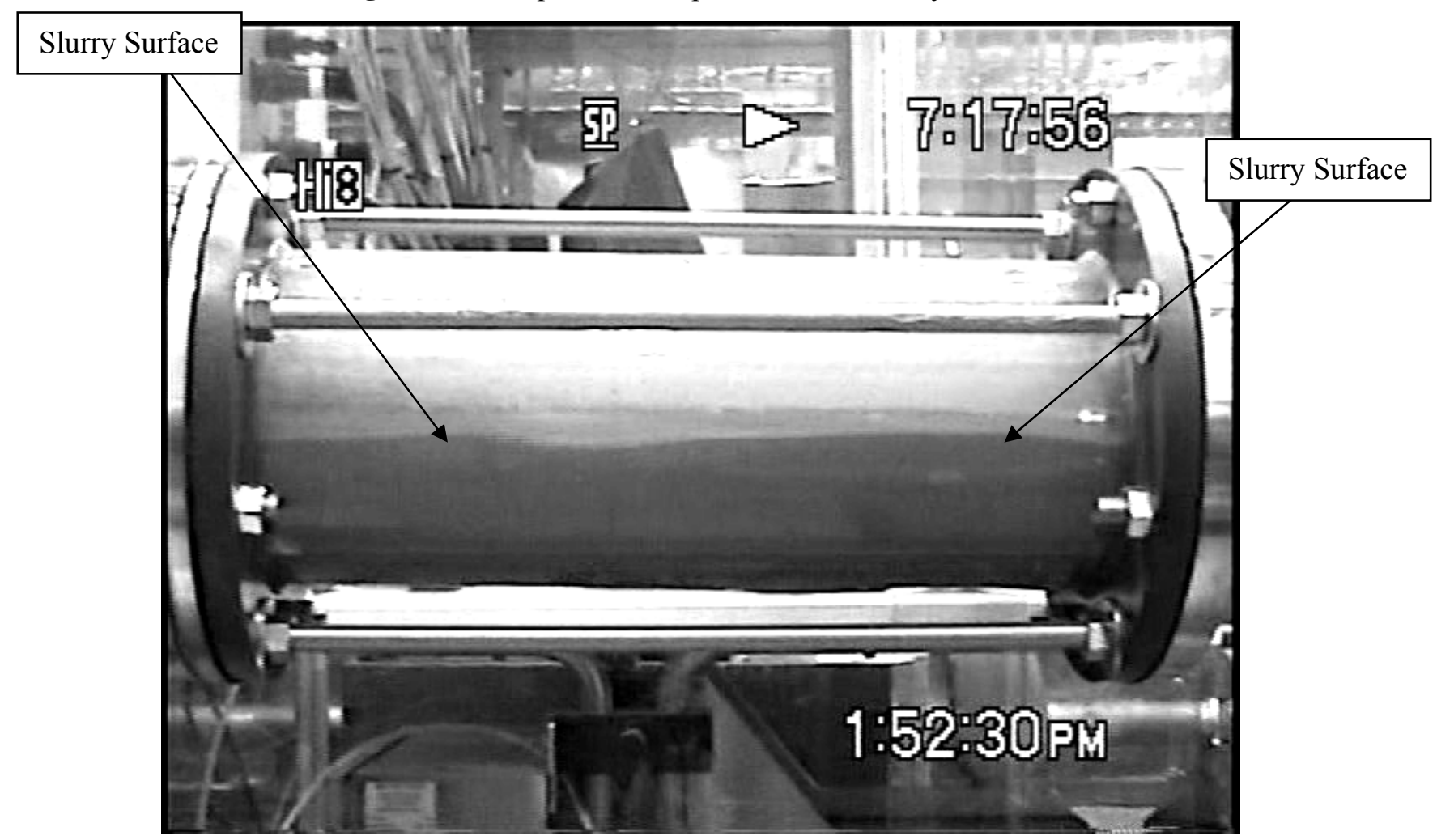

Figure A.12. Downstream, Slope $=1: 125$, Velocity $=5.5 \mathrm{ft} / \mathrm{s}$ 


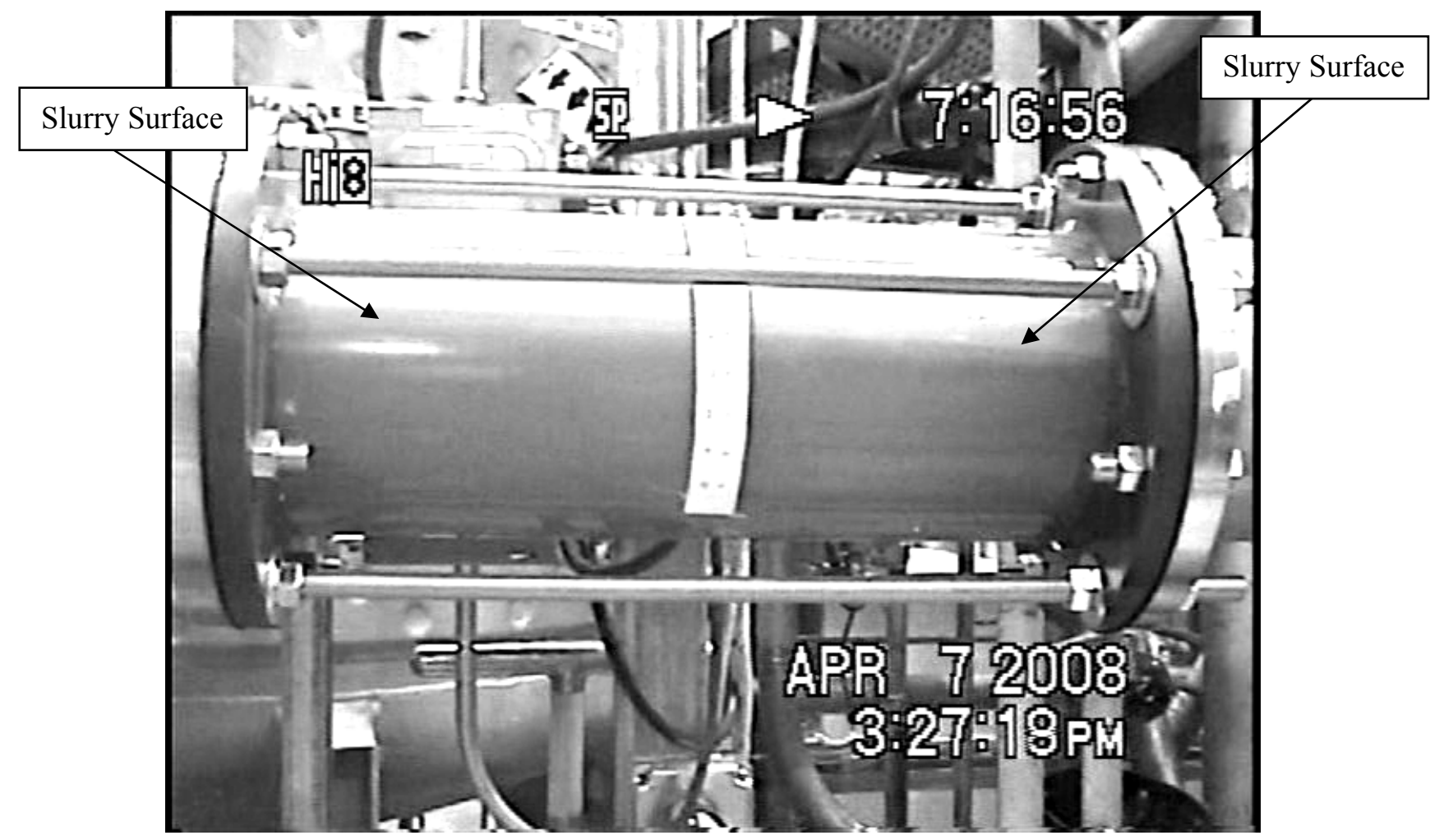

Figure A.13. Upstream, Slope $=1: 125$, Velocity $=5.0 \mathrm{ft} / \mathrm{s}$

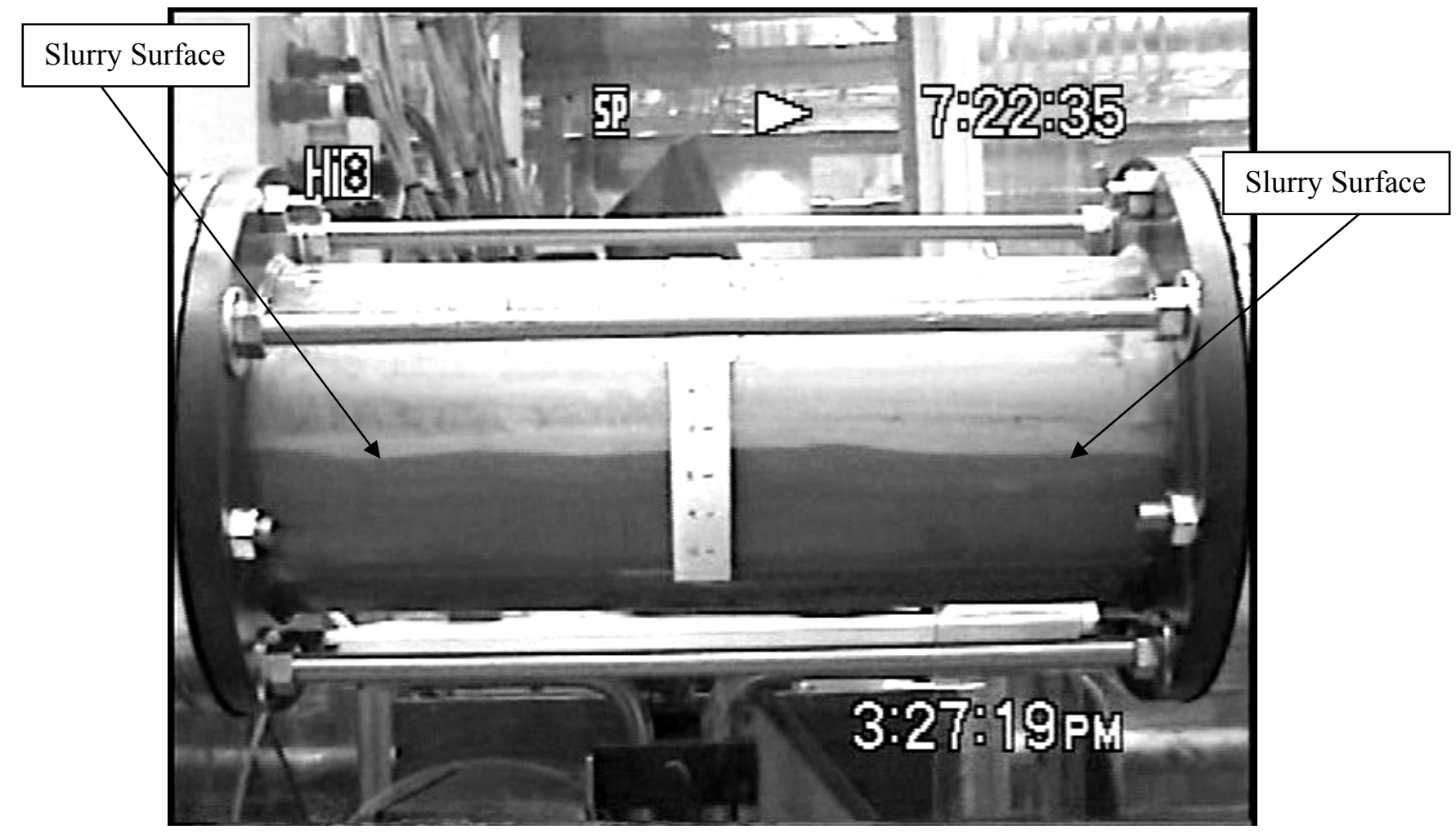

Figure A.14. Downstream, Slope $=1: 125$, Velocity $=5.0 \mathrm{ft} / \mathrm{s}$ 


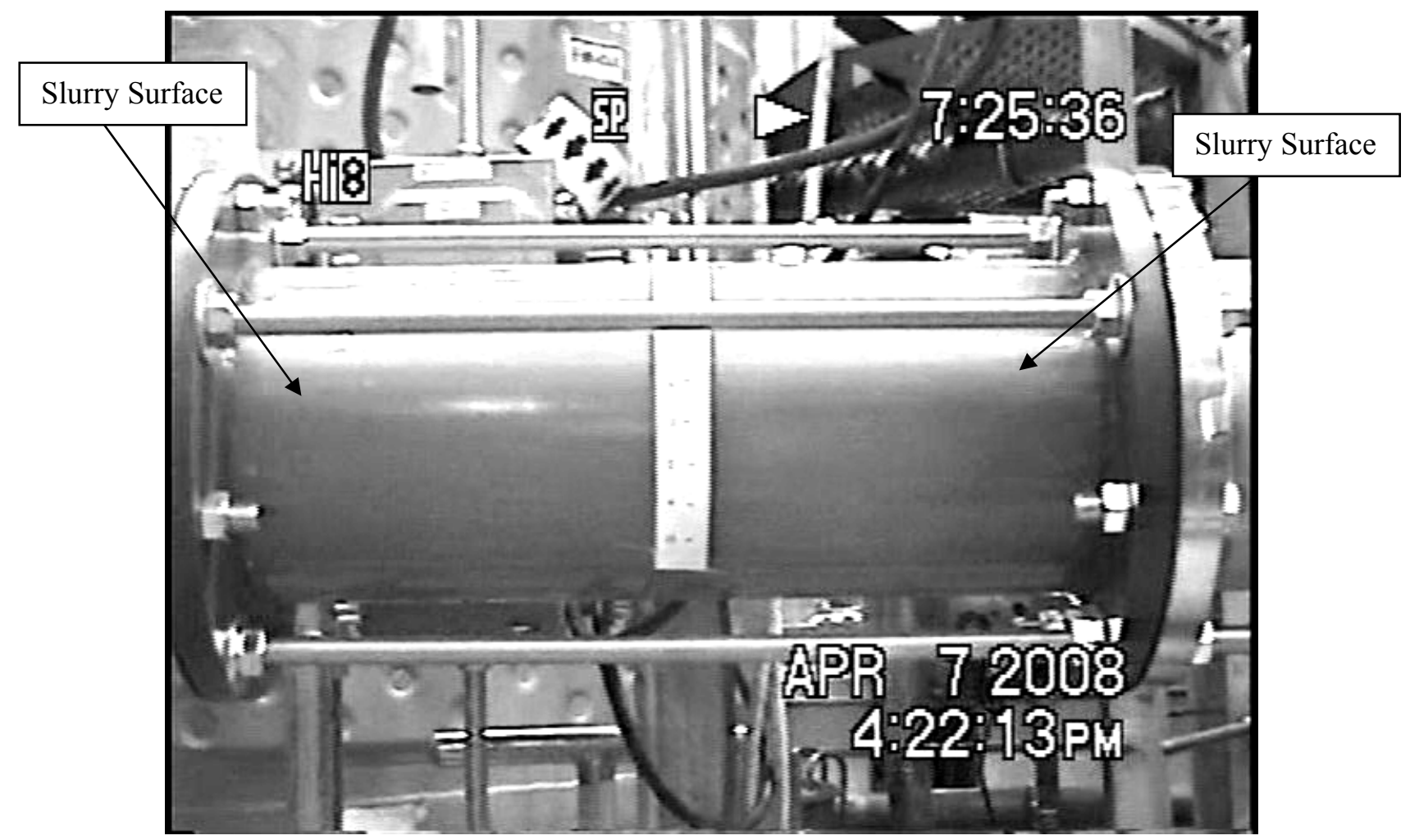

Figure A.15. Upstream, Slope $=1: 125$, Velocity $=4.5 \mathrm{ft} / \mathrm{s}$

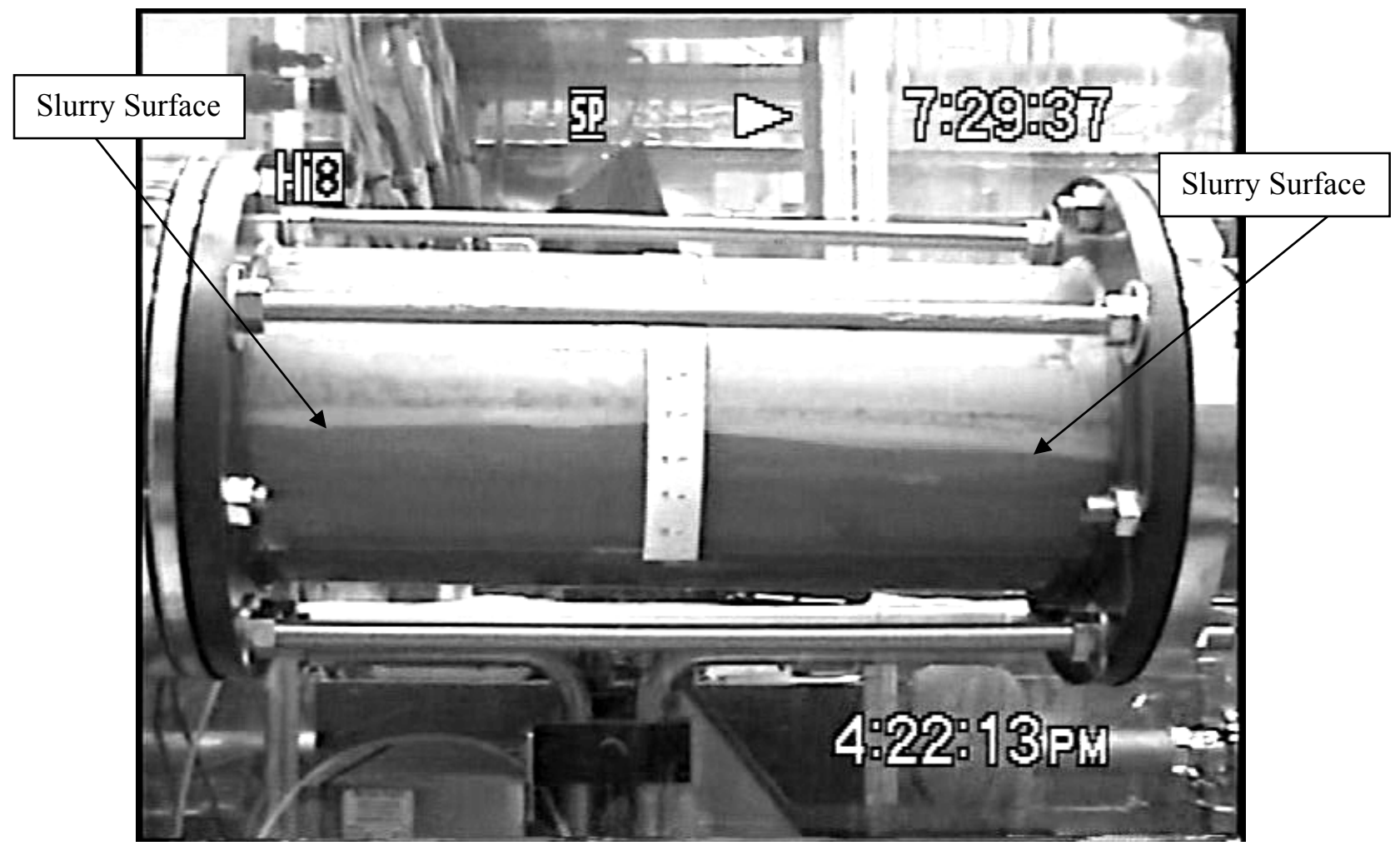

Figure A.16. Downstream, Slope $=1: 125$, Velocity $=4.5 \mathrm{ft} / \mathrm{s}$ 


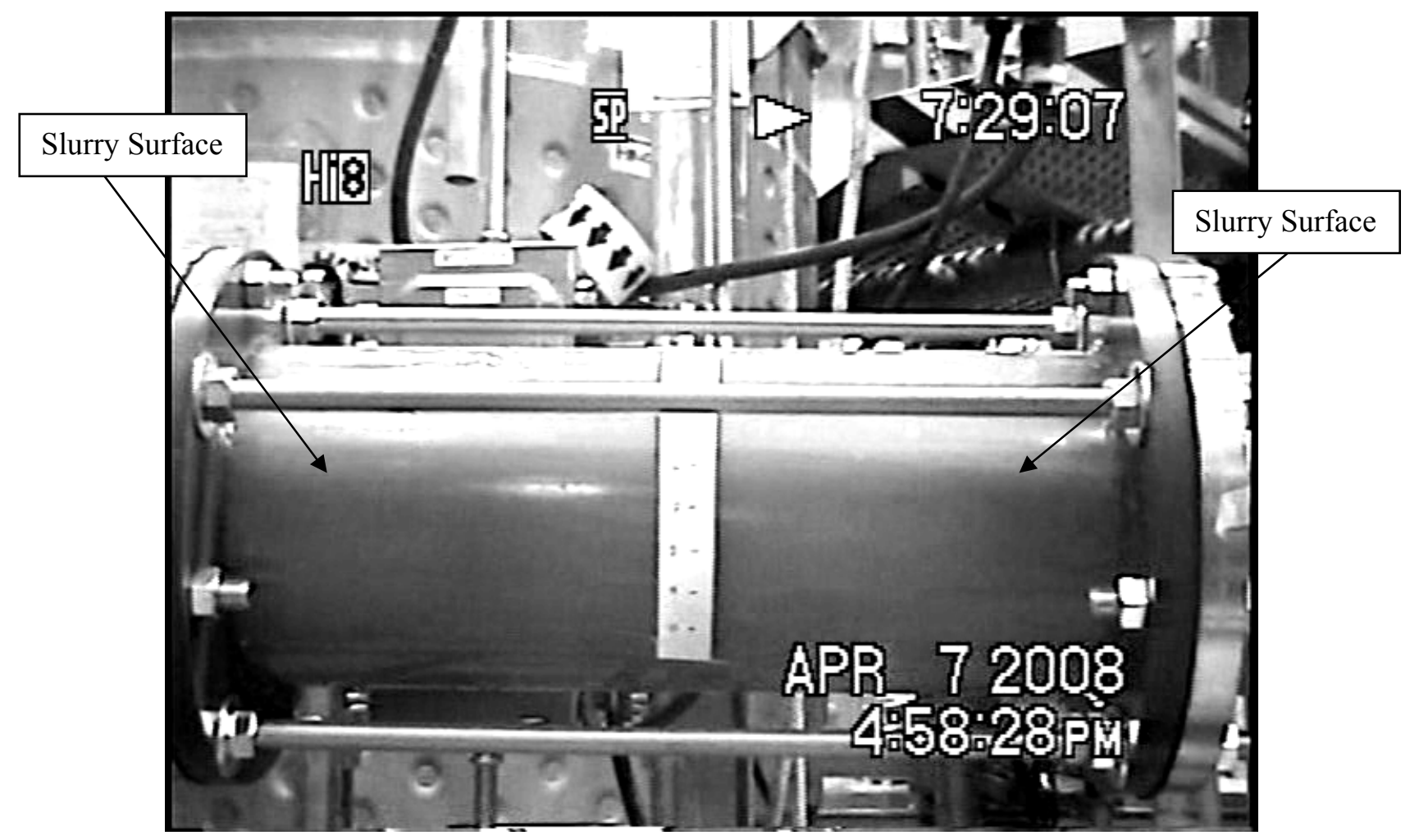

Figure A.17. Upstream, Slope $=1: 125$, Velocity $=4.0 \mathrm{ft} / \mathrm{s}$

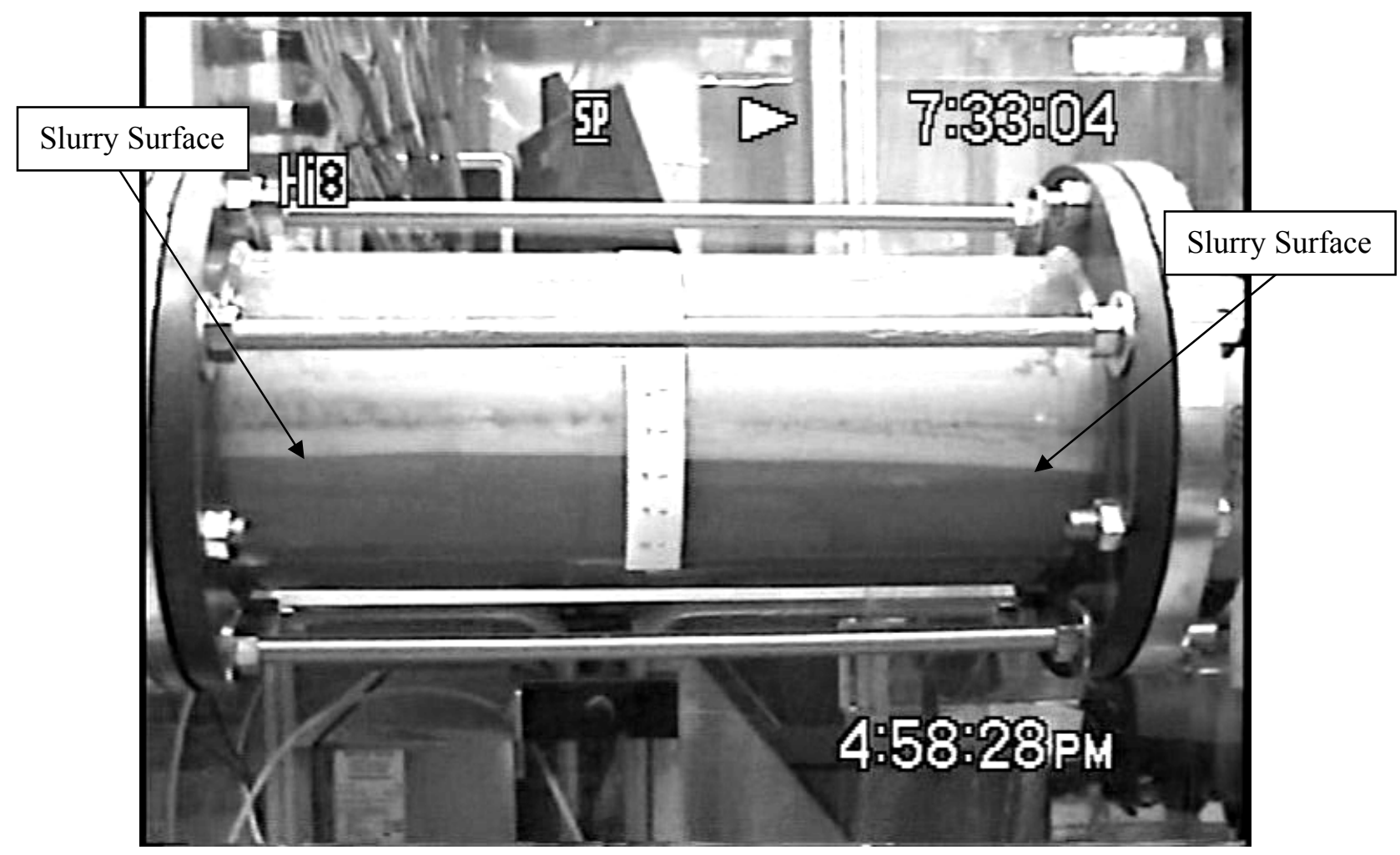

Figure A.18. Downstream, Slope $=1: 125$, Velocity $=4.0 \mathrm{ft} / \mathrm{s}$ 


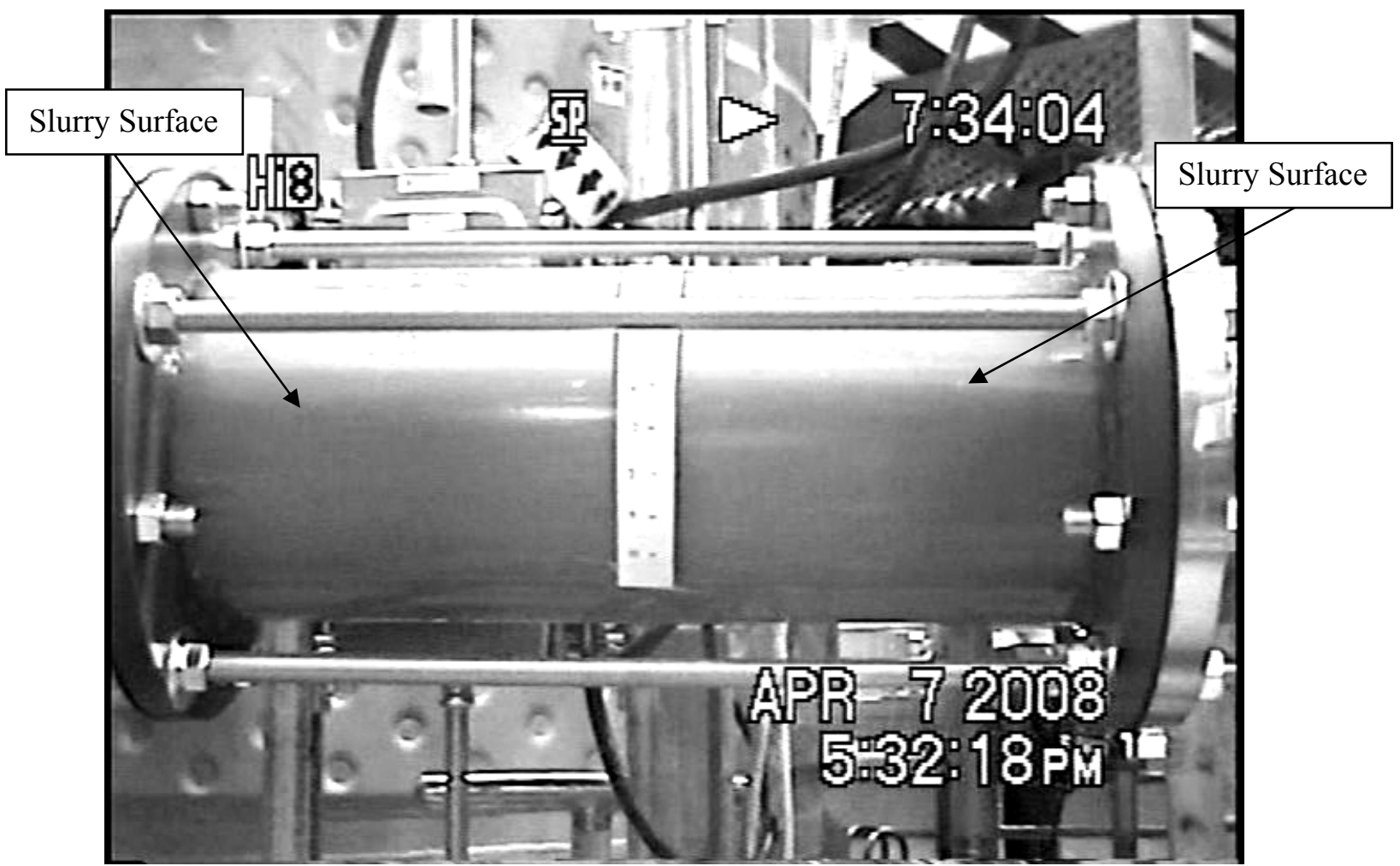

Figure A.19. Upstream, Slope $=1: 125$, Velocity $=3.5 \mathrm{ft} / \mathrm{s}$

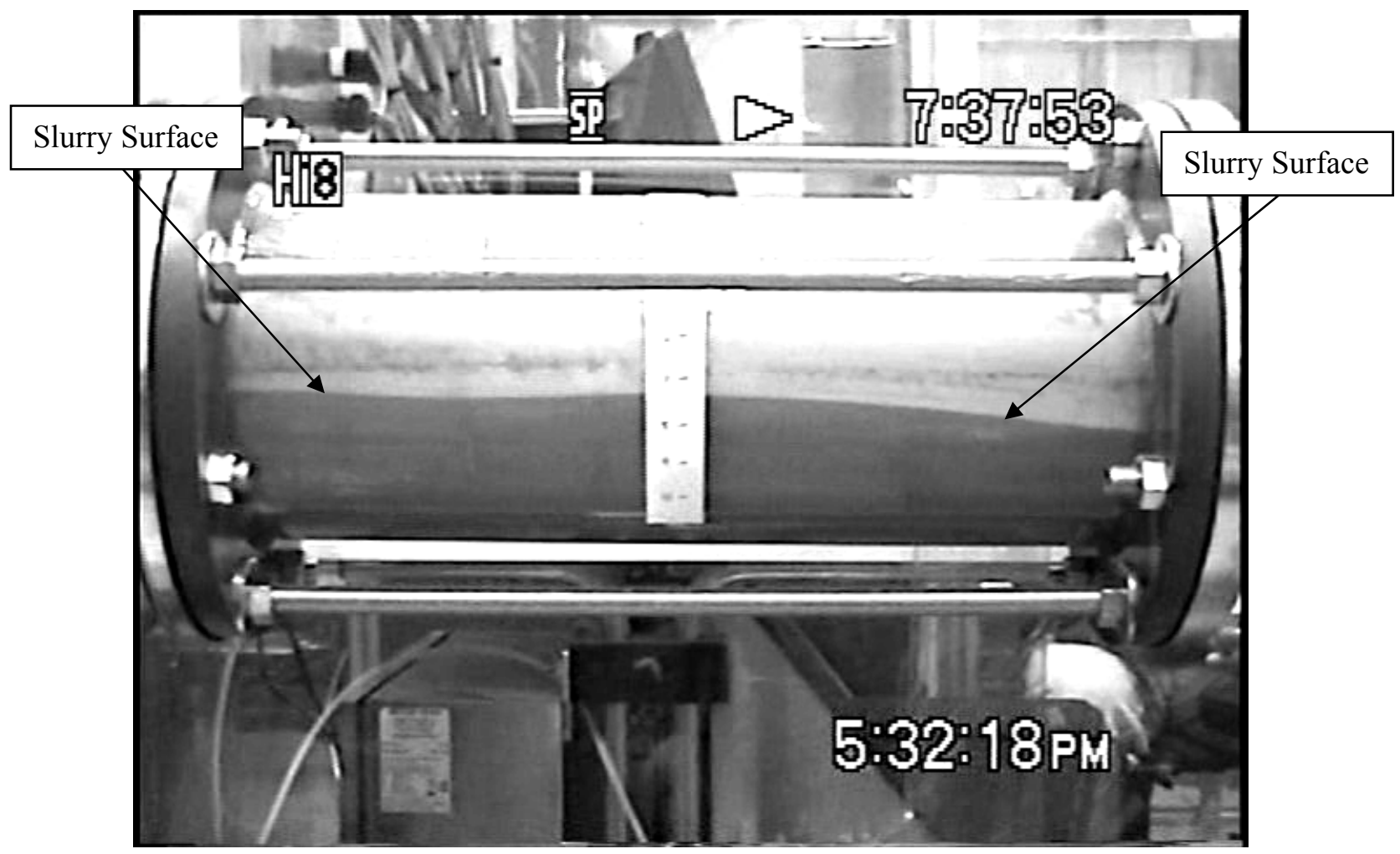

Figure A.20. Downstream, Slope $=1: 125$, Velocity $=3.5 \mathrm{ft} / \mathrm{s}$ 


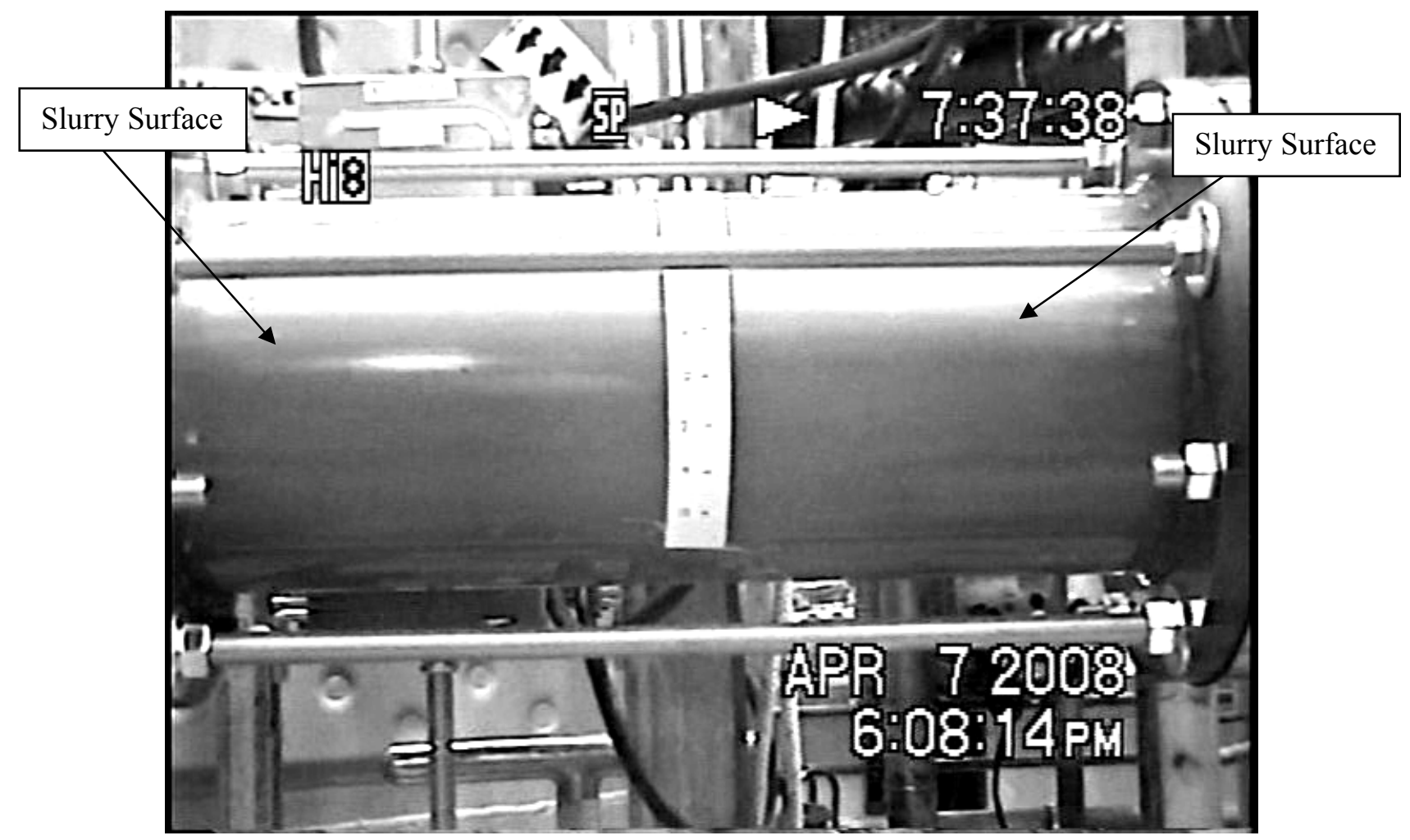

Figure A.21. Upstream, Slope $=1: 125$, Velocity $=3.0 \mathrm{ft} / \mathrm{s}$

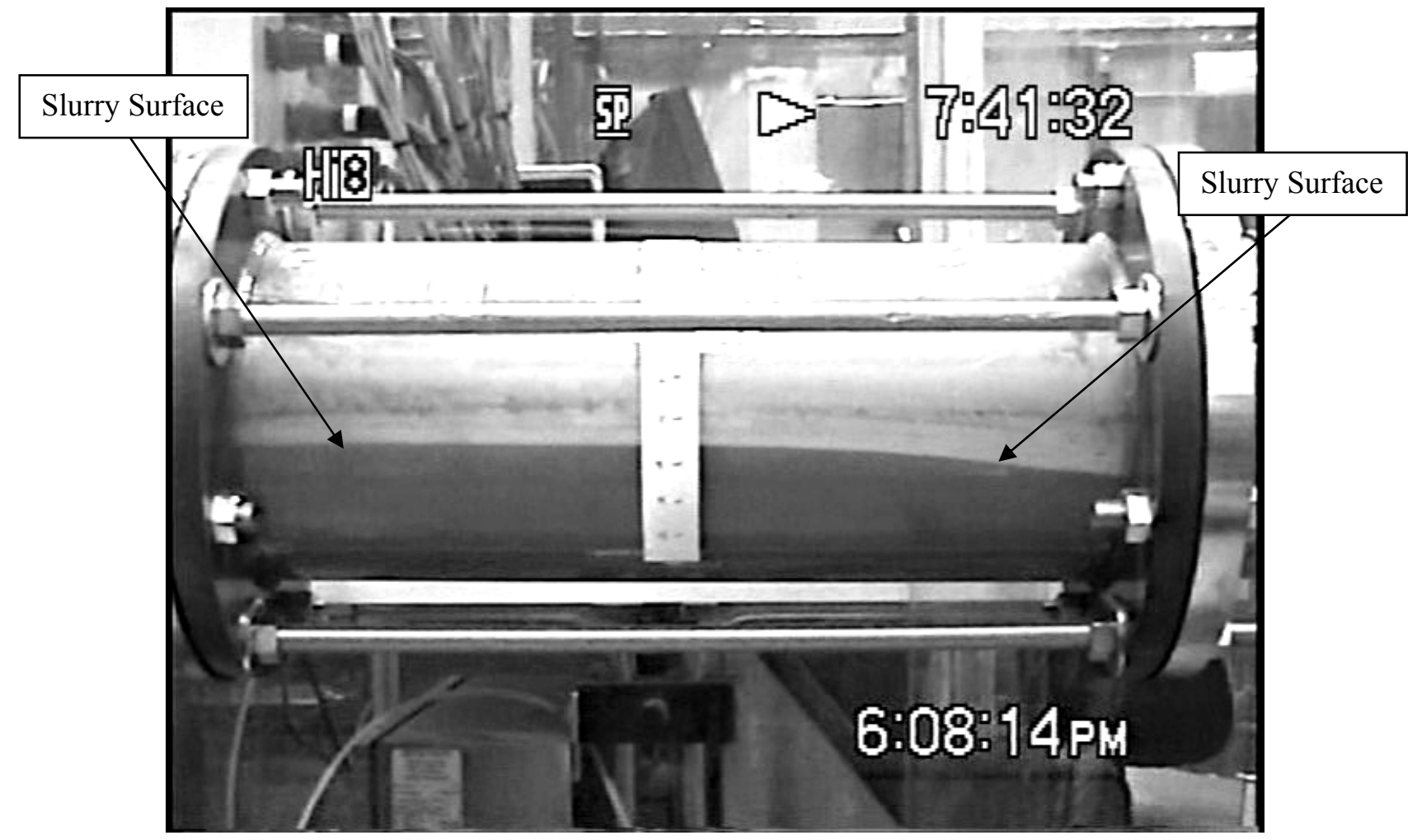

Figure A.22. Downstream, Slope $=1: 125$, Velocity $=3.0 \mathrm{ft} / \mathrm{s}$ 


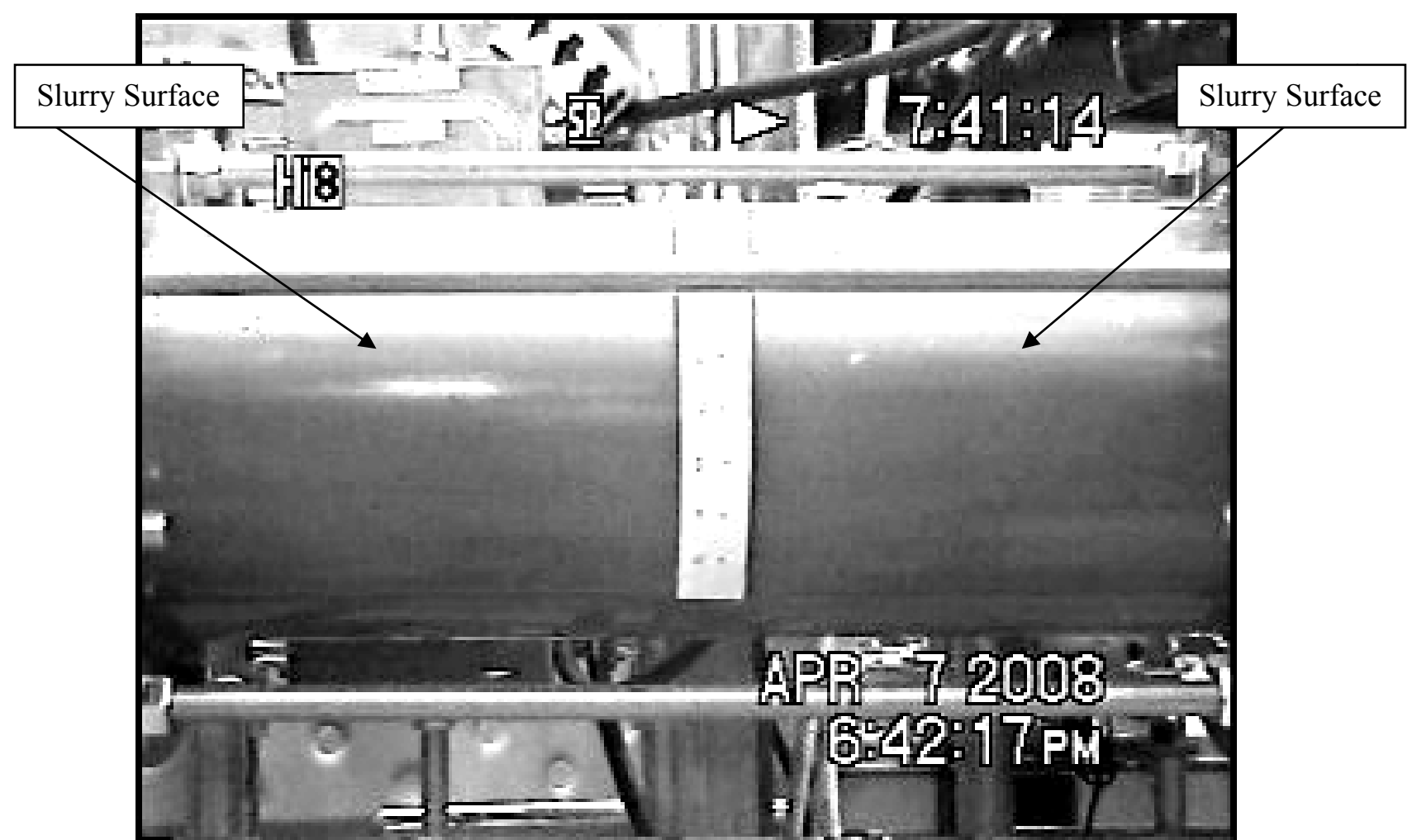

Figure A.23. Upstream, Slope $=1: 125$, Velocity $=2.5 \mathrm{ft} / \mathrm{s}$

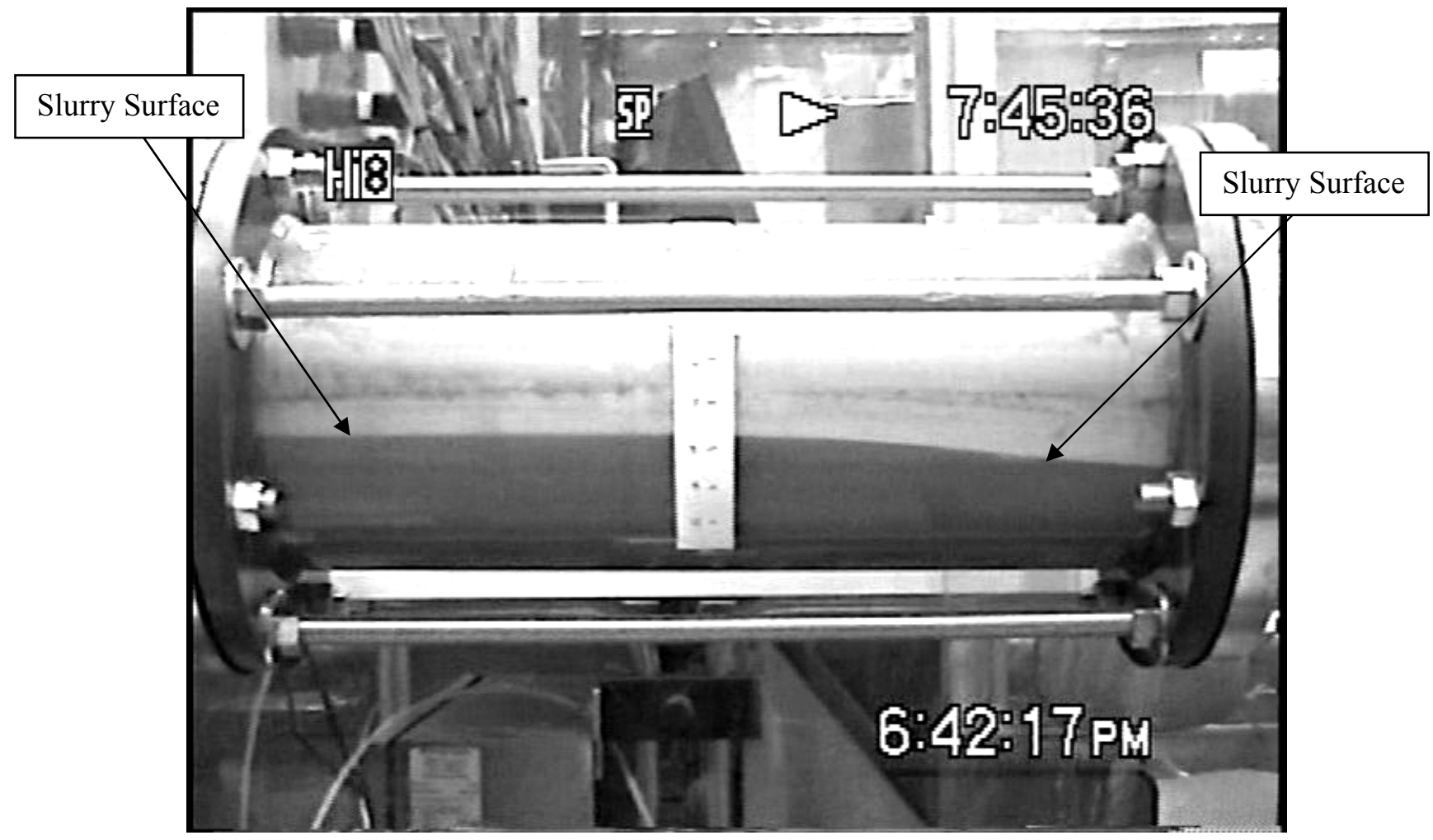

Figure A.24. Downstream, Slope $=1: 125$, Velocity $=2.5 \mathrm{ft} / \mathrm{s}$ 


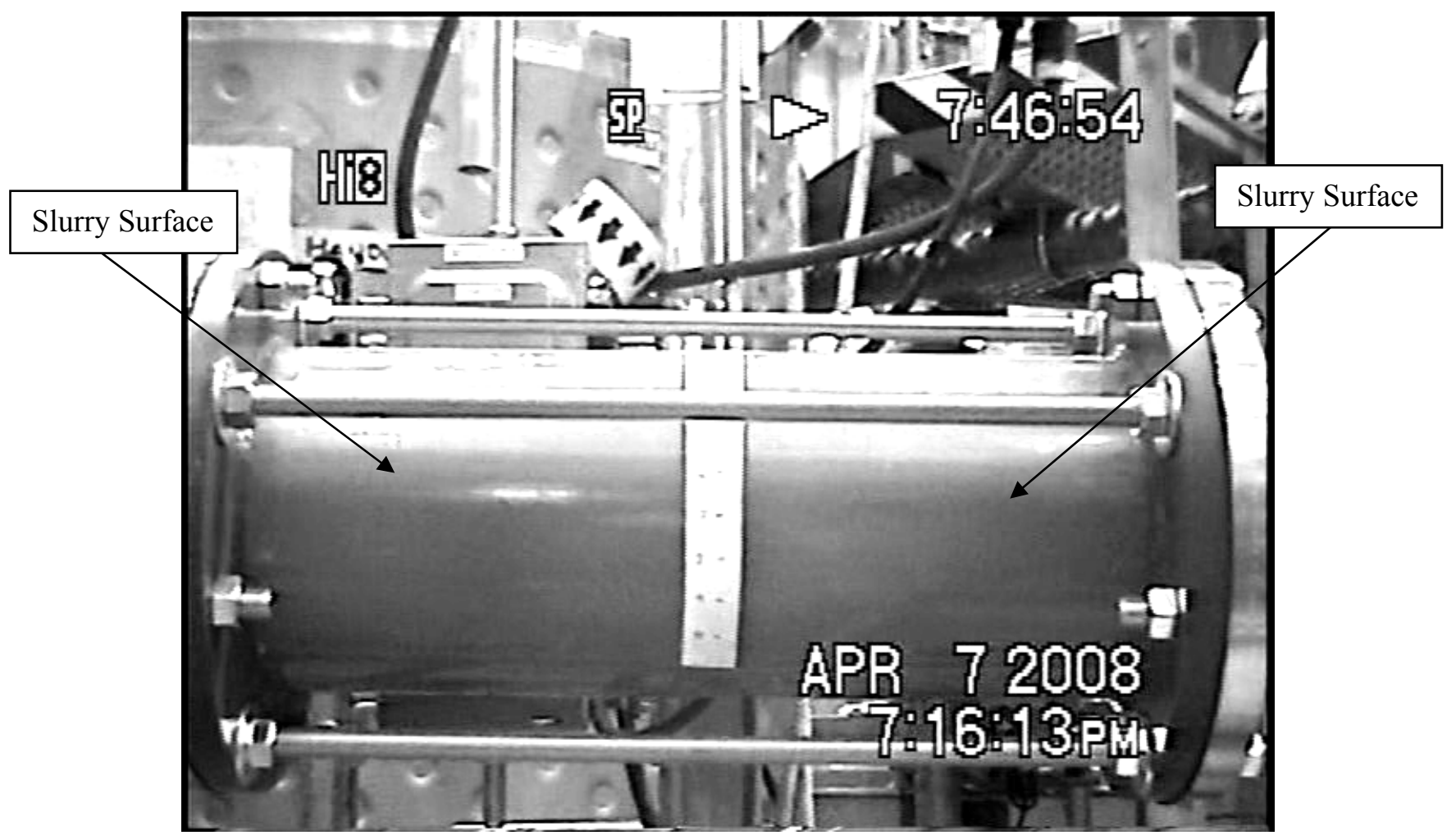

Figure A.25. Upstream, Slope $=1: 125$, Velocity $=2.0 \mathrm{ft} / \mathrm{s}$

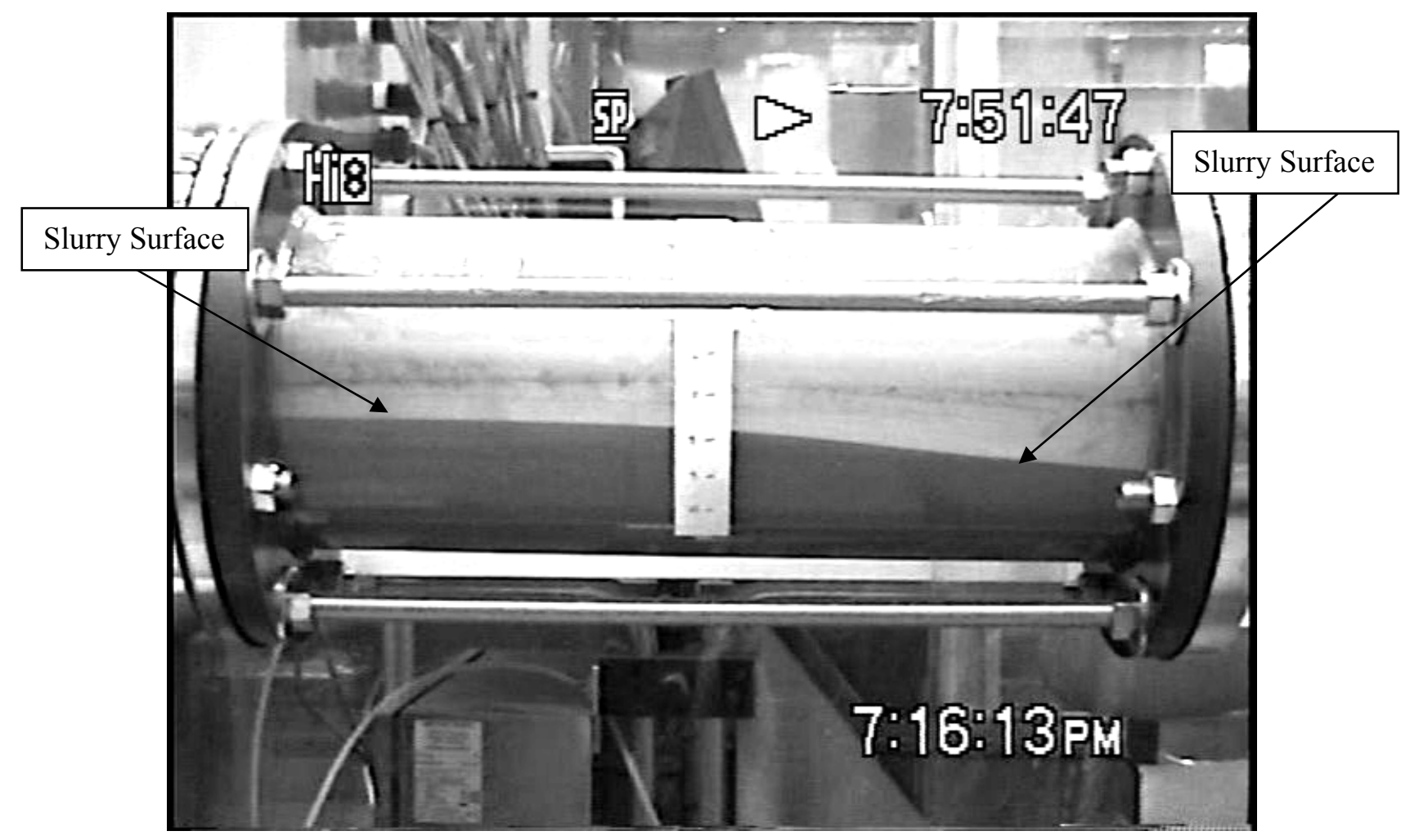

Figure A.26. Downstream, Slope $=1: 125$, Velocity $=2.0 \mathrm{ft} / \mathrm{s}$ 


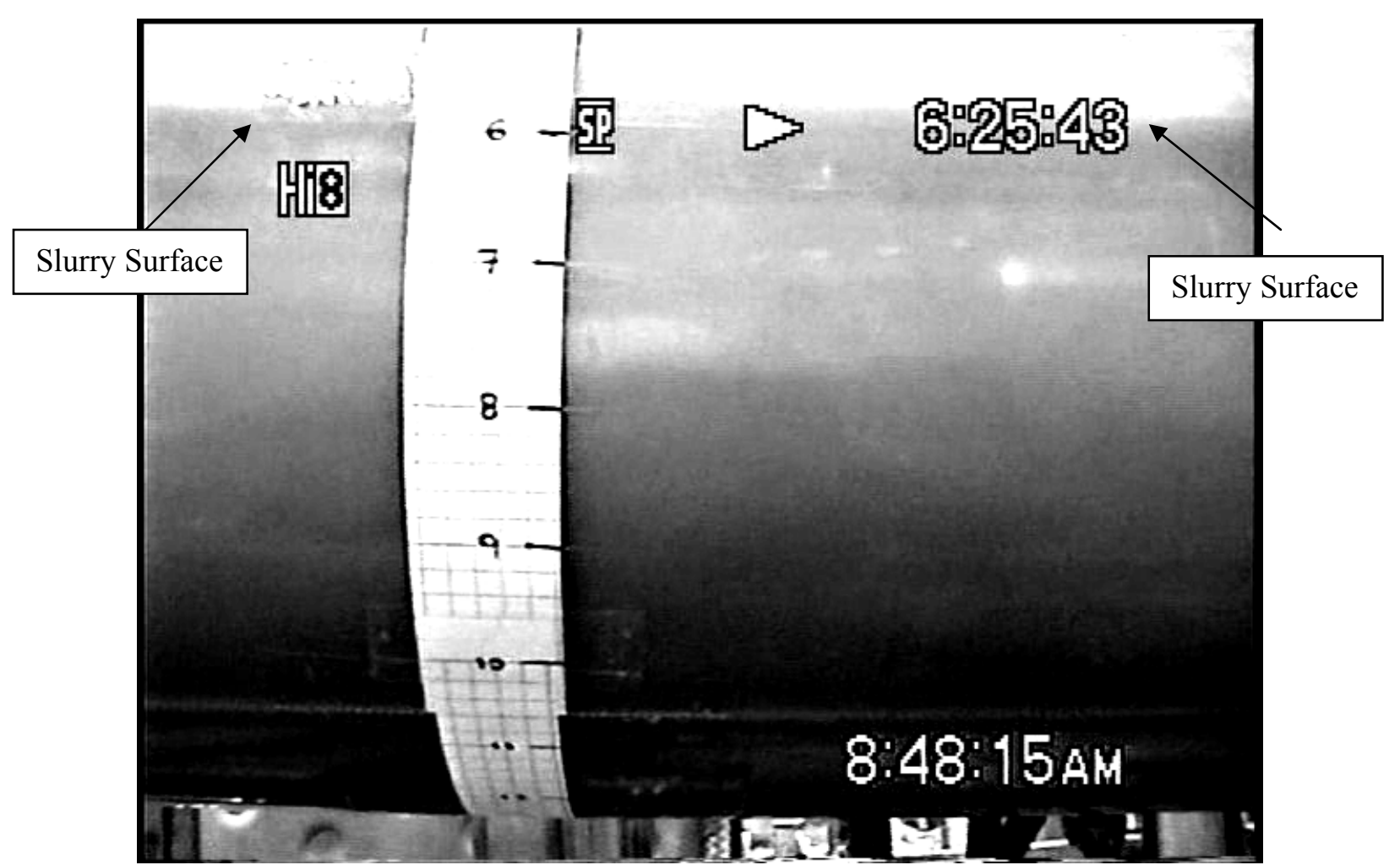

Figure A.27. Upstream, Slope $=1: 20$, Velocity $=8.0 \mathrm{ft} / \mathrm{s}$

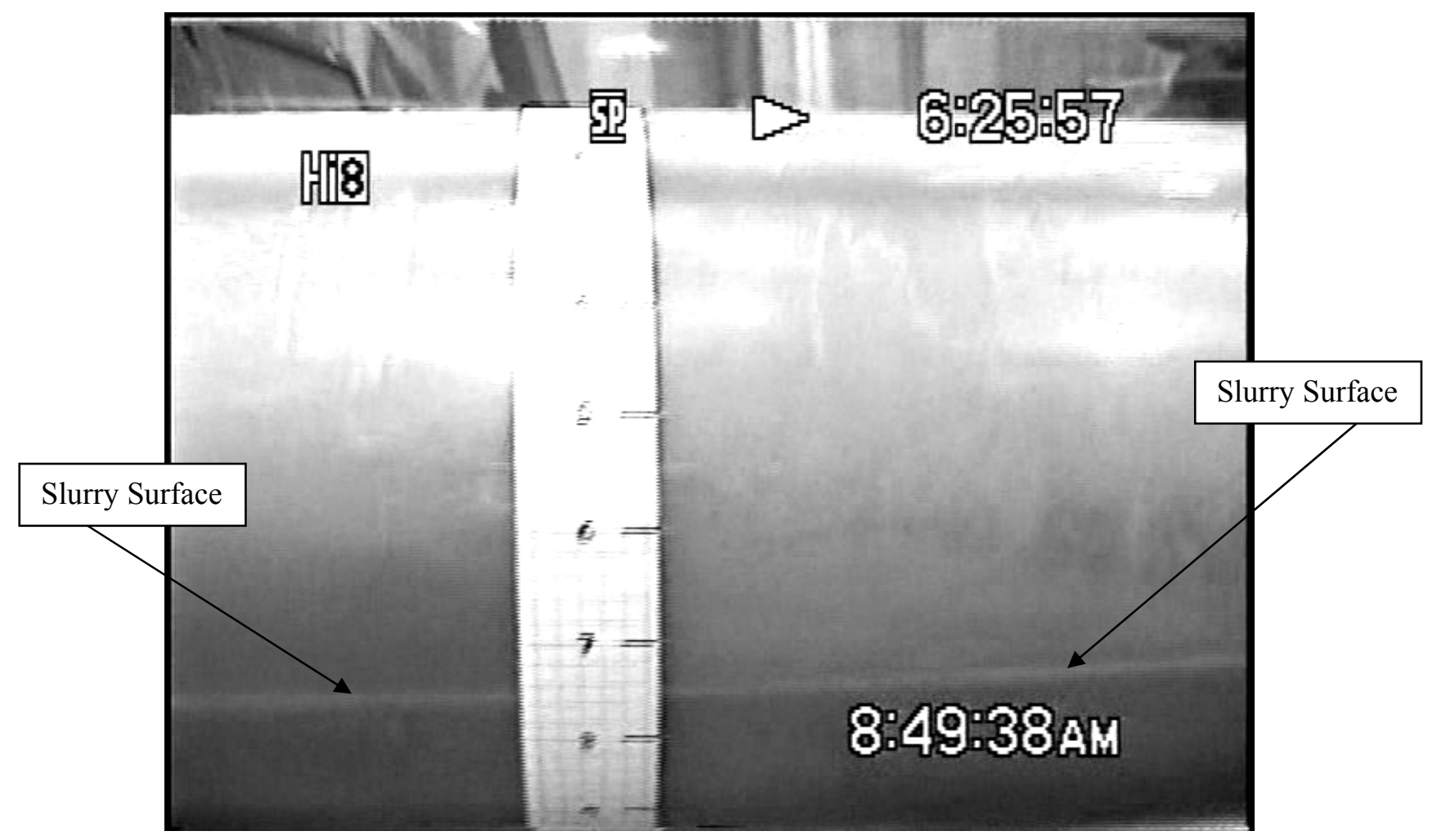

Figure A.28. Downstream, Slope $=1: 20$, Velocity $=8.0 \mathrm{ft} / \mathrm{s}$ 


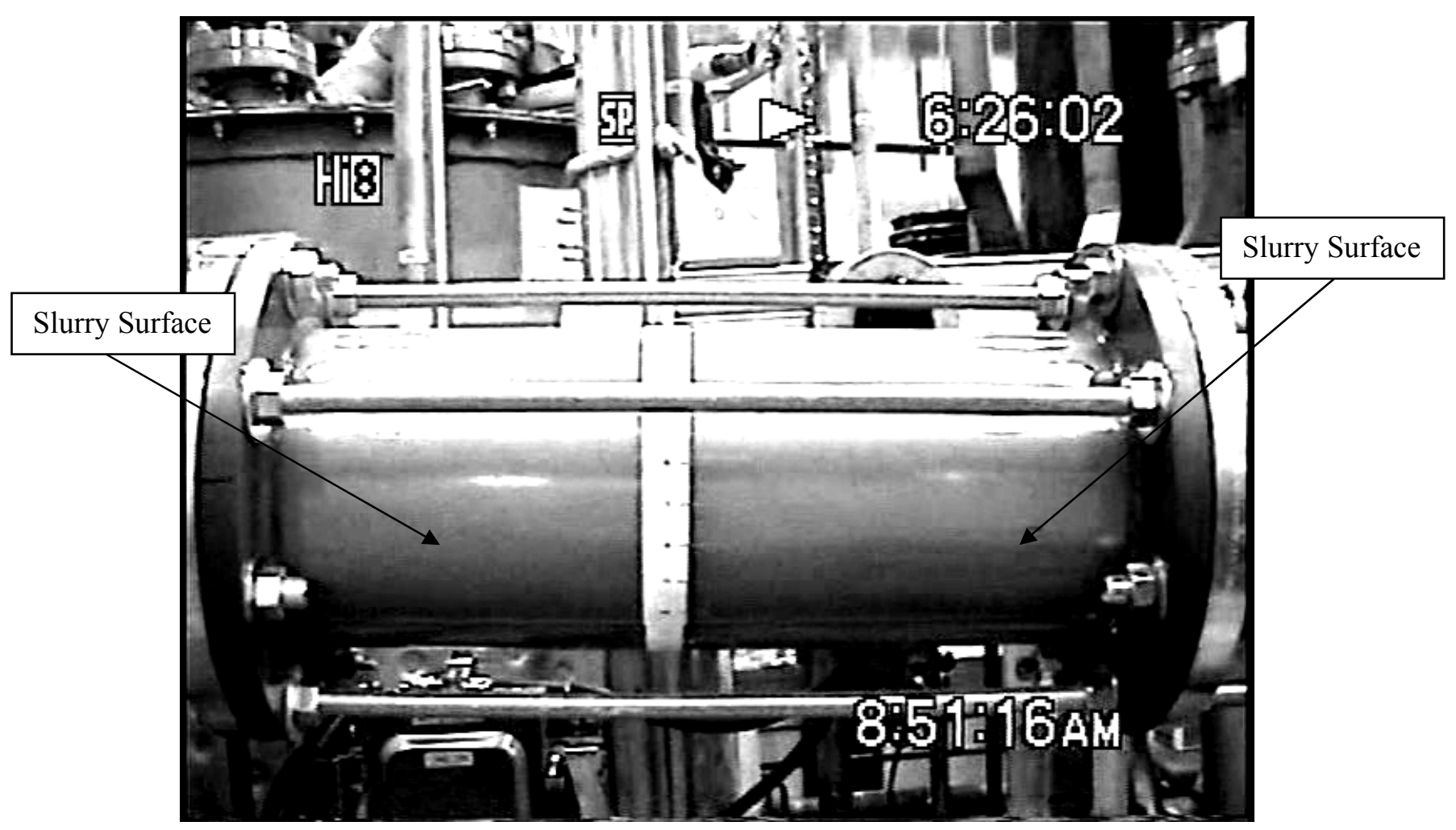

Figure A.29. Upstream, Slope $=1: 20$, Velocity $=8.0 \mathrm{ft} / \mathrm{s}$

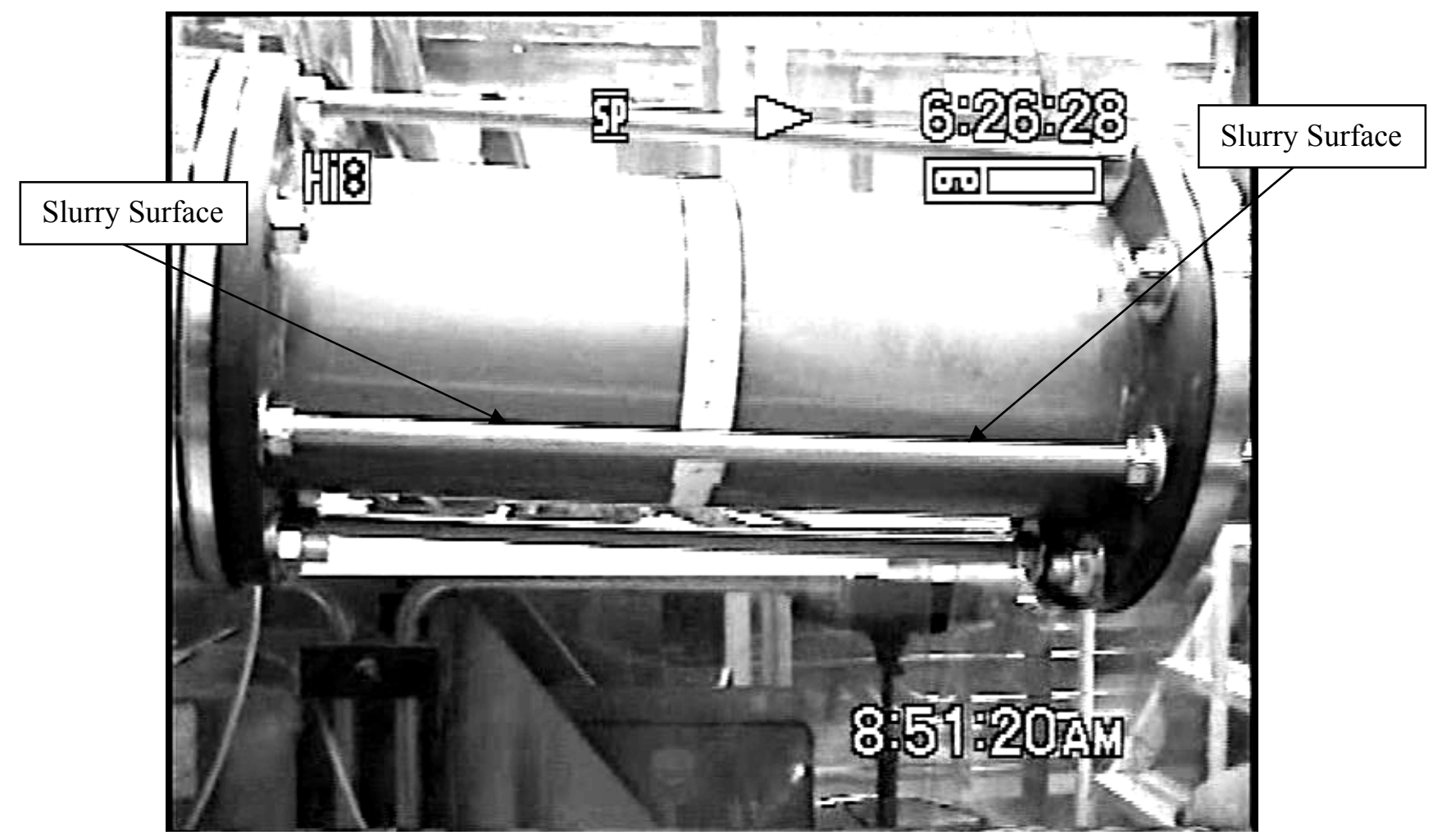

Figure A.30. Downstream, Slope $=1: 20$, Velocity $=8.0 \mathrm{ft} / \mathrm{s}$ 


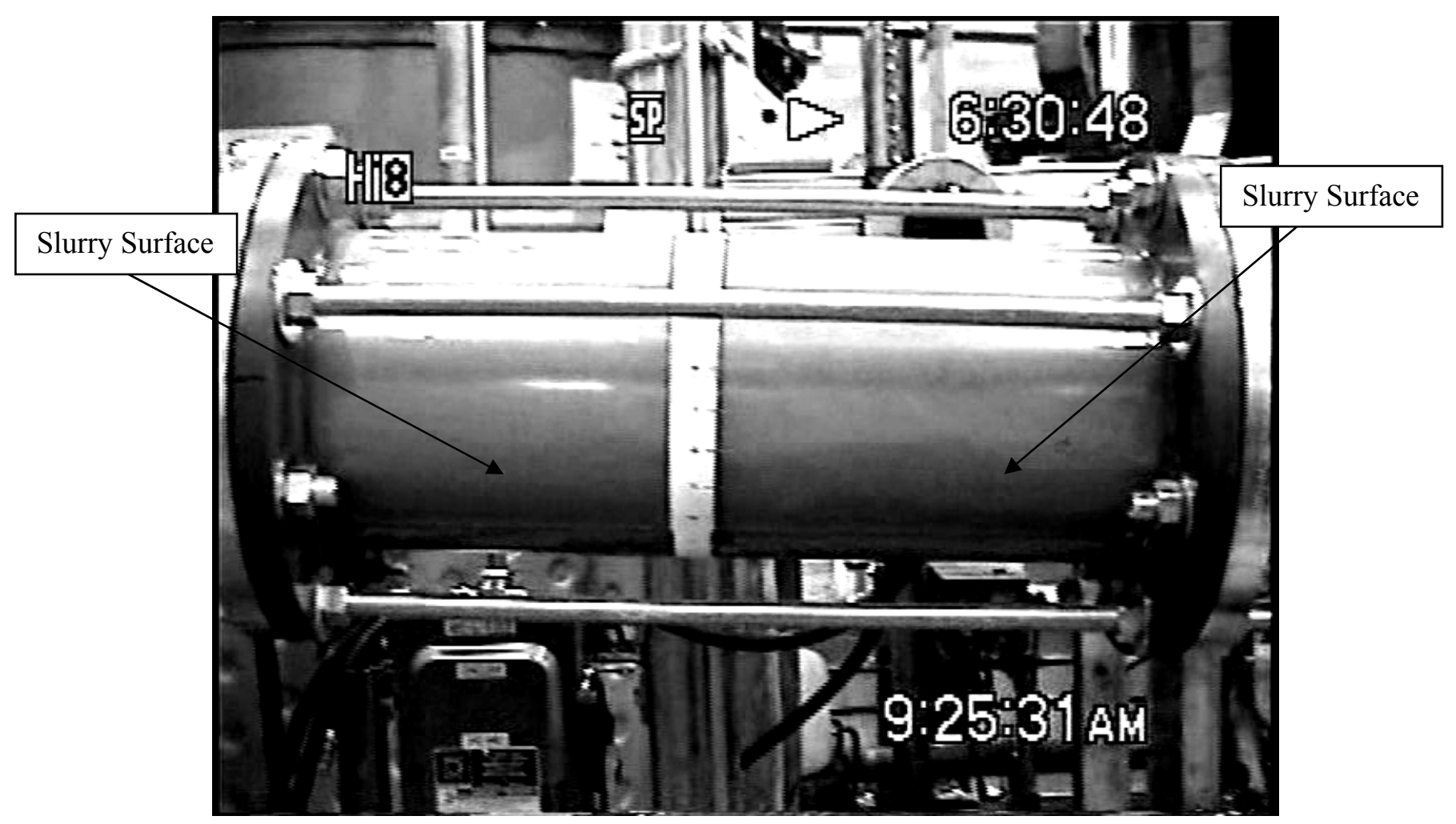

Figure A.31. Upstream, Slope $=1: 20$, Velocity $=7.0 \mathrm{ft} / \mathrm{s}$

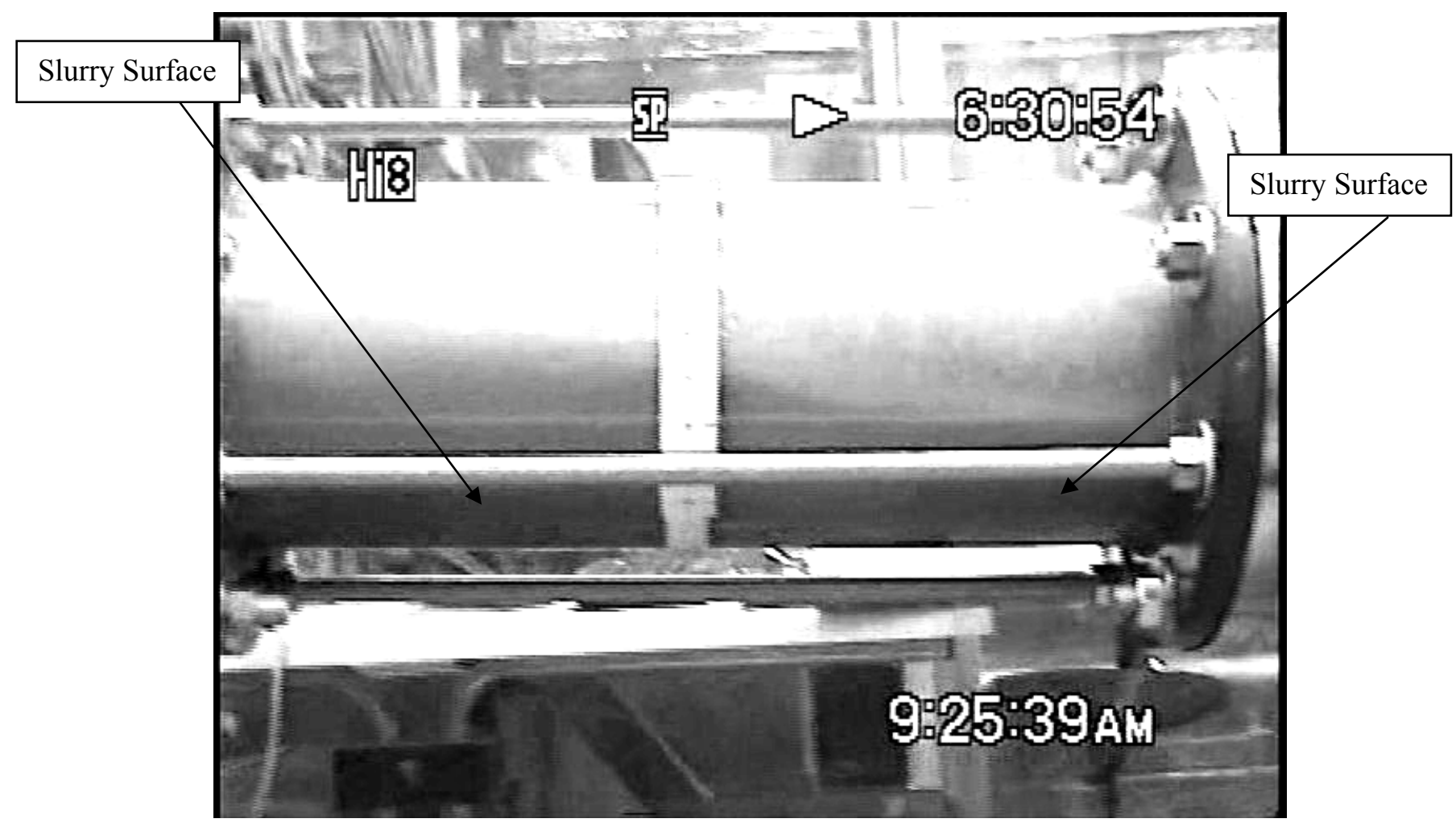

Figure A.32. Downstream, Slope $=1: 20$, Velocity $=7.0 \mathrm{ft} / \mathrm{s}$ 


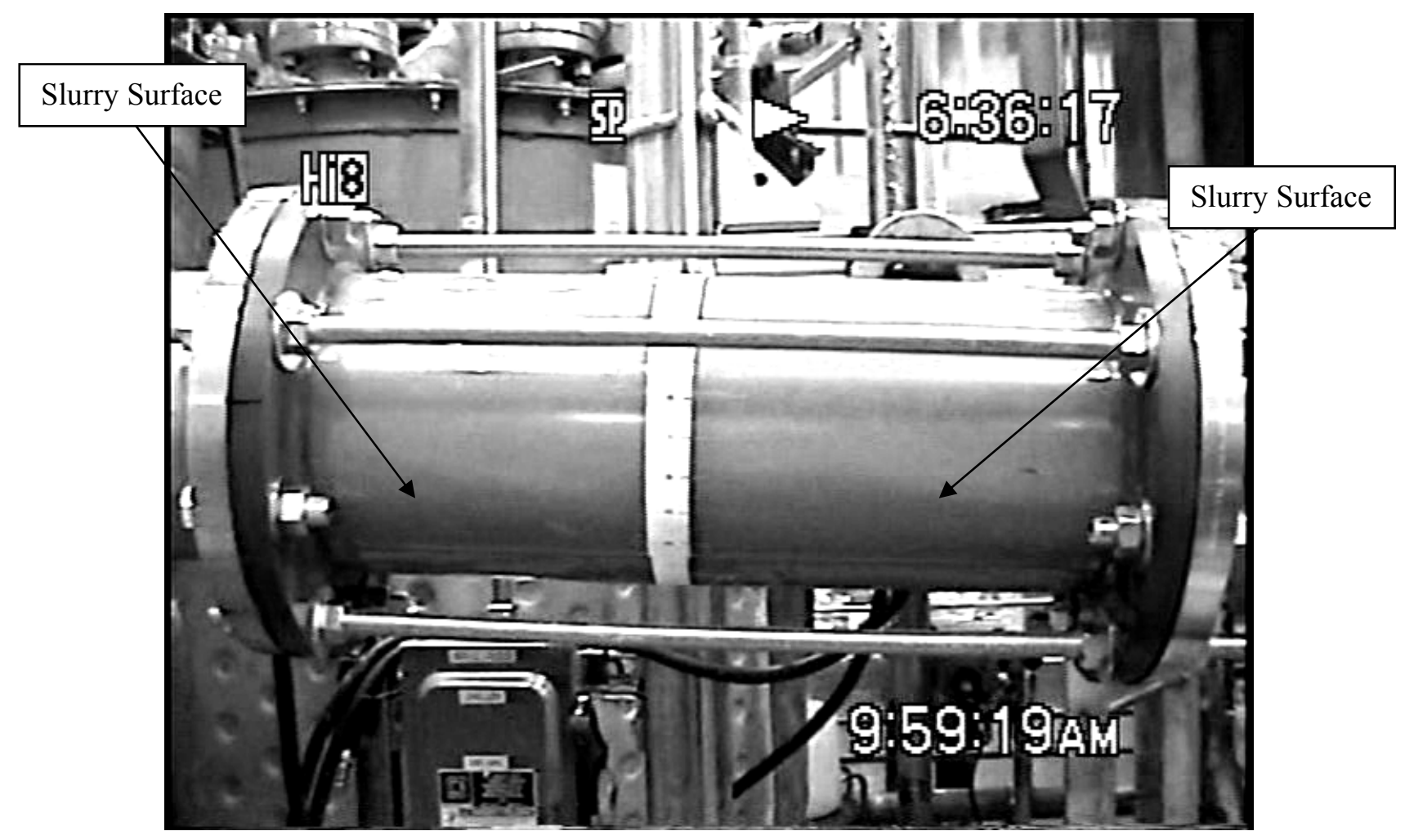

Figure A.33. Upstream, Slope $=1: 20$, Velocity $=6.0 \mathrm{ft} / \mathrm{s}$

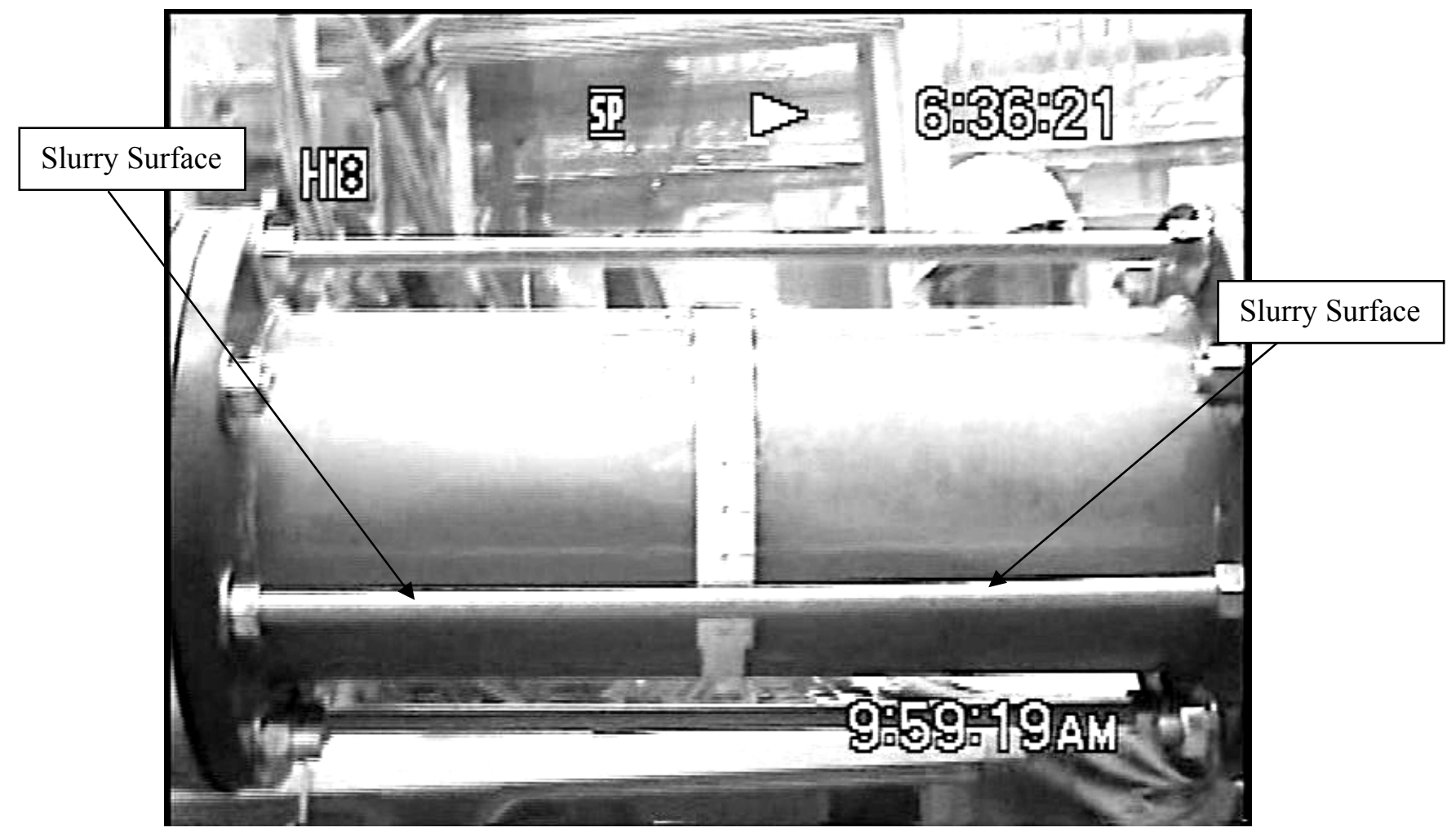

Figure A.34. Downstream, Slope $=1: 20$, Velocity $=6.0 \mathrm{ft} / \mathrm{s}$ 


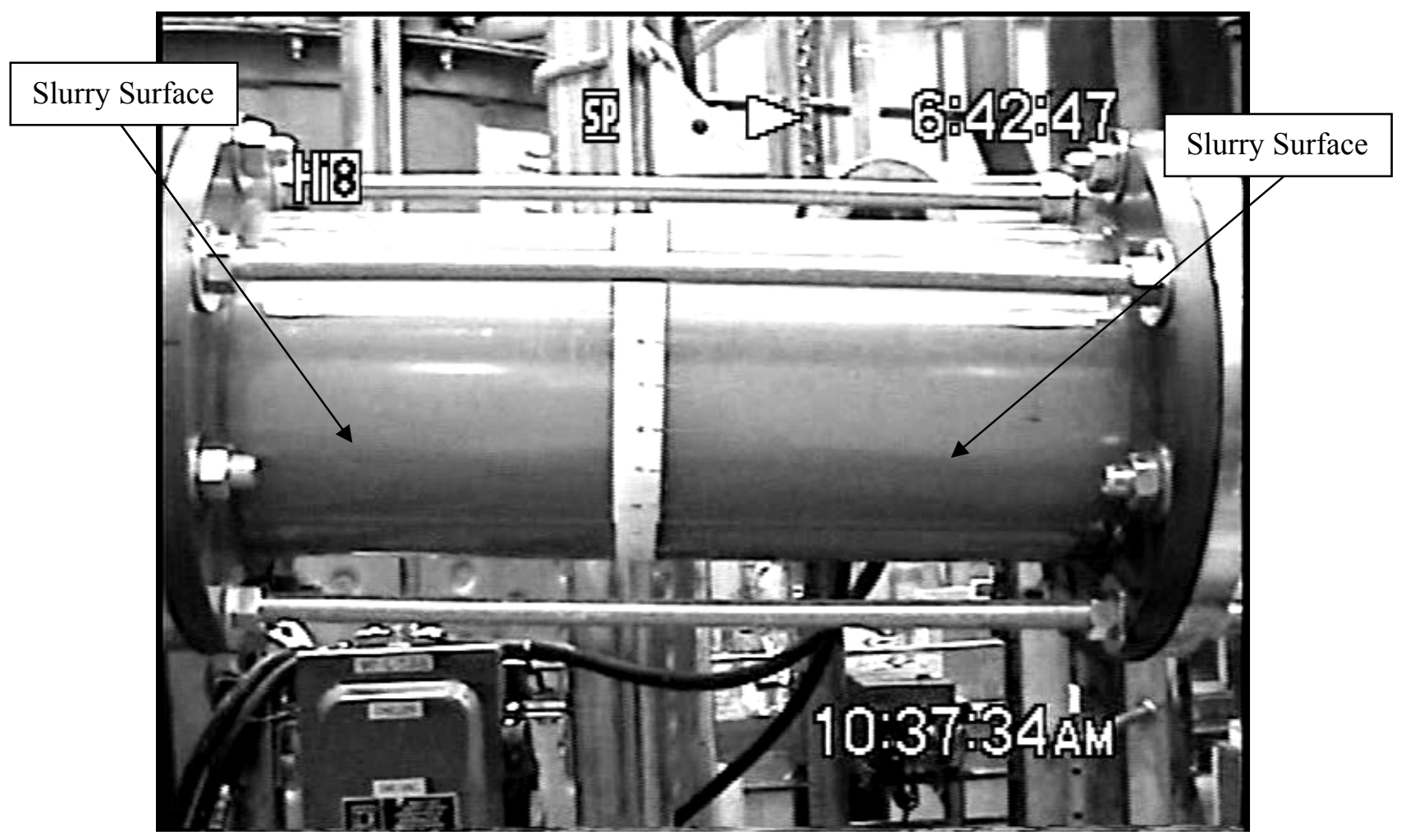

Figure A.35. Upstream, Slope $=1: 20$, Velocity $=5.0 \mathrm{ft} / \mathrm{s}$

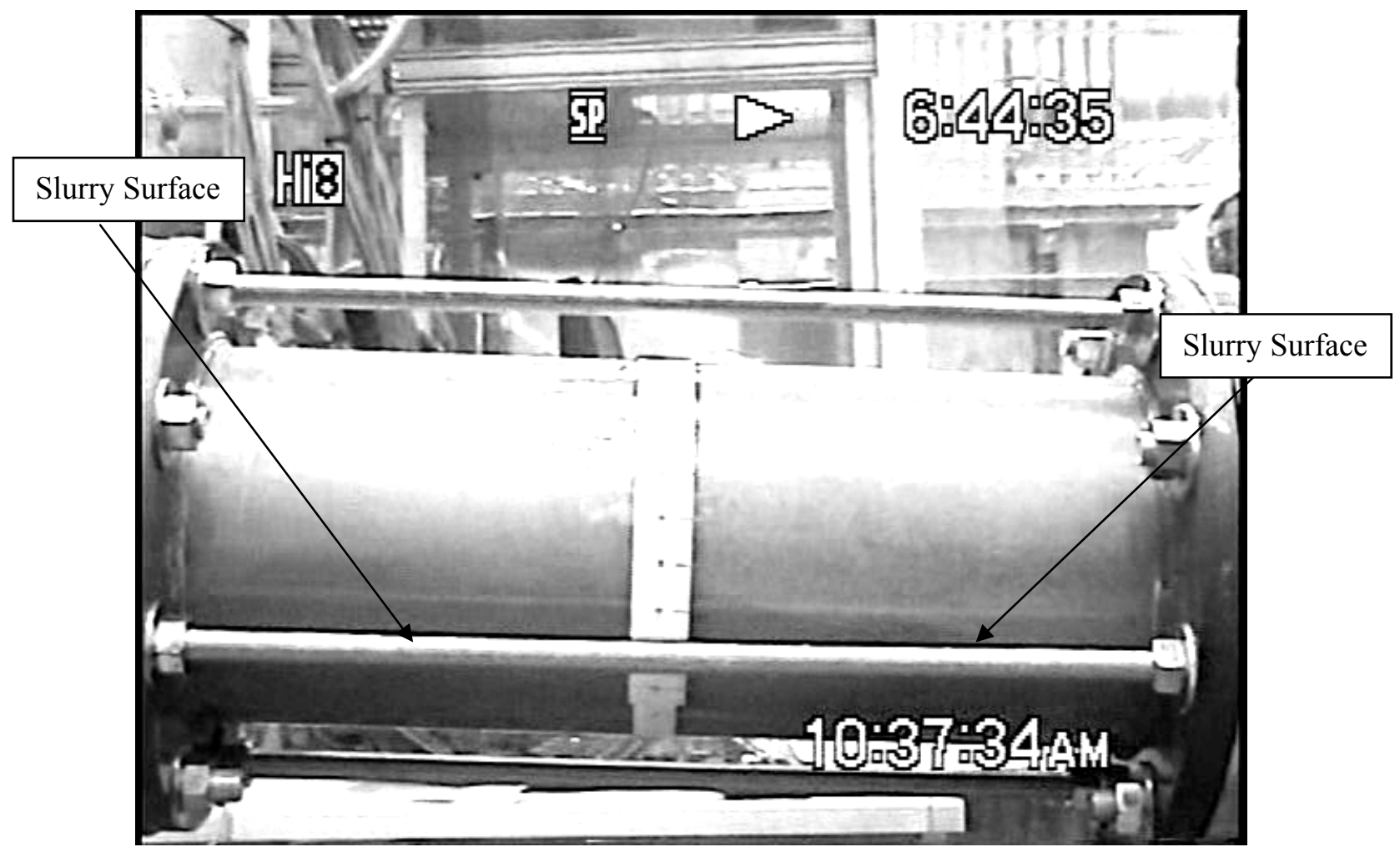

Figure A.36. Downstream, Slope $=1: 20$, Velocity $=5.0 \mathrm{ft} / \mathrm{s}$ 


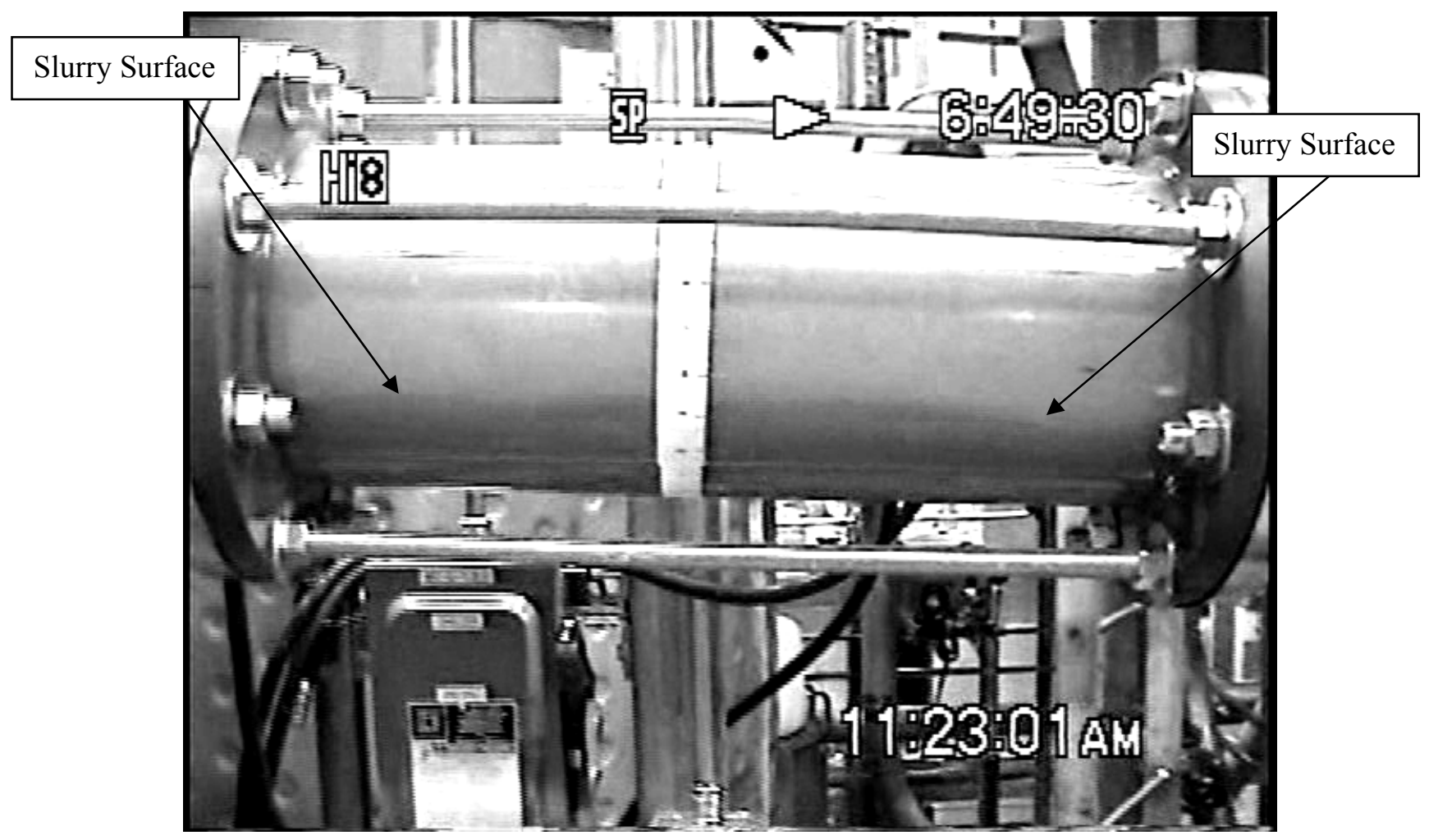

Figure A.37. Upstream, Slope $=1: 20$, Velocity $=4.0 \mathrm{ft} / \mathrm{s}$

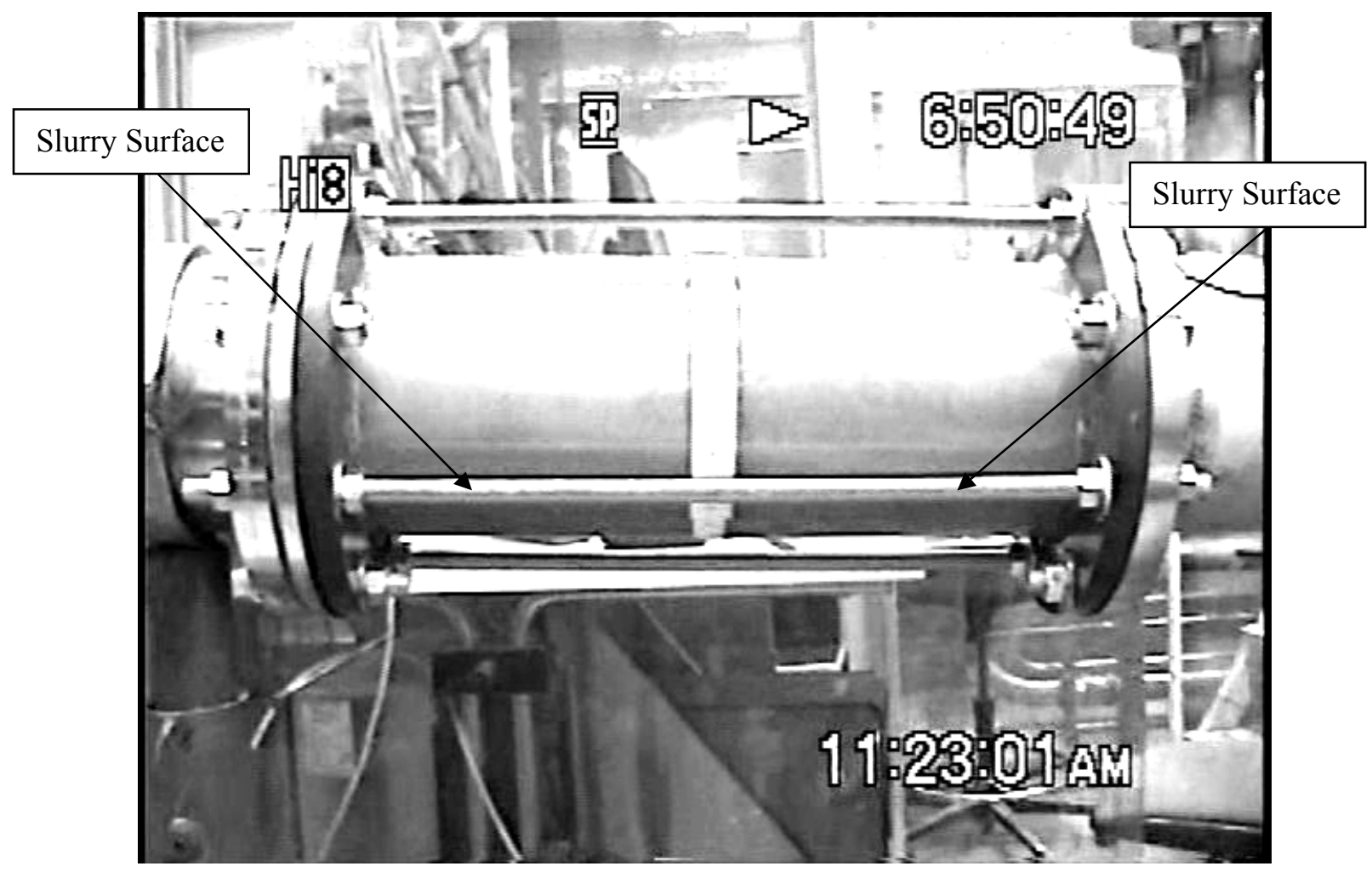

Figure A.38. Downstream, Slope $=1: 20$, Velocity $=4.0 \mathrm{ft} / \mathrm{s}$ 


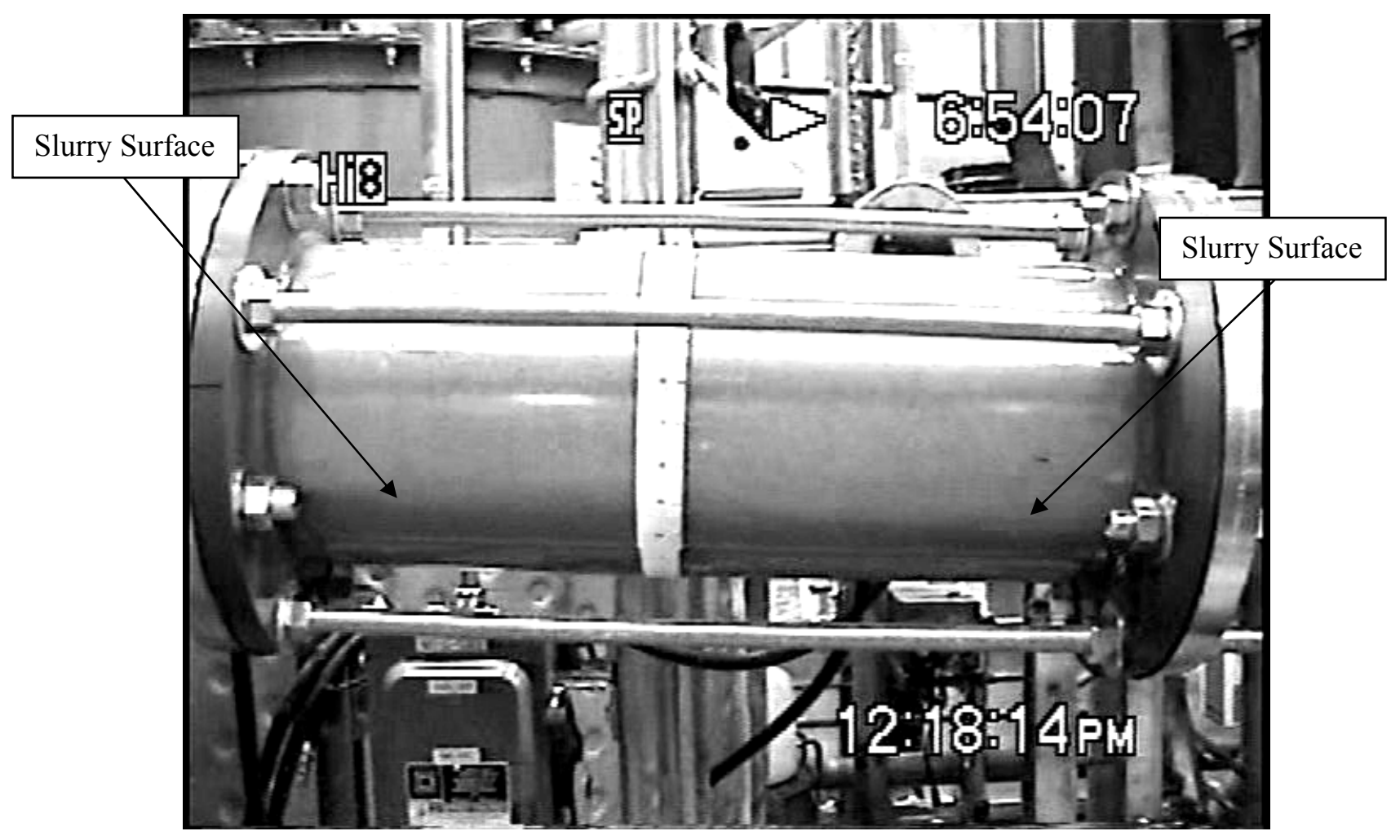

Figure A.39. Upstream, Slope $=1: 20$, Velocity $=3.0 \mathrm{ft} / \mathrm{s}-$ pump broke soon after

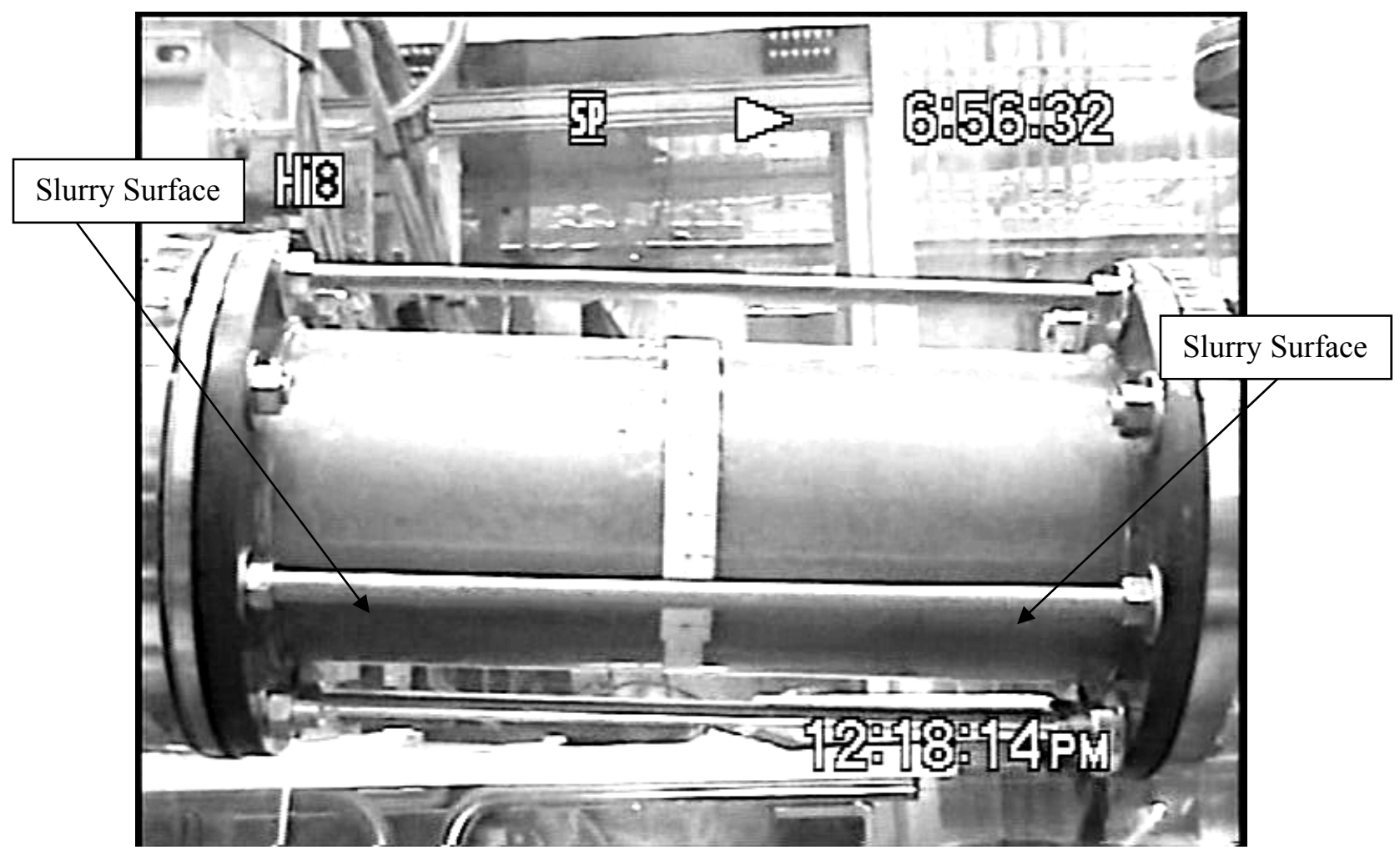

Figure A.40. Downstream, Slope $=1: 20$, Velocity $=3.0 \mathrm{ft} / \mathrm{s}$ 


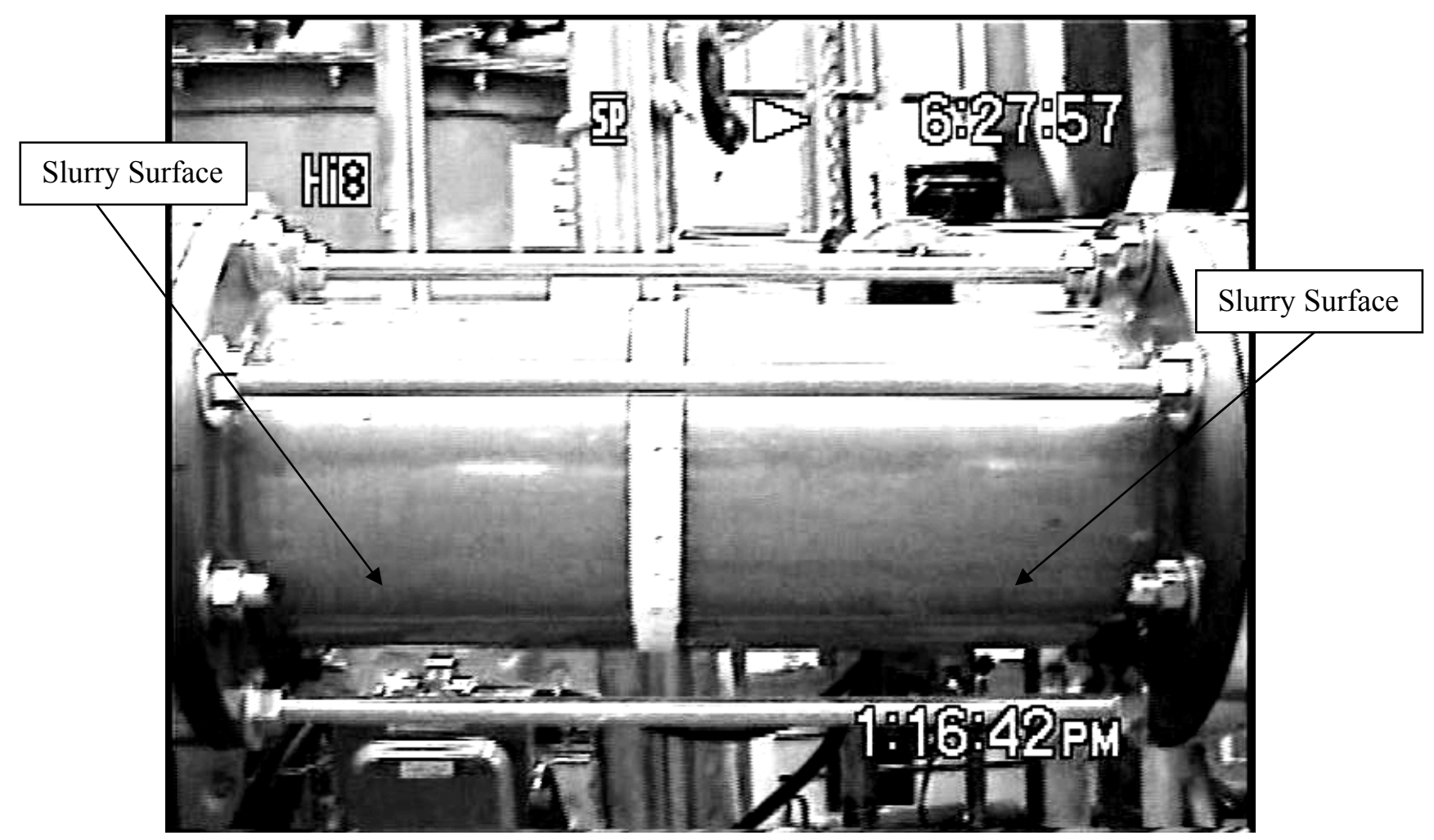

Figure A.41. Upstream, Slope $=1: 20$, Velocity $=2.0 \mathrm{ft} / \mathrm{s}$

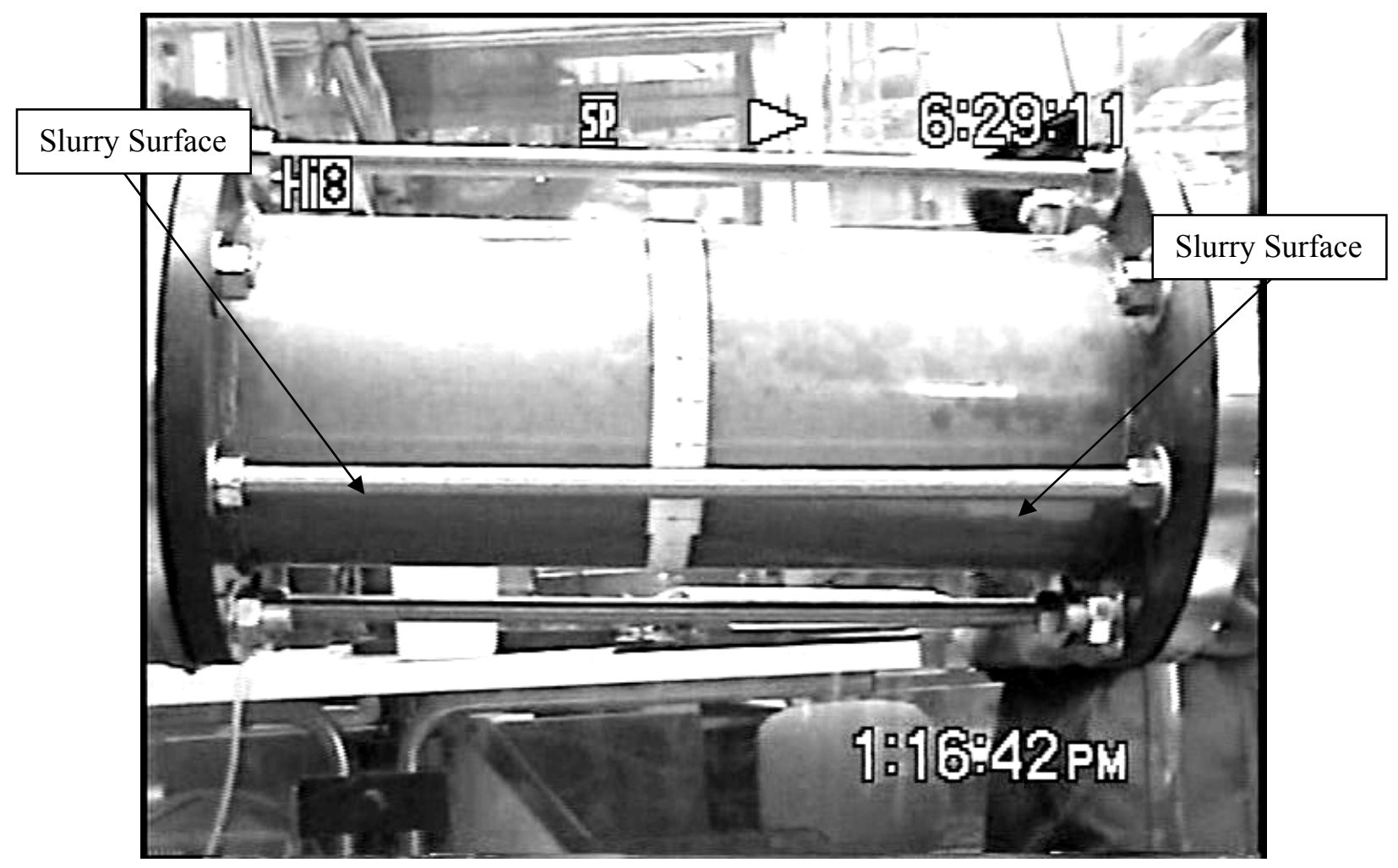

Figure A.42. Downstream, Slope $=1: 20$, Velocity $=2.0 \mathrm{ft} / \mathrm{s}$ 


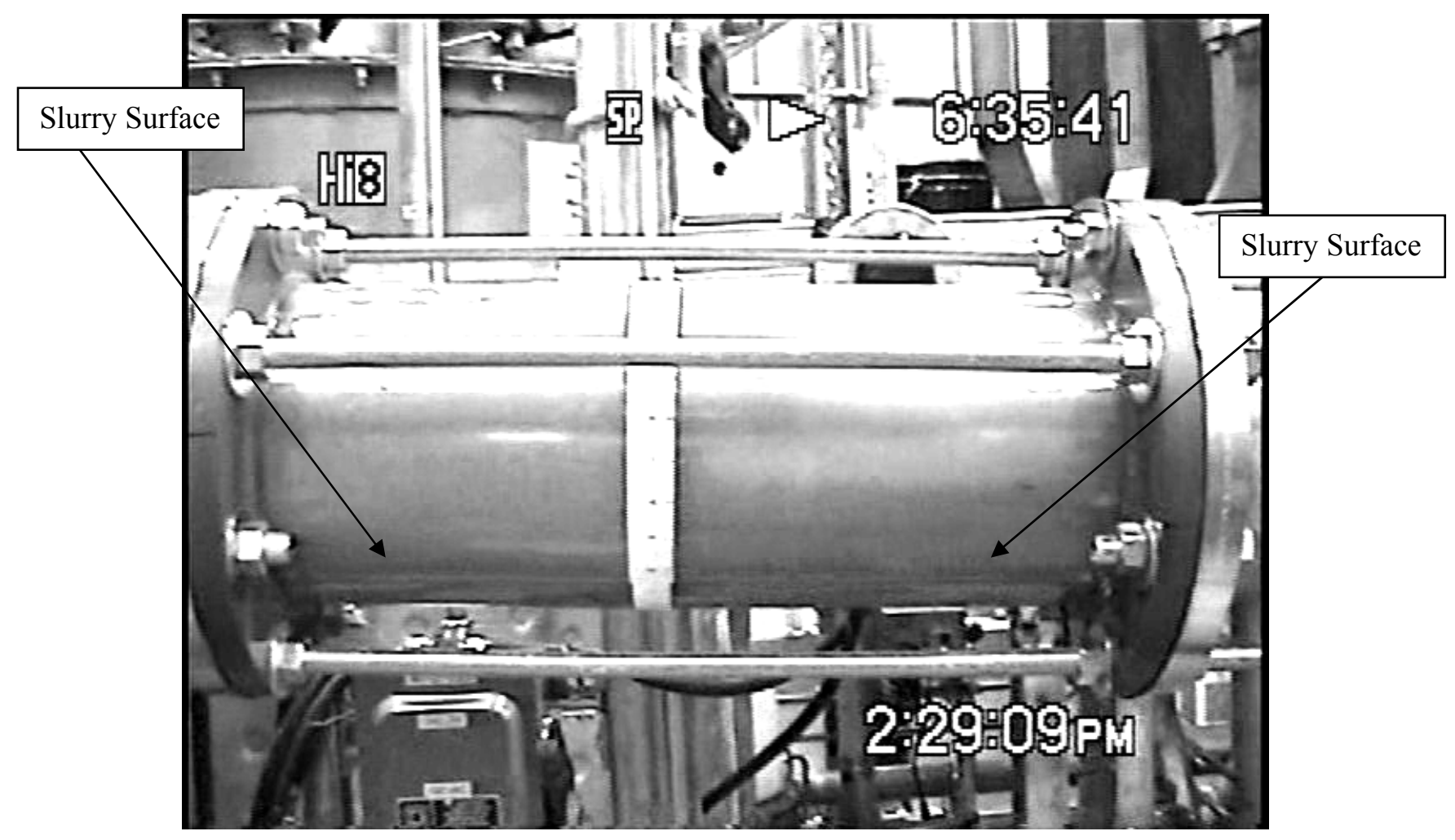

Figure A.43. Upstream, Slope $=1: 20$, Velocity $=1.5 \mathrm{ft} / \mathrm{s}$

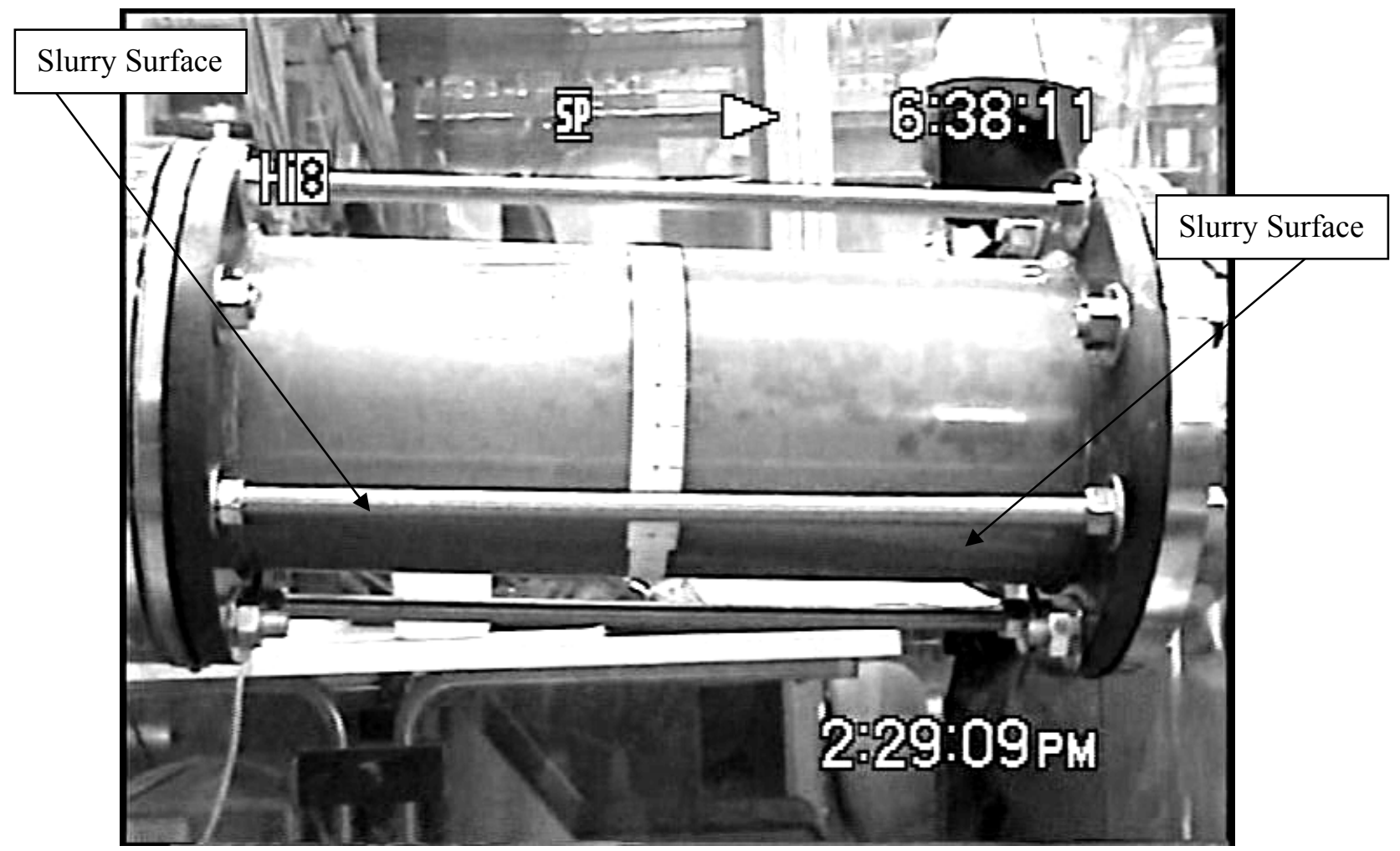

Figure A.44. Downstream, Slope $=1: 20$, Velocity $=1.5 \mathrm{ft} / \mathrm{s}$ 


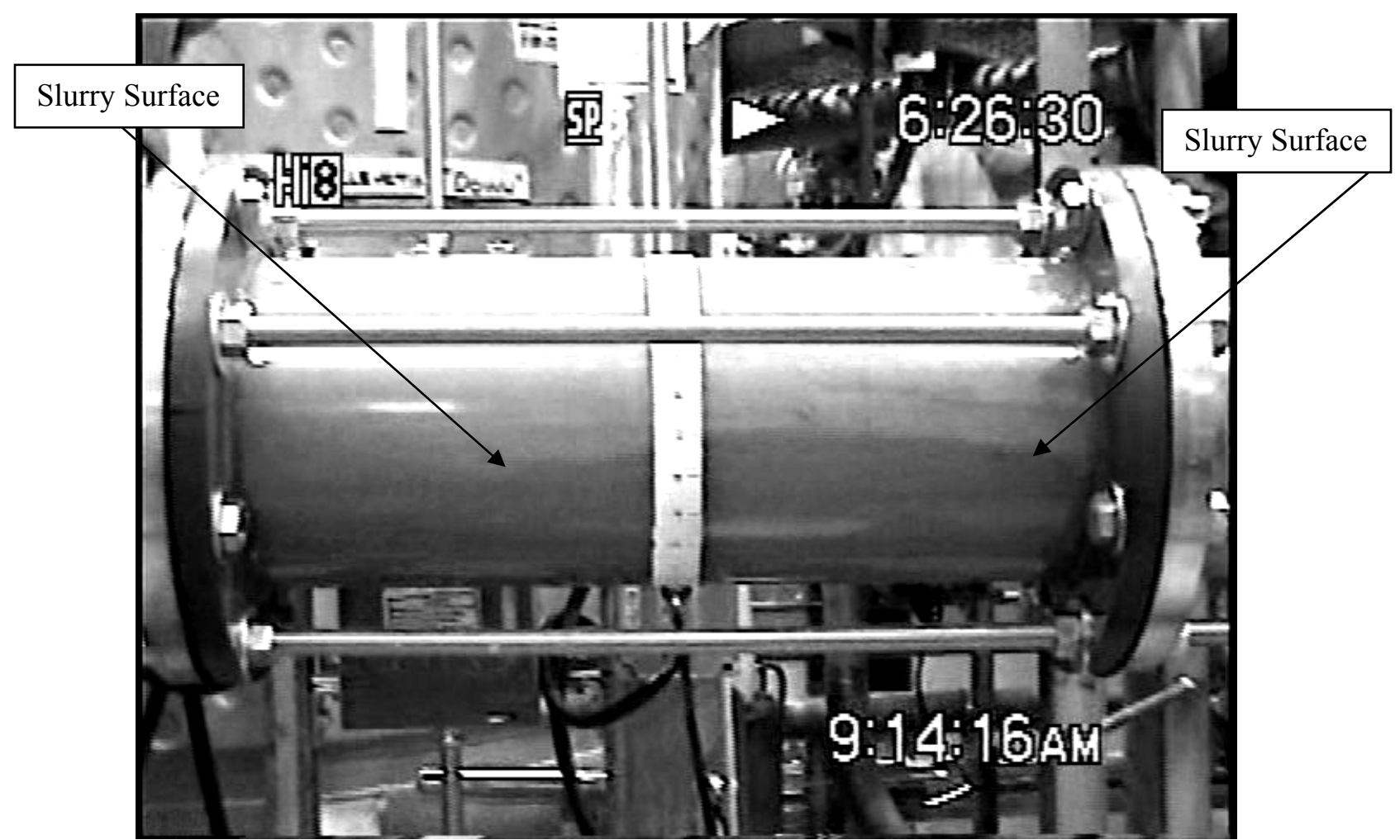

Figure A.45. Upstream, Slope $=1: 50$, Velocity $=8.0 \mathrm{ft} / \mathrm{s}$

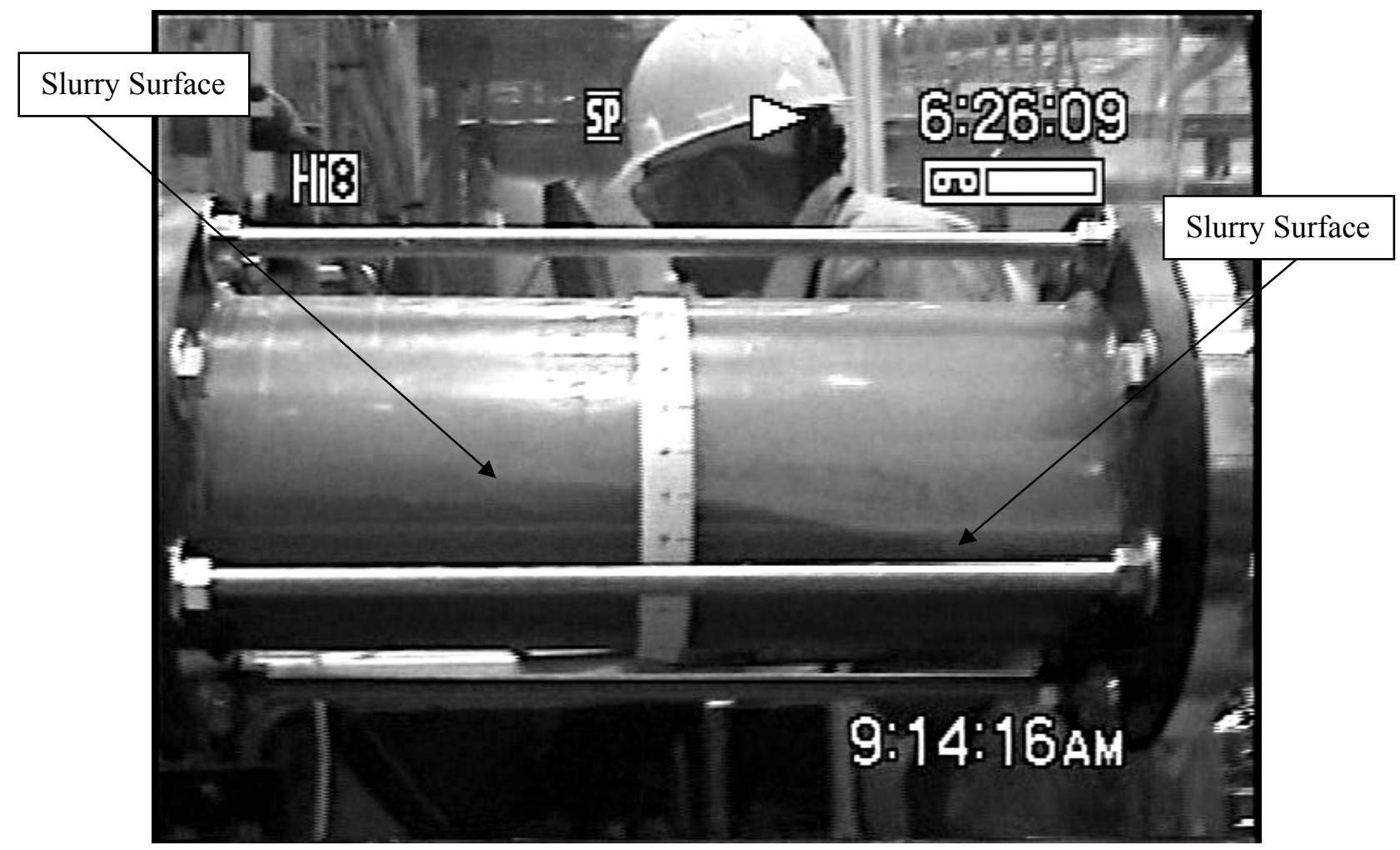

Figure A.46. Downstream, Slope $=1: 50$, Velocity $=8.0 \mathrm{ft} / \mathrm{s}$ 


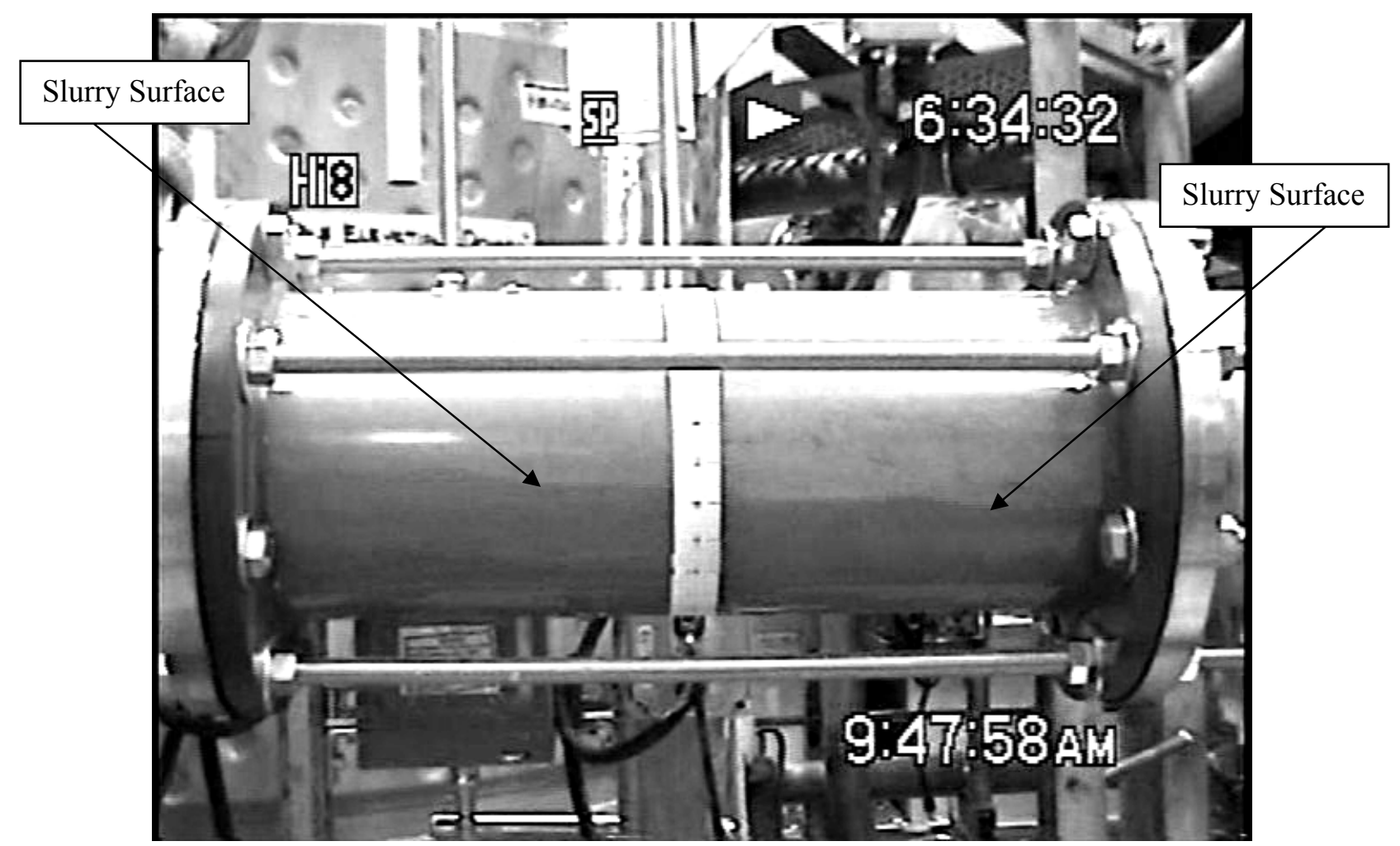

Figure A.47. Upstream, Slope $=1: 50$, Velocity $=7.0 \mathrm{ft} / \mathrm{s}$

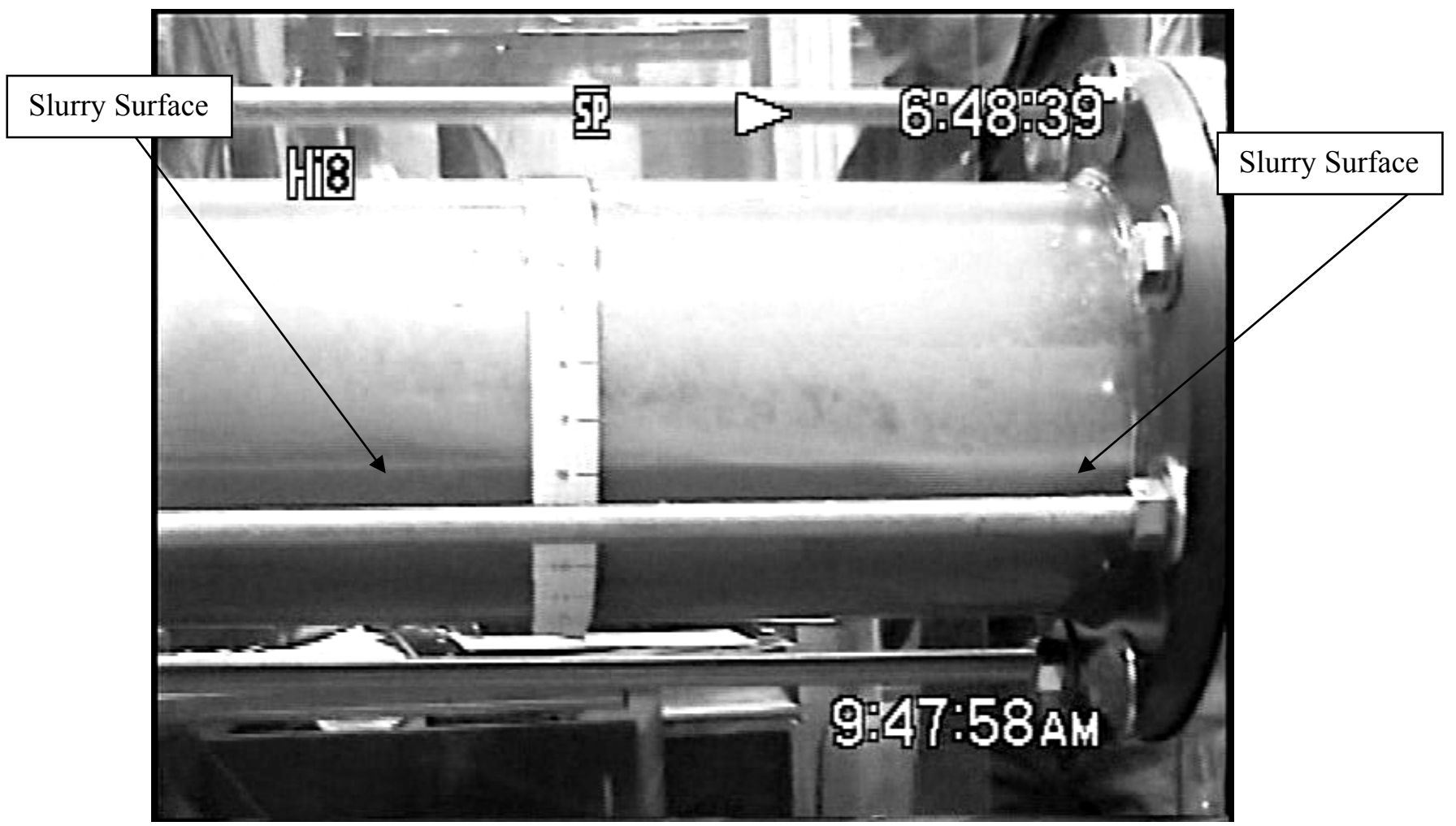

Figure A.48. Downstream, Slope $=1: 50$, Velocity $=7.0 \mathrm{ft} / \mathrm{s}$ 


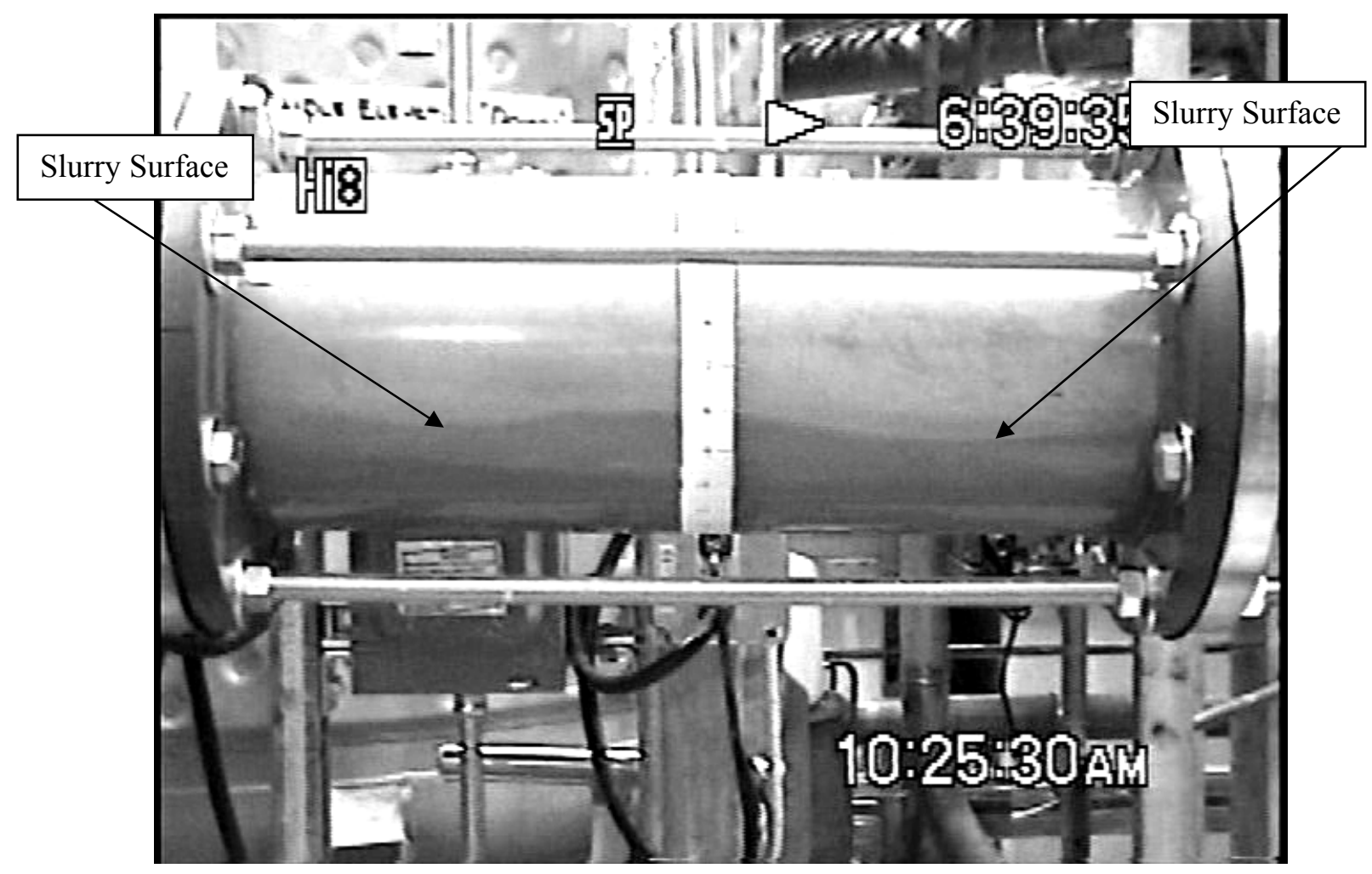

Figure A.49. Upstream, Slope $=1: 50$, Velocity $=6.0 \mathrm{ft} / \mathrm{s}$

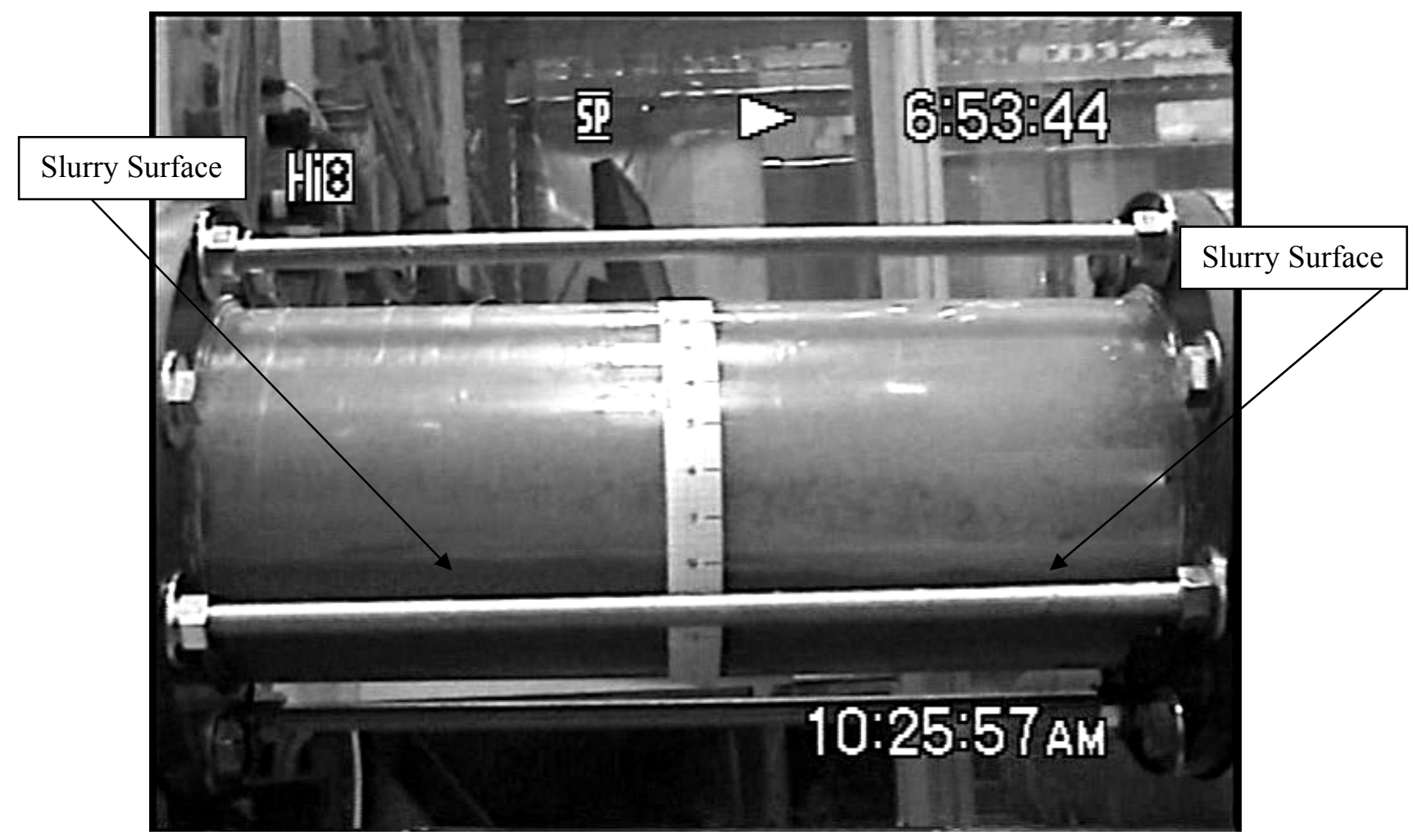

Figure A.50. Downstream, Slope $=1: 50$, Velocity $=6.0 \mathrm{ft} / \mathrm{s}$ 


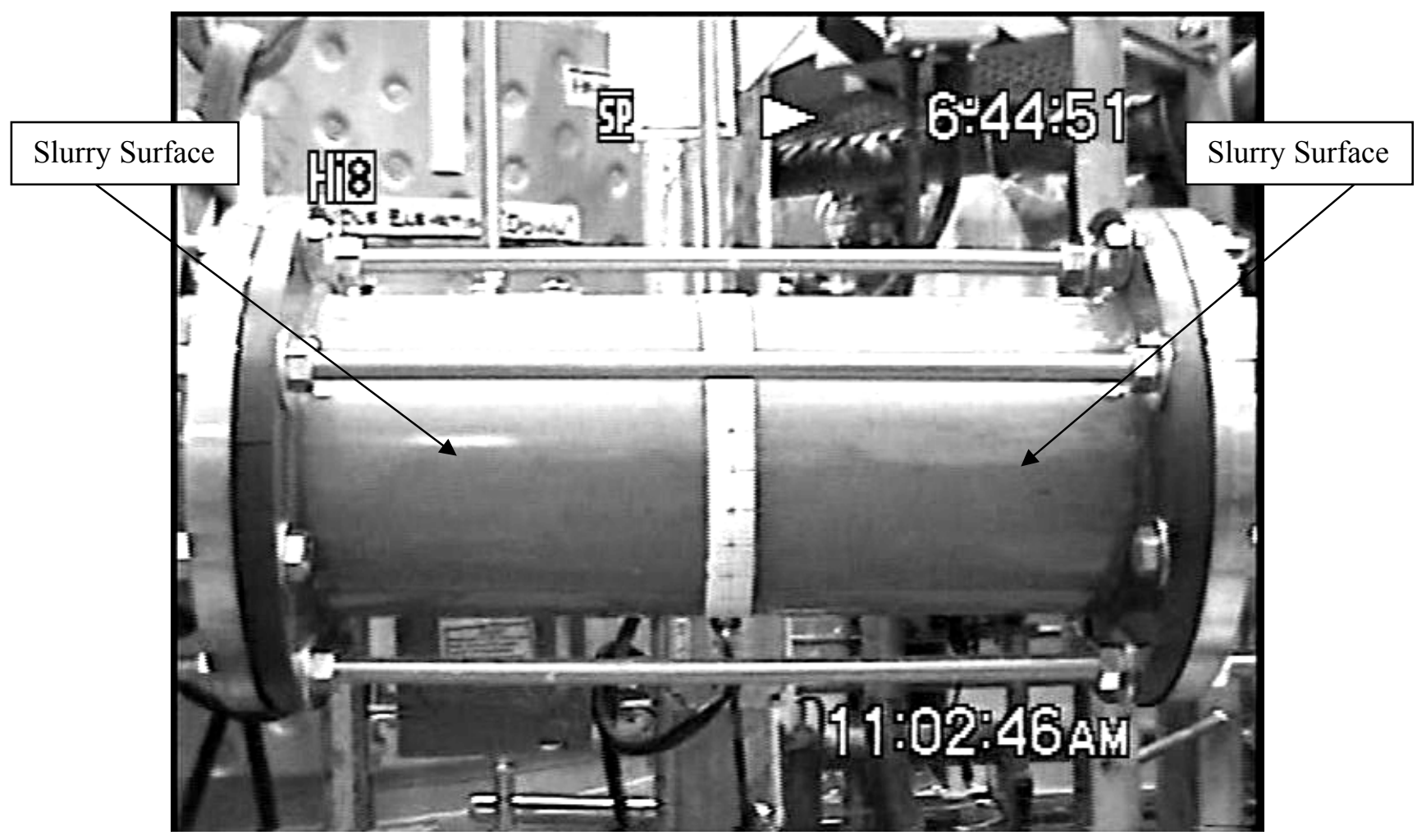

Figure A.51. Upstream, Slope $=1: 50$, Velocity $=5.0 \mathrm{ft} / \mathrm{s}$

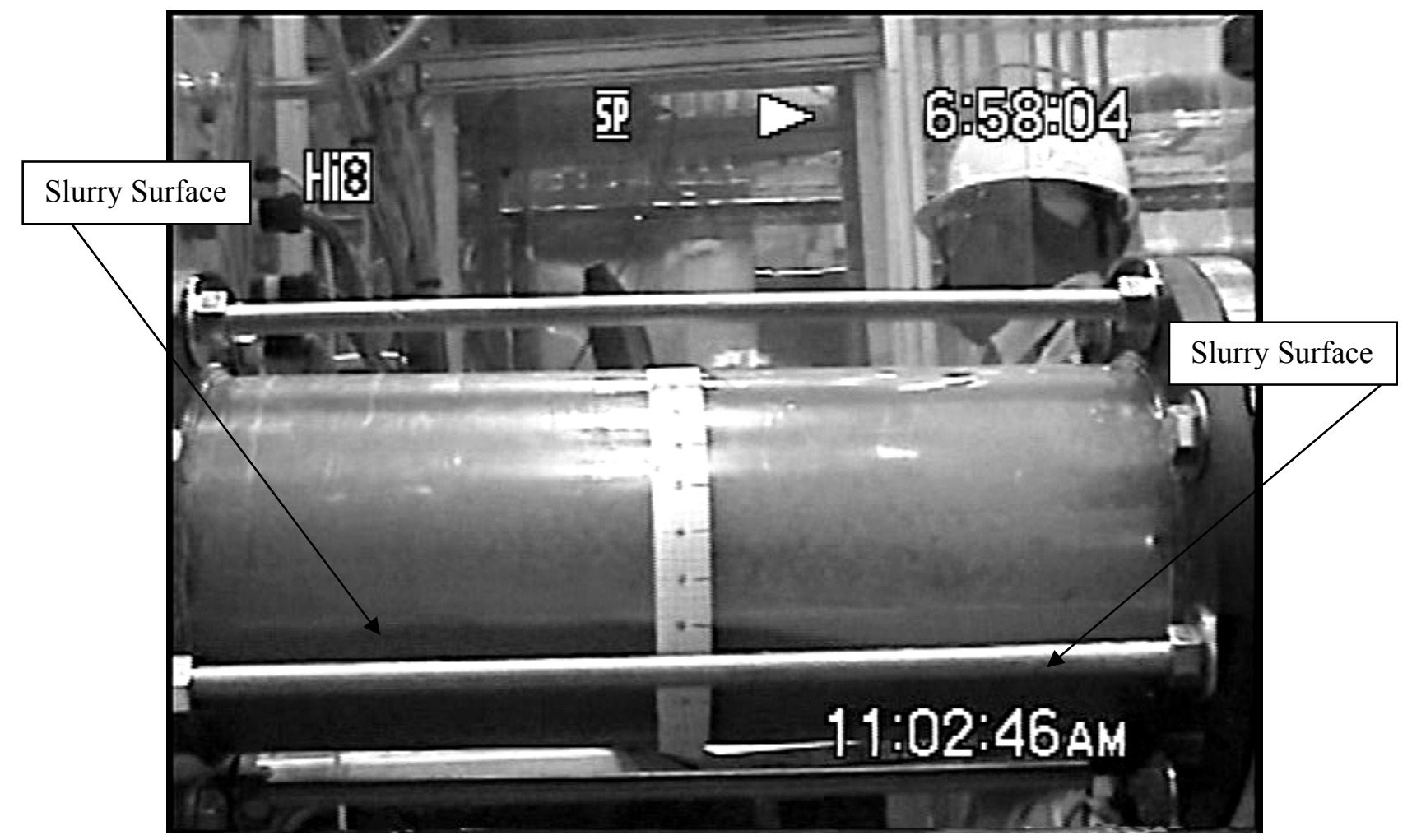

Figure A.52. Downstream, Slope $=1: 50$, Velocity $=5.0 \mathrm{ft} / \mathrm{s}$ 


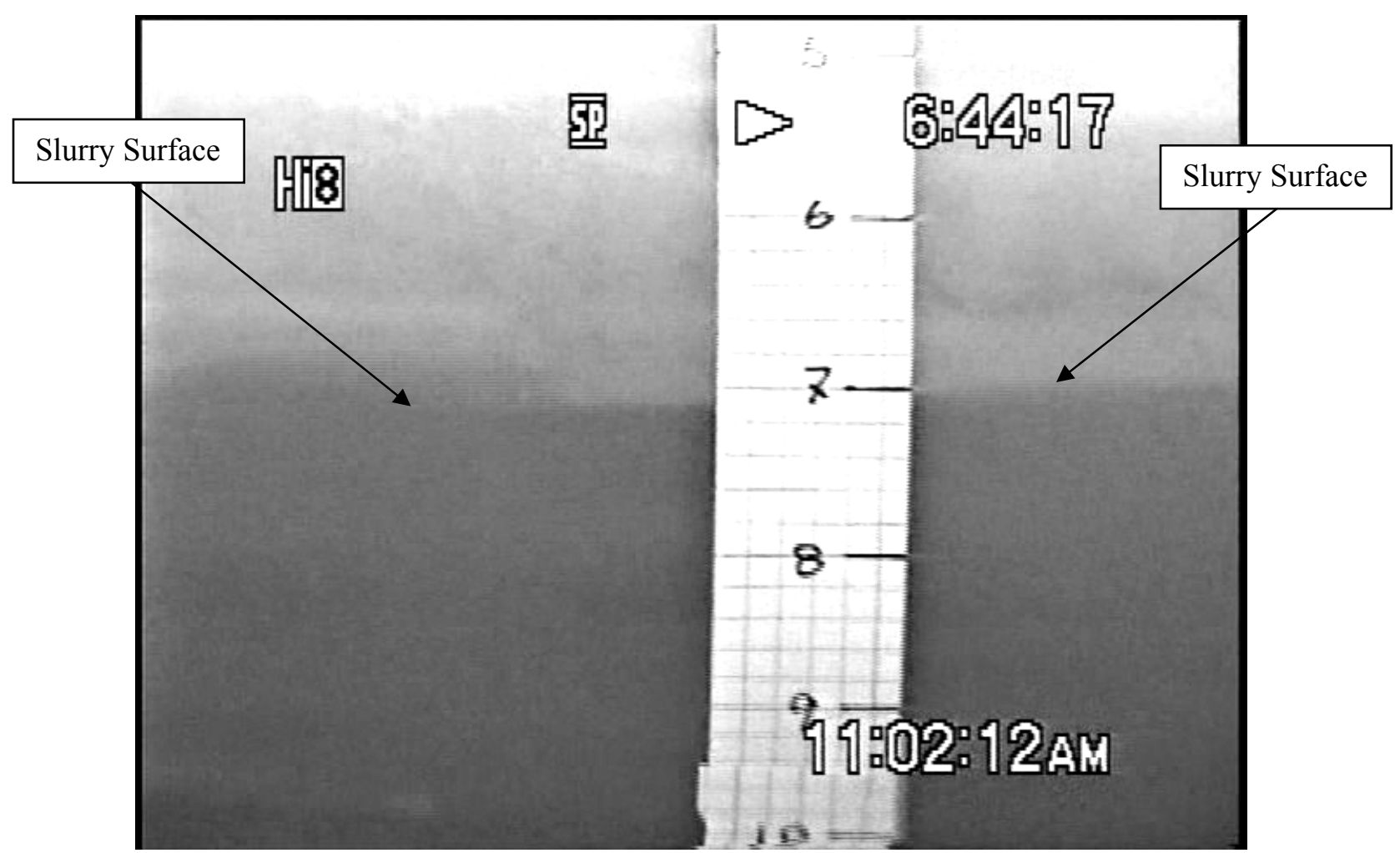

Figure A.53. Upstream, Slope $=1: 50$, Velocity $=5.0 \mathrm{ft} / \mathrm{s}$ 


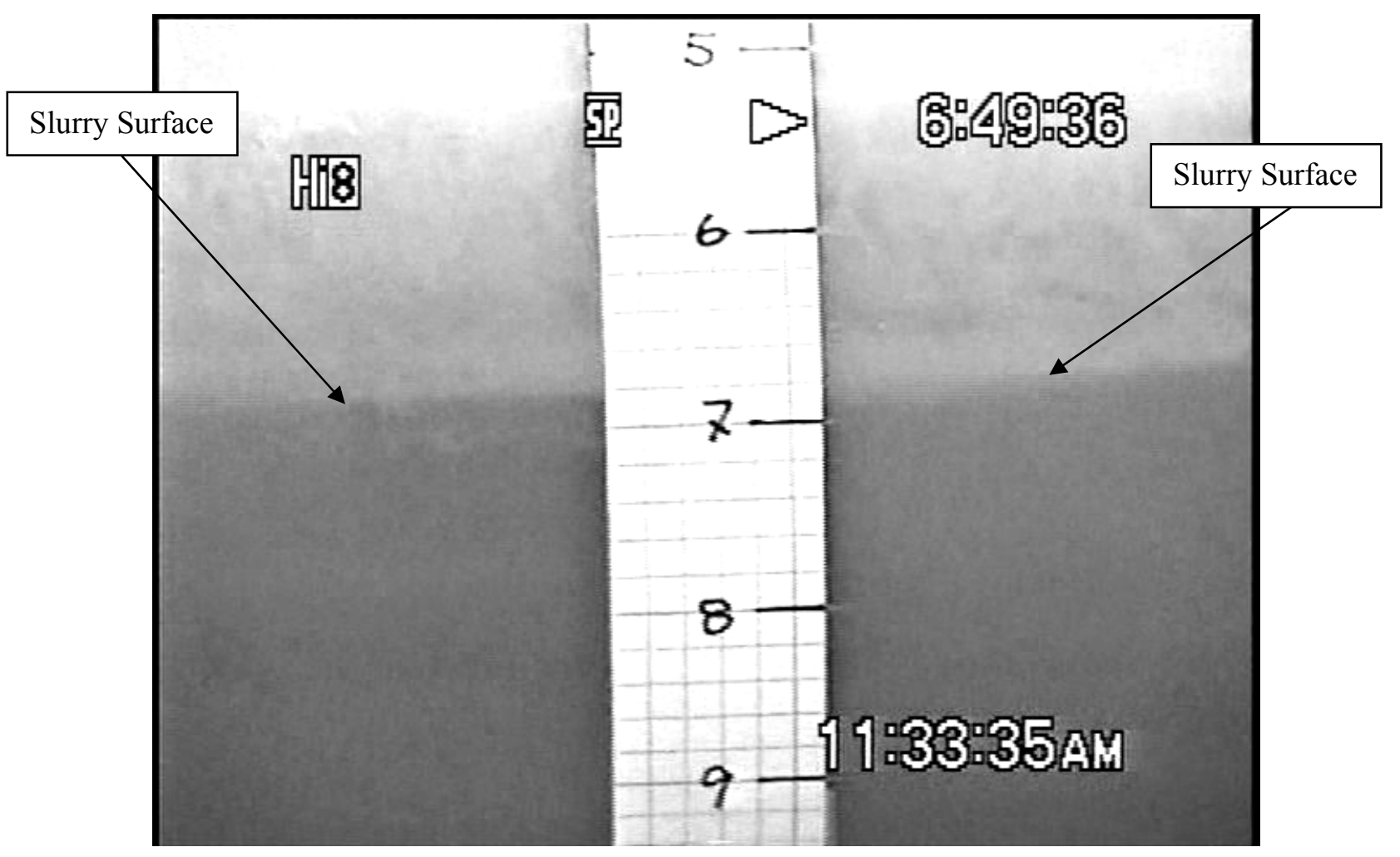

Figure A.54. Upstream, Slope $=1: 50$, Velocity $=4.0 \mathrm{ft} / \mathrm{s}$

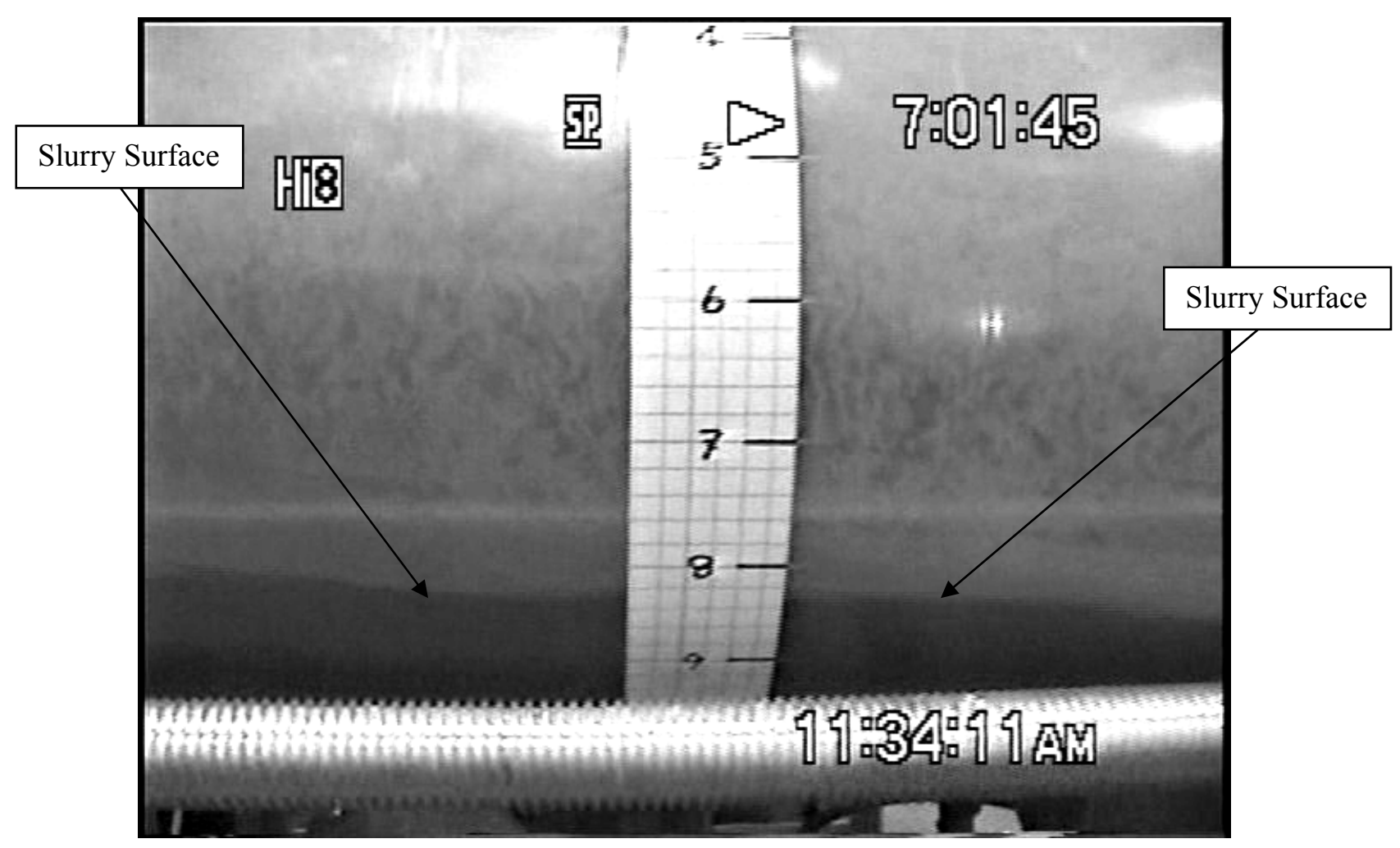

Figure A.55. Downstream, Slope $=1: 50$, Velocity $=4.0 \mathrm{ft} / \mathrm{s}$ 


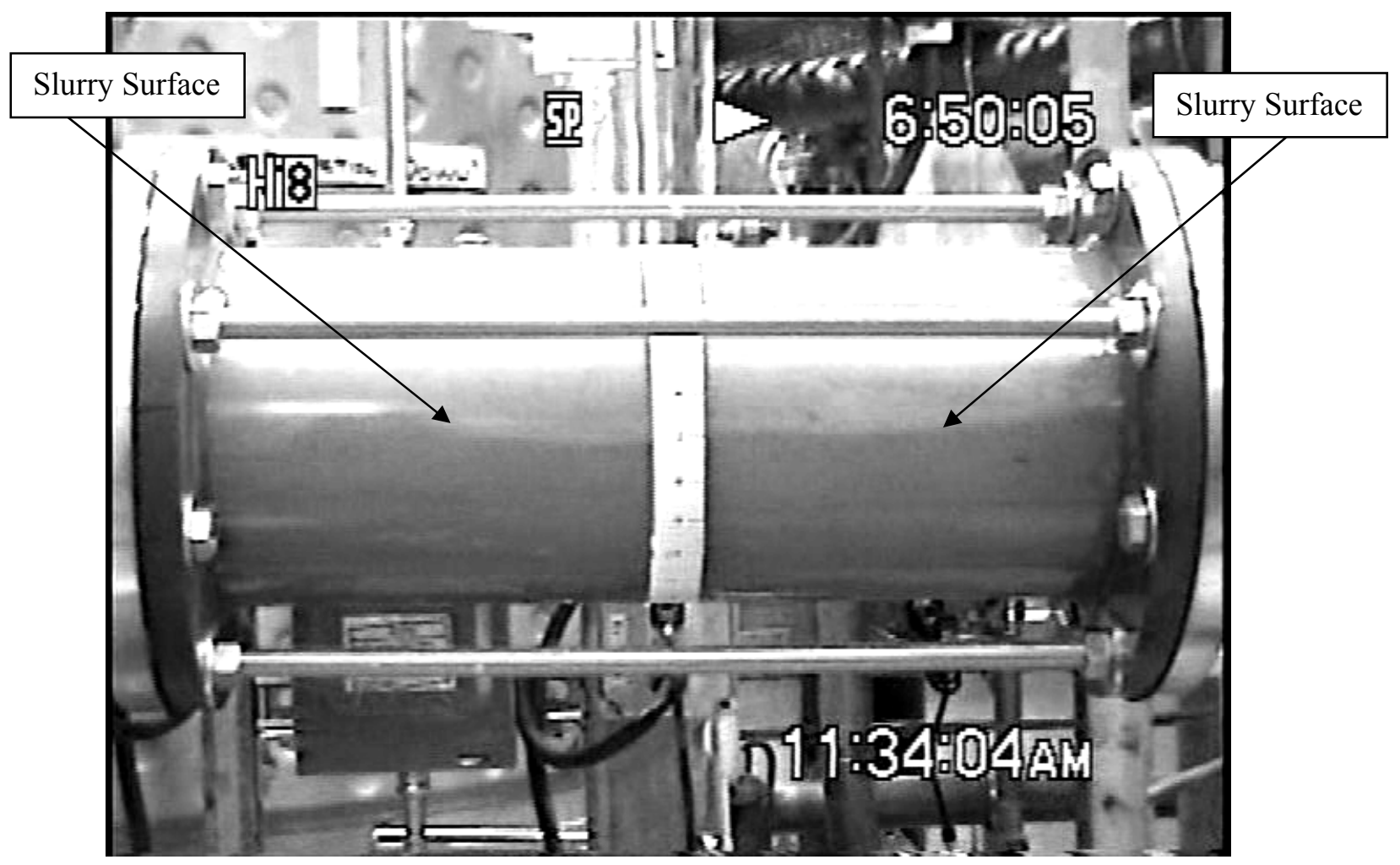

Figure A.56. Upstream, Slope $=1: 50$, Velocity $=4.0 \mathrm{ft} / \mathrm{s}$

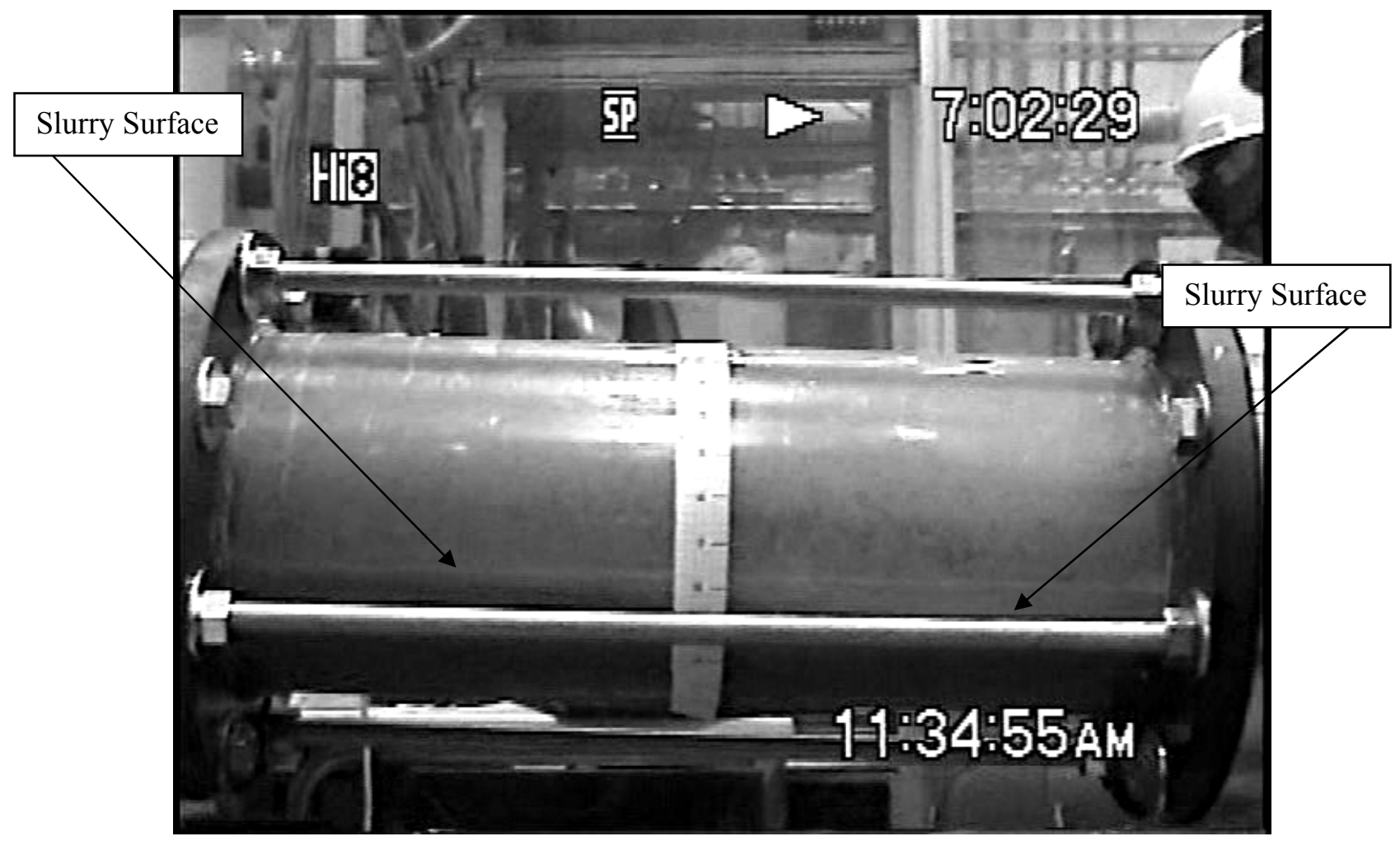

Figure A.57. Downstream, Slope $=1: 50$, Velocity $=4.0 \mathrm{ft} / \mathrm{s}$ 


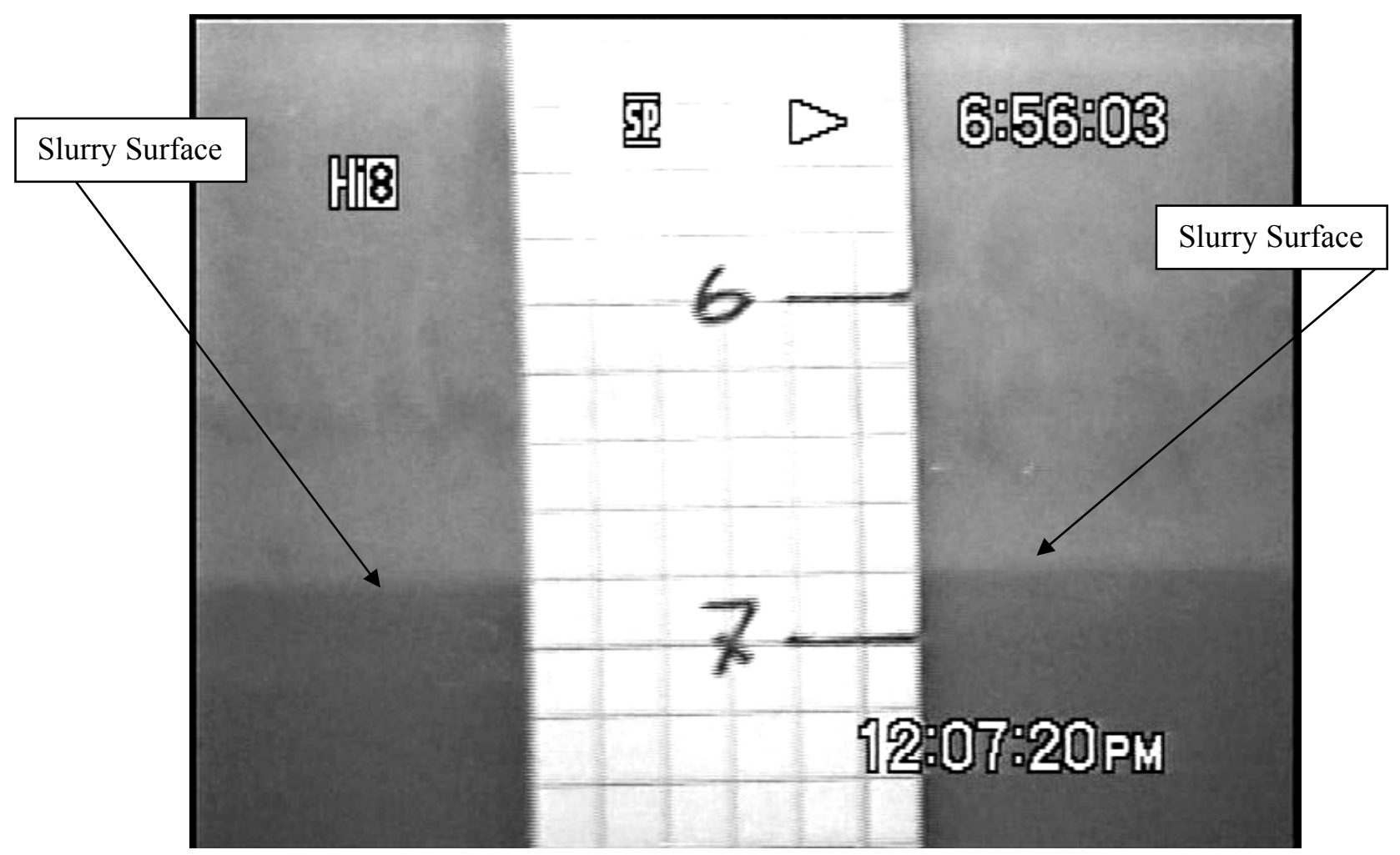

Figure A.58. Upstream, Slope $=1: 50$, Velocity $=3.0 \mathrm{ft} / \mathrm{s}$

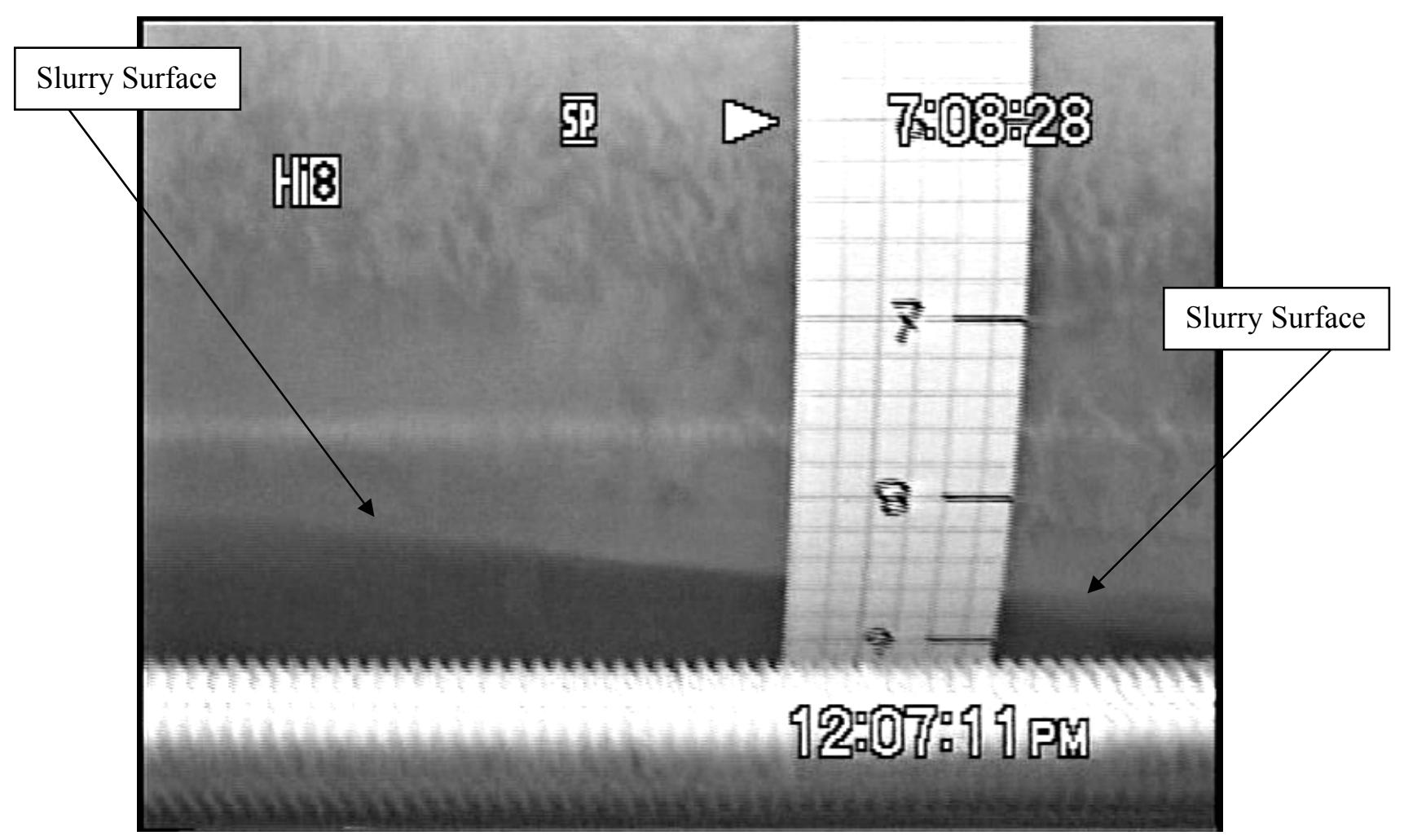

Figure A.59. Downstream, Slope $=1: 50$, Velocity $=3.0 \mathrm{ft} / \mathrm{s}$ 


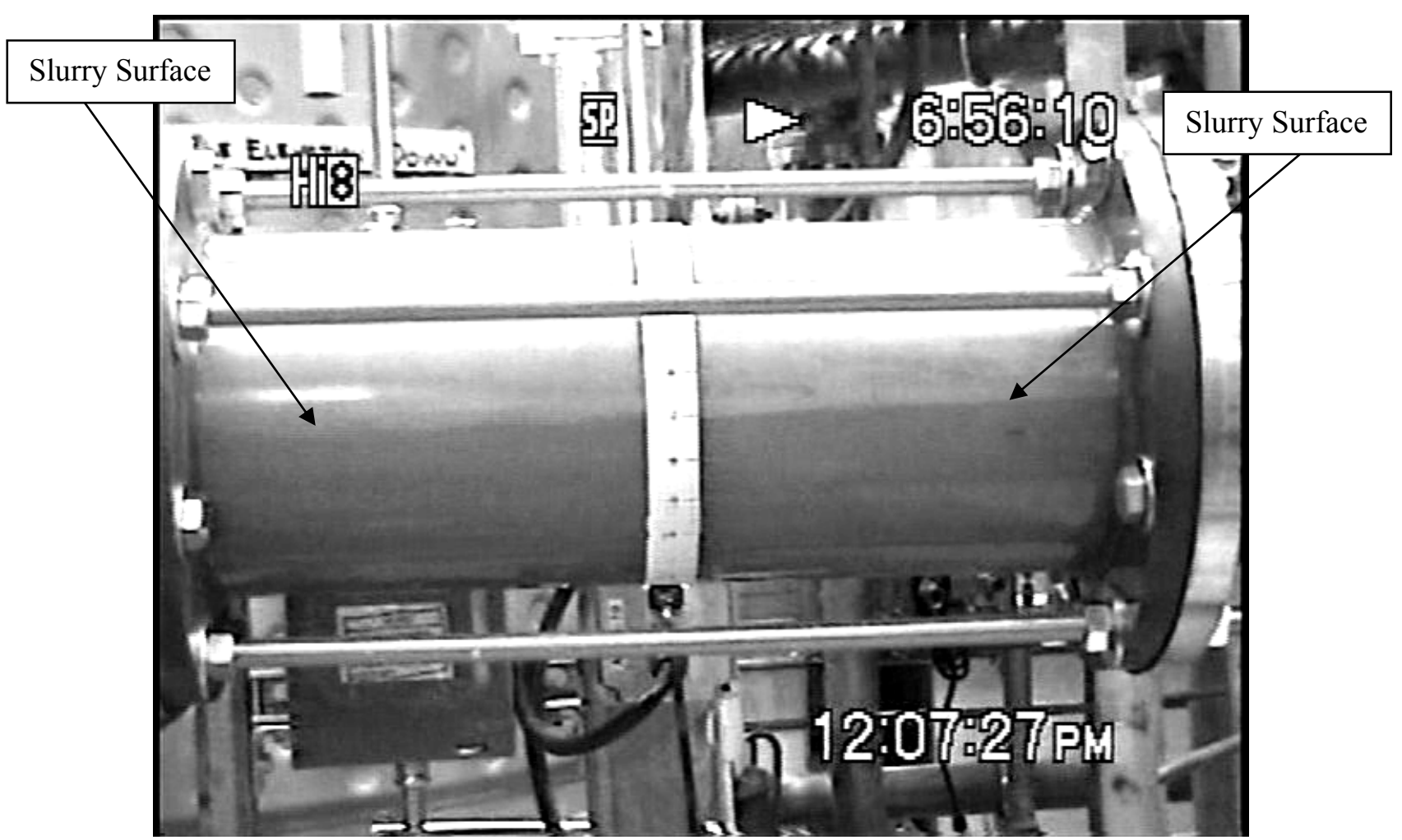

Figure A.60. Upstream, Slope $=1: 50$, Velocity $=3.0 \mathrm{ft} / \mathrm{s}$

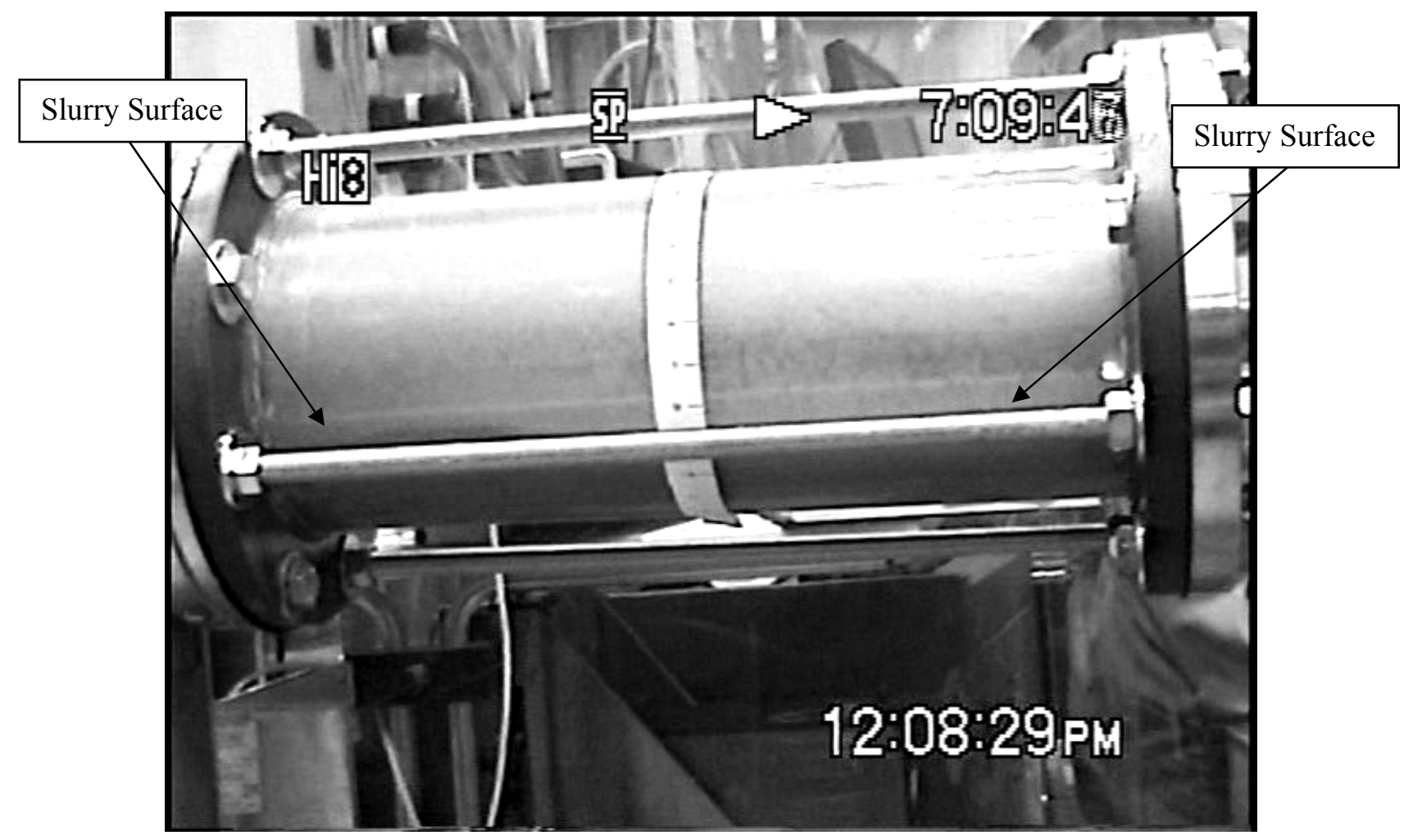

Figure A.61. Downstream, Slope $=1: 50$, Velocity $=3.0 \mathrm{ft} / \mathrm{s}$ 


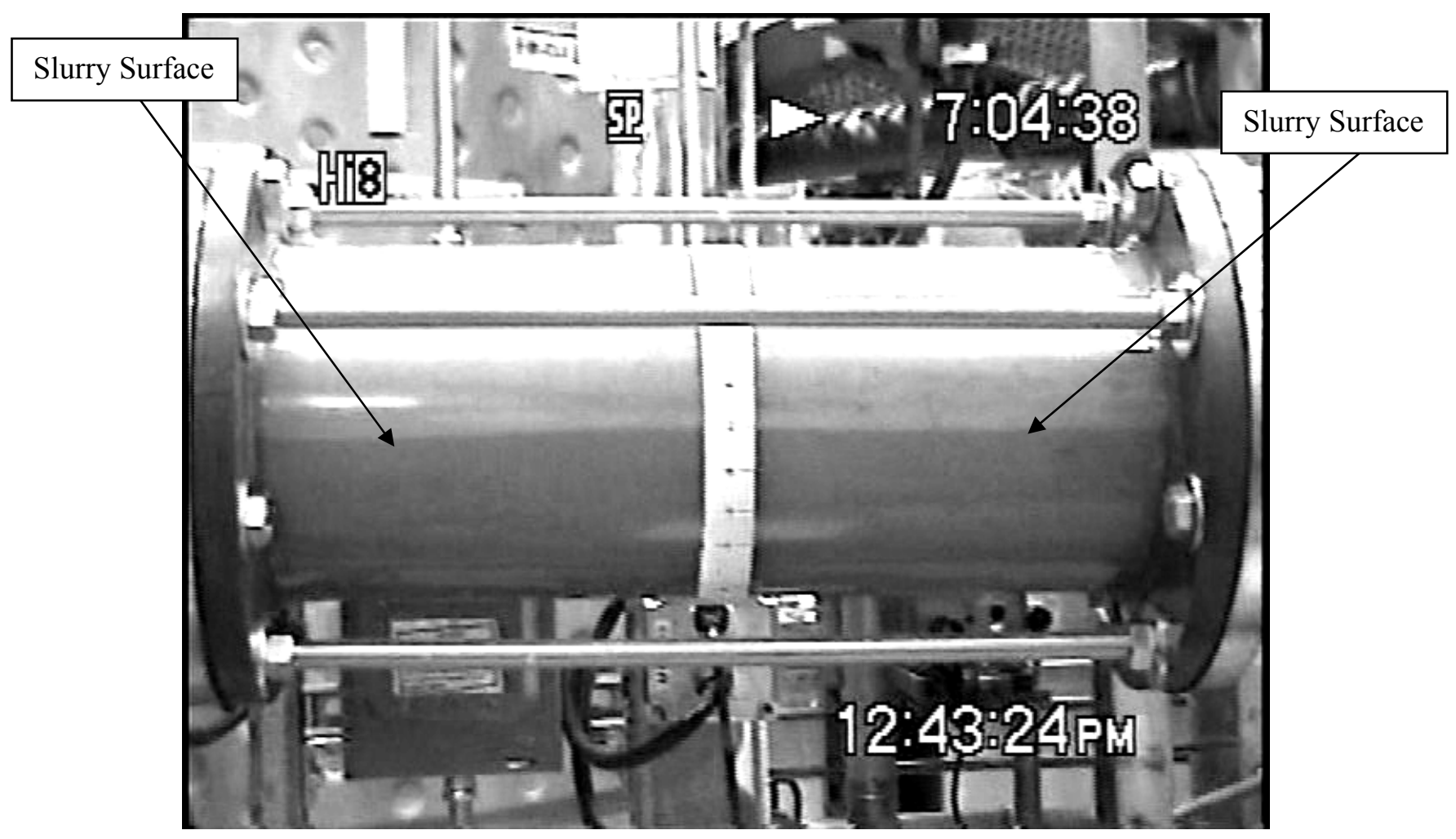

Figure A.62. Upstream, Slope $=1: 50$, Velocity $=2.0 \mathrm{ft} / \mathrm{s}$

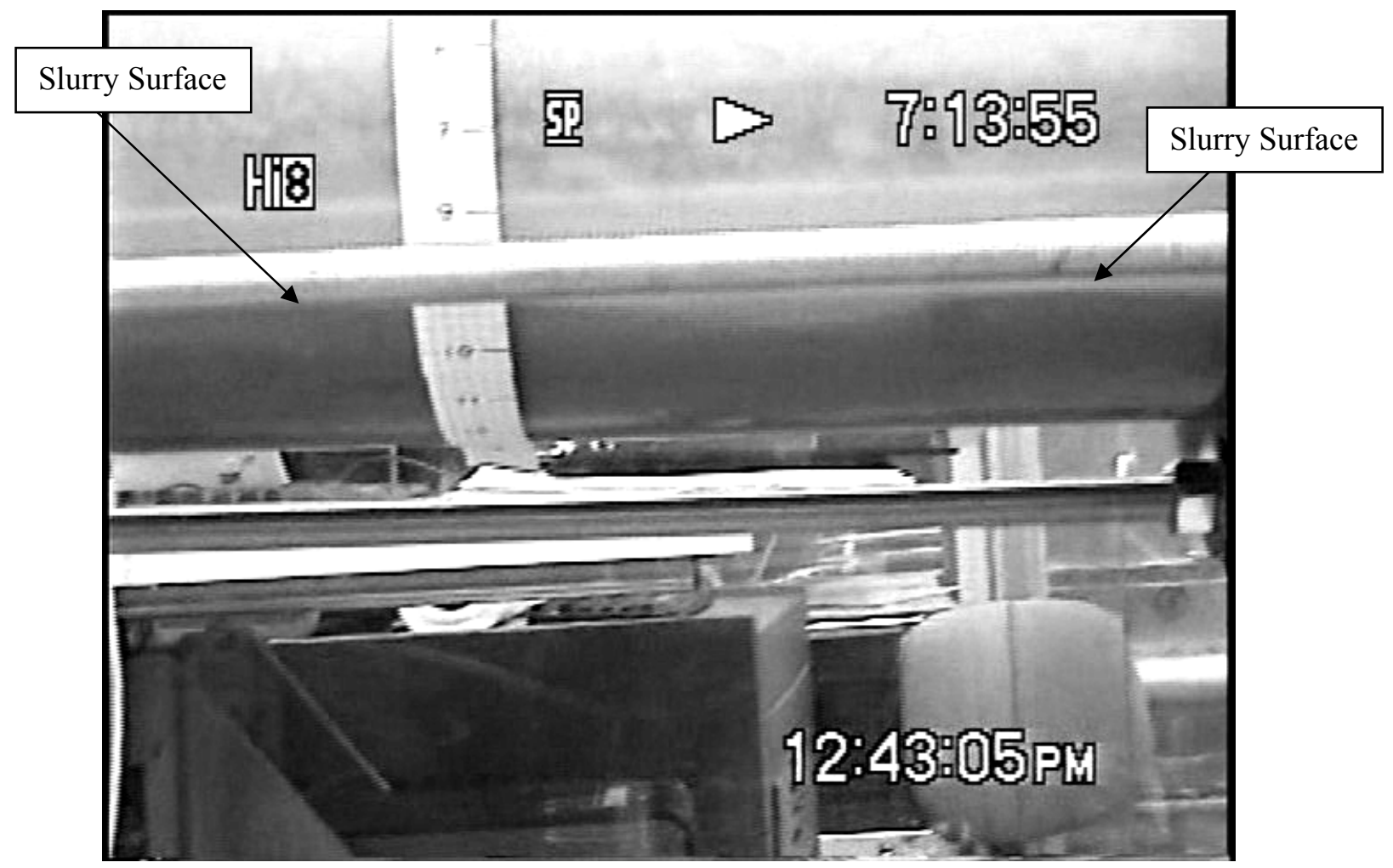

Figure A.63. Downstream, Slope $=1: 50$, Velocity $=2.0 \mathrm{ft} / \mathrm{s}$ 


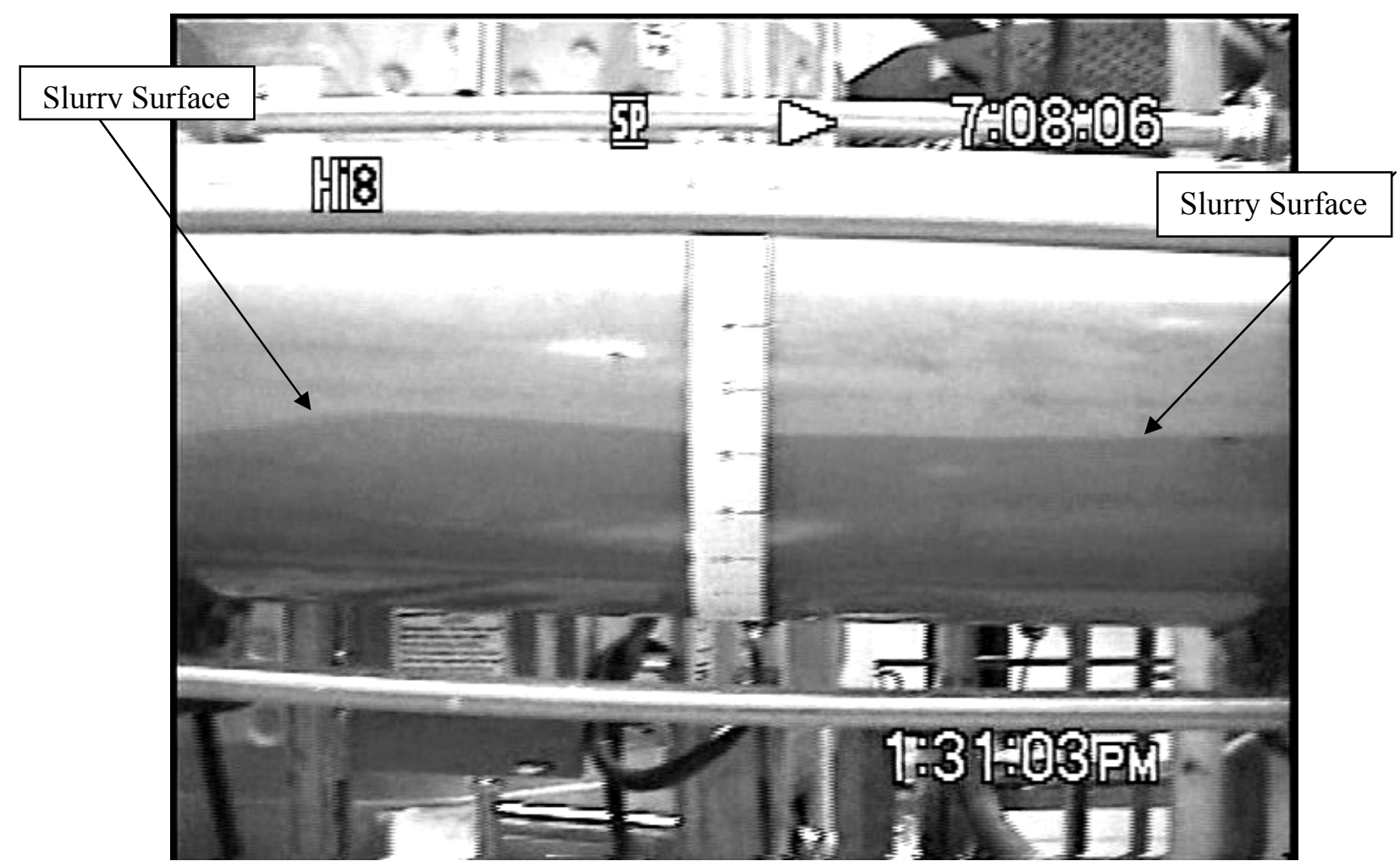

Figure A.64. Upstream, Slope $=1: 50$, Velocity $=1.0 \mathrm{ft} / \mathrm{s}$

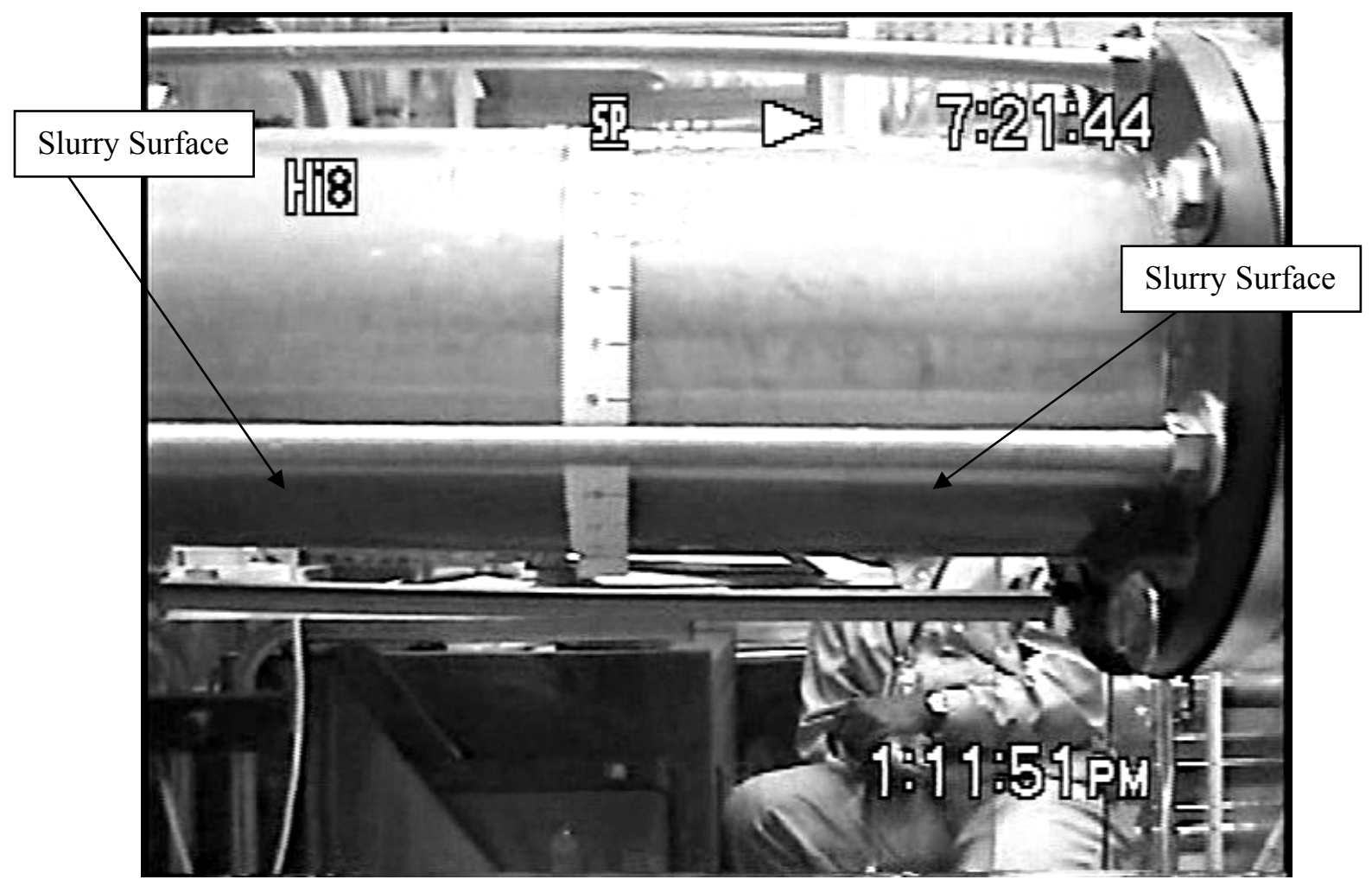

Figure A.65. Downstream, Slope $=1: 50$, Velocity $=1.0 \mathrm{ft} / \mathrm{s}$ 


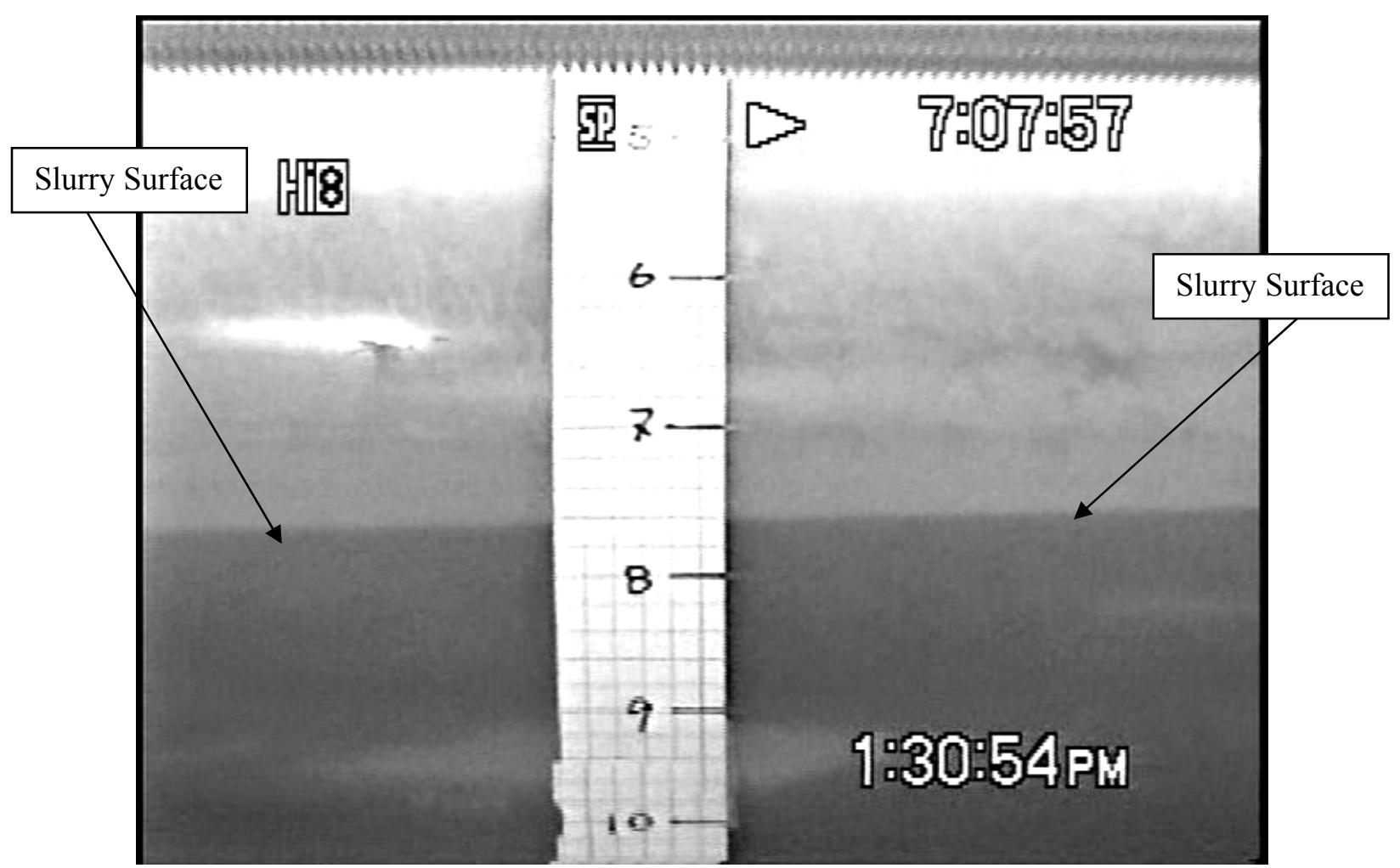

Figure A.66. Upstream, Slope $=1: 50$, Velocity $=1.0 \mathrm{ft} / \mathrm{s}$

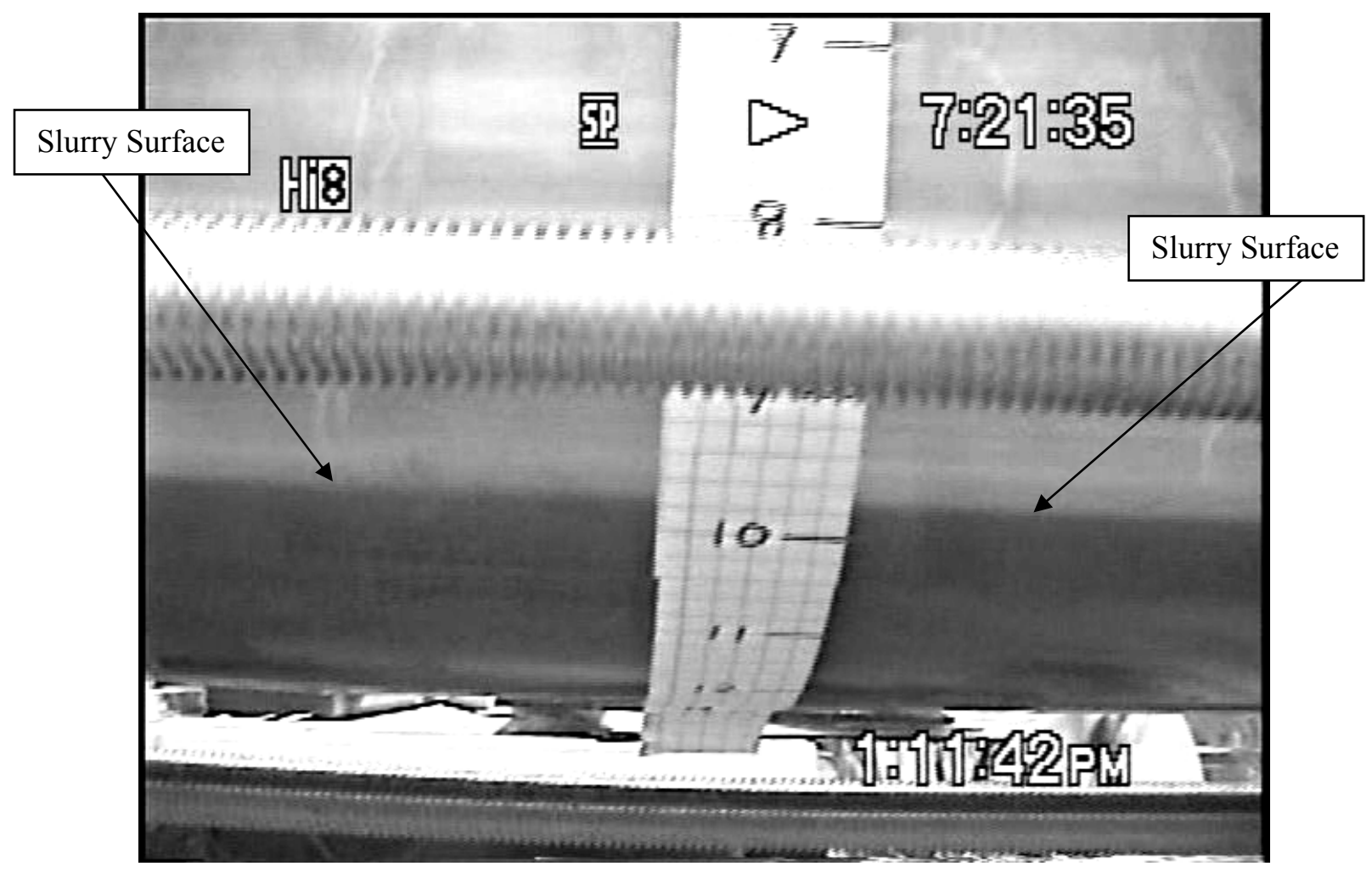

Figure A.67. Downstream, Slope $=1: 50$, Velocity $=1.0 \mathrm{ft} / \mathrm{s}$ 
Appendix B: Sketches of Slurry in Transparent Sections During Gravity-Driven Partially-Filled Pipe Flow Test Conditions 


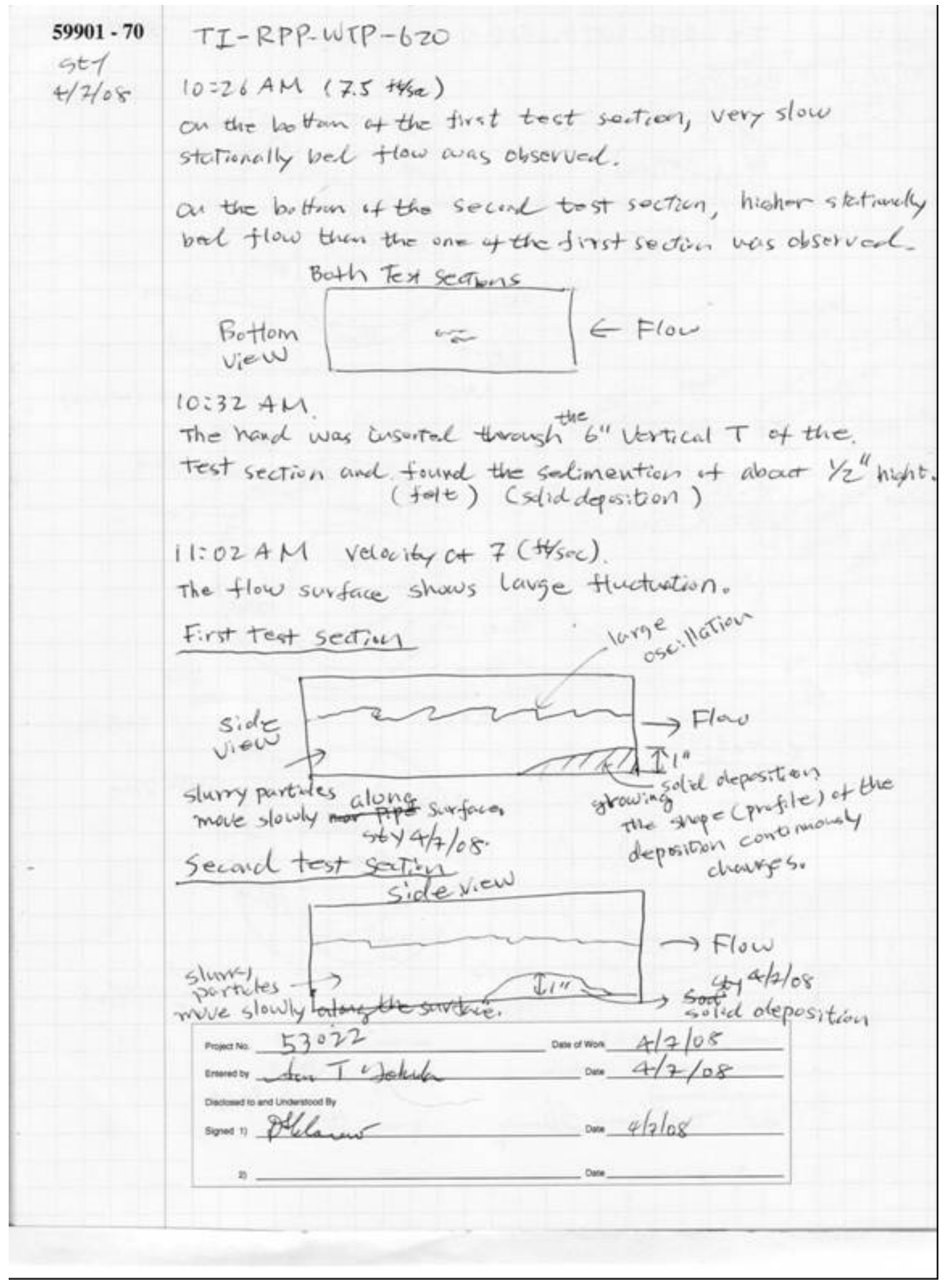




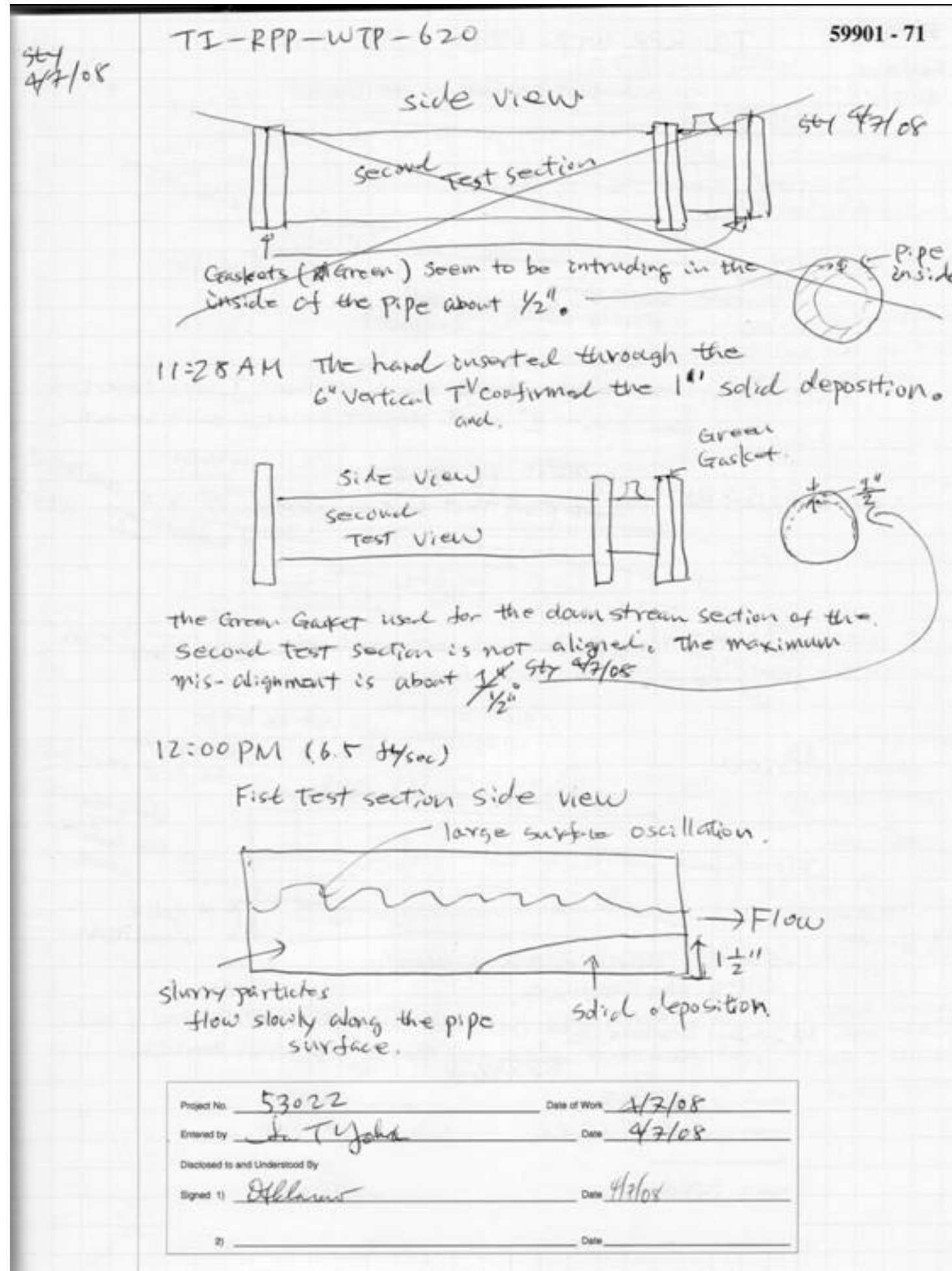




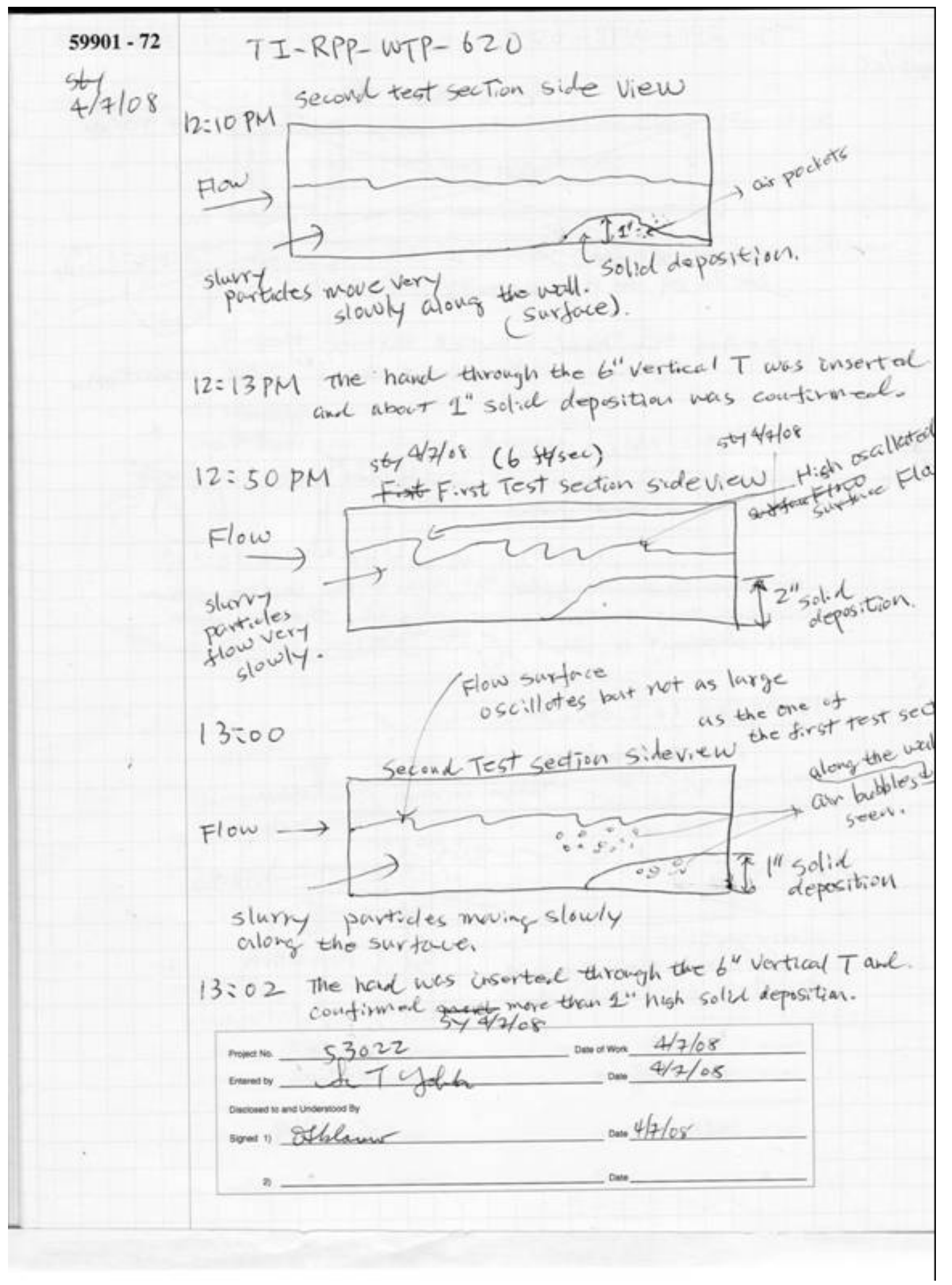




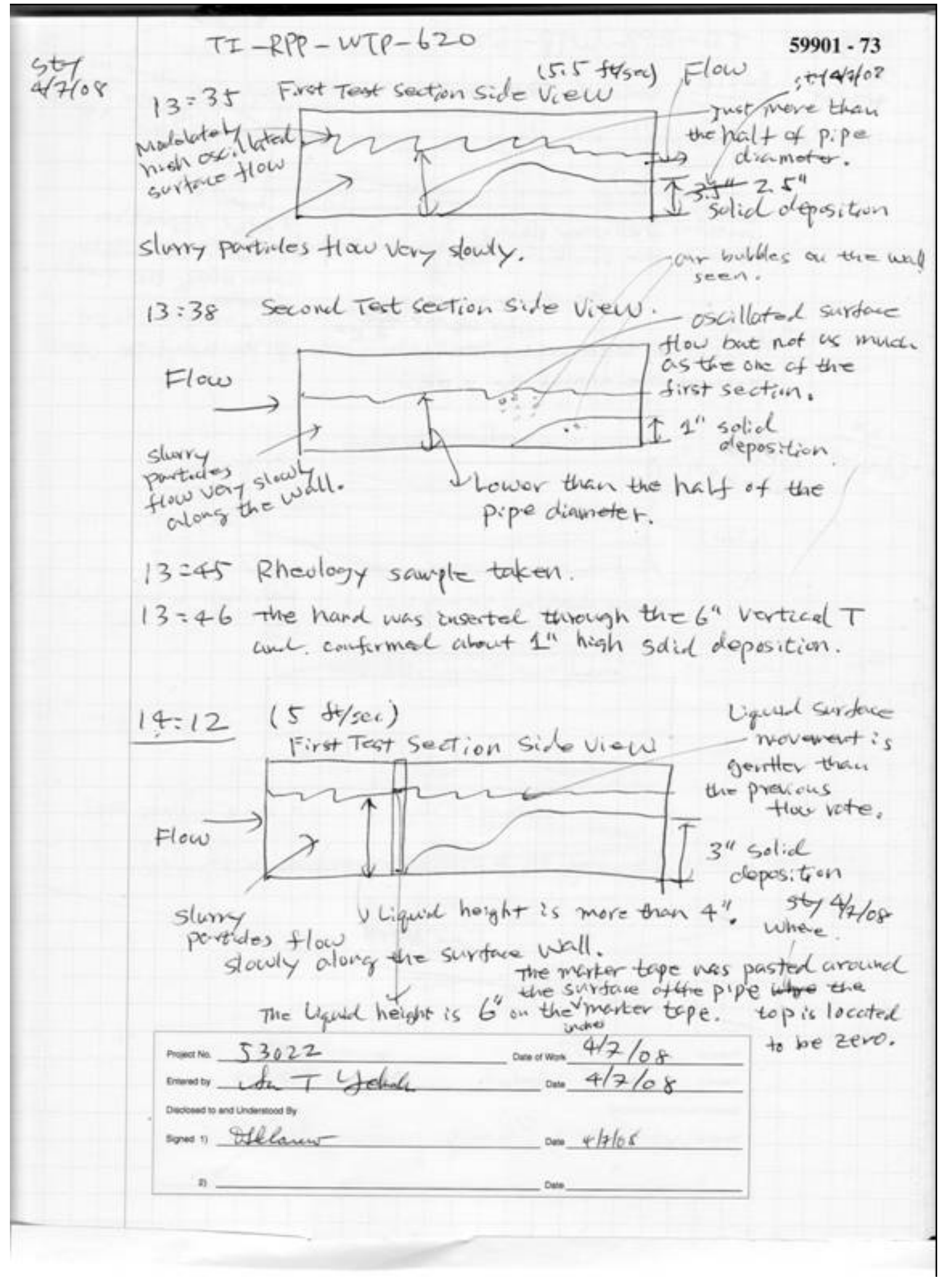




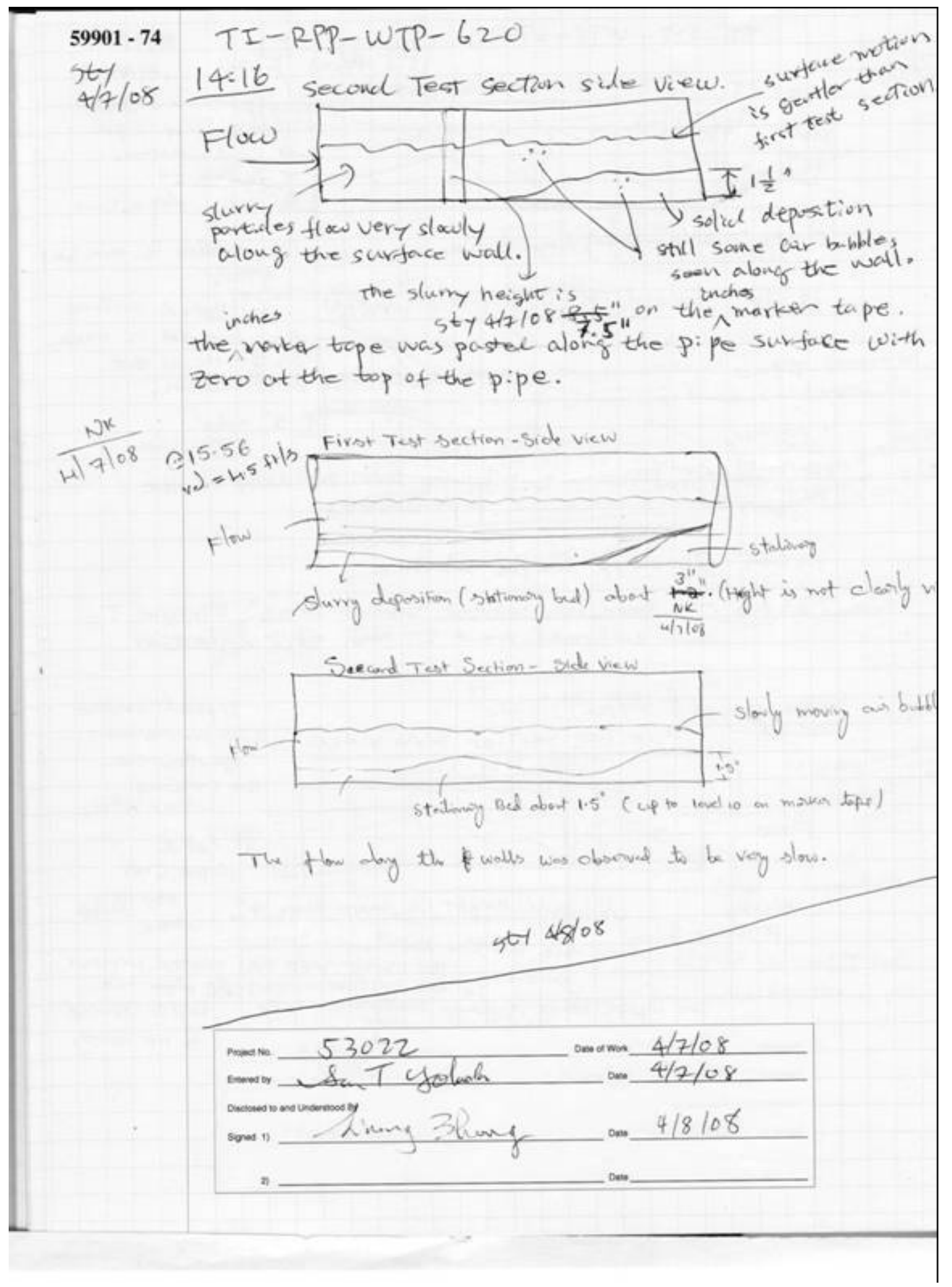




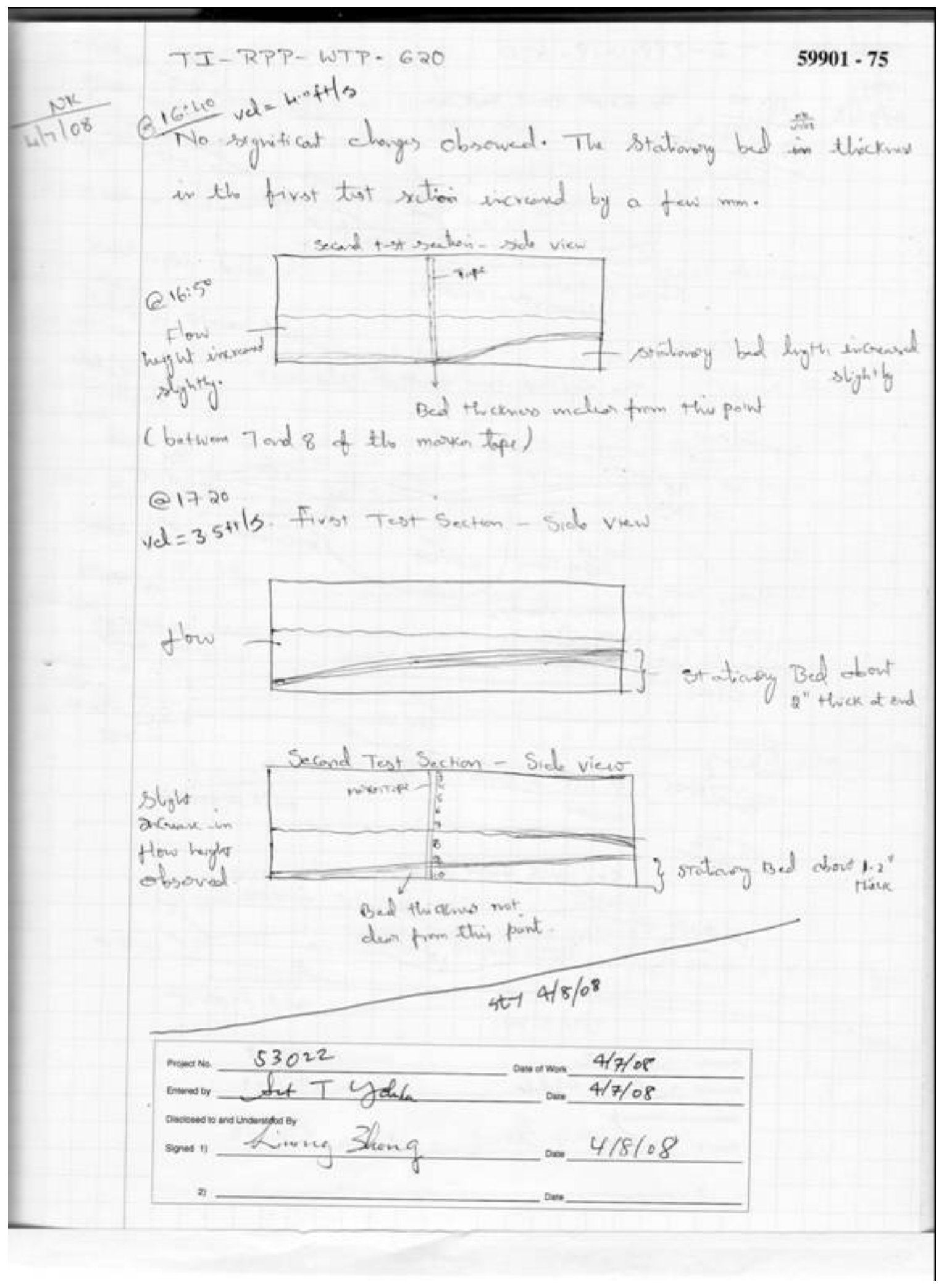




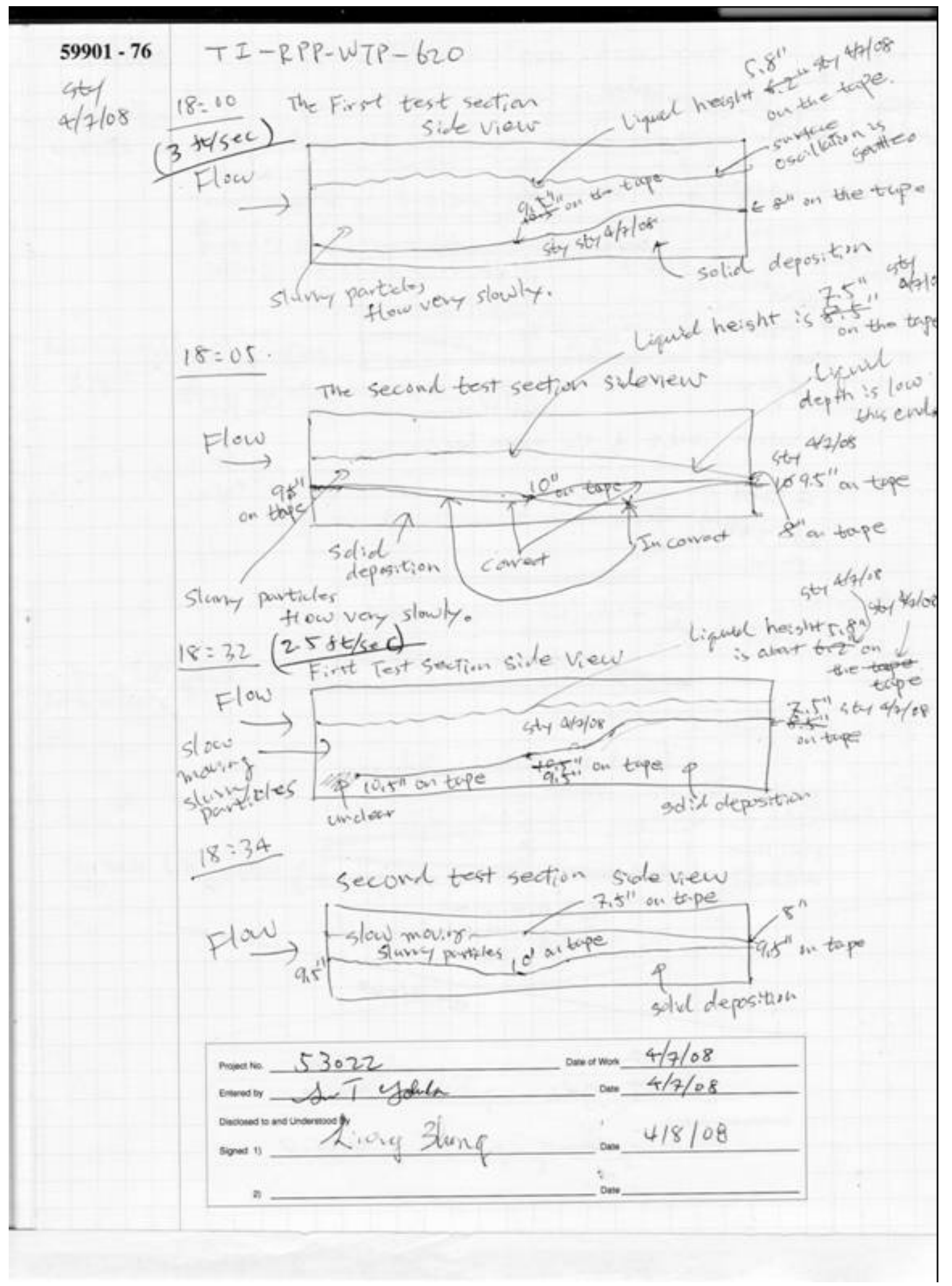


$5+1$ $4 / 7 / 08$

$19=00$ The tirst test section sile view

(2 $f 4 / s-c)$ Flow

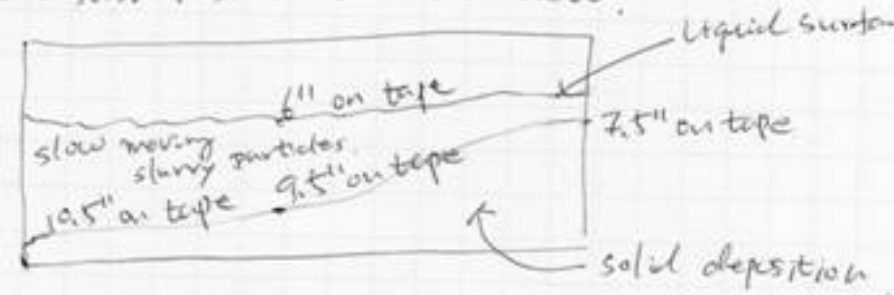

$19=08$

The second test section

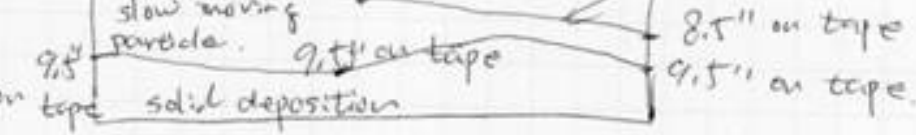

$19=38$

No flow

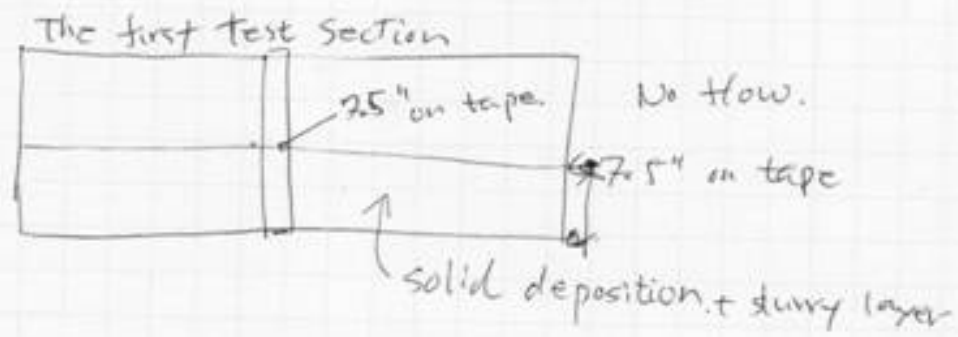

The second test section

No flow
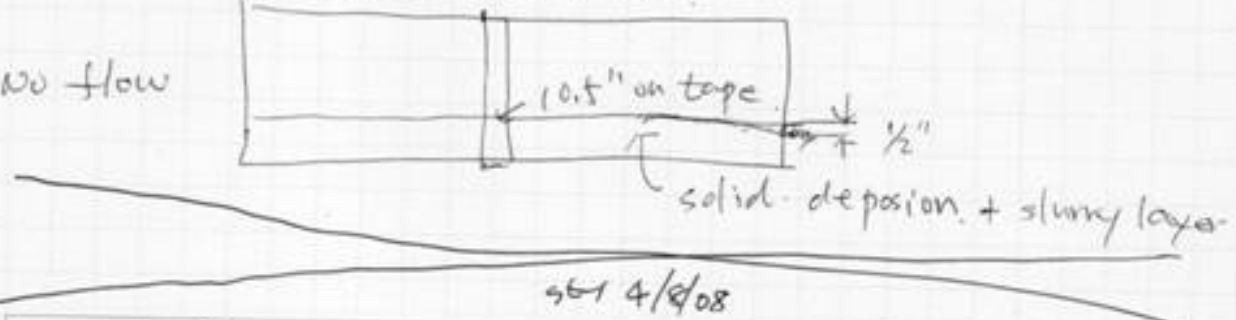

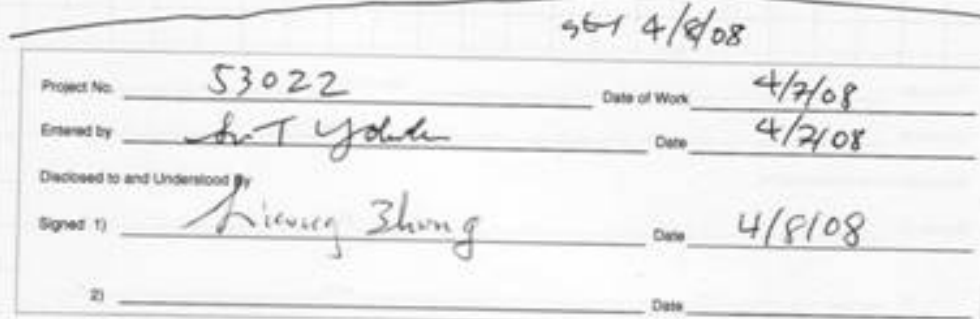




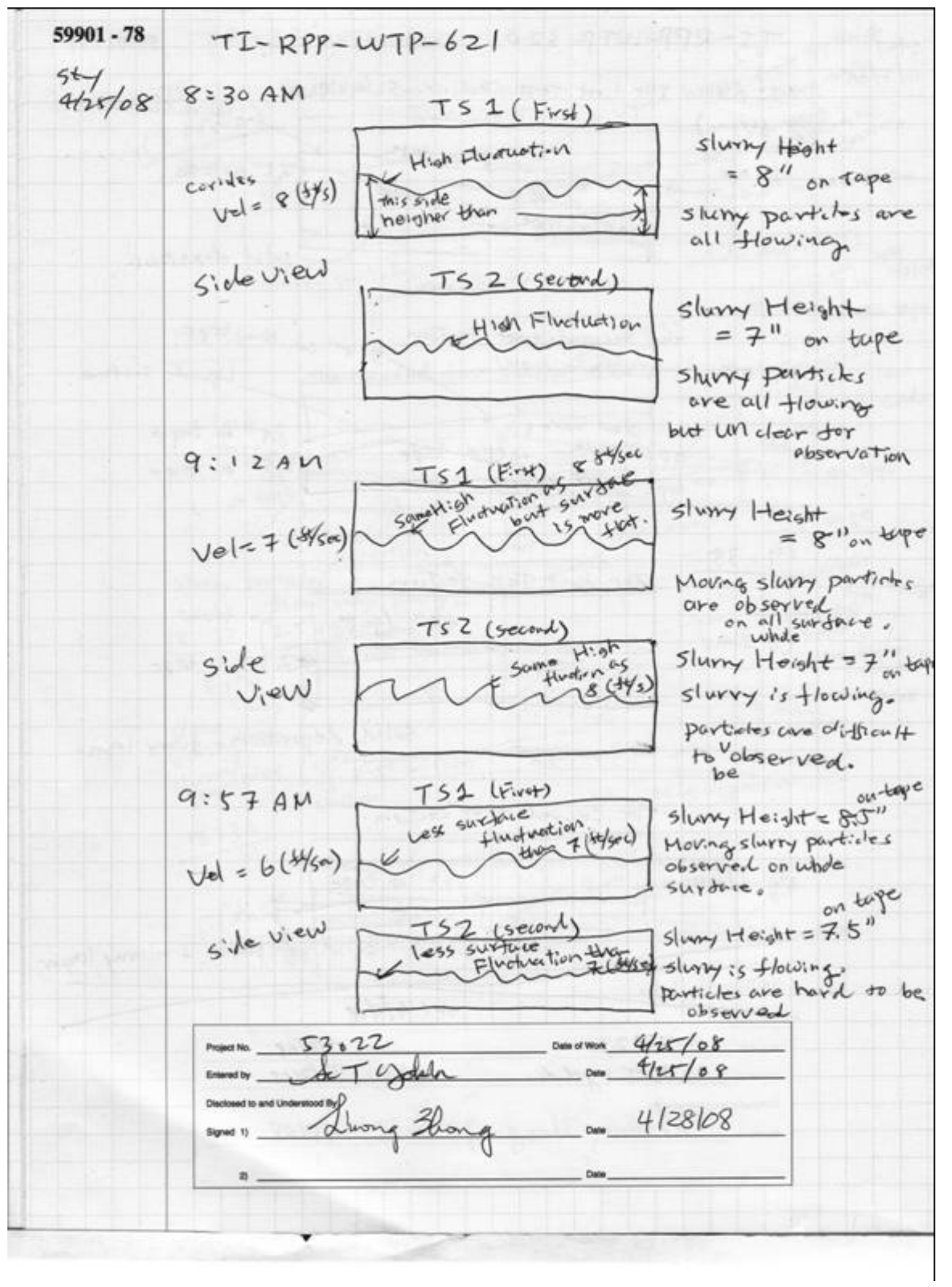




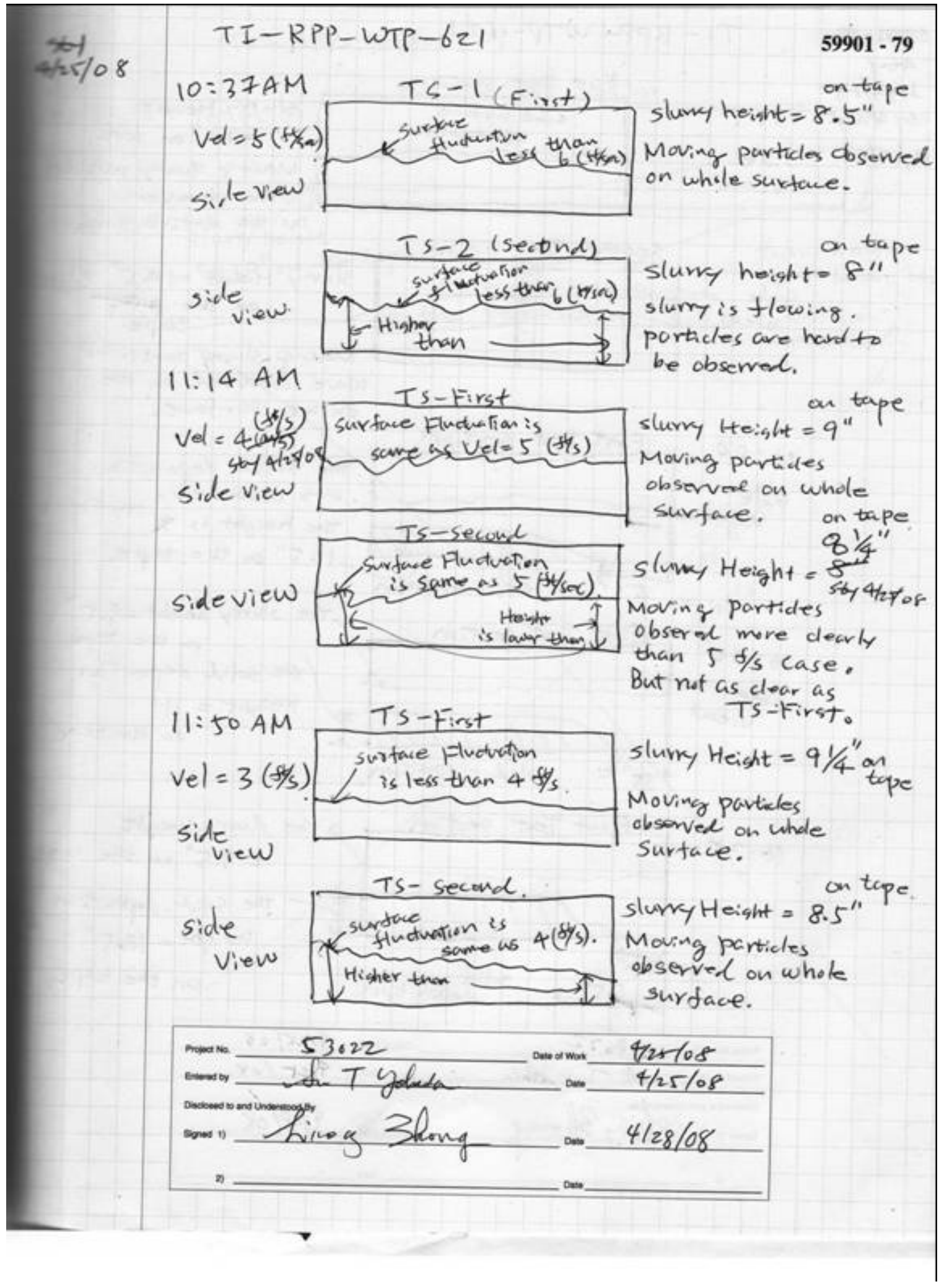




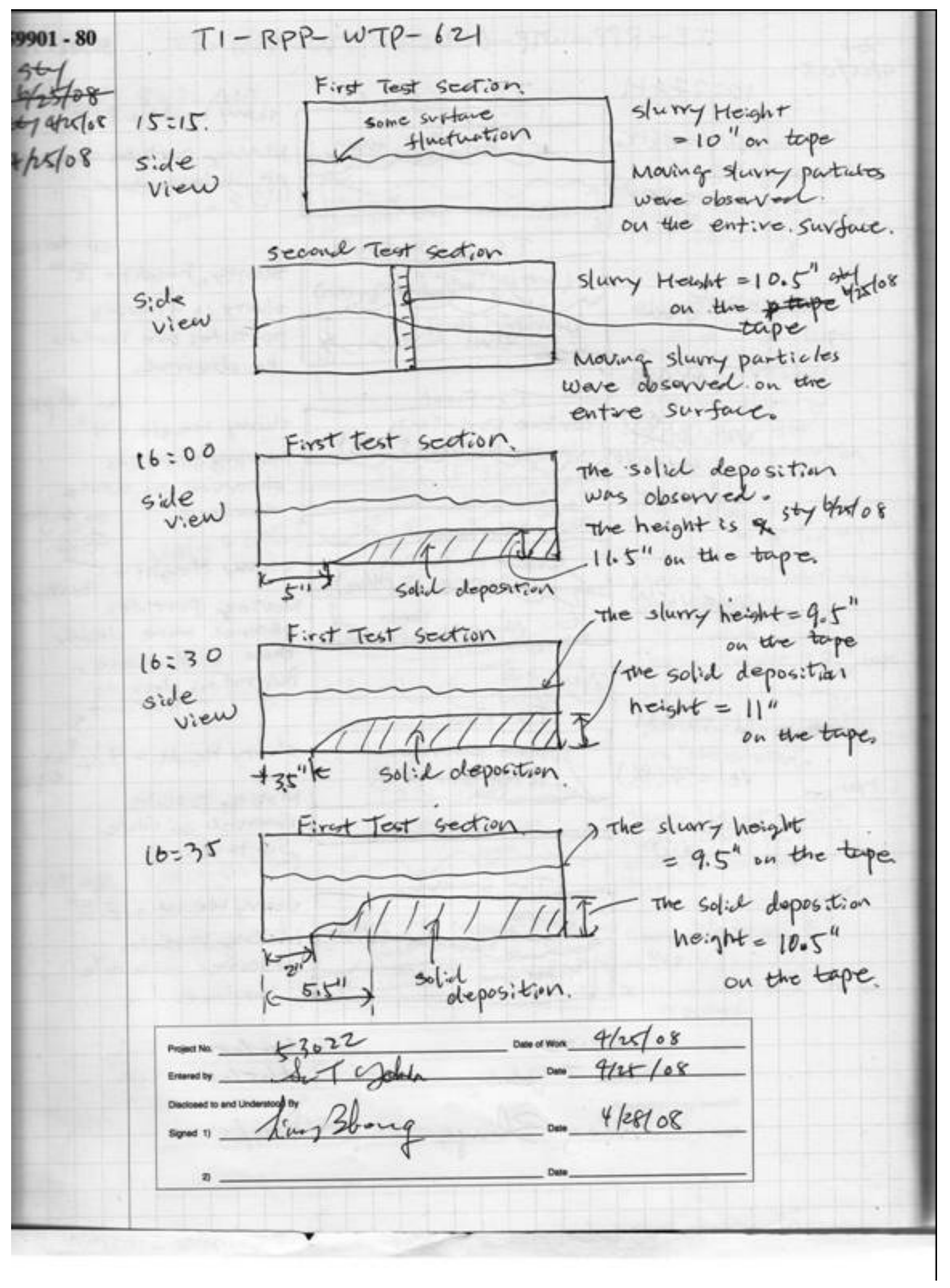




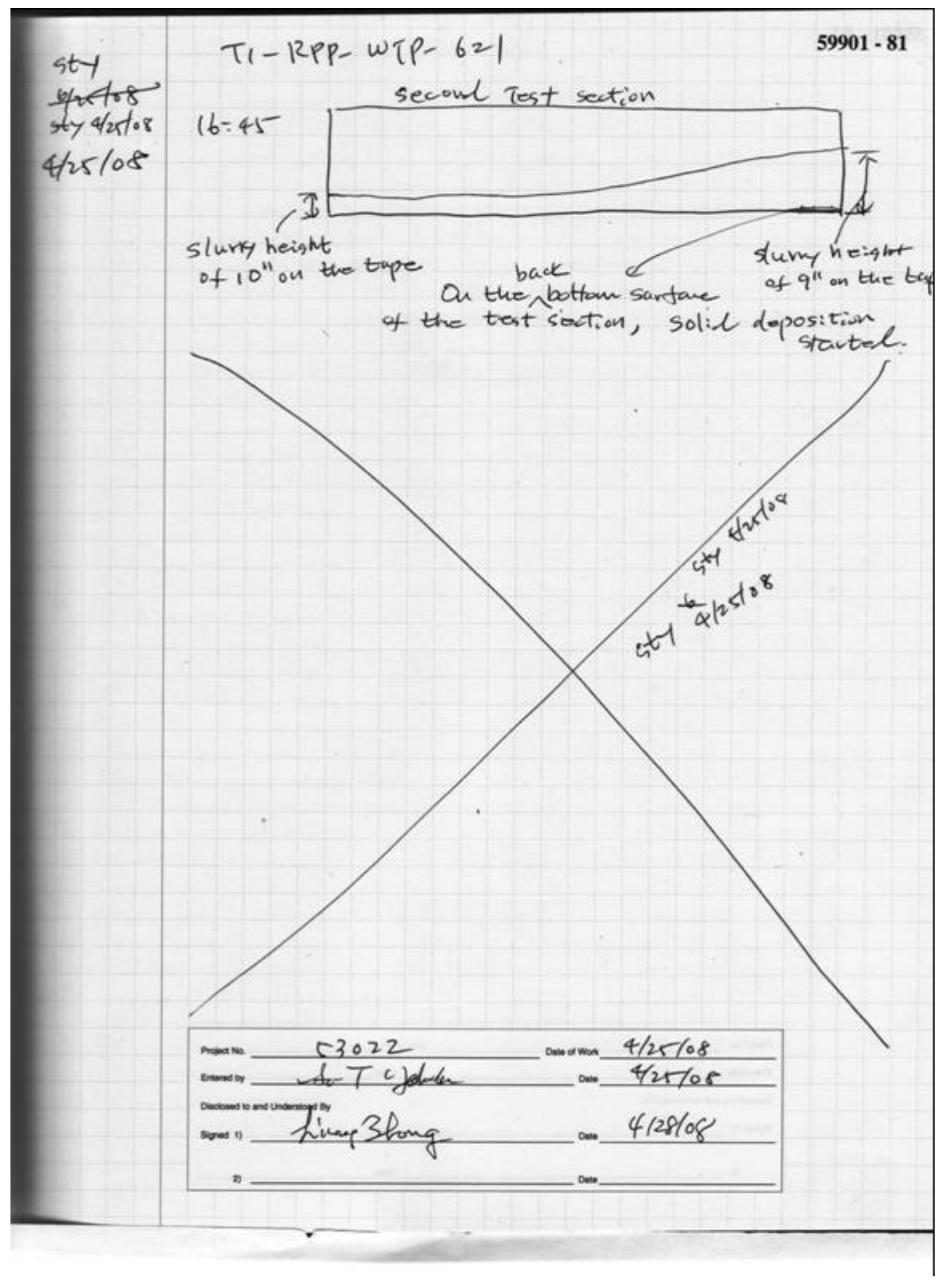

B. 13 


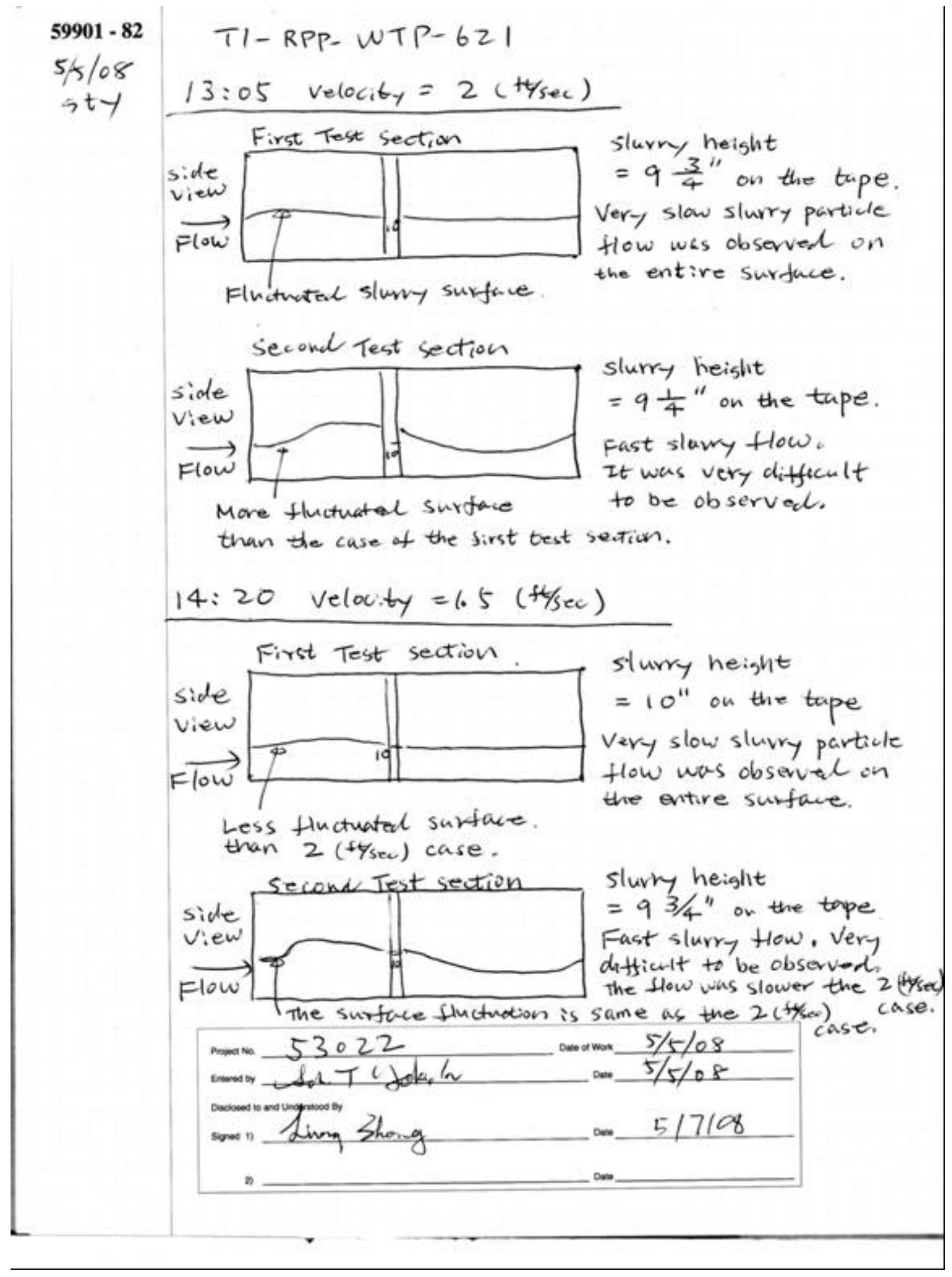




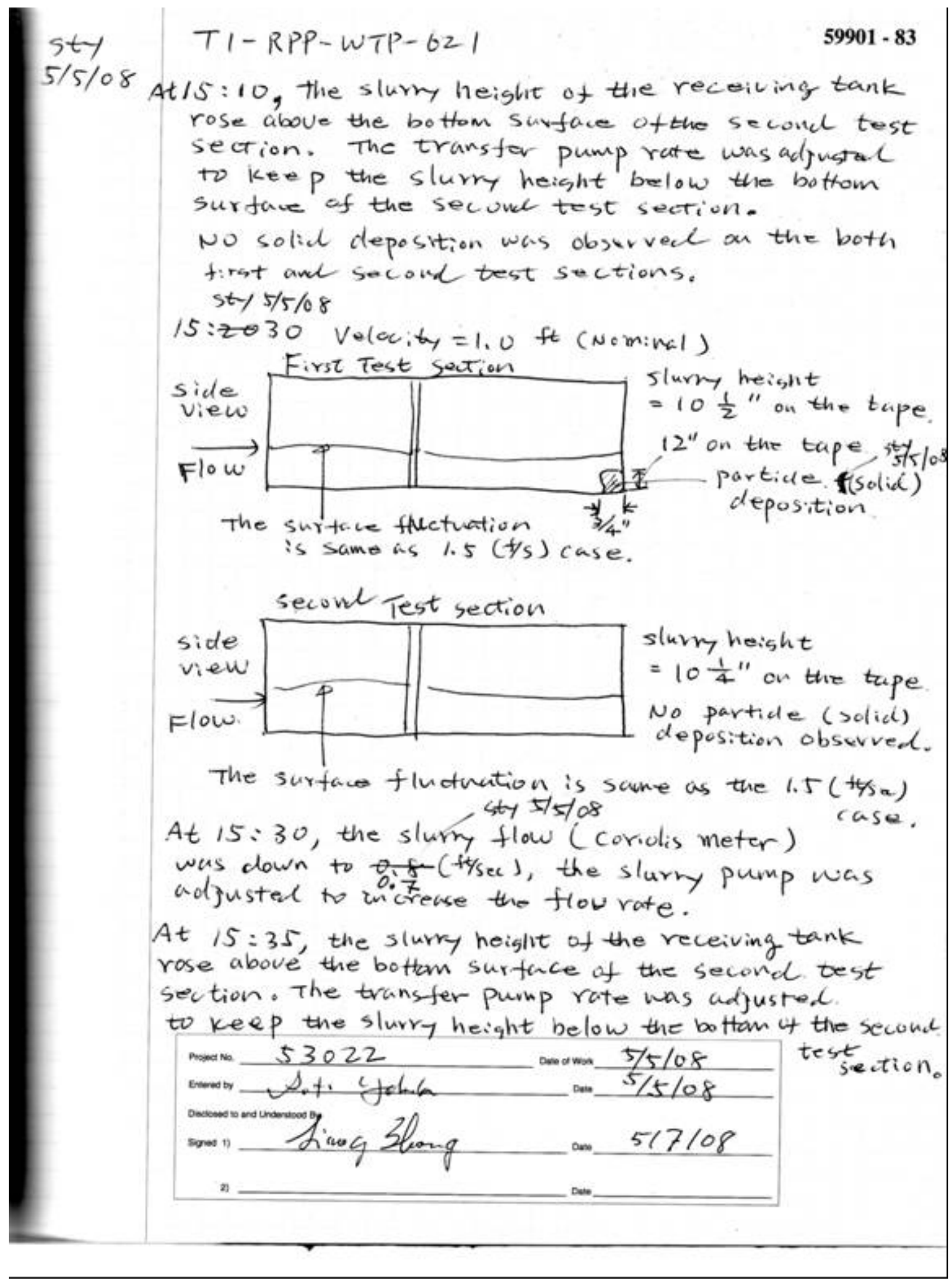




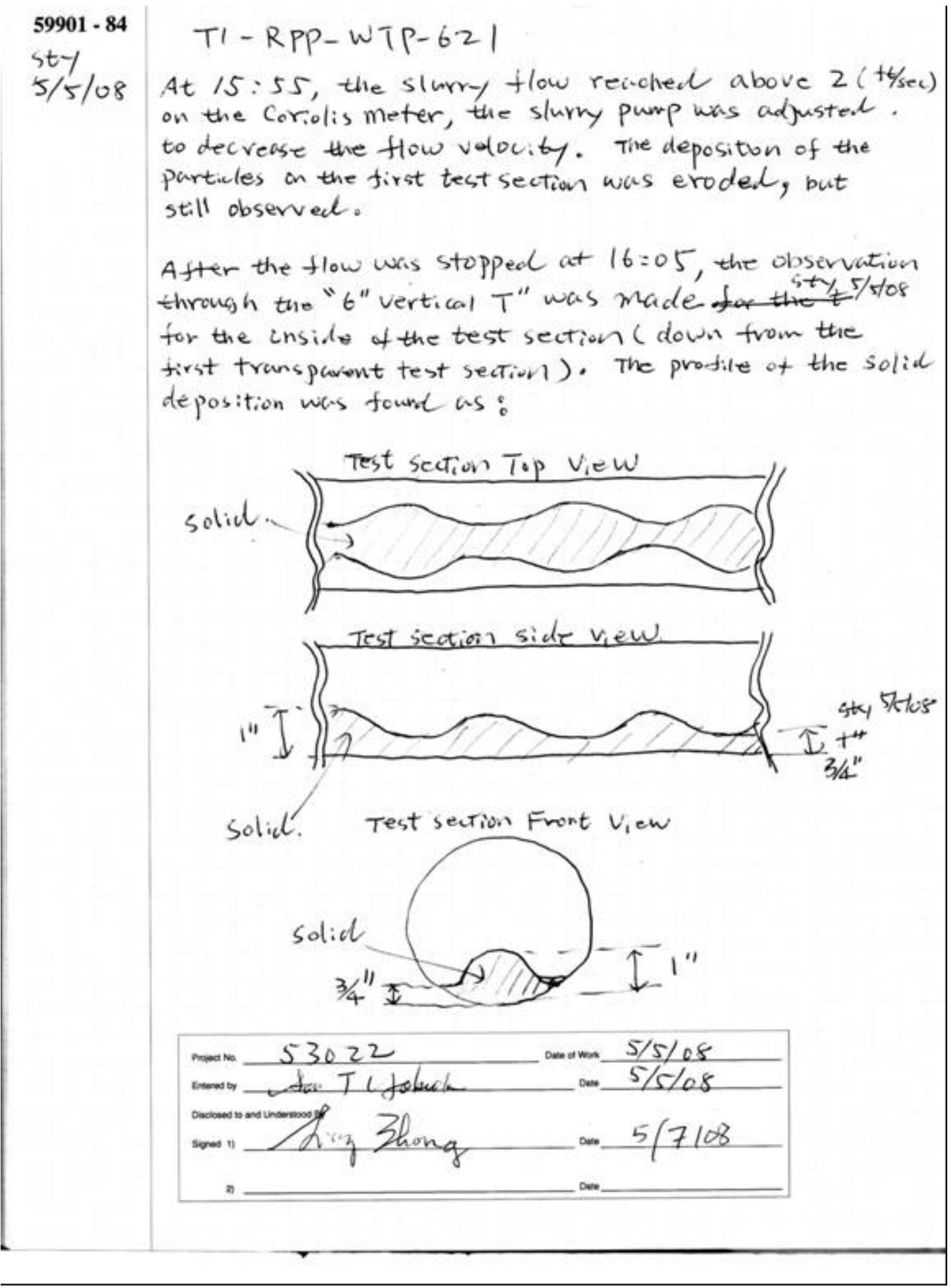




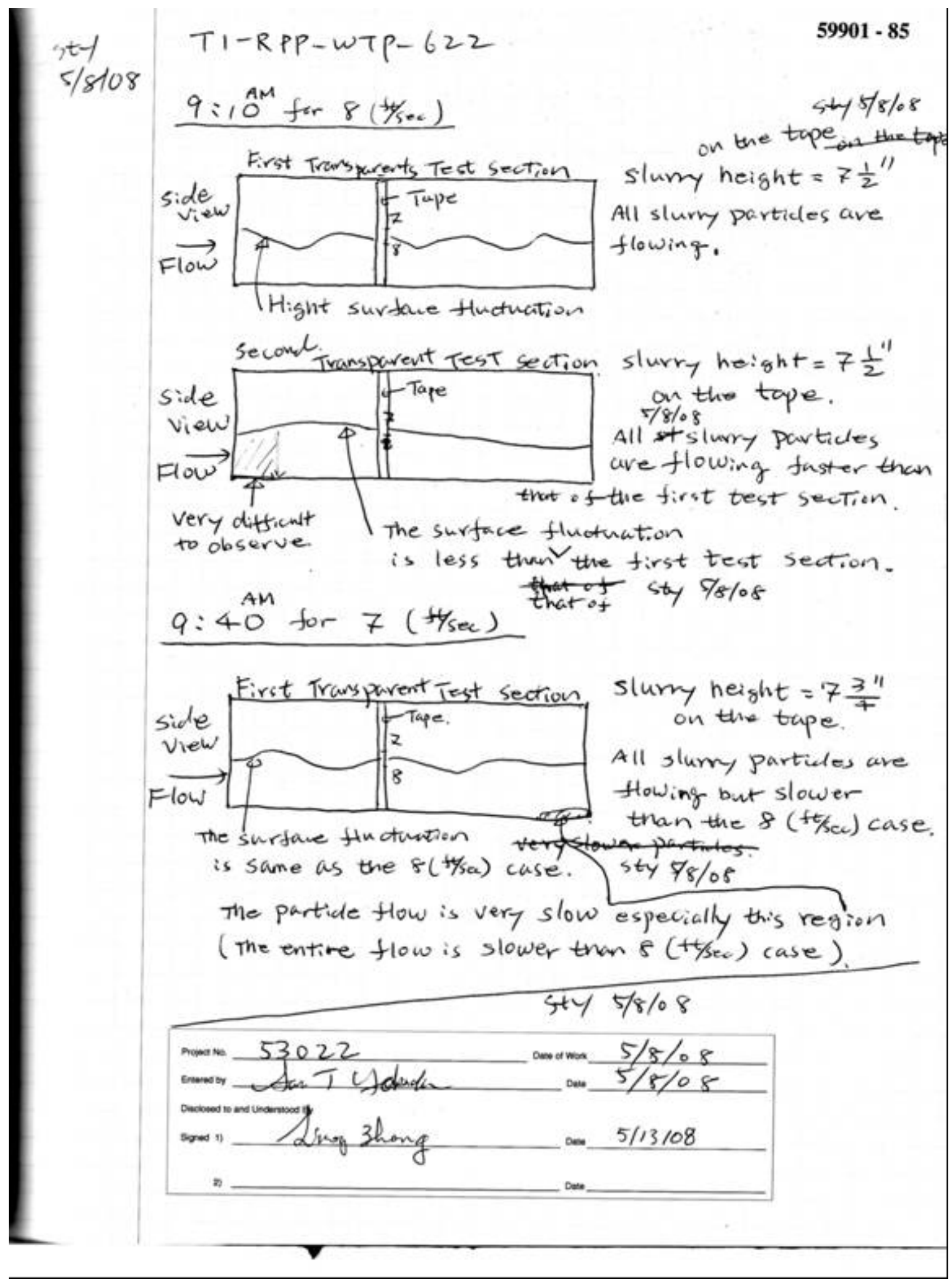




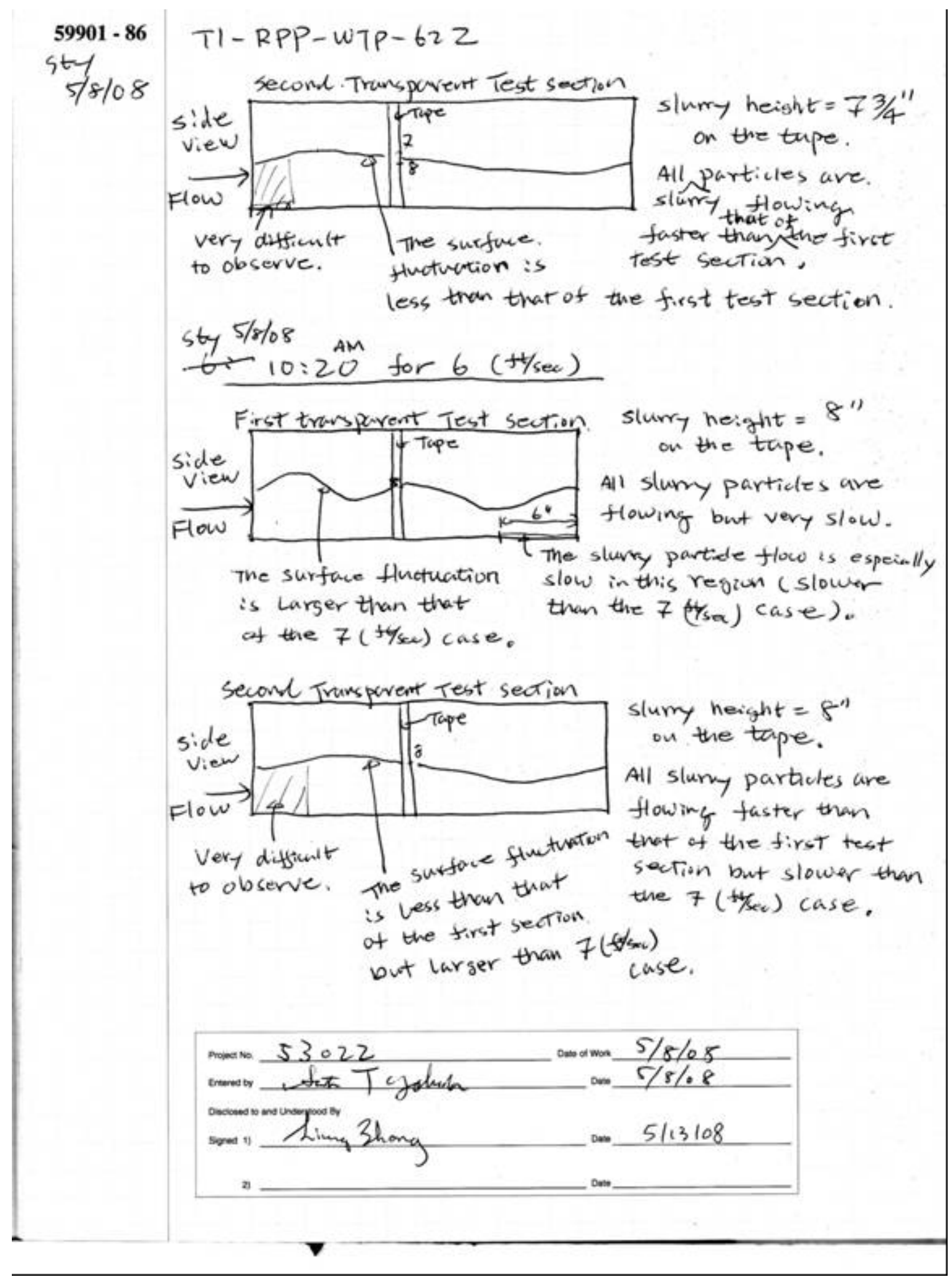




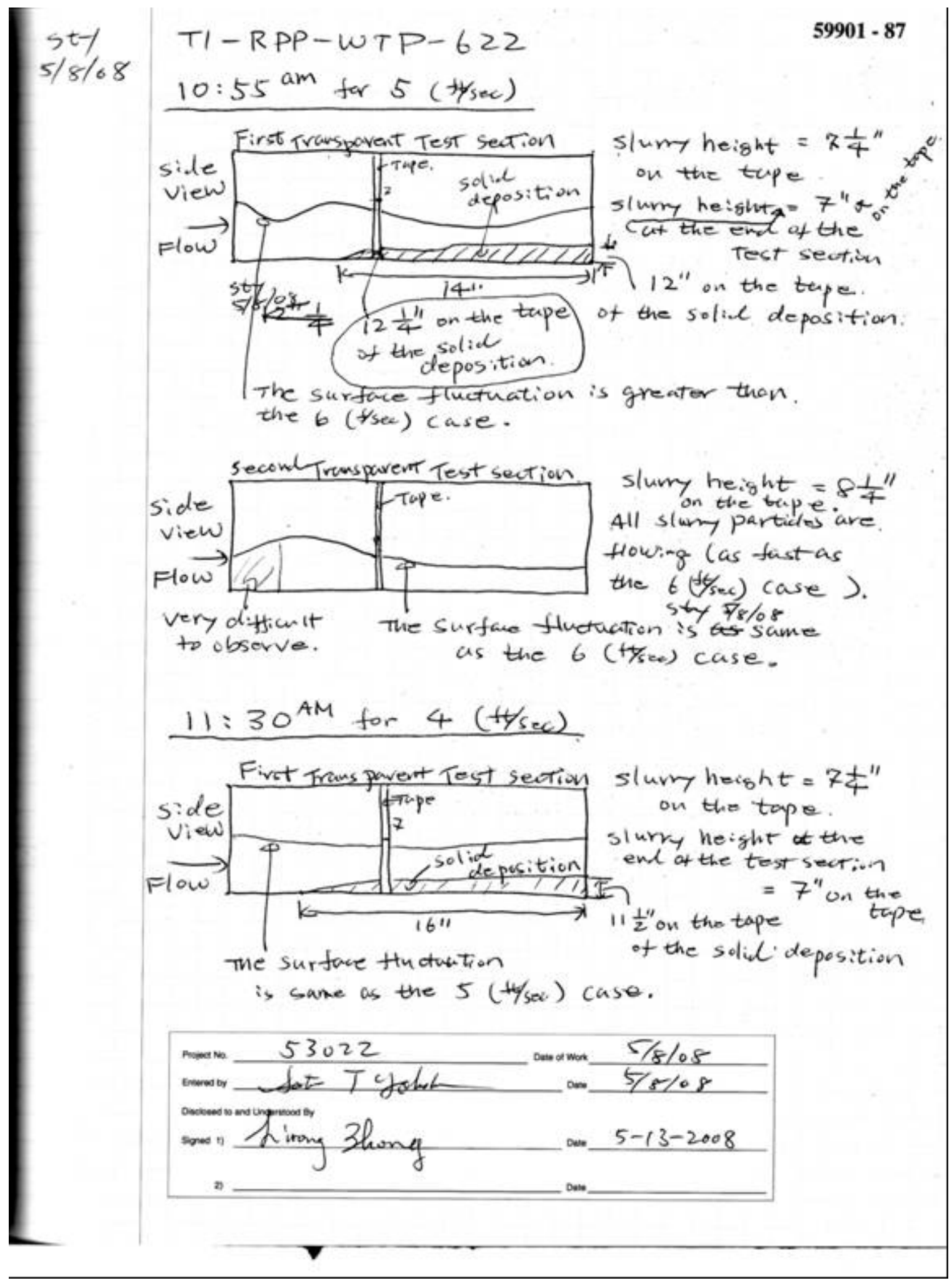




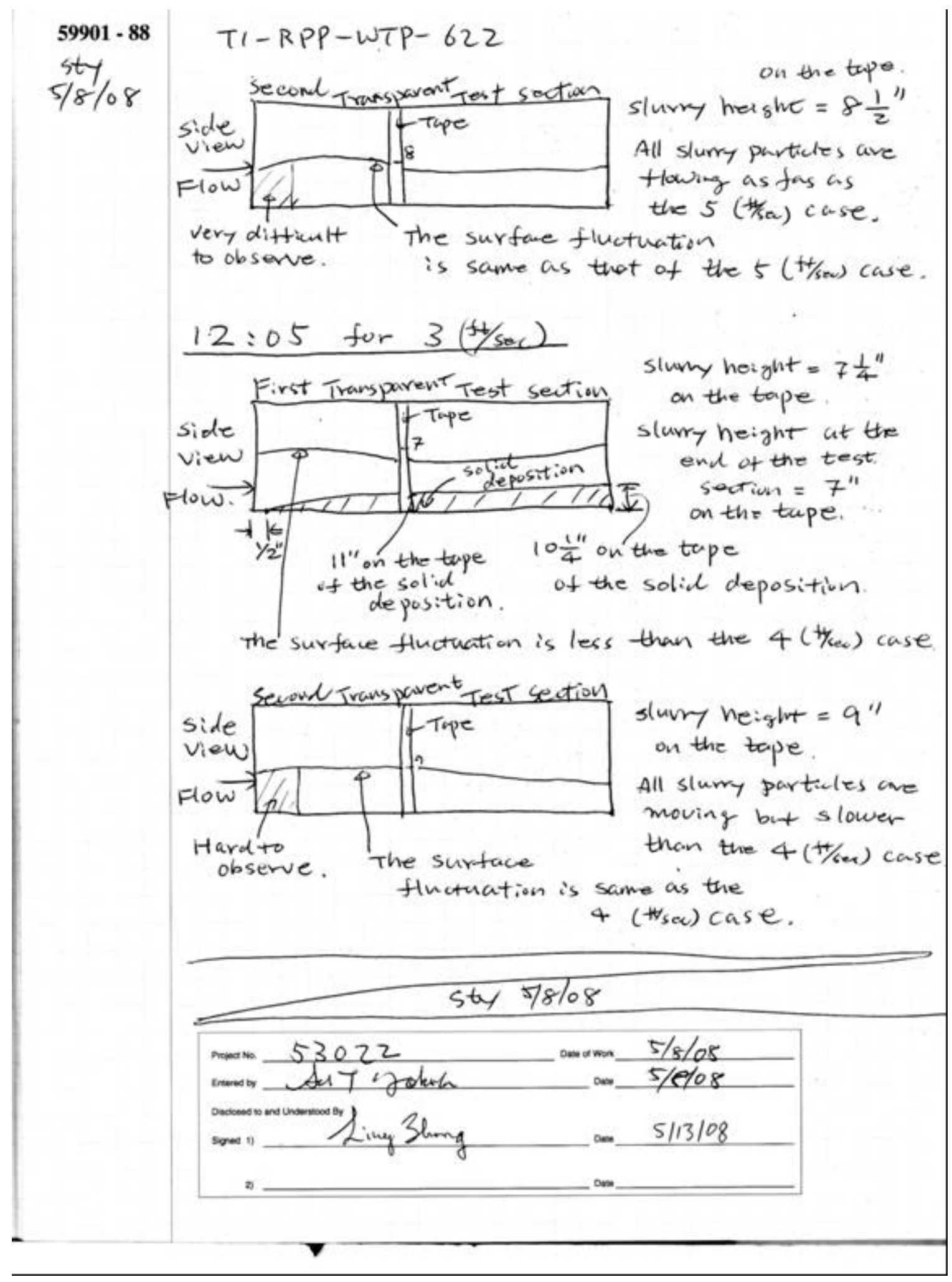




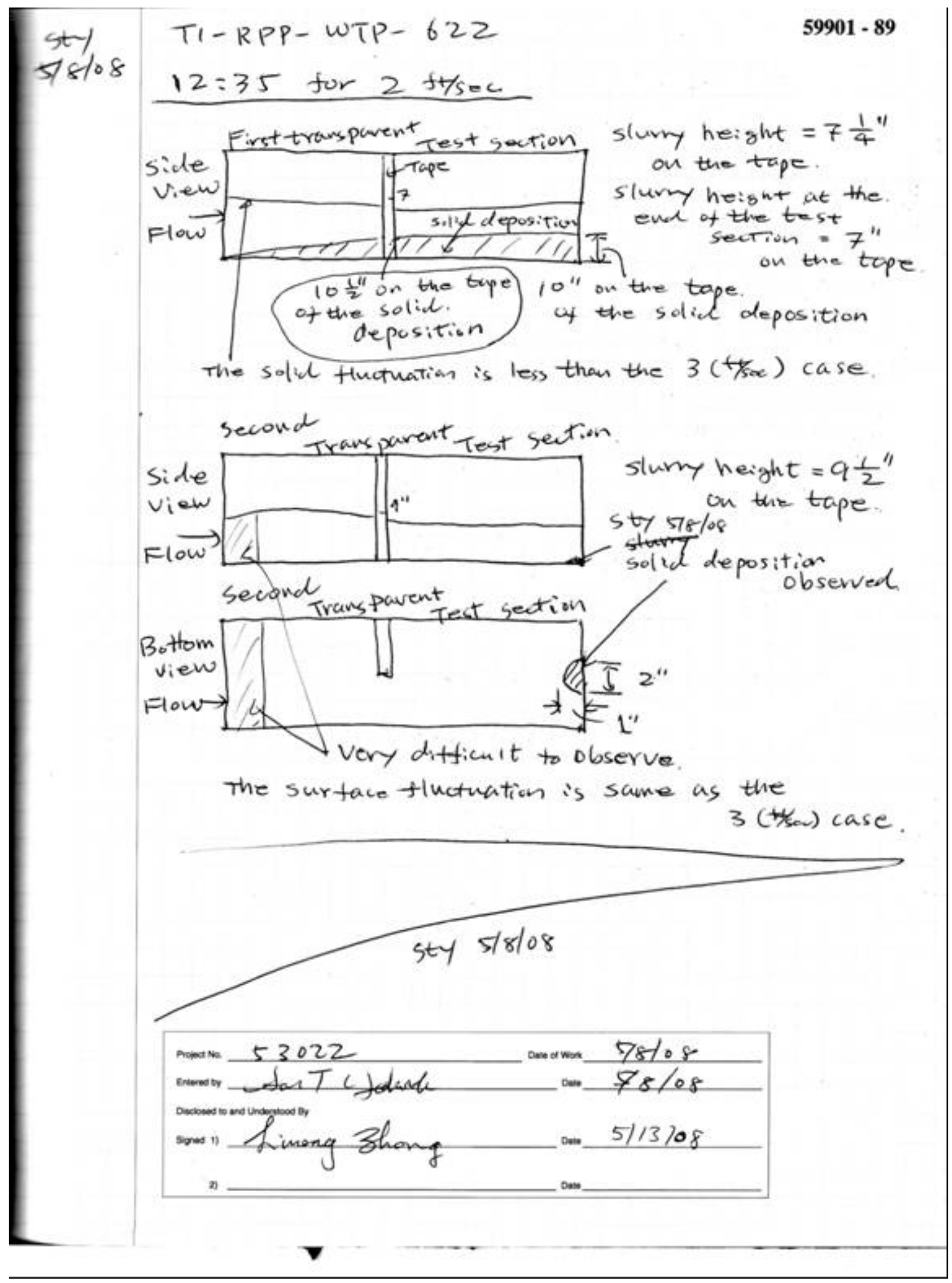




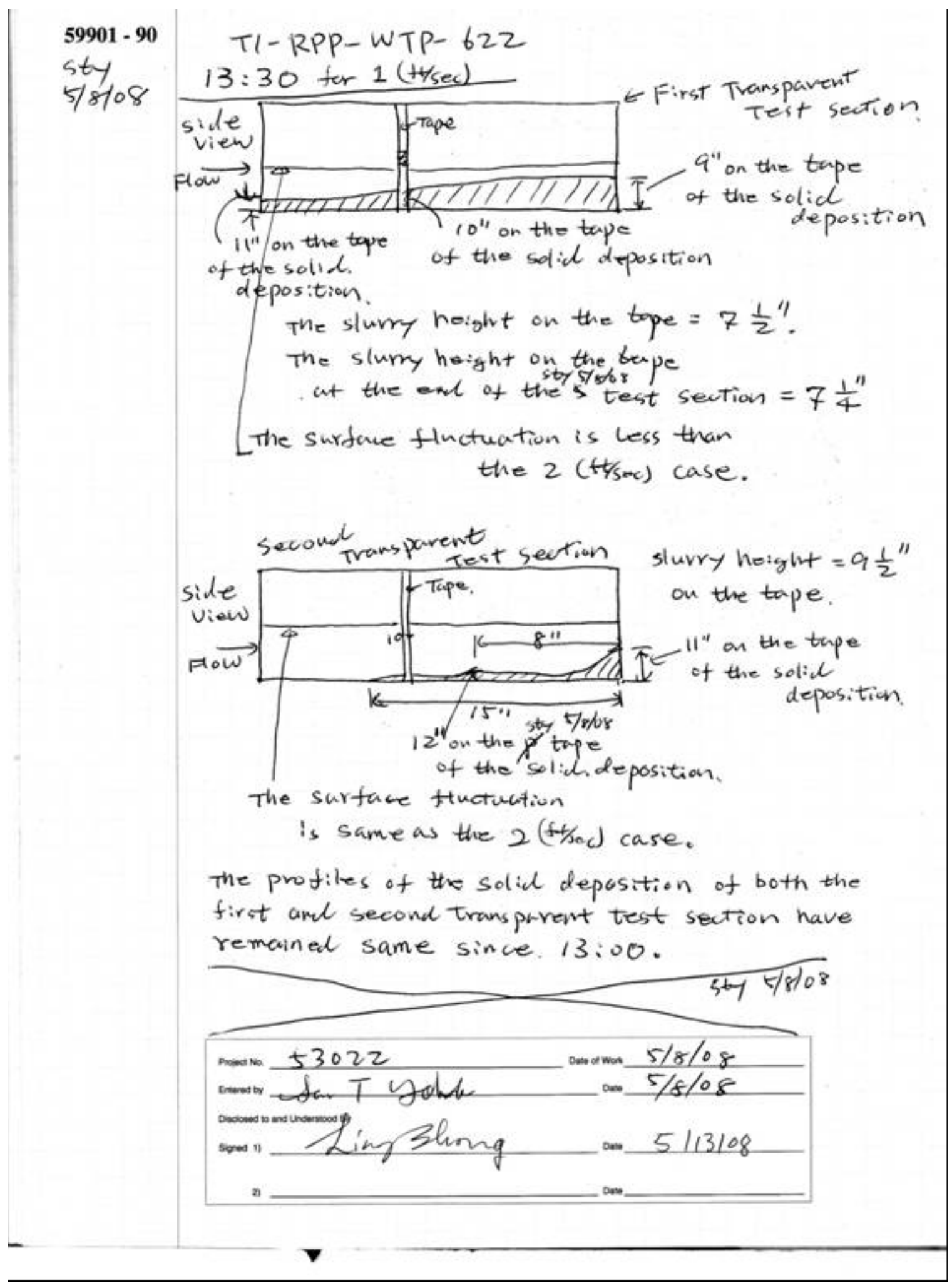




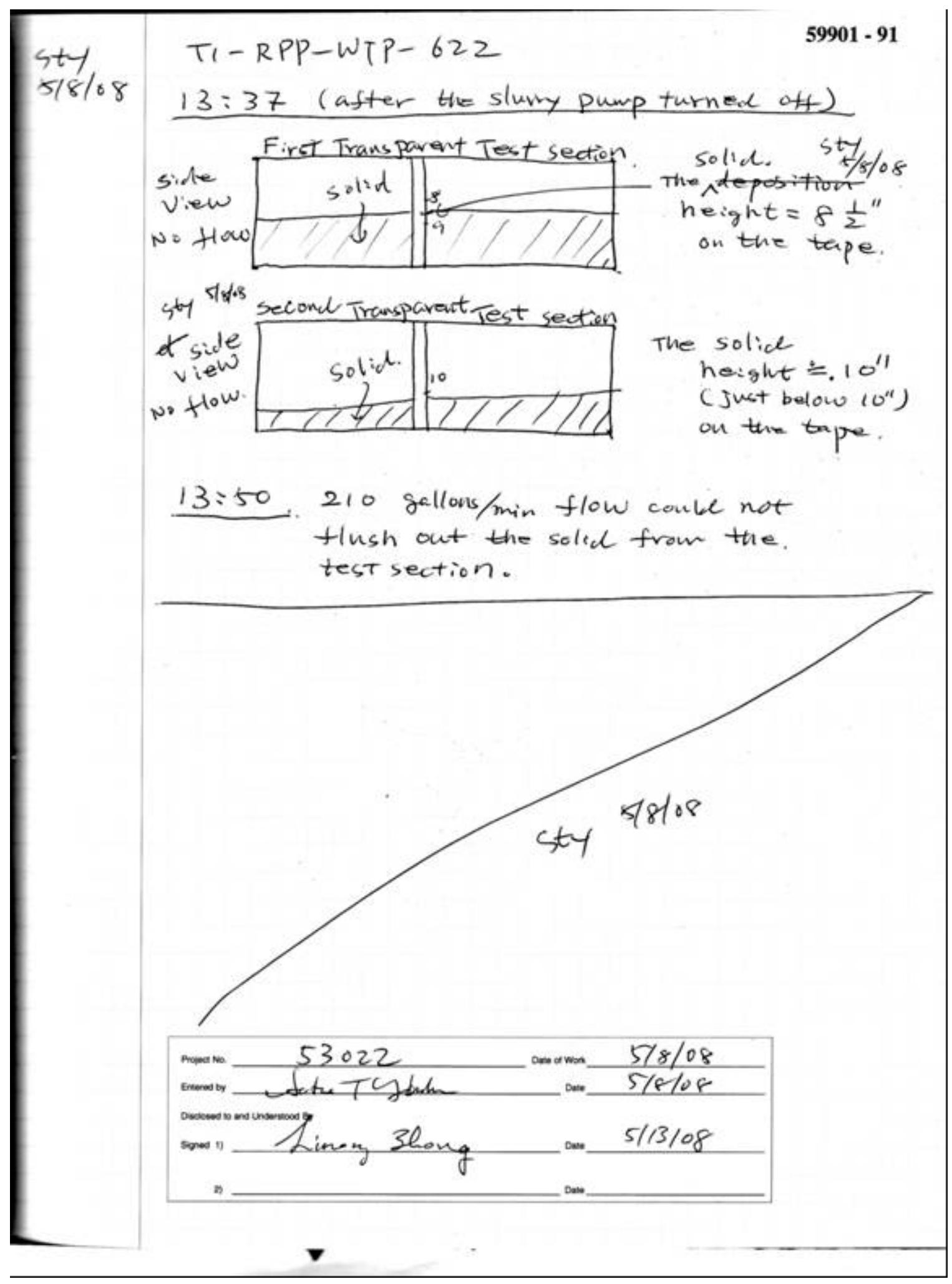


PNNL-17973

WTP-RPT-178 Rev. 0

\section{Distribution}

No. of

Copies

\section{ONSITE}

2 Bechtel National, Inc.

WTP R\&T Docs (2) H4-02

5 Pacific Northwest National Laboratory

H. E. Adkins

K7-15

M. J. Minette

P7-25

D. E. Kurath

K3-52

S. T. Yokuda

K7-15

Project Files

K3-52

Information Release (pdf)

Distr. 1 